
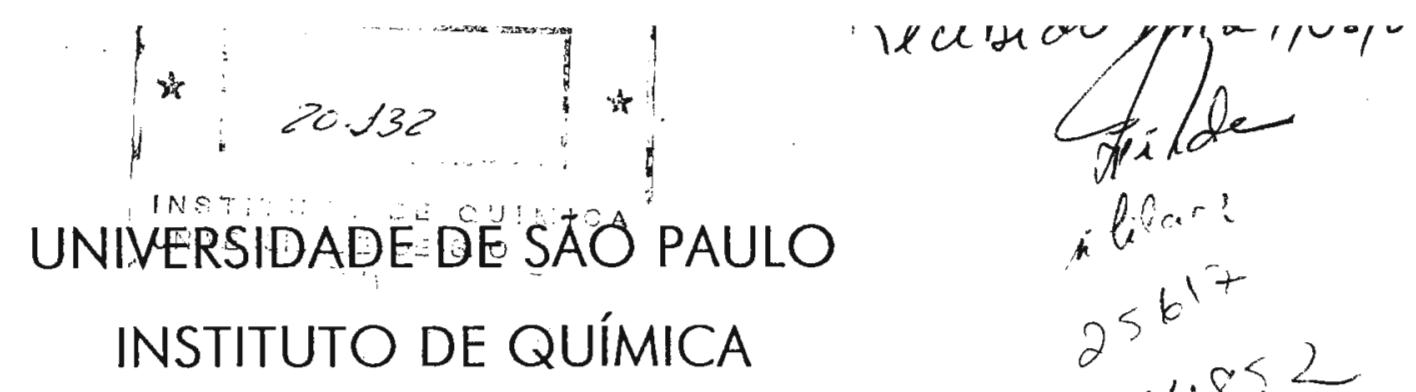

ilinar? $2^{5 k^{1+}}$ 1264852 INSTITUTO DE QUÍMICA

\title{
UMA INVESTIGAÇĀO TEÓRICA DE AGLOMERADOS DE SILÍCIO E NITROGÊNNIO E DA INCORPORAÇÃO DE ÁTOMOS DE NITROGÊNIO NA SUPERFÍCIE DO SILÍCIO
}

Leonardo Tsuyoshi Ueno

Tese de Doutorado.

Prof. Dr. Fernando Rei Ornellas

Orientador

São Paulo

04 de junho de 2002 


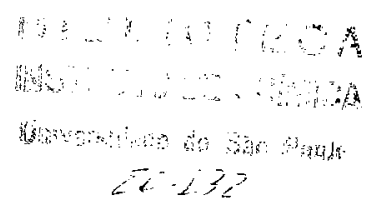

\section{DEDALUS - Acervo - CQ}

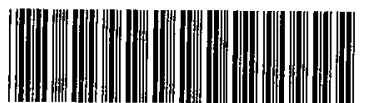

30100004824

Ficha Catalográfica

Elaborada pela Divisão de Biblioteca e

Documentação do Conjunto das Químicas da USP.

Ueno, Leonardo Tsuyoshi

U22i Uma investigação teórica de aglomerados de silício e nitrogênio e da incorporação de átomos de nitrogênio na superfície do silício / Leonardo Tsuyoshi Ueno. -- São Paulo, 2002.

$216 \mathrm{p}$.

Tese (doutorado) - Instituto de Química da Universidade de São Paulo. Departamento de Química Fundamental.

Orientador: Ornellas, Fernando Rei

1. Química teórica 2. Química quântica 3. Química de superfície I. T. II. Ornellas, Fernando Rei, orientador. 


\section{"Uma Investigação Teórica de Aglomerados de Silicio e Nitrogênio e da Incorporação de Átomos de Nitrogênio na Superfície do Silicio"}

\section{LEONARDO TSUYOSHI UENO}

Tese de Doutorado submetida ao Instituto de Química da Universidade de São Paulo como parte dos requisitos necessários à obtenção do grau de Doutor em Química - Área: Físico-Química.

Aprovado por:

Prof. Dr. FERNANDO REI ORNELLAS

IQ - USP

(Orientador e Presidente)

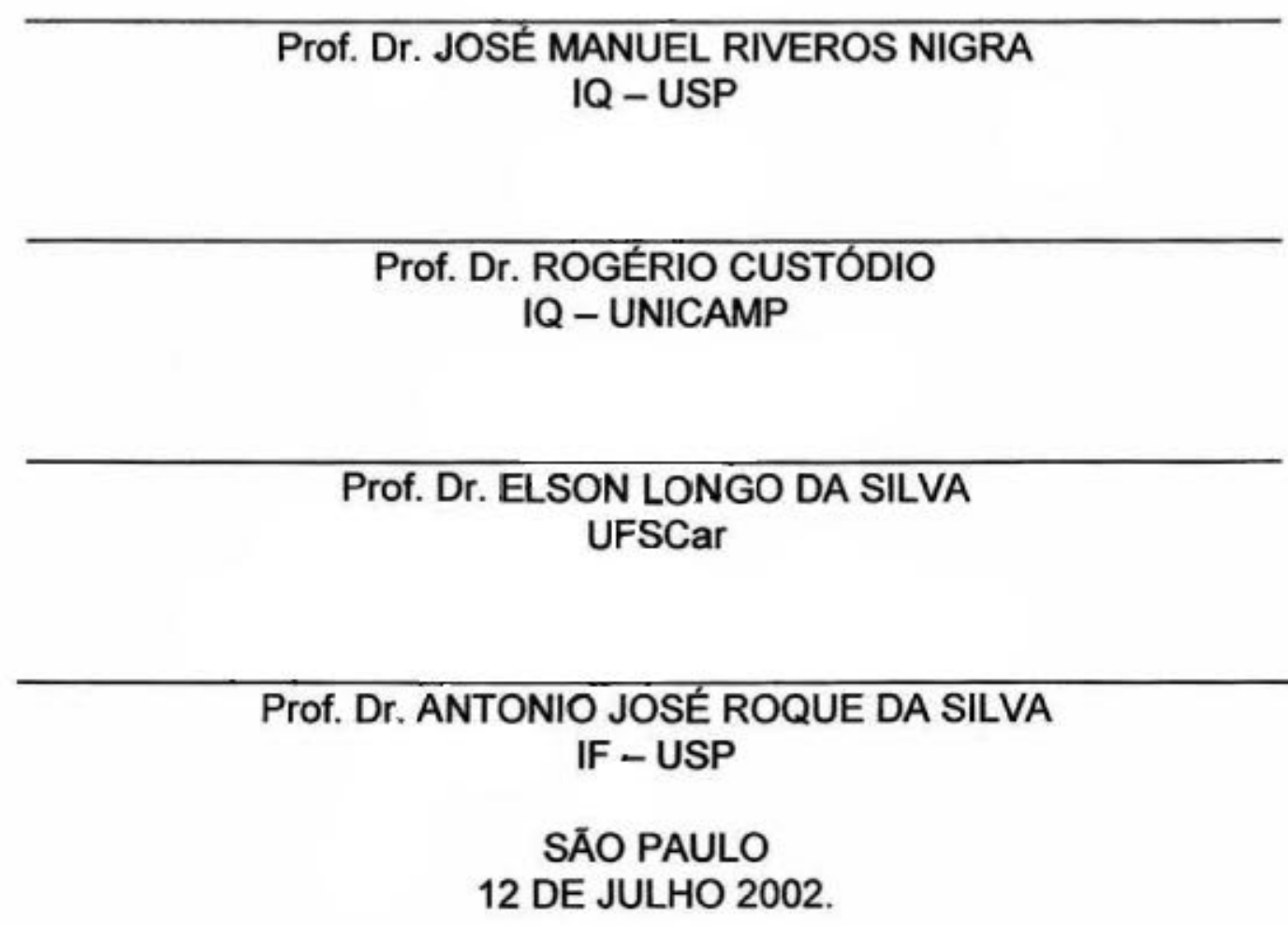




\section{AGRADECIMENTOS}

Ao Professor Fernando R. Ornellas, pela orientação sempre entusiasmada e competente, e, principalmente, pela amizade e compreensāo nesse período de tantos acontecimentos.

À minha namorada Katy, que tanto me incentivou e acreditou na realização e na importância dessa tese.

À minha família, que sempre me apoiou nas minhas escolhas.

Ao Borin, Levi, Guilherme, companheiros de trabalho aqui no Instituto de Química, pela agradável companhia e pelas conversas sempre enriquecedoras.

Aos meus queridos amigos: l.issa, Mrina, Catitiha, Daniei, Vânia, Suzi, Fabiana, Márcia Hein, Chico, Roberto, Luciana, Celina, Ket, Malu, Reginaldo e Silvia Helena que, cada um a seu modo, enriqueceram tanto a minha vida. Aos meus amigos da Assistência Acadêmica, Kalli, Marcelo e Silvana, pelo carinho e amizade sincera. À Andréa, por fazer com que eu "viva" cada vez mais.

Ao CNPq, pelo apoio financeiro, e ao Laboratório de Computação Científica Avançada (LCCA-USP), pelos recursos computacionais. 


\section{ÍNDICE}

LISTA DE FIGURAS iii

LISTA DE TABELAS vi

RESUMO ix

ABSTRACT $\quad x$

INTRODUÇÃO 1

MÉTODOS DA QUÍMICA QUÂNTICA 3

I. Método de Hartree-Fock 5

II. Correlação Eletrônica 16

III. Interação de Configurações 18

IV. Método do campo autoconsistente multiconfiguracional $\begin{array}{ll}\text { MCSCF } & 22\end{array}$

V. Teoria de Perturbação 25

VI. Coupled Cluster 31

VII. Funcional da Densidade 36

VIII. Referências 43

RESULTADOS

I. Sistemas do tipo $\mathrm{Si}_{\mathrm{x}} \mathrm{N}_{\mathrm{y}}$

1.1 Introdução 45

I.2 Abordagens teóricas 53

1.3 O sistema SiNN 55

1.4O sistema $\mathrm{Si}_{3} \mathrm{~N}_{2}$

$\begin{array}{ll}1.5 \text { Conclusōes } & 78\end{array}$

1.6 Referências 80 
II. Superfície e aglomerados de silício

II. 1 Estrutura das superfícies sólidas

- Relaxação e reconstrução da superfície

- Notação de superfícies reconstruídas

11.2 A superfície Si(100)

II.3 Abordagens teóricas

II. $4 \mathrm{O}$ sistema $\mathrm{Si}_{9} \mathrm{H}_{12}$

- Resultados Hartree-Fock

- Resultados Funcional da Densidade

- Resultados MP2

- Resultados CASSCF

II. $5 \mathrm{O}$ sistema $\mathrm{Si}_{15} \mathrm{H}_{16}$

- Resultados Hartree-Fock

- Resultados Funcional da Denciciade

- Resultados CASSCF

II.6 Conclusões

II.7 Referências

III. Adsorção de átomos de nitrogênio na superfície Si(100) III. 1 Introdução

- Adsorção - Ligação de moléculas à superfície

- Cerâmicas: conceitos básicos

- Nitreto de silício: propriedades e técnicas de síntese

- Estudos teóricos da interação de substâncias com a superfície Sil (100)

III.2 Abordagens teóricas

III.3 O sistema $\mathrm{Si}_{9} \mathrm{H}_{12}+1 \mathrm{~N}$ - quarteto

III. $4 \mathrm{O}$ sistema $\mathrm{Si}_{9} \mathrm{H}_{12}+1 \mathrm{~N}$ - dupleto

III.5 Conclusões

III.6 Referências 


\section{LISTA DE FIGURAS}

Figura 1. Contorno da superfície de energia potencial da molécula $\operatorname{SiNN}\left({ }^{3} \Sigma\right)$ calculado em nível de teoria MRSDC//cc-pVTZ.

Figura 2. Energias relativas $(e \mathrm{~m} \mathrm{kcal} / \mathrm{mol}$ ) dos isômeros do SiNN calculadas com a metodologia CCSD(T)/cc-pVTZ.

Figura 3. Geometrias dos pontos estacionários (em $\AA$ e graus) e energias relativas (em $\mathrm{kcal} / \mathrm{mol}$ ) para os estados singleto de espécies com fórmula $\mathrm{Si}_{3} \mathrm{~N}_{2}$.

Figura 4. Geometrias dos pontos estacionários (em $\AA$ e graus) e energias relativas (em $\mathrm{kcal} / \mathrm{mol}$ ) pc: os estados tripleto de espécies com fórmula $\mathrm{Si}_{3} \mathrm{~N}_{2}$.

Figura 5. Energias relativas $(\mathrm{em} \mathrm{kcal} / \mathrm{mol})$ dos pontos estacionários das estruturas do $\mathrm{Si}_{3} \mathrm{~N}_{2}$ e dos canais de dissociação obtidos com a metodologia MP2.

Figura 6. Representação do plano (643), de acordo com os índices de Miller. p.89

Figura 7. Vetores do retículo cristalino das superfícies $P+(110)(1 \times 1)$ e $\operatorname{Pt}(110)(1 \times 2)$.

Figura 8. Celas unitárias primitiva e convencional para a superfície reconstruída do $W(100)$.

Figura 9. Planos (100) e (001) da cela unitária convencional do silício.

Figura 10. Fração da superfície do silício com a cela unitária convencional em destaque.

Figura 11. Processo de reconstrução para a formaçāo da superfície Si(100)(2x1).p.95 
Figura 12. Aglomerado de fórmula $\mathrm{Si}_{9} \mathrm{H}_{12}$ com a numeração dos átomos de silício.

Figura 13. Aglomerado de fórmula $\mathrm{Si}_{15} \mathrm{H}_{16}$ com a numeração dos átomos de silício.

Figura 14. Representaçāo do orbital HOMO da estrutura $\mathrm{Si}_{9} \mathrm{H}_{12}$ singleto obtida com a utilizaçāo de orbitais restritos.

Figura 15. Representação do orbital $\mathrm{HOMO}$ da estrutura $\mathrm{Si}_{9} \mathrm{H}_{12}$ singleto obtida com a utilização de orbitais não-restritos.

Figura 15-A. Estrutura da forma polimórfica $\alpha-\mathrm{Si}_{3} \mathrm{~N}_{4}$ com a indicação da cela unitória.

Figura 15-B. Estrutura da forme polimórfica $\alpha-\mathrm{Si}_{3} \mathrm{~N}_{4}$ com a indicação da cela unitória.

Figura 16. Energia relativa e energia livre de Gibbs (entre parênteses), em $\mathrm{kcal} / \mathrm{mol}$, para as estruturas quarteto representativas ao longo do caminho de reaçāo da adsorçāo de $N$ na superfície Si(100) modelada pelo aglomerado $\mathrm{Si}_{9} \mathrm{H}_{12}$.

Figura 17. Parâmetros geométricos calculados para as estruturas quarteto representativas ao longo do caminho de reação da adsorção de $\mathrm{N}$ na superfície $\mathrm{Si}(100)$ modelada pelo aglomerado $\mathrm{Si}_{9} \mathrm{H}_{12}$.

Figura 18. Cargas atômicas e densidade de spin calculadas para as estruturas quarteto representativas ao longo do caminho de reação da adsorção de $\mathrm{N}$ na superfície $\mathrm{Si}(100)$ modelada pelo aglomerado $\mathrm{Si}_{9} \mathrm{H}_{12}$.

Figura 19. Freqüências vibracionais $\left(\mathrm{em} \mathrm{cm}^{-1}\right)$ e intensidades (entre parênteses, em $\mathrm{km} / \mathrm{mol}$ ) calculadas para modos vibracionais selecionados das estruturas quarteto I, II e IV. 
Figura 20. Freqüências vibracionais imaginárias $\left(\mathrm{em} \mathrm{cm}^{-1}\right)$ calculadas para as estruturas quarteto III e V.

Figura 21. Energias relativas $(\mathrm{em} \mathrm{kcal} / \mathrm{mol}$ ) para as estruturas quarteto sem vínculo representativas ao longo do caminho de reação da adsorção de $\mathrm{N}$ na superfície $\mathrm{Si}(100)$ modelada pelo aglomerado $\mathrm{Si}_{9} \mathrm{H}_{12}$.

Figura 22. Parâmetros geométricos calculados para as estruturas quarteto sem vínculo representativas ao longo do caminho de reaçāo da adsorção de $\mathrm{N}$ na superfície $\mathrm{Si}(100)$ modelada pelo aglomerado $\mathrm{Si}_{9} \mathrm{H}_{12}$.

Figura 23. Energias relativas $(\mathrm{em} \mathrm{kcal} / \mathrm{mol}$ ) para as estruturas dupleto sem vínculo representativas ao longo do caminho de reação da adsorção de $\mathrm{N}$ na superfície $\mathrm{Si}(100)$ modelada pelo aglomerado $\mathrm{Si}_{9} \mathrm{H}_{12}$.

Figura 24. Parâmetros geométricos zalculados para as estruturas dupleto sem vínculo representativas ao longo do caminho de reação da adsorção de $\mathrm{N}$ na superfície $\mathrm{Si}(100)$ modelada pelo aglomerado $\mathrm{Si}_{9} \mathrm{H}_{12}$.

Figura 25. Cargas atômicas e densidade de spin calculadas para as estruturas dupleto sem vínculo representativas ao longo do caminho de reação da adsorção de $\mathrm{N}$ na superfície $\mathrm{Si}(100)$ modelada pelo aglomerado $\mathrm{Si}_{9} \mathrm{H}_{12}$.

Figura 26. Freqüências vibracionais $\left(\mathrm{em} \mathrm{cm}^{-1}\right.$ ) e intensidades (entre parênteses, em $\mathrm{km} / \mathrm{mol}$ ) calculadas para modos vibracionais selecionados das estruturas dupleto sem vínculo I e IV.

Figura 27. Energias relativas $(\mathrm{em} \mathrm{kcal} / \mathrm{mol}$ ) para as estruturas dupleto e quarteto sem vínculo representativas ao longo do caminho de reação da adsorção de $\mathrm{N}$ na superfície $\mathrm{Si}(100)$ modelada pelo aglomerado $\mathrm{Si}_{9} \mathrm{H}_{12}$. 


\section{LISTA DE TABELAS}

Tabela 1. Distâncias otimizadas (em $\AA$ ) e freqüências harmônicas $\left(\mathrm{em}^{-1}\right.$ ) da molécula SiNN calculadas com várias metodologias.

Tabela 2. Geometrias otimizadas (em $\AA$ e graus), estabilidades relativas (em $\mathrm{kcal} / \mathrm{mol})$, e freqüências harmônicas $\left(\mathrm{em}^{-1}\right)$ dos isômeros do $\mathrm{SiN}_{2}$ calculados em nível CCSD(T)/cc-pVTZ.

Tabela 3. Freqüências harmônicas vibracionais calculadas $\left(\mathrm{em}^{-1}\right)$ e valores de $\hat{S}^{2}$ para vários aglomerados de $\mathrm{Si}_{3} \mathrm{~N}_{2}$ em níveis MP2 e SCF. p.70

Tabela 4. Parâmetros geométricos (em $\AA$ ) obtidos com orbitais restritos e a metodologia Hartree-Fock para $\therefore$ glomerado singleto $\mathrm{Si}_{9} \mathrm{H}_{12}$. ק. 106

Tabela 5. Parâmetros geométricos (em $\AA$ ) obtidos com orbitais não-restritos e a metodologia Hartree-Fock para o aglomerado singleto $\mathrm{Si}_{9} \mathrm{H}_{12}$. p.107

Tabela 6. Parâmetros geométricos (em $\AA$ ) obtidos com orbitais não-restritos e a metodologia Hartree-Fock para o aglomerado tripleto $\mathrm{Si}_{9} \mathrm{H}_{12}$.

Tabela 7. Parâmetros geométricos (em $\AA$ ) obtidos com orbitais restritos e a metodologia do Funcional da Densidade com o funcional B3LYP para o aglomerado singleto $\mathrm{Si}_{9} \mathrm{H}_{12}$.

Tabela 8. Parâmetros geométricos (em $\AA$ ) obtidos com orbitais não-restritos e a metodologia do Funcional da Densidade com o funcional B3LYP para o aglomerado singleto $\mathrm{Si}_{9} \mathrm{H}_{12}$.

Tabela 9. Parâmetros geométricos (em $\AA$ ) obtidos com orbitais não-restritos e a metodologia do Funcional da Densidade com o funcional B3LYP para o aglomerado tripleto $\mathrm{Si}_{9} \mathrm{H}_{12}$. 
Tabela 10. Parâmetros geométricos (em $\AA$ ) obtidos com a metodologia Teoria de Perturbaçāo de segunda ordem e a base 6-31G* para o aglomerado singleto e tripleto $\mathrm{Si}_{9} \mathrm{H}_{12}$.

Tabela 10-A.Energias de estabilizaçāo (em eV) obtidas para o aglomerado $\mathrm{Si}_{9} \mathrm{H}_{12}$ com várias metodologias e com a base 6-31G*.

Tabela 11. Parâmetros geométricos (em $\AA$ ) obtidos com testes para a escolha dos orbitais ativos com a metodologia CASSCF e a base $6-31 G^{*}$ para o aglomerado singleto $\mathrm{Si}_{9} \mathrm{H}_{12}$.

Tabela 12. Parâmetros geométricos (em $\AA$ ) obtidos com testes para a escolha dos orbitais ativos com a metodologia CASSCF e a base CEP-31G* para o aglomerado singleto $\mathrm{Si}_{9} \mathrm{H}_{12}$.

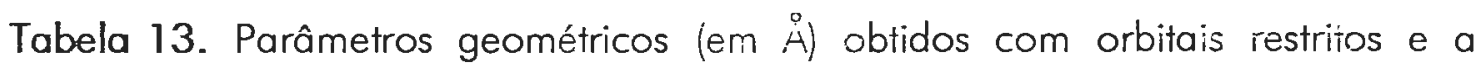
metodologia Hartree-Fock para o aglomerado singleto simétrico $\mathrm{Si}_{15} \mathrm{H}_{16}$.

Tabela 14. Parâmetros geométricos (em $\AA$ ) obtidos com orbitais restritos e a metodologia Hartree-Fock para o aglomerado $S_{i 5} \mathrm{H}_{16}$ singleto assimétrico com os silícios dímeros alternados.

Tabela 15. Parâmetros geométricos (em $\AA$ ) obtidos com orbitais restritos, a metodologia Hartree-Fock e a base CEP-31G* para o aglomerado singleto simétrico $\mathrm{Si}_{75} \mathrm{H}_{16}$.

Tabela 16. Parâmetros geométricos (em $\AA$ ) obtidos com orbitais restritos, a metodologia Hartree-Fock e a base CEP-31G* para o aglomerado $\mathrm{Si}_{15} \mathrm{H}_{16}$ singleto assimétrico com os silícios dímeros alternados.

Tabela 17. Parâmetros geométricos (em $\AA$ ) obtidos com orbitais restritos, a metodologia Hartree-Fock e as bases CEP-31G* e 6-31G* para o aglomerado $\mathrm{Si}_{15} \mathrm{H}_{16}$ singleto assimétrico com os silícios dímeros paralelos. 
Tabela 18. Parâmetros geométricos (em $\AA$ ) obtidos com orbitais restritos e a metodologia do Funcional da Densidade com o funcional B3LYP para o aglomerado singleto simétrico $\mathrm{Si}_{15} \mathrm{H}_{16}$.

p. 142

Tabela 19. Parâmetros geométricos (em $\AA$ ) obtidos com orbitais restritos e a metodologia do Funcional da Densidade com o funcional B3LYP para - aglomerado $\mathrm{Si}_{15} \mathrm{H}_{16}$ singleto assimétrico com os silícios dímeros alternados.

p. 143

Tabela 20. Parâmetros geométricos (em Å) obtidos com orbitais restritos, a metodologia CASSCF - CAS $(6,5)$ - e a base CEP-31G* para o aglomerado singleto simétrico $\mathrm{Si}_{15} \mathrm{H}_{16}$.

p. 145 


\section{RESUMO}

Nesta tese, utilizamos técnicas de química quântica para o estudo de sistemas contendo átomos de silício e nitrogênio. Nesse contexto, o trabalho aqui apresentado procurou concentrar-se em três tópicos principais: aglomerados de silício e nitrogênio, a superfície $\operatorname{Si}(100)$ e a interaçāo de um átomo de nitrogênio com essa superfície. Estudamos inicialmente os aglomerados de fórmula $\mathrm{SiNN}$ e $\mathrm{Si}_{3} \mathrm{~N}_{2}$, onde procuramos caracterizar de forma rigorosa a estabilidade e a natureza das ligações químicas das várias espécies. Com relação ao sistema SiNN, os resultados utilizando cálculos de alto nível mostraram a necessidade de novos dados experimentais para a caracterização inequívoca dessa espécie. Além disso, obtivemos os primeiros resultados para as propriedades de quatro novas estruturas. Estudamos a estrutura de várias espécies com fórmula $\mathrm{Si}_{3} \mathrm{~N}_{2}$, e obtivemos como mínimo global uma estrutura planar contendo apenas ligaçōes Si-N.

Para a simulação da superfície Si(100) utilizamos os aglomerados de fórmula $\mathrm{Si}_{9} \mathrm{H}_{12}$ e $\mathrm{Si}_{15} \mathrm{H}_{16}$. Apenas a metodologia do Funcional da Densidade indicou a existência de uma estrutura distorcida para $\circ \mathrm{Si}_{9} \mathrm{H}_{12}$. Os cálculos CASSCF mostraram a necessidade do uso de funções multideterminantais. Com relação ao aglomerado $\mathrm{Si}_{15} \mathrm{H}_{16}$, obteve-se uma estrutura distorcida com os dímeros alternados como a forma mais estável. Entretanto, o uso do CASSCF mostrou ser a forma simétrica a mais estável.

Com base no estudo dos aglomerados $\mathrm{Si}_{9} \mathrm{H}_{12}$ e $\mathrm{Si}_{15} \mathrm{H}_{16}$, partimos para a investigação dos mecanismos envolvidos no processo de interação e incorporação de átomos de nitrogênio na superfície de silício. Estruturas com simetria de spin quarteto e dupleto foram estudadas, sendo os mecanismos bastante semelhantes, com o nitrogênio interagindo inicialmente com um dos silícios dímeros para em seguida poder formar duas outras estruturas, uma com o nitrogênio ligado aos dois silícios dímeros e outra com o nitrogênio inserido no interior do aglomerado. Esta última estrutura corresponde à forma mais estável. Os resultados mostram claramente que a reação é bastante favorável do ponto de vista energético. Questionamos também o uso de vínculos durante a otimizaçāo das estruturas por impedir um devido relaxamento apropriado dos átomos de silício da primeira e segunda camadas. 


\section{ABSTRACT}

In this thesis, quantum chemical techniques were used to study molecular systems containing silicon and nitrogen atoms. In this context, the work was concentrated on three main topics: silicon-nitrogen clusters, the $\mathrm{Si}(100)$ surface, and the interaction of a nitrogen atom with that surface. We studied initially the clusters $\mathrm{SiNN}$ and $\mathrm{Si}_{3} \mathrm{~N}_{2}$, where we tried to characterize with rigour the stability and the nature of the chemical bonds of the various species. Concerning the system SiNN, using high level calculation, the results showed the necessity of new experimental data for the unequivocal characterization of this species. Moreover, the properties of four new structures were described for the first time in this study. The structures of various species with formula $\mathrm{Si}_{3} \mathrm{~N}_{2}$ were studied, and the global minimum corresponds to a planar structure containing only Si-N bonds.

For the simulation of $\mathrm{Si}(100)$ surface, the clusters $\mathrm{Si}_{9} \mathrm{H}_{12}$ and $\mathrm{Si}_{15} \mathrm{H}_{10}$ were used. Density Functional Theory predicted the existence of an asymmetric geometry for the $\mathrm{Si}_{9} \mathrm{H}_{12}$ cluster. The CASSCF calculations showed the necessity of using multideterminantal wave functions. Concerning the $\mathrm{Si}_{15} \mathrm{H}_{16}$ cluster, the most stable structure corresponds to a distorted one with alternated dimers. However, the CASSCF methodology showed that the symmetric structure is the most stable.

Based on the results for the $\mathrm{Si}_{9} \mathrm{H}_{12}$ and $\mathrm{Si}_{15} \mathrm{H}_{16}$ clusters, we started to investigate the mechanism involved in the interaction and incorporation of a nitrogen atom into the silicon surface. Structures with quartet and doublet spin symmetry were studied, being their mechanisms very similar, with the nitrogen atom interacting initially with one silicon dimer; after that two other structures can be formed, one with the nitrogen bonded to two silicon dimers, and the other with the nitrogen bonded to one silicon dimer and two internal silicons. This last structure corresponds to the most stable species. The results show clearly that the reaction is very favorable energetically. The use of geometrical constraints during the optimization was questioned since it prevents the proper relaxation of the silicon atoms in the first and second layers. 


\section{INTRODUÇÃO}

estudo de sistemas químicos utilizando técnicas da mecânica quântica tem sofrido, nos últimos anos, uma grande popularização. Isso se deve ao enorme desenvolvimento computacional que permite que cálculos que até pouco tempo atrás eram bastante difíceis de serem efetuados, em virtude de limitações de memória, por exemplo, possam ser realizados rotineiramente e sem dificuldades até em simples computadores pessoais. Outro fator importante nessa divulgação é a facilidade cada vez maior na utilização das diversas metodologias com o lançamento de soffwares mais simples de serem manuseados, não sendo necessário um grande conhecimento teórico para se poder estudar um determinado sistema de interesse com a aproximaçāo desejada. Nesse sentido, um bom exemplo de soffware de fácil utilização é o Gaussian, onde o emprego de algumas palavras chaves permitem a realização de um cálculo, de modo que praticamente qualquer pessoa hoje em dia é capaz de fazer um "estudo teórico". Essa facilidade tem a vantagem de popularizar e nōo tornar essa área da química tão inacessível para a maioria dos químicos, fazendo com que se possa aceitar cada vez mais os resultados teóricos como uma ferramenta útil e auxiliar para o estudo experimental. Por outro lado, existe um aspecto que tem que ser levado em consideração, pois o que tem acontecido é que muitas pessoas utilizam esses programas sem terem uma formação adequada, ou seja, não conhecem as vantagens e limitações de cada metodologia, como abordar da melhor maneira um determinado sistema químico, etc, e como qualquer cálculo leva a um valor de energia ou outras propriedades, ficam sem saber analisar corretamente e criticamente esses dados.

O desenvolvimento computacional das metodologias teóricas e os programas a elas associados têm permitido o estudo de sistemas cada vez mais complexos e ampliado a área de aplicação dos cálculos teóricos. Sistemas que até poucos anos atrás não eram possíveis de serem estudados agora são, como, por exemplo, biomoléculas, solventes, solvatação de íons e moléculas, superfícies e reações sobre as mesmas. Essa ampliação das áreas de estudo tem permitido uma interação cada vez maior do químico experimental com o teórico, e a tendência é que essa interação aumente cada vez mais.

Nesta tese procuramos estudar de maneira crítica e sistemática diversos sistemas contendo átomos de silício e nitrogênio. O nosso interesse e a escolha por esse tipo de 
sistema surgiu porque percebemos a pouca quantidade de trabalhos teóricos e experimentais de aglomerados contendo esses átomos. Além disso, esses sistemas são um ponto de partida para a obtenção de uma cerâmica muito importante, o nitreto de silício, $\mathrm{Si}_{3} \mathrm{~N}_{4}$.

$\mathrm{O}$ nosso ponto de partida foi o sistema triatômico $\mathrm{SiNN}$, e em seguida $\circ \mathrm{Si}_{3} \mathrm{~N}_{2}$. Nesse período, outras possibilidades, como $\circ \mathrm{Si}_{2} \mathrm{~N}$ e $\circ \mathrm{Si}_{2} \mathrm{~N}_{2}$, também foram estudadas no grupo. Em seguida, nosso interesse se voltou para a compreensão dos processos envolvidos na reação de átomos de nitrogênio com uma superfície de silício, sendo esse um dos processos experimentais para a síntese de filmes finos de nitreto de silício. Para isso, focalizamos inicialmente a nossa atenção na superfície de silício, com a questão de como representá-la adequadamente, ou seja, determinar o número de átomos de silício e a metodologia adequados. Determinada uma estrutura mínima para a representação da superfície, procuramos compreender os mecanismos envolvidos na reaçāo e incorporação de átomos de nitrogênio na mesma.

Na parte relativa aos métodos da química quântica procuramos apresentar as características básicas de cada metodologia, sem nos atermos muito aos detalhe formais. $\mathrm{Na}$ parte dos resultados apresentamos detalhadamente o histórico de cada sistema estudado, bem como as metodologias adotadas e as discussōes a partir dos resultados obtidos. 
MÉTODOS DA QUÍMICA QUÂNTICA 
ponto central no estudo de sistemas químicos, do ponto de vista teórico, reside na solução da equação de Schrödinger. Essa equação, que é uma equação diferencial de segunda ordem, é basicamente dependente apenas do número de elétrons, do número de núcleos e suas cargas e da separação entre todas essas partículas. Sua solução, entretanto, apresenta dificuldades imensas, pelo grande número de variáveis e o acoplamento entre elas. Quanto maior o número de partículas maior o grau de dificuldade para a obtenção de uma solução numérica. Do ponto de vista químico, onde idealmente busca-se resultados muito precisos, muitas vezes da ordem de poucos $\mathrm{kcal} / \mathrm{mol}$, essa dificuldade é ainda mais acentuada, porque muitos sistemas de interesse consistem de dezenas a centenas de átomos.

Face a essas dificuldades, ao longo de várias décadas, foram desenvolvidas técnicas de aproximação para a resolução da equação de Schrödinger. $O$ método de Hartree-Fock é um exemplo dessa aproximaçāo; suas equaçōes básicas foram desenvolvidas em 1930, e hoje serve como um referencial para cálculos mais sofisticados, conhecidos como pós-Hartree-Fock. A vantagem dessa metodologia reside na sua relativa simplicidade teórica, facilidade de implementação numérica e baixo custo computacional, o que permite hoje em dia que sistemas químicos bastante complexos possam ser estudados com um alto grau de confiança. Além disso, introduz um conceito muito importante para os químicos, que é o de orbital molecular, de grande valia para a compreensão qualitativa da estrutura eletrônica de um determinado sistema químico. Neste capítulo, procuraremos fazer uma revisāo concisa dos vários métodos de cálculo de estrutura eletrônica usados nesta tese, começando com o método Hartree-Fock, passando a seguir aos desenvolvimentos posteriores que procuraram introduzir correlação eletrônica de forma variacional e perturbacional, e terminando com a abordagem do funcional da densidade. Maiores detalhes com relação às metodologias podem ser obtidos em alguns artigos e livros textos. ${ }^{1-7}$ 


\section{MÉTODO DE HARTREE-FOCK}

Conforme mencionado, a metodologia Hartree-Fock é o primeiro passo para a maioria dos cálculos mecânico-quânticos aplicados a sistemas atômicos e moleculares. Para facilitar a sua utilização, normalmente adota-se uma aproximação inicial, conhecida como aproximação de Born-Oppenheimer. Isso nos permite utilizar técnicas de separação de variáveis para auxiliar na resolução da equação de Schrödinger para sistemas moleculares. Essa aproximação se baseia na grande diferença de massa existente entre os elétrons e os núcleos, que faz com que possamos, como uma boa aproximação, considerar os elétrons movendo-se em um campo gerado pelos núcleos fixos. Para entendermos essa aproximação de maneira simplificada, partiremos do Hamiltoniano total não-relativístico para um sistema de partículas carregadas (elétrons a núcleos) em unidades atômicas:

$$
\mathbf{H}=-\sum_{\mu} \frac{1}{2 \mathrm{~m}_{\mu}} \nabla_{\mu}^{2}-\sum_{i} \frac{1}{2} \nabla_{i}^{2}-\sum_{\mu, i} \frac{\mathrm{Q} \mu}{\mathbf{r}_{\mu}-\mathbf{r}_{i} \mid}+\sum_{i<j \mid} \frac{1}{\mathbf{r}_{j}-\mathbf{r}_{j} \mid}+\sum_{\mu<\nu} \frac{\mathrm{Q}_{\mu} \mathrm{Q} \mathbf{r}_{\mu}-\mathbf{r}_{v}}{\mid}
$$

onde adotamos os índices $i, j \ldots$ para indicar os elétrons e $\mu, v \ldots$ para os núcleos.

Podemos separar o Hamiltoniano acima em duas partes:

$$
\begin{aligned}
& \mathbf{H}=\mathbf{T}_{\text {nucl }}+\mathbf{H}_{\mathrm{el}} \\
& \mathbf{T}_{\text {nucl }}=-\sum_{\mu} \frac{1}{2 \mathrm{~m}_{\mu}} \nabla_{\mu}^{2} \\
& \mathbf{H}_{\mathrm{el}}=-\sum_{i} \frac{1}{2} \nabla_{i}^{2}-\sum_{\mu, i} \frac{\mathrm{Q} \mu}{\mathbf{r}_{\mu}-\mathbf{r}_{i} \mid}+\sum_{i<j} \frac{1}{\mathbf{r}_{i}-\mathbf{r}_{j} \mid}+\sum_{\mu<\nu} \frac{Q \mu \mathrm{Q} v}{\mathbf{r}_{\mu}-\mathbf{r}_{v}}
\end{aligned}
$$

Dentro da aproximação de Born-Oppenheimer temos os elétrons movendo-se relativamente aos núcleos fixos, de maneira que podemos ignorar inicialmente o termo relativo à energia cinética dos núcleos ( $\left.\boldsymbol{T}_{\text {nucl }}\right)$ e concentrarmo-nos no que é chamado de Hamiltoniano eletrônico $\left(\boldsymbol{H}_{\text {ell }}\right.$. Esse Hamiltoniano depende parametricamente das coordenadas nucleares, de modo que a solução da equação é feita sobre uma 
determinada configuração nuclear fixa. Com isso, o interesse passa a ser na solução da equação:

$$
H_{\mathrm{el}}(\mathbf{r} ; \mathbf{R}) \Psi_{\mathrm{el}}(\mathbf{r} ; \mathbf{R})=\mathrm{E}_{\mathrm{el}}(\mathbf{R}) \Psi_{\mathrm{el}}(\mathbf{r} ; \mathbf{R})
$$

onde $\mathbf{r}$ refere-se ao conjunto das coordenadas dos elétrons e $\mathbf{R}$ ao dos núcleos. $\mathbf{A}$ solução da equação acima, para várias configurações nucleares, permite a obtençāo do que é conhecido como superfície de energia potencial, que corresponde ao potencial onde os núcleos se movem. Essa aproximação leva também ao conceito de geometria molecular, que corresponde à configuração nuclear que resulta na menor energia em uma determinada superfície potencial.

A funçāo de onda aproximada, que chamaremos de $\Psi_{\mathrm{BO}}$, agora pode ser dada por:

$$
\Psi_{\mathrm{BO}}(\mathbf{r} ; \mathbf{R})=\Psi_{\mathrm{el}}(\mathbf{r} ; \mathbf{R}) \cdot \Psi_{\mathrm{nucl}}(\mathbf{R})
$$

onde a função $\Psi_{\text {nucl }}$ é solução da equação:

$$
\left[\mathrm{T}_{\text {nucl }}(\mathbf{R})+\mathrm{E}_{\mathrm{el}}(\mathbf{R})\right] \Psi_{\text {nucl }}(\mathbf{R})=\mathrm{E} \Psi_{\text {nucl }}(\mathbf{R})
$$

A solução da equação acima permite o estudo das vibrações, rotações e translações de uma molécula, que é de fundamental importância para muitas formas de espectroscopia, como infravermelho, Raman, microondas, etc.

Os erros causados pela aproximação de Born-Oppenheimer são muito pequenos, de modo que o estudo de estrutura eletrônica concentra-se apenas na resolução da equação envolvendo o Hamiltoniano eletrônico $\left(\mathbf{H}_{\mathrm{el}}\right)$.

A partir das limitações já expostas, como o uso de um Hamiltoniano nãorelativístico e a aproximação de Born-Oppenheimer, o problema se resume em como proceder para a resolução da equação eletrônica de Schrödinger. Essa equação pode ser resolvida exatamente apenas para sistemas monoeletrônicos, de modo que para os demais casos tem-se que recorrer a outras aproximações. Como os efeitos relativísticos foram deixados de lado na escolha do Hamiltoniano, o spin dos elétrons é introduzido de uma maneira ad hoc. Os elétrons possuem número quântico de spin igual a $1 / 2$, e as 
funçōes de spin correspondentes são chamadas de $\alpha$ e $\beta$, e obedecem às relações de ortonormalidade:

$$
\begin{aligned}
& \langle\alpha \mid \alpha\rangle=\langle\beta \mid \beta\rangle=1 \\
& \langle\alpha \mid \beta\rangle=\langle\beta \mid \alpha\rangle=0
\end{aligned}
$$

O fato do elétron possuir spin fracionário, ou seja, ser um férmion, tem conseqüência na propriedade da função de onda, que deve ser antissimétrica na troca das coordenadas espaciais e de spin entre dois elétrons. O princípio de Pauli, que estabelece que dois elétrons não podem possuir todos os números quânticos iguais, é uma conseqüência direta dessa propriedade de antissimetria. Uma maneira bastante conveniente de construir uma funçāo de onda que satisfaça essa propriedade de antissimetria é a utilização de um determinante, conhecido como Determinante de Slater (DS). Nas colunas desse determinante temos as funçōes dependentes das coordenacias espaciais e de spin, para cada elétron, definidas como spin orbitais, enquanto que nas linhas temos as coordenadas dos elétrons. Para o caso geral de $N$ elétrons e $N$ orbitais, o determinante de Slater apresenta a seguinte forma:

$$
\Phi_{\mathrm{DS}}=\frac{1}{\sqrt{N !}}\left|\begin{array}{cccc}
\phi_{1}(1) & \phi_{2}(1) & \ldots & \phi_{N}(1) \\
\phi_{1}(2) & \phi_{2}(2) & \ldots & \phi_{N}(2) \\
\ldots & \ldots & \ldots & \ldots \\
\phi_{1}(N) & \phi_{2}(N) & \ldots & \phi_{N}(N)
\end{array}\right|, \operatorname{com}\left\langle\phi_{i} \mid \phi_{j}\right\rangle=\delta_{i, j} \text { para } \forall \mathrm{i}, \mathrm{j}
$$

Essas funções são obtidas através do produto de uma função de onda espacial com uma função de spin ( $\alpha$ ou $\beta$ ), que assim passam a ser conhecidas como spinorbitais. Seu componente dependente das coordenadas espaciais é normalmente chamado de orbital atômico ou molecular, dependendo se o sistema em estudo for um átomo ou uma molécula.

A função de onda antissimétrica mais simples que pode ser usada para descrever o estado fundamental de um sistema de $N$ elétrons é o determinante de Slater. A partir dessa escolha de um único determinante para a função de onda, pode-se utilizar o princípio variacional para obter o que é conhecido como equações de Hartree-Fock (HF). A importância dessas equações reside no fato de serem um ponto de partida para 
maiores aproximações, dando origem aos métodos semi-empíricos, ou a resultados mais precisos, com a inclusão de mais determinantes, levando a uma convergência para uma solução exata da equação eletrônica de Schrödinger.

Para o cálculo da energia de um determinante de Slater é conveniente representar a função como uma soma de permutaçōes dos elementos diagonais do determinante. $O$ produto dos elementos da diagonal será representado por $\Pi$ e o símbolo $\Phi$ representará a funçāo de onda determinantal.

$$
\begin{aligned}
& \Phi=\mathbf{A}\left[\phi_{1}(1) \phi_{2}(2) \cdots \phi_{N}(N)\right]=\mathbf{A} \Pi \\
& \mathbf{A}=\frac{1}{\sqrt{N !}} \sum_{p=0}^{N-1}(-1)^{p} \mathbf{P}=\frac{1}{\sqrt{N !}}\left[1-\sum_{i j} \mathbf{P}_{i j}+\sum_{i j k} \mathbf{P}_{i j k}-\ldots\right]
\end{aligned}
$$

O operador 1 é a identidade, enquanto $\mathbf{P}_{i j}$ gera todas as possíveis permutaçís nas coordenadas de dois elétrons, $\mathbf{P}_{i j k}$ gera as permutaçōes entre três elétrons e assim por diante.

O Hamiltoniano eletrônico para um sistema de muitos elétrons é escrito da seguinte maneira:

$$
H_{e}=T_{e}+V_{n e}+V_{e e}+V_{n n}
$$

onde,

$$
\begin{aligned}
& \mathrm{T}_{\mathrm{e}}=-\sum_{i}^{N} \frac{1}{2} \nabla_{i}^{2} \\
& \mathbf{v}_{\mathrm{ne}}=-\sum_{\mu, i} \frac{\mathrm{Q}_{\mu}}{\left|\mathbf{r}_{\mu}-\mathbf{r}_{i}\right|} \\
& \mathbf{v}_{\mathrm{ee}}=\sum_{i<j} \frac{1}{\left|\mathbf{r}_{i}-\mathbf{r}_{j}\right|} \\
& \mathbf{v}_{\mathrm{nn}}=\sum_{\mu<v} \frac{\mathrm{Q}_{\mu} \mathrm{Q}_{\mathrm{v}}}{\left|\mathbf{r}_{\mu}-\mathbf{r}_{\mathrm{v}}\right|}
\end{aligned}
$$


Podemos rescrever o Hamiltoniano acima em funçāo dos operadores de um e de dois elétrons, definidos a seguir:

$$
\begin{aligned}
& \mathbf{H}_{\mathrm{e}}=\sum_{i} \mathbf{h}_{i}+\sum_{j>i} \mathbf{g}_{i j}+\mathbf{V}_{\mathrm{nn}} \\
& \mathbf{h}_{i}=\frac{1}{2} \nabla_{i}^{2}-\sum_{\mu} \frac{\mathrm{Q}_{\mu}}{\left|\mathbf{r}_{\mu}-\mathbf{r}_{i}\right|} \\
& \mathbf{g}_{i j}=\frac{1}{\left|\mathbf{r}_{i}-\mathbf{r}_{j}\right|}
\end{aligned}
$$

operador de um elétron $\mathbf{h}_{i}$ descreve o movimento do elétron $\boldsymbol{i}$ em um campo gerado pelos núcleos, enquanto $\mathbf{g}_{i j}$ descreve a repulsão elétron-elétron.

Utilizando as relaçōes acima, podemos escrever as seguintes expressões para a energia do determinante de Slater:

$$
\begin{aligned}
& E=\langle\Phi|H| \Phi\rangle \\
& E=\sum_{\rho}(-1)^{\rho}\langle\Pi|H| P \Pi\rangle
\end{aligned}
$$

O termo de repulsão nuclear não depende das coordenadas eletrônicas, de modo que contribui como uma constante para o valor da energia:

$$
\left\langle\Phi\left|V_{\mathrm{nn}}\right| \Phi\right\rangle=V_{\mathrm{nn}}\langle\Phi \mid \Phi\rangle=V_{\mathrm{nn}}
$$

No caso do operador de um elétron, apenas o operador identidade fornecerá valores não nulos. Realizando a integração apenas para a coordenada do elétron 1 temos:

$$
\left\langle\Pi\left|\mathbf{h}_{1}\right| \Pi\right\rangle=\left\langle\phi_{1}(1)\left|\mathbf{h}_{1}\right| \phi_{1}(1)\right\rangle=h_{1}
$$

Todos os elementos de matriz acima envolvendo permutaçōes das coordenadas dos elétrons corresponderão a termos nulos. 
Considerando o operador de dois elétrons, somente o operador identidade e $\mathbf{P}_{i j}$ fornecerão termos não nulos. A permutação de três elétrons fornecerá uma integral de overlap entre dois orbitais moleculares diferentes, que será igual a zero. $O$ operador identidade dará origem à seguinte integral:

$$
\left\langle\Pi\left|\mathbf{g}_{12}\right| \Pi\right\rangle=\left\langle\phi_{1}(1) \phi_{2}(2)\left|\mathbf{g}_{12}\right| \phi_{1}(1) \phi_{2}(2)\right\rangle=J_{12}
$$

onde $J_{12}$ é chamado de integral de Coulomb. Esse termo pode ser interpretado classicamente como sendo a repulsão entre duas distribuições de cargas descritas por $\phi_{1}^{2}(1)$ e $\phi_{2}^{2}(2)$. O operador de permutação $\mathbf{P}_{i j}$ fornece por sua vez o seguinte resultado:

$$
\left\langle\Pi\left|\mathbf{g}_{12}\right| \mathbf{P}_{12} \Pi\right\rangle=\left\langle\phi_{1}(1) \phi_{2}(2)\left|\mathbf{g}_{12}\right| \phi_{2}(1) \phi_{1}(2)\right\rangle=K_{12}
$$

onde $K_{12}$ é conhecido como integral de troca (exchange) e não possui uma interpretação clássica como a integral de Coulomb.

Dessa maneira, podemos obter a expressão para a energia de um sistema descrito por um determinante de Slater:

$$
E=\sum_{i=1}^{N} h_{i}+\frac{1}{2} \sum_{i=1}^{N} \sum_{j=1}^{N}\left(J_{i j}-K_{i j}\right)^{t}+V_{\mathrm{nn}}
$$

Para que a expressão acima possa ser utilizada na determinação das equaçōes de Hartree-Fock, servindo-se do método variacional, é conveniente reescrevê-la em termos do que são conhecidos como operadores de Coulomb e de troca:

$$
E=\sum_{i}^{N}\left\langle\phi_{i}\left|\mathbf{h}_{i}\right| \phi_{i}\right\rangle+\frac{1}{2} \sum_{i j}^{N}\left(\left\langle\phi_{j}\left|\mathbf{J}_{i}\right| \phi_{j}\right\rangle-\left\langle\phi_{j}\left|\mathbf{K}_{i}\right| \phi_{j}\right\rangle\right)+V_{\mathrm{nn}}
$$

onde

$$
\begin{aligned}
& \mathbf{J}_{i}\left|\phi_{j}(2)\right\rangle=\left\langle\phi_{i}(1)\left|\mathbf{g}_{12}\right| \phi_{i}(1)\right\rangle\left|\phi_{j}(2)\right\rangle \\
& \mathbf{K}_{i}\left|\phi_{j}(2)\right\rangle=\left\langle\phi_{i}(1)\left|\mathbf{g}_{12}\right| \phi_{j}(1)\right\rangle\left|\phi_{i}(2)\right\rangle
\end{aligned}
$$


Escrita a expressão para a energia de um determinante, o interesse passa a ser a determinação dos "melhores" orbitais, ou seja, aqueles que levam a uma energia mínima. Esses orbitais devem ser obtidos com a condiçāo de que os mesmos permaneçam ortogonais e normalizados. Para isso, utiliza-se a técnica dos multiplicadores de Lagrange, que requer que pequenas variações nos orbitais não causem mudanças no funcional de Lagrange, ou seja, o funcional deve ser estacionário com respeito às mudanças dos Norbitais.

$$
\begin{aligned}
& L=E-\sum_{i j}^{N} \lambda_{i j}\left(\left\langle\phi_{i} \mid \phi_{j}\right\rangle-\delta_{i j}\right) \\
& \delta L=\delta E-\sum_{j}^{N} \lambda_{i j}\left(\left\langle\delta \phi_{i} \mid \phi_{j}\right\rangle+\left\langle\phi_{i} \mid \delta \phi_{j}\right\rangle\right)=0
\end{aligned}
$$

onde $\lambda_{i j}$ são conhecidos como multiplicadores de Lagrange. As expressōes acima levam às equaçōes de Hartree-Fock:

$$
\begin{gathered}
\mathbf{F}_{i} \phi_{i}=\sum_{j}^{N} \lambda_{i j} \phi_{j} \\
\mathbf{F}_{i}=\mathbf{h}_{i}+\sum_{j}^{N}\left(\mathbf{J}_{j}-\mathbf{K}_{j}\right)
\end{gathered}
$$

onde $\boldsymbol{F}_{\boldsymbol{i}}$ é conhecido como operador de Fock. Essa equação pode ser simplificada pela escolha de uma transformação unitária que torna os multiplicadores de Lagrange diagonais $\left(\lambda_{i j} \rightarrow 0\right.$ e $\left.\lambda_{i l} \rightarrow \varepsilon_{i}\right)$. Isso é possível pois a funçāo de onda Hartree-Fock, ou seja, construída apenas como um único determinante, é invariante sob qualquer transformação unitária entre os spin orbitais. Os orbitais ф' que satisfazem essas condições são conhecidos como canônicos, e levam à equação:

$$
\mathrm{F}_{i} \phi_{i}^{\prime}=\varepsilon_{i} \phi_{i}^{\prime}
$$


Os multiplicadores de Lagrange $\varepsilon_{i}$ são interpretados como energias orbitais, pois obedecem à relação:

$$
\varepsilon_{i}=\left\langle\phi_{i}^{\prime}\left|F_{i}\right| \phi_{i}^{\prime}\right\rangle=h_{i}+\sum_{j}^{N}\left(J_{i j}-K_{i j}\right)
$$

Os orbitais canônicos são geralmente delocalizados e formam uma base para representações irredutíveis do grupo de ponto da molécula, ou seja, eles apresentam certas propriedades de simetria características da molécula e do operador de Fock. Esses orbitais são convenientes para fornecer uma interpretação física para os multiplicadores de Lagrange (energias orbitais). Nesse contexto, o potencial de ionização, imaginando os orbitais "congelados", corresponde ao módulo da energia orbital de onde o elétron foi removido (orbital $k$ ):

$$
E_{N}-E_{N-1}^{k}=h_{1}+\sum_{i=1}^{N}\left(J_{k i}-K_{k i}\right)=\varepsilon_{k}
$$

A afinidade eletrônica de uma molécula neutra é dada pela energia orbital do orbital k virtual onde o elétron será incorporado.

$$
E_{N+1}^{k}-E_{N}=\varepsilon_{k}
$$

Os resultados acima correspondem ao teorema de Koopman, e são uma primeira aproximação para valores de potencial de ionização e da afinidade eletrônica.

Para sistemas atômicos e diatômicos a equação de Hartree-Fock pode ser resolvida numericamente, mas para os demais casos a obtenção dos orbitais deve ser feita a partir de expansōes em termos de funções base conhecidas. Essa expansão traz a vantagem de transformar a equação diferencial em uma série de equações algébricas e que podem ser resolvidas com técnicas conhecidas de matrizes. Normalmente, essa expansāo é feita sobre orbitais atômicos, ou seja, sobre funções centradas nos núcleos, e é chamada de Combinação Linear de Orbitais Atômicos (Linear Combination of Atomic Orbitals - LCAO), embora esses orbitais não sejam necessariamente soluçōes HartreeFock do problema atômico. 


$$
\phi_{i}=\sum_{\alpha}^{M} c_{\alpha i} \chi_{\alpha}
$$

A substituição da expansão acima na equação de Hartree-Fock leva à equação matricial conhecida como de Roothaan-Hall:

$$
\begin{gathered}
\mathrm{FC}=\mathrm{SC} \varepsilon \\
F_{\alpha \beta}=\left\langle\chi_{\alpha}|\mathrm{F}| \chi_{\beta}\right\rangle \\
S_{\alpha \beta}=\left\langle\chi_{\alpha} \mid \chi_{\beta}\right\rangle
\end{gathered}
$$

A matriz $\mathbf{S}$ contém a sobreposição entre as funçōes base, enquanto que a matriz $\mathbf{F}$ contém os elementos da matriz de Fock. Cada elemento $F_{\alpha \beta}$ pode ser escrito da seguinte maneira:

$$
\begin{gathered}
\left\langle\chi_{\alpha}|\mathbf{F}| \chi_{\beta}\right\rangle=\left\langle\chi_{\alpha}|\mathbf{h}| \chi_{\beta}\right\rangle+\sum_{j}^{\text {OMocup. }}\left\langle\chi_{\alpha}\left|\mathbf{J}_{j}-\mathbf{K}_{j}\right| \chi_{\beta}\right\rangle \\
\left\langle\chi_{\alpha}|\mathbf{F}| \chi_{\beta}\right\rangle=D_{\alpha \beta} h_{\alpha \beta}+\sum_{\gamma}^{\text {OA OA }} \sum_{\delta}^{O A} D_{\gamma \delta}\left(\left\langle\chi_{\alpha} \chi_{\gamma}|\mathbf{g}| \chi_{\beta} \chi_{\delta}\right\rangle-\left\langle\chi_{\alpha} \chi_{\gamma}|\mathbf{g}| \chi_{\delta} \chi_{\beta}\right\rangle\right)
\end{gathered}
$$

onde

$$
\begin{aligned}
& D_{\gamma \delta}=\sum_{j}^{\text {OMocup. }} \mathrm{c}_{\gamma j} \mathrm{c}_{\delta j} \\
& \mathbf{g}=\frac{1}{\left|\mathbf{r}_{1}-\mathbf{r}_{2}\right|} \\
& h_{\alpha \beta}=\left\langle\chi_{\alpha}|\mathbf{h}| \chi_{\beta}\right\rangle
\end{aligned}
$$

Os elementos $D_{\gamma \delta}$ pertencem à matriz conhecida como matriz densidade. A expressão da energia em função dos orbitais atômicos apresenta a forma:

$$
E=\sum_{\alpha \beta}^{M} D_{\alpha \beta} h_{\alpha \beta}+\frac{1}{2} \sum_{\alpha \beta \gamma \delta}^{M}\left(D_{\alpha \beta} D_{\gamma \delta}-D_{\alpha \delta} D_{\delta \beta}\left\langle\chi_{\alpha} \chi_{\gamma}|\mathbf{g}| \chi_{\beta} \chi_{\delta}\right\rangle\right)+V_{\mathrm{nn}}
$$


Para a obtenção dos orbitais moleculares, ou seja, dos coeficientes $c_{\alpha i}$, é necessário diagonalizar a matriz de Fock da equação de Roothaan-Hall, mas os elementos da matriz de Fock só são conhecidos se todos os demais coeficientes forem conhecidos. Para resolver isso adota-se um procedimento iterativo conhecido como campo auto-consistente (self-consistent field - SCF). Basicamente, no método SCF seguese as seguintes etapas:

1) Calcular das integrais de um e dois elétrons;

2) Utilizar uma aproximação inicial para os coeficientes dos orbitais moleculares;

3) Obter a matriz densidade inicial;

4) Formar a matriz de Fock a partir das integrais de um elétron e da matriz densidade multiplicada pelas integrais de dois elétrons;

5) Diagonalizar a matriz de Fock, formando uma nova série de coeficientes.

6) Formar uma nova matriz densidade e repetir os passos 4 e 5 até que não ocorra mais uma mudança significativa, dentro de um certo limite, nessa matriz densidade.

A série de coeficientes finais determina a solução SCF. A solução final leva à formação de $M$ orbitais, sendo que $N$ correspondem aos orbitais ocupados e $M-N$ aos não ocupados ou virtuais.

À medida que o número de funções de base aumenta há uma melhora na descrição dos orbitais moleculares. Quando a base atinge o limite de saturação, ou seja, teoricamente o número de termos tende ao infinito, obtém-se o que é conhecido como o limite Hartree-Fock. Na prática, esse limite é atingido quando a energia não mais varia, dentro de certos limites, com a melhora da base. Isso significa a obtenção da melhor funçāo de onda descrita por apenas um único determinante.

Nas expressões acima não se preocupou com a forma dos orbitais moleculares, ou spin-orbitais, que são obtidos pelo produto de um orbital espacial com a função de spin $\alpha$ ou $\beta$. Se não existe uma restrição quanto à forma do orbital espacial obtém-se 
uma função de onda não-restrita (unrestricted Hantree-Fock wave function - UHF). Para um sistema com número par de elétrons e simetria de spin singleto, normalmente utilizase a condição dos orbitais moleculares possuírem as mesmas funções espaciais para os elétrons $\alpha$ e $\beta$. Dessa maneira obtém-se funçōes de onda restritas (restricted Hartree-Fock wave function - RHF). Há ainda a possibilidade de se utilizar orbitais restritos para 0 estudo de sistemas com camadas abertas, com isso força-se que os elétrons de um orbital duplamente ocupado sejam descritos pela mesma função espacial, mas os elétrons desemparelhados por orbitais distintos. Essa função de onda é conhecida como restrita de camada aberta (restricted open-shell Hartree-Fock wave function - ROHF).

Pelo fato da função de onda UHF não possuir essa restrição espacial, a energia calculada é sempre igual ou menor que a RHF ou ROHF. A função UHF tem a desvantagem de não ser normalmente uma autofunção de $S^{2}$. Isso significa que uma função L'HF singleto pode conter contribuições de estados excitados tripleło, quiniteto, etc. Do mesmo modo uma função dupleto pode conter contribuiçōes de estados quarteto, sexteto, etc. 


\section{CORRELAÇÃO ELETRÔNICA}

A metodologia Hartree-Fock fornece, com uma base suficientemente extensa, aproximadamente $99 \%$ da energia exata de um sistema usando o Hamiltoniano não relativístico. Apesar disso, o $1 \%$ da energia restante é importante para a descrição de diversos fenômenos químicos, e essa diferença é conhecida como energia de correlação eletrônica. Essa diferença de energia surge porque no método Hartree-Fock os elétrons são tratados como partículas independentes, e a interação instantânea entre eles é substituída por uma interaçāo elétrica "média".

método Hartree-Fock determina a melhor função de onda escrita na forma de um único determinante. Desse modo, uma maneira de melhorar essa função consiste em adicionar mais determinantes de Slater. Com isso a idéia de elétrons contidos em certos orbitais deve ser abandonada e ser substituída pelo conceito de densidade eletrônica. Como a solução Hartree-Fock fornece quase a totalidade da energia de um sistema, normalmente utiliza-se essa função como ponto de partida para as correçōes. A função de onda multideterminantal pode ser escrita da seguinte maneira:

$$
\Psi=a_{0} \Phi_{0}+\sum_{i=1} a_{i} \Phi_{i}
$$

Na expressão acima, $\Phi_{0}$ corresponde ao determinante Hartree-Fock, enquanto os demais termos $\Phi_{j}$ são obtidos a partir de substituiçōes de orbitais ocupados por virtuais, simbolicamente representando um processo de excitação. Com isso obtém-se determinantes unicamente, duplamente, triplamente, etc excitados em relação ao determinante de referência.

Existem três métodos mais conhecidos para o cálculo da energia de correlação: Interação de Configurações, Teoria de Perturbação e Coupled Cluster. Essas três metodologias serão comentadas a seguir, onde também incluímos uma seção sobre MCSCF, pois é de grande valia para descrever corretamente a estrutura eletrônica de um sistema além de ajudar na recuperação da chamada energia de correlação estática. 
Na última seção desse capítulo, são também apresentados alguns detalhes da metodologia do Funcional da Densidade que, apesar de nāo ser formalmente uma técnica $a b$ initio, tem despertado muito interesse nos últimos anos, por não exigir um custo computacional elevado como das metodologias pós-Hartree-Fock e, em muitos casos, fornecer resultados comparáveis aos métodos mais rigorosos. 


\section{INTERAÇÃO DE CONFIGURAÇŌES}

método Interação de Configuraçōes (Configuration Interaction - Cl) baseia-se no princípio variacional, de maneira semelhante ao método Hartree-Fock. A função de onda é escrita como uma combinação linear de determinantes, onde os coeficientes da expansão são determinados de modo que a energia seja a menor possível. Os orbitais moleculares utilizados para construir os determinantes de Slater excitados são mantidos fixos durante o cálculo. Eles podem corresponder aos orbitais HF ou a um outro tipo convenientemente definido.

Desse modo, a funçāo de onda apresenta a seguinte forma:

$$
\Psi_{C l}=a_{0} \Phi_{S C F}+\sum_{S} a_{s} \Phi_{S}+\sum_{D} a_{D} \Phi_{D}+\sum_{T} a_{T} \Phi_{T}+\ldots=\sum_{i=0} a_{i} \Phi_{i}
$$

onde os índices S, D e T indicam que os determinantes têm excitações simples, duplas e triplas, respectivamente, em relação ao determinante com a configuração Hartree-Fock.

Utilizando o método dos multiplicadores de Lagrange para a minimização da energia com a condição de que a função de onda $C /$ seja normalizada leva à seguinte equação matricial:

$$
\left(\begin{array}{ccccc}
H_{00}-E & H_{01} & \ldots & H_{0 j} & \ldots \\
H_{10} & H_{11}-E & \ldots & H_{1 j} & \ldots \\
\ldots & \ldots & \ldots & \ldots & \ldots \\
H_{\mathrm{j} 0} & \ldots & \ldots & H_{\mathrm{jj}}-E & \ldots \\
\ldots & \ldots & \ldots & \ldots & \ldots
\end{array}\right)\left(\begin{array}{c}
a_{0} \\
a_{1} \\
\ldots \\
a_{\mathrm{j}} \\
\ldots
\end{array}\right)=\left(\begin{array}{c}
0 \\
0 \\
\ldots \\
0 \\
\ldots
\end{array}\right)
$$

onde $H_{i j}=\left\langle\Phi_{i}|H| \Phi_{j}\right\rangle$. A equação acima pode ser escrita de uma forma mais sucinta como $(\mathbf{H}-E) \mathbf{a}=\mathbf{0}$ ou $\mathbf{H a}=$ Ea. A solução da equação corresponde a diagonalizar a matriz $C l$, e a energia $C l$ é a energia $E$ mais baixa, enquanto o segundo autovalor mais baixo corresponde à energia do primeiro estado excitado e assim por diante. 
Os elementos de matriz $H_{i j}$ podem ser determinados de maneira semelhante ao modo utilizado para obter a energia de um único determinante no caso Hartree-Fock. Esses elementos podem ser expressos em termos de integrais envolvendo os orbitais moleculares, pois os determinantes podem ser expandidos como uma soma de produtos de orbitais moleculares. Como o hamiltoniano não contém termos de spin, se dois determinantes diferem no spin total o elemento de matriz torna-se igual a zero. Essa situação ocorre no caso em que um elétron é excitado de um spin-orbital $\alpha$ para um $\beta$. Se o interesse é em obter uma função de onda de um estado singleto, somente determinantes singleto podem ser incluídos na expansão $\mathrm{Cl}$. No caso do operador hamiltoniano conter termos como spin-órbita, os elementos de matriz entre determinantes singleto e tripleto não são necessariamente iguais a zero, o que faz com que a função de onda $\mathrm{Cl}$ seja uma mistura de estados singleto e tripleto.

Uma simplificação na expansão da função de onda $C$ pode ser obtida com a escolha adequada da combinação lirear dos determinantes, de modo que sejam autofunções de spin corretas para o estado que se pretende estudar. Essa combinação linear é chamada de configurações adaptadas de spin (spin-adapted configurations SAC).

Se o sistema contém simetria, uma simplificação da matriz $\mathrm{Cl}$ ocorre pois alguns dos elementos da matriz serão iguais a zero. A simetria de um determinante é dada pelo produto direto das simetrias dos orbitais moleculares. Como o operador hamiltoniano pertence à representação totalmente simétrica, se dois determinantes pertencem a diferentes representaçōes irredutíveis o elemento de matriz será igual a zero.

Duas regras importantes para a determinação dos elementos de matriz $H_{i j}$ são as regras de Slater-Condon e o teorema de Brillovin. A regra de Slater-Condon diz que os elementos $H_{i j}$ são diferentes de zero se os dois determinantes diferirem em zero, um ou dois spin orbitais moleculares. Já o teorema de Brillouin diz que o elemento de matriz entre o determinante de referência Hartree-Fock e determinantes unicamente excitados é igual a zero. 
A funçāo de onda onde todos os determinantes possíveis sāo incluídos é conhecida como função de onda $\mathrm{Cl}$ completa (full Cl), sendo que a limitação nesse caso passa a ser a base atômica adotada, ou seja, o número de orbitais moleculares, ocupados e virtuais, formados. Poucos sistemas químicos são possíveis de serem tratados utilizando a função full $\mathrm{Cl}$, pois o elevado número de determinantes inviabiliza seu uso em cálculos computacionais de sistemas mais complexos. No entanto, cálculos full $\mathrm{Cl}$ são tomados como referências para a comparação com outros métodos mais aproximados, uma vez que essa metodologia fornece o melhor resultado possível de um sistema para uma determinada base atômica. Para tornar a metodologia Cl uma ferramenta de uso prático e viável há a necessidade de reduzir o número de determinantes. Truncar a expansão de modo a incluir apenas os determinantes com excitações simples nāo leva a alguma melhora sobre o resultado Hartree-Fock, pois os elementos de matriz entre esses determinantes e o de referência é igual a zero (teorema de Brillouin). Somente os determinantes duplamente excitados possuem elementos de matriz diferente de zero com o determinante Hartree-Fock, de modo que o nível $\mathrm{Cl}$ mais baixo e que causa uma melhora no resultado HF é o $C I D$, onde apenas os determinantes com excitaçōes duplas são incluídos. Embora os determinantes unicamente excitados apresentem elementos de matriz igual a zero com o determinante HF, eles entram indiretamente na função de onda pois os elementos de matriz com os determinantes duplamente excitados são diferentes de zero. Isso leva ao método CISD. As próximas aproximações são CIDT e CISDTQ, onde são incluídos determinantes com excitações triplas e quádruplas, respectivamente. No caso CISDTQ os resultados obtidos são próximos do full $\mathrm{Cl}$, mas mesmo truncando a expansão da função nesse nível ainda existe um número muito elevado de configurações, de modo que só pode ser aplicado a um número restrito de moléculas pequenas e ainda com uma base atômica também pequena. Desse modo, o único método $C$ que é aplicável para um grande número de moléculas é o CISD. Para moléculas não muito grandes e bases de tamanho médio o método CISD recupera de 80 a $90 \%$ da energia de correlação, mas à medida que a molécula aumenta esse valor vai diminuindo.

A principal deficiência do método CISD é não ser extensivo no tamanho /size extensive). À medida que o sistema aumenta o número de elétrons o método CISD recupera cada vez menos a porcentagem da energia de correlação. Uma maneira de 
corrigir essa limitação consiste em adicionar uma correção, sendo a mais comum a criada por Davidson, onde as contribuições quádruplas são aproximadas por:

$$
\Delta E_{\mathrm{Q}}=\left(1-\alpha_{0}^{2}\right) \Delta E_{\mathrm{CIS}[}
$$

Essa correção é representada por CISD + Q(Davidson), e nela o termo $a_{0}$ corresponde ao coeficiente relacionado à função Hartree-Fock de referência.

Uma aproximação bastante conhecida é o Cl Quadrático /Quadratic Cl QCISD). Esta é obtida a partir de um cálculo CISD mas com a inclusão de alguns termos de modo a que a função de onda seja extensiva no tamanho (size extensive). Normalmente os resultados obtidos são próximos aos do CCSD, que será descrito adiante, mas com a diferença do QCISD ter um número um pouco menor de termos.

Os métodos $\mathrm{Cl}$ descritos até o momento consideram somente as configurações geradas pela excitaçāo de elétrons de um único determinante, no caso, o determinante Hartree-Fock. Entretanto, uma função do tipo MCSCF pode ser utilizada como referência, fazendo com que o CISD envolva a excitação simples e dupla dos elétrons de todos os determinantes. Desse modo tem-se o método CISD com múltiplas referências /multireference configuration interaction - MRCl). Cálculos $M R C /$ com muitas configurações de referência fornecem resultados muito precisos, mas são muito exigentes do ponto de vista computacional. Mesmo truncando a expansão $\mathrm{MRCl}$ em excitaçōes simples e duplas, muitas vezes forma-se um número muito grande de configurações, que pode tornar o cálculo inviável. Desse modo, uma outra aproximação é utilizada, onde são selecionadas as configuraçōes que apresentam uma "interaçāo" com o(s) determinante(s) de referência acima de um certo valor. Essa "interação" é calculada utilizando a teoria de perturbação de segunda ordem (MP2). Esse método apresenta uma desvantagem na hora de comparar a energia de uma molécula em diferentes geometrias, pois a superfície de energia potencial pode tornar-se descontínua. Isso ocorre pois uma determinada configuração que é importante em um certo ponto pode nāo ser em outro, por apresentar uma "interação" menor que o valor limite, sendo excluída na função de onda. 


\section{MÉTODO DO CAMPO AUTOCONSISTENTE}

\section{MULTICONFIGURACIONAL - MCSCF}

O método MCSCF (multi-configuration self-consistent field) é semelhante ao método interação de configurações no aspecto onde os coeficientes dos determinantes são otimizados, mas existe uma flexibilização adicional onde os orbitais moleculares que compōem os determinantes são também otimizados.

Como normalmente está limitado a um certo número de determinantes, ele não é muito adequado se a intenção é obter boa parte da energia de correlação, pois a relaxação dos orbitais moleculares nāo é muito favorável nesse sentido. Nesse caso seria mais útil aumentar o número de determinantes e manter fixos os orbitais moleculares. A funçāo com um único determinante Hartree-Fock normalmente fornece bons resultados na descrição da estruturo eletrônica, mas em muitos casos ela falha, e desse modo o método MCSCF pode ser utilizado como uma ferramenta no caso da necessidade de uso de funções de onda multi-determinantais.

A maior dificuldade do método MCSCF consiste em selecionar os orbitais necessários para descrever corretamente a estrutura eletrônica. Essa seleção é necessária pois não existe a necessidade de realizar a otimização de todos os orbitais de um sistema, - que torna o processo computacionalmente muito dispendioso. Uma aproximação bastante utilizada é o CASSCF (complete active space self-consistent field), onde as configurações sāo geradas a partir da separação dos orbitais moleculares em orbitais ativos e inativos. Os orbitais ativos são normalmente os orbitais ocupados mais energéticos e os não ocupados (virtuais) menos energéticos de um cálculo RHF. Os demais orbitais sāo chamados de inativos, possuindo uma ocupação igual a 2 ou 0 , ou seja, estão duplamente ocupados ou vazios. Um cálculo do tipo full Clé realizado com os orbitais ativos, e todas as configurações com simetria adequada são selecionadas no cálculo MCSCF. A seleção de quais orbitais farão parte do espaço ativo deve ser feita cuidadosamente e manualmente, levando em conta o problema químico a ser estudado e a disponibilidade computacional. 
O cálculo full $\mathrm{Cl}$ realizado com os orbitais ativos limita bastante o número de orbitais a serem selecionados, por gerar um número muito grande de configurações. Devido a essas limitações, normalmente o número de elétrons e orbitais selecionados é menor que 10 ou 12. Com esse número reduzido fica clara a necessidade de se escolher com muito cuidado os orbitais a serem otimizados.

Normalmente, para cada orbital ocupado selecionado para o espaço ativo existe um orbital virtual correspondente, de modo que o número de elétrons e orbitais acabam sendo próximos. $O$ critério de energia na seleção dos orbitais é muitas vezes utilizado. $O$ orbital ocupado mais alto e o mais baixo virtual obtidos em um cálculo RHF normalmente são os mais importantes a serem incluídos no espaço ativo. Um problema surge quando se utiliza uma base atômica muito extensa, pois passa a existir um número muito grande de orbitais virtuais com energias baixas, dificultando a escolha. Outro problema é que se - sistema apresenta um caráter multi-configuraciona! a função de onda Ritif estará qualitativamente errada. A seleção dos orbitais ativos a partir de funções de onda inadequadas pode levar a resultados equivocados. Uma maneira de resolver esse problema consiste na utilização de orbitais naturais. Orbitais naturais são aqueles que diagonalizam a matriz densidade, sendo os autovalores iguais ao número de ocupação do orbital. Orbitais com ocupações diferentes de 0 ou 2 para um sistema de camada fechada são normalmente os mais importantes para serem incluídos no espaço ativo. Como a funçāo RHF fornece apenas valores de 0 ou 2, é necessária a realizaçāo de um cálculo com correlação eletrônica para a obtenção de números diferentes de 0 ou 2. Muitas vezes realiza-se um cálculo MP2 (ver próxima seção) antes do MCSCF, levando a resultados melhores se comparados com os orbitais RHF. Mas esse procedimento pode novamente falhar se a função RHF for ruim, de modo que a correçāo utilizando o MP2 não é suficiente para corrigir a deficiência, levando a resultados inadequados no cálculo MCSCF.

É importante salientar que o método CASSCF tende a fornecer resultados não equilibrados, pois a energia de correlação obtida provém exclusivamente dos orbitais presentes no espaço ativo, enquanto que nada é realizado com os orbitais inativos. Esse problema não ocorre se forem utilizados todos os orbitais do espaço de valência, mas tal procedimento não é viável para a maioria dos sistemas químicos de interesse. 
O método MCSCF exige um grande cuidado na seleção correta dos orbitais a serem usados no espaço ativo, de modo a fornecer uma descrição correta da estrutura eletrônica do sistema de estudo. Isso faz com que a utilização desse método não seja uma "caixa preta", onde todos os processos são realizados automaticamente, como no caso do Hartree-Fock ou MP2. 


\section{TEORIA DE PERTURBAÇÃO}

A idéia central dos métodos que utilizam a teoria da perturbaçāo é que a solução do problema em estudo difere muito pouco da de um problema cuja soluçāo é conhecida de modo exata ou aproximada. O operador Hamiltoniano é separado em duas partes, um termo de referência $\left(\mathbf{H}_{0}\right)$ e uma perturbação $\left(\mathbf{H}^{\prime}\right)$, sendo este último termo "pequeno" em relação ao operador de referência.

$$
\begin{gathered}
\mathbf{H}=\mathbf{H}_{0}+\lambda \mathbf{H}^{\prime} \\
\mathbf{H}_{0} \Phi_{i}=E_{i} \Phi_{i}, i=0,1,2, \ldots, \infty
\end{gathered}
$$

As soluções do Hamiltoniano $\mathbf{H}_{0}$ acima formam uma série completa, cujos termos podemos considerar como sendo ortenormais se o operador for hermiticno. A varićvel $\lambda$ é um parâmetro que determina a intensidade da perturbação. Nas expressões abaixo consideraremos a perturbação como independente do tempo e a função de onda do operador $\mathrm{H}_{0}$ como sendo não degenerada. A equação de Schrödinger do sistema perturbado é igual a:

$$
H \Psi=W \Psi
$$

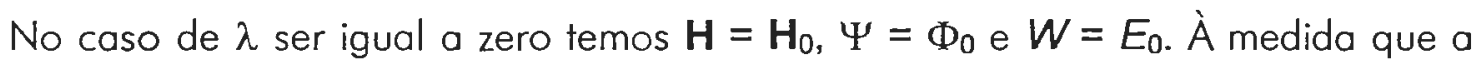
perturbação auménta, a energia $(W)$ e a função de onda $(\Psi)$ devem variar continuamente, de modo que eles podem ser escritos como uma expansão de Taylor em função do parâmetro de perturbação $\lambda$.

$$
\begin{gathered}
W=\lambda^{0} W_{0}+\lambda^{1} W_{1}+\lambda^{2} W_{2}+\lambda^{3} W_{3}+\ldots \\
\Psi=\lambda^{0} \Psi_{0}+\lambda^{1} \Psi_{1}+\lambda^{2} \Psi_{2}+\lambda^{3} \Psi_{3}+\ldots
\end{gathered}
$$

No caso de $\lambda=0$ temos que $\Psi_{0}=\Phi_{0}$ e $W_{0}=E_{0}$, sendo que o sistema nesse caso é chamado de não perțurbado, sendo a energia $E_{0}$ e função de onda $\Phi_{0}$ de ordem zero, 
respectivamente. Os termos $W_{1}, W_{2}, W_{3} \ldots$ e $\Psi_{1}, \Psi_{2}, \Psi_{3} \ldots$ correspondem às correçōes de primeira, segunda e terceira ordens, respectivamente.

Uma condição adotada e que é bastante útil é que a função de onda perturbada seja normalizada intermediariamente, ou seja, a sobreposição (overlap) entre essa função e a função não perturbada é igual a 1 .

$$
\begin{gathered}
\left\langle\Psi \mid \Phi_{0}\right\rangle=1 \\
\left\langle\Psi_{0}+\lambda \Psi_{1}+\lambda^{2} \Psi_{2}+\ldots \mid \Phi_{0}\right\rangle=1 \\
\left\langle\Psi_{0} \mid \Phi_{0}\right\rangle+\lambda\left\langle\Psi_{1} \mid \Phi_{0}\right\rangle+\lambda^{2}\left\langle\Psi_{2} \mid \Phi_{0}\right\rangle+\ldots=1 \\
\left\langle\Psi_{i \neq 0} \mid \Phi_{0}\right\rangle=0
\end{gathered}
$$

A conseqüência da expressão acima é que todos os termos de correção são ortogonais com relação à função de onda de referência.

Expandindo o hamiltoniano perturbado temos:

$$
\begin{gathered}
\left(H_{0}+\lambda H^{\prime}\right)\left(\lambda^{0} \Psi_{0}+\lambda^{1} \Psi_{1}+\lambda^{2} \Psi_{2}+\ldots\right)= \\
\left(\lambda^{0} W_{0}+\lambda^{1} W_{1}+\lambda^{2} W_{2}+\ldots\right)\left(\lambda^{0} \Psi_{0}+\lambda^{1} \Psi_{1}+\lambda^{2} \Psi_{2}+\ldots\right)
\end{gathered}
$$

A partir da expressão acima podemos separar os termos com o mesmo expoente de $\lambda$.

$$
\begin{aligned}
& \lambda^{0}: \mathrm{H}_{0} \Psi_{0}=W_{0} \Psi_{0} \\
& \lambda^{1}: \mathrm{H}_{0} \Psi_{1}+\boldsymbol{H}^{\prime} \Psi_{0}=W_{0} \Psi_{1}+W_{1} \Psi_{0} \\
& \lambda^{2}: \mathrm{H}_{0} \Psi_{2}+H^{\prime} \Psi_{1}=W_{0} \Psi_{2}+W_{1} \Psi_{1}+W_{2} \Psi_{0} \\
& \lambda^{n}: \mathrm{H}_{0} \Psi_{n}+H^{\prime} \Psi_{n-1}=\sum_{i=0}^{n} W_{i} \Psi_{n-i}
\end{aligned}
$$


As equaçōes acima representam as perturbações de ordem zero, de primeira, segunda e de enésima ordem. A equação de ordem zero corresponde à equação do sistema não perturbado. A equaçăo de primeira ordem apresenta dois termos desconhecidos, a correção de primeira ordem da energia, $W_{1}$, e da função de onda, $\Psi_{1}$. Como a solução da equação de Schrödinger não perturbado fornece uma série completa de funções, pode-se utilizar esse conjunto para expandir a função de onda corrigida de primeira ordem. Essa aproximação é conhecida como Rayleigh-Schrödinger. Com isso temos as expressões abaixo.

$$
\begin{gathered}
\Psi_{i}=\sum_{i} c_{i} \Phi_{i} \\
\left(H_{0}-W_{0}\right)\left(\sum_{i} c_{i} \Phi_{i}\right)+\left(H^{\prime}-W_{1}\right) \Phi_{0}=0
\end{gathered}
$$

Multiplicando a equação acima pela esquerda por $\Phi_{0}^{*}$ e integrando leva à correção da energia. A expressão abaixo mostra que a correçāo de primeira ordem na energia corresponde ao valor médio do operador de perturbação sobre a função não perturbada.

$$
\mathbf{w}_{1}=\left\langle\Phi_{0}\left|H^{\prime}\right| \Phi_{0}\right\rangle
$$

A correção de primeira ordem na função de onda pode ser obtida multiplicando a equação relativa a $\lambda^{1}$ por $\Phi_{j \neq 0}$ e integrando, o que permite obter os coeficientes da expansão:

$$
c_{j}=\frac{\left\langle\Phi_{j}\left|H^{\prime}\right| \Phi_{0}\right\rangle}{E_{0}-E_{j}}
$$

Pela expressão acima vemos que a correção é obtida a partir da função de onda e energia do sistema não perturbado. 
A partir das equaçōes de correção de segunda ordem pode-se obter as expressões da correção da energia e da função de onda de maneira semelhante à utilizada na correção de primeira ordem.

$$
\begin{gathered}
\Psi_{2}=\sum_{i} d_{i} \Phi_{i} \\
W_{2}=\sum_{i} c_{i}\left\langle\Phi_{0}\left|H^{\prime}\right| \Phi_{i}\right\rangle=\sum_{i \neq 0} \frac{\left\langle\Phi_{0}\left|H^{\prime}\right| \Phi_{i}\right\rangle\left\langle\Phi_{i}\left|H^{\prime}\right| \Phi_{0}\right\rangle}{E_{0}-E_{i}} \\
d_{j}=\sum_{i \neq 0} \frac{\left\langle\Phi_{j}\left|H^{\prime}\right| \Phi_{i}\right\rangle\left\langle\Phi_{i}\left|H^{\prime}\right| \Phi_{0}\right\rangle}{\left(E_{0}-E_{j}\right)\left(E_{0}-E_{i}\right)}-\frac{\left\langle\Phi_{j}\left|H^{\prime}\right| \Phi_{0}\right\rangle\left\langle\Phi_{0}\left|H^{\prime}\right| \Phi_{0}\right\rangle}{\left(E_{0}-E_{j}\right)^{2}}
\end{gathered}
$$

A complexidade das fórmulas aumenta à medida que as correções são feitas para ordens superiores. $O$ importante é mencionar que todas as correções foocem ser expressas em termos de elementos de matriz do operador de perturbaçāo sobre a função de onda não perturbada e das energias também nāo perturbadas.

As expressões acima são de caráter geral. Para a utilização das equações acima no cálculo da energia de correlação normalmente utiliza-se a teoria de perturbação de Møller-Plesset (MP). O Hamiltoniano não perturbado escolhido é uma soma dos operadores de Fock, que leva em conta a repulsão média elétron-elétron duas vezes. Desse modo a perturbação torna-se a diferença entre a repulsão exata $\mathbf{V}_{\text {ee }}$ menos duas vezes o operador $\left\langle\mathbf{V}_{\mathrm{ee}}\right\rangle$. Essa escolha do termo de perturbação não satisfaz a exigência de que seja pequeno em relação ao hamiltoniano nāo perturbado, mas apresenta a vantagem de que são conhecidas as soluçōes do sistema não perturbado, que corresponde à função de onda Hartree-Fock.

$$
\mathbf{H}_{0}=\sum_{i=1}^{N} \mathbf{F}_{i}=\sum_{i=1}^{N}\left(\mathbf{h}_{i}+\sum_{j=1}^{N}\left(\mathbf{J}_{i j}-\mathbf{K}_{i j}\right)\right)=\sum_{i=1}^{N} \mathbf{h}_{i}+2\left\langle\mathbf{V}_{\mathrm{ee}}\right\rangle
$$




$$
\begin{gathered}
\mathbf{H}_{0}=\sum_{i=1}^{N} \mathbf{h}_{i}+\sum_{i=1}^{N} \sum_{j=1}^{N}\left\langle\mathbf{g}_{i j}\right\rangle \\
\mathbf{H}^{\prime}=\mathbf{H}-\mathbf{H}_{0}=\mathbf{V}_{e e}-\sum_{i=1}^{N} \sum_{j=1}^{N}\left(\mathbf{J}_{i j}-\mathbf{K}_{i j}\right)=\mathbf{V}_{e e}-2\left\langle\mathbf{V}_{e e}\right\rangle \\
\mathbf{H}^{\prime}=\sum_{i=1}^{N} \sum_{j>i}^{N} \mathbf{g}_{i j}-\sum_{i=1}^{N} \sum_{j=1}^{N}\left\langle\mathbf{g}_{i j}\right\rangle
\end{gathered}
$$

A função de onda de ordem zero é o determinante de Hartree-Fock e a energia corresponde à soma das energias orbitais. A correção de primeira ordem na energia é dada por:

$$
W_{1}=\left\langle\Phi_{0}\left|H^{\prime}\right| \Phi_{0}\right\rangle=\left\langle\mathbf{V}_{\text {ee }}\right\rangle-2\left\langle\mathbf{V}_{\text {ee }}\right\rangle=-\left\langle\mathbf{V}_{\text {ee }}\right\rangle
$$

A correção de primeira ordem serve como uma correçāo à soma a mais da repulsão elétron-elétron na energia de ordem zero, de modo que a soma de $W_{1}$ e $W_{0}$ leva à energia Hartree-Fock.

Desse modo a correção na energia Hartree-Fock começa apenas a partir da correção de segunda ordem. A solução de menor energia para o sistema nāo perturbado é a função de onda Hartree-Fock, enquanto que as demais soluções correspondem a determinantes de Slater excitados. Para a correção de segundá ordem, existem elementos de matrizes do operador de perturbação entre o determinante Hartree-Fock e os determinantes excitados. Como a perturbaçāo corresponde a um operador de dois elétrons, todos os termos relacionados a excitaçōes triplas, quádruplas,... correspondem a elementos de matriz iguais a zero para o cálculo da energia corrigida. Através do teorema de Brillouin pode-se mostrar que elementos de matriz com determinantes unicamente excitados correspondem a valor zero. Com isso, a correção da energia passa a ser: 


$$
W_{2}=\sum_{i<j}^{\text {ocup. virt. }} \sum_{a<b}^{\left\langle\Phi_{0}\left|\mathrm{H}^{\prime}\right| \Phi_{i j}^{a b}\right\rangle\left\langle\Phi_{i j}^{a b}\left|\mathrm{H}^{\prime}\right| \Phi_{0}\right\rangle}
$$

Para a correção de segunda ordem da função de onda, existe o termo $\left\langle\Phi_{j}\left|H^{\prime}\right| \Phi_{i}\right\rangle\left\langle\Phi_{i}\left|H^{\prime}\right| \Phi_{0}\right\rangle$, e a partir dele temos que no segundo termo $\Phi_{i}$ deve ser igual a um determinante duplamente excitado para corresponder a um termo não nulo, enquanto que no primeiro termo $\Phi_{j}$ deve ser igual a um determinante unicamente, duplamente, triplamente ou quadruplamente excitado, lembrando que a perturbação corresponde a um operador de dois elétrons. O cálculo MP2 normalmente recupera de 80 a $90 \%$ da energia de correlação, e é muito popular por ser o método mais econômico para a inclusão de correlação.

Os métodos perturbativos citados diferem dos méiodos variacionuis, cono, por exemplo, Interação de Configurações, onde existe um limite inferior para a energia. Nos métodos perturbativos isso não ocorre necessariamente, podendo-se obter energias mais baixas que as exatas. Mas isso não chega a ser um problema pois na maioria dos casos o que interessa é a diferença de energia, e o importante é que os erros permaneçam constantes o máximo possível. $O$ fato dos métodos perturbativos serem extensivos pelo tamanho (size extensivity) é uma grande vantagem nesse sentido, se comparado com alguns métodos $C /$ truncados.

Uma limitação desse método é a suposição de que a função de onda de ordem zero é uma boa aproximação para a funçāo de onda real. Com isso, quanto pior for a função Hartree-Fock para a descrição de um determinado sistema, maior será o número de correções a serem incluídas para se atingir um certo grau de precisão. Se a função de onda apresenta um caráter multiconfiguracional, a expansāo feita sobre o único determinante apresenta uma fraca convergência. 


\section{COUPLED CLUSTER}

A idéia fundamental da teoria coupled cluster consiste em expressar a função de onda através da forma exponencial abaixo.

$$
\begin{gathered}
\Psi_{C C}=e^{T} \Phi_{0} \\
\mathrm{e}^{\mathrm{T}}=1+\mathrm{T}+\frac{1}{2} \mathrm{~T}^{2}+\frac{1}{6} \mathrm{~T}^{3}+\ldots=\sum_{\mathrm{k}=0}^{\infty} \frac{1}{\mathrm{k} !} \mathrm{T}^{\mathrm{k}}
\end{gathered}
$$

onde o operador $\mathbf{T}$ corresponde $\mathrm{a}$ :

$$
\mathrm{T}=\mathrm{T}_{1}+\mathrm{T}_{2}+\mathrm{T}_{3}+\ldots+\mathrm{T}_{N}
$$

operador $T_{i}$ atua sobre a função de onda de referência $\Phi_{0}$, que por sua vez pode ser a função Hartree-Fock, gerando determinantes de Slater excitados. Como exemplo, podemos ilustrar a ação dos operadores $T_{1}$ e $T_{2}$ sobre $\Phi_{0}$.

$$
\begin{gathered}
\mathrm{T}_{1} \Phi_{0}=\sum_{i}^{o c} \sum_{a}^{\text {virt }} t_{i}^{a} \Phi_{i}^{a} \\
\mathrm{~T}_{2} \Phi_{0}=\sum_{i<j}^{o c} \sum_{a<b}^{\text {virt }} t_{i j}^{a b} \Phi_{i j}^{a b}
\end{gathered}
$$

Nas expressōes acima representamos os orbitais através dos índices $i$ e $j$, que correspondem a orbitais ocupados, que são excitados para os orbitais virtuais $a$ e $b$. Os termos $t$, que correspondem aos coeficientes da expansão, são chamados de amplitudes.

A partir das expressões acima podemos reescrever o operador exponencial da seguinte maneira: 


$$
\begin{aligned}
e^{T} & =1+T_{1}+\left(T_{2}+\frac{1}{2} T_{1}^{2}\right)+\left(T_{3}+T_{2} T_{1}+\frac{1}{6} T_{1}^{3}\right)+ \\
& +\left(T_{4}+T_{3} T_{1}+\frac{1}{2} T_{2}^{2}+\frac{1}{2} T_{2} T_{1}^{2}+\frac{1}{24} T_{1}^{4}\right)+\ldots
\end{aligned}
$$

O primeiro termo da expansão gera a função Hartree-Fock, enquanto o segundo gera todas as excitaçōes simples. No primeiro parênteses existem dois termos, que levam às duplas excitações. $O$ primeiro termo $\left(\mathbf{T}_{2}\right)$ é chamado de conectado e o segundo $\left(\mathbf{T}_{1}^{2}\right)$ de desconectado. $O$ mesmo pode ser dito em relação ao segundo parênteses, que gera excitações triplas, onde existe o termo conectado $T_{3}$ e os desconectados $\left(T_{2} T_{1}, T_{1}^{3}\right)$, que consistem num produto de operadores. Fisicamente, o termo conectado $\mathbf{T}_{3}$ corresponde a três elétrons interagindo simultaneamente, enquanto que os produtos desconectados, como $\mathbf{T}_{2} \mathbf{T}_{1}$, correspondem a um elétron interagindo com um par eietrônico.

A equação de Schrödinger utilizando a função de onda exponencial passa a ser:

$$
\mathrm{He}^{\mathrm{T}} \Phi_{0}=E \mathrm{e}^{\mathrm{T}} \Phi_{0}
$$

Multiplicando à esquerda por $\Phi_{0}^{\star}$ e integrando obtém-se:

$$
\begin{gathered}
\left\langle\Phi_{0}\left|\mathrm{He}^{\top}\right| \Phi_{0}\right\rangle=\mathrm{E}_{\mathrm{cc}}\left\langle\Phi_{0} \mid \mathrm{e}^{\mathrm{T}} \Phi_{0}\right\rangle \\
\left\langle\Phi_{0}\left|\mathrm{He}^{\top}\right| \Phi_{0}\right\rangle=\mathrm{E}_{\mathrm{cc}}\left\langle\Phi_{0} \mid\left(1+\mathrm{T}_{1}+\mathrm{T}_{2}+\ldots\right) \Phi_{0}\right\rangle \\
\mathrm{E}_{\mathrm{cc}}=\left\langle\Phi_{0}\left|\mathrm{He}^{\top}\right| \Phi_{0}\right\rangle
\end{gathered}
$$

Expandindo o termo exponencial $\mathrm{e}^{\top}$ e lembrando que os elementos da matriz hamiltoniana correspondem a zero se o determinante excitado diferir em três ou mais orbitais em relação ao determinante Hartree-Fock, chega-se às relações abaixo. 


$$
\begin{gathered}
\mathrm{E}_{\mathrm{cc}}=\left\langle\Phi_{0} \mid \mathrm{H}\left(1+\mathrm{T}_{1}+\mathrm{T}_{2}+\frac{1}{2} \mathrm{~T}_{1}^{2}\right) \Phi_{0}\right\rangle \\
\mathrm{E}_{\mathrm{cc}}=\left\langle\Phi_{0}|\mathrm{H}| \Phi_{0}\right\rangle+\left\langle\Phi_{0}|\mathrm{H}| \mathrm{T}_{1} \Phi_{0}\right\rangle+\left\langle\Phi_{0}|\mathrm{H}| \mathrm{T}_{2} \Phi_{0}\right\rangle+\frac{1}{2}\left\langle\Phi_{0}|\mathrm{H}| \mathrm{T}_{1}^{2} \Phi_{0}\right\rangle \\
\left.\mathrm{E}_{\mathrm{cc}}=\mathrm{E}_{0}+\sum_{i}^{o c} \sum_{a}^{v i r t} t_{i}^{a}\left\langle\Phi_{0}|\mathrm{H}| \Phi_{i}^{a}\right\rangle+\sum_{i<j}^{o c} \sum_{a<b}^{v i r t}\left(t_{i j}^{a b}+t_{i}^{a} t_{j}^{b}-t_{i}^{b} t_{i}^{a}\right\rangle \Phi_{0}|\mathrm{H}| \Phi_{i j}^{a b}\right\rangle
\end{gathered}
$$

De acordo com o teorema de Brillouin, o primeiro elemento de matriz entre o determinante Hartree-Fock e o determinante com excitações simples é zero. Expandindo o segundo termo de matriz em função dos orbitais temos:

$$
\mathrm{E}_{\mathrm{cc}}=\mathrm{E}_{0}+\sum_{i<j}^{o c} \sum_{a<i}^{\mathrm{vir}}\left(t_{i j}^{a b}+t_{i}^{a} t_{j}^{b}-t_{i}^{b} t_{j}^{a}\right)\left(\left\langle\phi_{i} \phi_{j} \mid \phi_{a} \phi_{b}\right\rangle-\left\langle\phi_{i} \phi_{j} \mid \phi_{b} \phi_{a}\right\rangle\right)
$$

As equações para a obtenção dos coeficientes, ou amplitudes, são obtidas multiplicando-se a equação de Schrödinger $\left(\mathrm{He}^{\top} \Phi_{0}=E \mathrm{e}^{\top} \Phi_{0}\right)$ pela esquerda por determinantes unicamente, duplamente, triplamente, etc, excitados e integrando.

Se todos os operadores $\mathbf{T}_{N}$ foreth utilizados, todos os possíveis determinantes excitados serão gerados, sendo o resultado idêntico ao full Cl. Como essa possibilidade é viável apenas para poucos sistemas químicos, costuma-se truncar a expansāo de $\mathbf{T}_{N}$ para um número restrito de termos a fim de que essa metodologia possa ter alguma utilidade prática. A inclusão apenas de $\mathbf{T}_{1}$ nāo leva a qualquer melhora, pois o elemento de matriz entre determinantes unicamente excitados e o determinante Hartree-Fock é zero. A aproximação mais simples consiste em incluir o termo $T_{2}$, que certamente leva em conta a maior parte da correlação dinâmica. A partir da experiência com a metodologia $\mathrm{Cl}$ sabe-se que os determinantes unicamente excitados influem bastante nas propriedades de uma molécula, de modo que é importante incluí-la, e com isso obtém-se a aproximação conhecida como CCSD. Nesse caso, a expansão do termo exponencial torna-se: 


$$
\begin{gathered}
\Psi_{\mathrm{CCSD}}=\mathrm{e}^{\mathrm{T}_{1}+\mathrm{T}_{2}} \Phi_{0} \\
\Psi_{\mathrm{CCSD}}=\left[1+\mathrm{T}_{1}+\left(\mathrm{T}_{2}+\frac{1}{2} \mathrm{~T}_{1}^{2}\right)+\left(\mathrm{T}_{2} \mathrm{~T}_{1}+\frac{1}{6} \mathrm{~T}_{1}^{3}\right)+\left(\frac{1}{2} \mathrm{~T}_{2}^{2}+\frac{1}{2} \mathrm{~T}_{2} \mathrm{~T}_{1}^{2}+\frac{1}{24} \mathrm{~T}_{1}^{4}\right)+\ldots\right] \Phi_{0}
\end{gathered}
$$

A energia CCSD é dada pela expressão de $E_{C C}$ mostrada acima. Para obter as equaçōes que levam aos termos de amplitude é só multiplicar a equação de Schrödinger por determinantes unicamente e duplamente excitados e realizar a integração:

$$
\begin{aligned}
& \mathrm{He}^{\top} \Phi_{0}=E \mathrm{e}^{\top} \Phi_{0} \\
& \left\langle\Phi_{m}^{e}|H|\left(1+T_{1}+\left(T_{2}+1 / 2 T_{1}^{2}\right)+\left(T_{2} T_{1}+1 / 6 T_{1}^{3}\right)\right) \Phi_{0}\right\rangle=E_{\mathrm{ccsD}}\left\langle\Phi_{m}^{e} \mid T_{1} \Phi_{0}\right\rangle \\
& \left\langle\Phi_{m n}^{\mathrm{ef}}|\mathbf{H}|\left(1+\mathbf{T}_{1}+\left(\mathbf{T}_{2}+1 / 2 \mathbf{T}_{1}^{2}\right)+\left(\mathbf{T}_{2} \mathbf{T}_{1}+\frac{1}{6} \mathbf{T}_{1}^{3}\right)+\left(1 / 2 \mathbf{T}_{2}^{2}+1 / 2 \mathbf{T}_{2} \mathbf{T}_{1}^{2}+1 / 24 \mathbf{T}_{1}^{4}\right)\right) \Phi_{0}\right\rangle= \\
& E_{\mathrm{CCSD}}\left\langle\Phi_{m n}^{e f} \mid\left(\mathrm{T}_{2}+1_{2} \mathrm{~T}_{1}^{2}\right) \Phi_{0}\right\rangle
\end{aligned}
$$

Substituindo a expressão de $E_{C C}$ nas equações acima obtém-se uma série de equações acopladas não lineares para as amplitudes simples e duplas, e a determinação destas deve ocorrer de modo iterativo. Uma vez que as amplitudes são conhecidas podese calcular a energia e a função de onda eletrônica.

Para os casos onde a configuração Hartree-Fock é dominante, a metodologia CCSD consegue recuperar de 90 a $95 \%$ da energia de correlação. $O$ restante desses efeitos de correlação, que são devidos às excitações superiores, pode ser estimado com precisão utilizando alguns dos métodos de aproximação descritos a seguir. É interessante obter um modo de monitorar os cálculos a fim de determinar quando a correlação não dinâmica passa a ser importante. Se os orbitais não são os mais adequados para descrever as configurações excitadas na expansão da função de onda, pode-se esperar que os efeitos de uma relaxação orbital possam ser muito importantes. Essa relaxação é governada principalmente pelas excitações simples, e se ocorre uma grande contribuição das excitaçōes simples na função de onda pode-se deduzir que os orbitais Hartree-Fock não são os mais adequados para descrever a correlação do sistema, e que a correlação não dinâmica é importante. $O$ diagnóstico- $T_{1}$ é definido como a norma do vetor de 
amplitude das excitaçōes simples dividido pela raiz quadrada do número de elétrons, e é um indicativo da correlação nāo dinâmica e da qualidade da função de onda CCSD.

$$
T_{1}=\frac{\left|t_{1}\right|}{\sqrt{N}}
$$

A partir de várias comparações adota-se que quando $T_{1}>0,02$ a função de referência possui um significativo caráter multi-configuracional, e um cálculo coupled cluster com múltiplas referências passa a ser necessário.

O próximo passo no sentido de melhorar a aproximação CCSD é truncar a expansão de $T$ incluindo os termos $T_{1}, T_{2}$ e $T_{3}$, levando ao método conhecido como CCSDT. As equaçōes nesse caso são significativamente mais complexas que no CCSD, e o seu uso tem sido restrito a sistemas químicos com poucos átomos. Uma alternativa que in:ul: : peiturbação e adicionar ao resultado CCSD. No método conhecido como CCSD(T) utiliza-se as equações do MP4 mas com as amplitudes CCSD ao invés dos coeficientes da função de onda corrigida. Existe ainda um termo adicional que vem do MP5, relacionado ao acoplamento entre as excitaçōes simples e triplas. 


\section{FUNCIONAL DA DENSIDADE}

A Teoria do Funcional da Densidade tem tido uma utilização cada vez maior nos últimos anos como uma ferramenta eficaz no estudo de diversos sistemas químicos. Ela busca determinar a estrutura eletrônica fundamental de um sistema químico baseado na distribuição da densidade eletrônica. Ela tem permitido o estudo da densidade e da energia em moléculas, aglomerados e sólidos, sendo uma alternativa aos métodos $a b$ initio tradicionais, cujas propriedades são obtidas em termos das funções de onda. Essa técnica foi muito utilizada pelos físicos para o estudo da estrutura eletrônica de sólidos, mas recentemente passou a ser utilizada pelos químicos para o estudo de sistemas contendo poucos átomos. Uma característica dessa técnica é que a obtenção de resultados mais precisos depende apenas da escolha do funcional Exc, que será descrito en seguida, adequado, ao contrário das metodologias $a b$ initio tradicionais, onde a picrisiuo nos resultudos pode ser aumentada sistematicamente. $O$ desenvolvimento de funcionais cada vez mais eficazes tem permitido a obtenção de resultados muito precisos, comparáveis aos dos métodos ab initio mais sofisticados, com a vantagem de computacionalmente não requerer muitos recursos.

A base da Teoria do Funcional da Densidade (Density Functional Theory, DFT) é que a energia eletrônica do estado fundamental é determinado completamente pela densidade eletrônica, conforme demonstrado por Hohenberg e Kohn. ${ }^{8}$ Desse modo, existe uma correspondência única entre a densidade eletrônica de um sistema e a sua energia, mas a dificuldade que existe é que o funcional que conecta essas duas quantidades não é em princípio conhecido. O grande desafio na teoria DFT reside em descobrir funcionais que conectem a densidade eletrônica com a energia de maneira adequada, fornecendo resultados comparáveis aos obtidos com as metodologias ab initio tradicionais.

O funcional da energia, que depende da densidade eletrônica, pode ser dividido em três partes: energia cinética, $T[\rho]$, atração entre núcleo e elétron, $E_{n e}[\rho]$, e repulsão elétron-elétron, $E_{e}[\rho]$. Dentro da aproximação de Born-Oppenheimer, a repulsão núcleo-núcleo é uma constante. De modo semelhante à teoria Hartree-Fock, temos que 
$E_{\text {eel }}[\rho]$ pode ser dividido em duas partes, $\left.\int \rho\right]$ e $K[\rho]$, que correspondem aos termos de Coulomb e Troca, respectivamente. $O$ primeiro modelo adotado para o estudo de sistemas atômicos e moleculares foi considerar os elétrons como constituintes de um gás

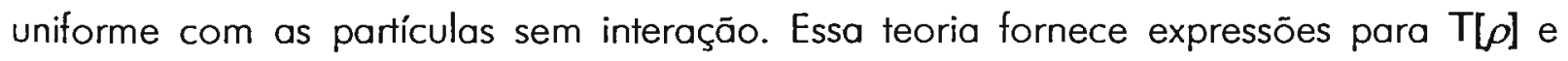
$K[\rho]$, constituindo o modelo conhecido como Thomas-Fermi-Dirac. Esse modelo não fornece valores precisos de energia e apresenta a desvantagem de representar inadequadamente a energia cinética e de não prever a existência de ligação química. Para a correção dessa limitação é necessário considerar um gás não uniforme de elétrons, levando em conta não apenas a densidade eletrônica, mas também sua derivada.

Na base do uso do funcional da densidade na química está a adoção da linguagem de orbitais, conforme proposto por Kohn e Sham. A idéia básica do formalismo de Kohn e Sham reside em separar o termo de energia cinética em duas partes, uma que pode ser caiculada exatamente e outra que corresponderia a uma pequena correção. Essa aproximação é justificada pelo fato do modelo de gás uniforme não representar adequadamente a energia cinética. Inicialmente podemos considerar 0 Hamiltoniano descrito da seguinte maneira:

$$
H_{\lambda}=T+V_{e x t}(\lambda)+\lambda V_{e e}
$$

onde $\lambda$ assume valores de 0 a 1 . Quando $\lambda=1$ temos que $V_{\text {ext }}$ corresponde ao potencial criado pelos núcleos $\left(V_{n e}\right)$, enquanto que para valores menores que $1 \quad 0$ potencial externo $\left(V_{\text {ext }}\right)$ é ajustado de maneira a obter a mesma densidade eletrônica do sistema real, ou seja, com todos os elétrons interagindo. Quando $\lambda=0$ tem-se um sistema com os elétrons não interagindo, de modo que se pode obter uma solução exata para a equação de Schrödinger, obtendo-se um determinante de Slater formado por orbitais moleculares $\phi_{i}$. Desse modo a energia cinética é expressa por:

$$
T_{S}=\sum_{i=1}^{N}\left\langle\phi_{i}\left|-\frac{1}{2} \nabla^{2}\right| \phi_{i}\right\rangle
$$


Essa equação é uma aproximação para o caso onde $\lambda=1$, ou seja, com os elétrons interagindo. Um ponto chave na teoria de Kohn e Sham é calcular a energia cinética real de um sistema a partir da suposição dos elétrons não interagindo, sendo que a diferença entre a energia cinética exata e a aproximada é muito pequena. Essa diferença de energia é incorporada no termo de correlação e troca $\left(E_{x c}\right)$, que é de grande importância para o DFT. A energia DFT pode ser escrita da seguinte maneira:

$$
E_{\mathrm{DFT}}[\rho]=T_{s}[\rho]+E_{n e}[\rho]+J[\rho]+E_{X C}[\rho]
$$

onde o índice $S$ no termo de energia cinética indica que este está sendo calculado com o determinante de Slater. Desse modo, o termo de correlação e troca pode ser obtido pela diferença entre a energia exata e a energia acima:

$$
\left.\Sigma_{X C}[\rho]=(\pi \rho]-T_{S}[\rho]\right)+\left(E_{e e}[\rho]-J[\rho]\right)
$$

A primeira parte contém a energia de correlação cinética, enquanto a segunda contém a energia de correlação de troca e potencial (exchange e potential). É importante notar que a definição de energia de correlação no DFT é diferente da do método ab initio. Neste último caso, a energia de correlação é definida como a diferença entre a energia exata e a correspondente Hartree-Fock, enquanto que a energia de troca é a diferença entre a energia de repulsão eletrônica e a energia de Coulomb.

O grande desafio no DFT consiste em obter uma fórmula adequada para o termo de correlação e troca. Se esse termo é conhecido, o procedimento passa a ser semelhante ao do método Hartree-Fock, onde busca-se minimizar a energia a partir de uma série de orbitais, que são construídos com a condição de serem ortogonais. Para a descoberta desses orbitais, utiliza-se o método dos multiplicadores de Lagrange sobre a energia DFT, do mesmo modo como feito no caso Hartree-Fock, obtendo-se uma série de equações, conhecidas como Kohn-Sham. Essas equações são semelhantes aos do Hartree-Fock, onde os multiplicadores de Lagrange são também associados com a energia orbital. Importante notar que, diferentemente do método Hartree-Fock, se a expressão exata de $E_{x c}[\rho]$ for utilizada, obtém-se a energia exata, incluindo a correlação eletrônica. As equaçōes de Kohn-Sham estāo mostradas abaixo: 


$$
\begin{gathered}
\mathbf{h}_{K S} \phi_{i}=\varepsilon_{i} \phi_{i} \\
\mathbf{h}_{K S}=-\frac{1}{2} \nabla^{2}+\mathbf{V}_{\text {efetivo }} \\
\mathbf{V}_{\text {efetivo }}(\mathbf{r})=\mathbf{V}_{\mathrm{ne}}(\mathbf{r})+\int \frac{\rho\left(\mathbf{r}^{\prime}\right)}{\left|\mathbf{r}-\mathbf{r}^{\prime}\right|} d \mathbf{r}^{\prime}+\mathbf{V}_{\mathrm{xc}}(\mathbf{r})
\end{gathered}
$$

Os orbitais acima podem os obtidos numericamente ou através de uma expansão em termos de funçōes base conhecidas, do mesmo modo que nas equações de Roothaan-Hall na metodologia Hartree-Fock. A medotodologia DFT tem o potencial de fornecer a energia exata, incluindo a energia de correlação, se for utilizada a forma exata de Exc. Com isso o DFT apresenta a possibilidade de incluir um elemento muito complicado nos cálculos ab initio, a energia de correlação, com um custo computacional equivalente ao Hartree-Fock.

Os métodos DFT diferem entre si pela escolha da forma do funcional para a energia de correlação e troca. Como não existe uma regra de como deve ser a forma desse funcional, muitos têm sido propostos ultimamente, e a preferência de um ou outro depende da comparação com resultados experimentais ou com métodos ab initio mais sofisticados.

Uma aproximação muito utilizada consiste em separar $E_{x C}[\rho]$ em duas partes, uma de troca $E_{\mathrm{X}}$ e outra de correlação $E_{\mathrm{c}}$. Cada uma dessas energias é escrita em termos de uma energia por partícula, ou densidade de energia, $\varepsilon_{x}$ e $\varepsilon_{c}$ :

$$
E_{\mathrm{xc}}[\rho]=E_{\mathrm{x}}[\rho]+E_{\mathrm{c}}[\rho]=\int \rho(\mathbf{r}) \varepsilon_{\mathrm{x}}[\rho(\mathbf{r})] \mathrm{d} \mathbf{r}+\int \rho(\mathbf{r}) \varepsilon_{\mathrm{c}}[\rho(\mathbf{r})] \mathrm{d} \mathbf{r}
$$

O potencial $\mathbf{V}_{\mathrm{xc}}(\mathbf{r})$ é dado pela relação:

$$
\mathbf{V}_{x c}(\mathbf{r})=\frac{\partial E_{x c}[\rho]}{\partial \rho(\mathbf{r})}=\varepsilon_{x c}[\rho(\mathbf{r})]+\rho(\mathbf{r}) \frac{\partial \varepsilon_{x c}(\mathbf{r})}{\partial \rho(\mathbf{r})}
$$

Nas aproximaçōes da densidade local (local density approximation, LDA), a densidade é localmente tratada como um gás de elétrons uniforme ou como uma função 
que varia muito pouco. No caso onde a densidade dos elétrons $\alpha$ é diferente dos $\beta, L D A$ é substituido pela aproximação da densidade de spin local flocal spin density approximation, LSDA). Nos sistemas de camada fechada $\angle S D A$ é igual a LDA. Apesar da simplicidade do método $\angle S D A$, esta fornece resultados comparáveis aos obtidos com a metodologia Hartree-Fock. As energias de troca (exchange) nos dois casos são dadas pelas relações:

$$
\begin{gathered}
E_{x}^{\mathrm{LDA}}[\rho]=-C_{x} \int \rho^{4 / 3}(\mathbf{r}) \mathrm{d} \mathbf{r} \\
\varepsilon_{x}^{\mathrm{LDA}}[\rho]=-C_{x} \rho^{1 / 3} \\
E_{x}^{\mathrm{LSDA}}[\rho]=-2^{1 / 3} C_{x} \int\left[\rho_{\alpha}^{4 / 3}+\rho_{\beta}^{4 / 3}\right](\mathbf{r}) \mathrm{d} \mathbf{r} \\
\underbrace{\mathrm{LSDA}}_{x}[\rho]=-2^{1 / 3} C_{x}\left[\rho_{\alpha}^{1 / 3}+\rho_{\beta}^{1 / 3}\right]
\end{gathered}
$$

Um progresso em relação ao $\angle S D A$ consiste em considerar um gás de elétrons não uniforme. Nesse caso as energias de correlação e troca passam a ser dependentes não apenas da densidade eletrônica, mas também do gradiente da densidade. Esses métodos são conhecidos como aproximação de gradiente generalizado (generalized gradient approximation, GGA). Muitos funcionais utilizando essa aproximação têm sido utilizados e têm tido aceitação cada vez maior. Perdew e Wang (PW86) e Becke (B ou B88) ${ }^{10}$ propuseram correçōes para a energia de troca LSDA. Perdew e. Wang também propuseram um funcional de troca similar ao B88 para ser utilizado com o funcional de correlação PW91. Muitos funcionais para a energia de correlação tem sido propostos, sendo que o sugerido por Lee, Yang e Parr (LYP) ${ }^{\prime \prime}$ tem tido uma grande aceitação. Perdew também propôs uma correçāo do resultado $L S D A$ para a energia de correlação, conhecida como $\mathrm{P} 86^{12,13}$ sendo modificada em seguida por Perdew et al., que propuseram o PW91. ${ }^{14}$

Os métodos $\angle S D A$ geralmente fornecem bons resultados para estruturas moleculares, freqüências vibracionais e densidades de carga em sistemas que apresentam ligações químicas fortes, ou seja, excetuando as ligações de hidrogênio e de van der Waals, mas nāo sāo muito úteis para a obtenção de dados termoquínaicos. Os métodos 
GGA, por sua vez, fornecem bons resultados termodinâmicos, com erros da ordem de 6 $\mathrm{kcal} / \mathrm{mol}$, e fornecem dados estruturais e energéticos consistentes para sistemas com pontes de hidrogênio. No caso de sistemas com ligações muito fracas, como no caso das interaçōes de van der Waals, os métodos GGA aparentemente falham.

Uma forma que tem sido utilizada para expressar energia de troca consiste em realizar uma combinaçāo de resultados de funcionais de troca $\angle S D A$, exata e de correçōes do tipo GGA. Modelos que incluem termos de troca exatos, ou seja, idênticos aos do método Hartree-Fock, são conhecidos como métodos híbridos. Como exemplo temos o funcional com três parâmetros de Becke (B3): ${ }^{15}$

$$
E_{\mathrm{xc}}^{\mathrm{B} 3}=(1-a) E_{\mathrm{x}}^{\mathrm{LSDA}}+a E_{\mathrm{x}}^{\text {exato }}+b \Delta E_{\mathrm{x}}^{\mathrm{B} 88}+E_{\mathrm{c}}^{\mathrm{LSDA}}+c \Delta E_{\mathrm{c}}^{\mathrm{GGA}}
$$

onde os parâmetros $a, b$ e $c$ são obtidos de modo a reproduzir resultados experimentais.

Em geral os métodos GGA fornecem valores de geometrias e freqüências vibracionais para moléculas estáveis da mesma qualidade ou melhor que os obtidos com MP2, com a vantagem de ser computacionalmente comparável ao Hartree-Fock. Para sistemas contendo um caráter multiconfiguracional, onde normalmente MP2 não descreve corretamente, métodos DFT normalmente fornecem resultados de qualidade comparável os obtidos com a metodologia Coupled Cluster. Outra vantagem é que os métodos DFT baseados em orbitais não restritos no estudo de sistemas com camadas abertas, não sofrem muito o efeito da contaminação de spin, ou seja, $\left\langle S^{2}\right\rangle$ é normalmente próximo de $S_{2}\left(S_{z}+1\right)$.

Normalmente, interaçōes fracas como as do tipo de van der Waals não são bem descritas. Métodos $L D A$ geralmente causam um superestimação das ligaçōes, prevendo a atraçāo, por exemplo, de átomos de gases nobres, enquanto que métodos GGA acabam fornecendo uma interação repulsiva. Ligaçōes de hidrogênio, entretanto, são normalmente bem descritos pelos métodos DFT. Existem indicações de que energias relativas e estruturas dos estados de transiçāo nāo sāo tão confiáveis como os métodos tradicionais, mas ainda há a necessidade de um maior número de sistemas estudados para se ter uma idéia mais precisa. 
Os métodos DFT até o presente não são adequados para o estudo de estados excitados com simetria igual ao do estado fundamental. A ausência de uma função de onda torna difícil assegurar a ortogonalidade entre o estado fundamental e os estados excitados.

BILLIOTECA 


\section{REFERÊNCIAS}

1. A. Szabo, Modern Quantum Chemistry: Introduction to Advanced Electronic Structure Theory, Dover Publications, Inc., N. Y., 1989.

2. F. Jensen, Introduction to Computational Quantum Chemistry, Wiley, Chichester, England, 1995; pp 112-117.

3. R. McWeeny, Methods of Molecular Quantum Mechanics, Academic Press, 1992.

4. R. J. Bartlett, J. Phys. Chem. 93, 1697 (1989).

5. P. R. Taylor, Lecture Notes in Quantum Chemistry II/European Summer School in Quantum Chemistry, B. O. Roos (ed.), Springer Verlag, 1994.

6. W. Kohn, A. D. Becke e R. G. Parr, J. Phys. Chem. 100, 1297: (1996).

7. E. J. Baerends e O. V. Gritsenko, J. Phys. Chem. A 101, 5383 (1997).

8. P. Hohenberg e W. Kohn, Phys. Rev. 136, B864 (1964).

9. J. D. Perdew e Y. Wang, Phys. Rev. B 33, 8800 (1986).

10. A. D. Becke, Phys. Rev. B 38, 3098 (1988).

11. C. Lee, W. Yang e R. G. Parr, Phys. Rev. B 37, 785 (1988).

12. J. P. Perdew, Phys. Rev. B 33, 8822 (1986).

13. J. P. Perdew, Phys. Rev. B 34, 7406 (1986).

14. J. P. Perdew, J. A. Chevary, S. H. Vosko, K. A. Jackson, M. R. Pederson, D. J. Singh e C. Fiolhais, Phys. Rev. B 46, 6671 (1992).

15. A. D. Becke, J. Chem. Phys. 98,5648 (1993). 


\section{SISTEMAS DO TIPO Si $\mathrm{S}_{y}$}




\subsection{INTRODUÇÃO}

grande desenvolvimento que se tem observado na área da química computacional tem permitido o estudo de sistemas químicos com um grau de precisão e confiança nos resultados muito grande. Um exemplo nesse sentido é o estudo de aglomerados moleculares, ou seja, moléculas de pequenas dimensões, onde pode-se obter atualmente dados dentro de uma precisão química, com erros da ordem de poucos $\mathrm{kcal} / \mathrm{mol}$. Uma vantagem da abordagem teórica no estudo desses sistemas é que em muitos casos existe uma grande dificuldade em se obter os aglomerados experimentalmente, pois estes costumam ser instáveis e/ou muito reativos, de modo que a obtenção de parâmetros geométricos, energias de ligação, etc, torna-se muito difícil. Uma outra dificuldade ocorre, no caso de aglomerados contendo dezenas de átomos, em obter a geometria dos mesmos, pois são muito pequenos para serem determinados a partir de técnicas de difração e grandes o bastante para técnicas espectroscópicas. Mas novas técnicas experimentais como a deposição química de vapor e a espectrometria de massa de neutralização-reionização têm estimulado muito os investigadores no estudo desses novos compostos. ${ }^{1-3}$ Em vista dessas limitações, o estudo teórico tem a vantagem de poder fornecer as informações necessárias e complementares para os experiméntalistas, de modo a ajudá-los na interpretação correta dos resultados.

O estudo de aglomerados moleculares tem despertado muito interesse pois são estruturas que se encontram, dimensionalmente falando, entre átomos e sólidos, fazendo com que propriedades como geometria, estrutura eletrônica e ligações químicas sejam muito distintas das de um sólido. Nesses aglomerados as propriedades mencionadas passam a ser influenciadas pelas ligaçōes químicas locais, não dependendo das influências em larga escala, como observada nos sólidos.

Inicialmente, houve um grande interesse nos aglomerados contendo átomos metálicos, para em seguida se concentrar também nos semicondutores. Nesse sentido, podemos mencionar $\circ$ artigo de Raghavachari e Curtiss, ${ }^{4}$ onde são apresentados resultados de aglomerados de boro, alumínio, carbono, silício, fósforo e enxofre com número de átomos variando de 2 a 12 e utilizando as teorias Gaussian-1 e Gaussian-2. 
Com relação ao estudo de aglomerados metálicos, podemos citar como exemplo o trabalho de Nayak et al., ${ }^{5}$ onde são apresentados resultados de geometrias e energias de ligação de aglomerados de $\mathrm{Ni}$ com até 23 átomos e a utilização de potenciais empíricos e simulação de dinâmica molecular.

Vários estudos teóricos e experimentais foram realizados para aglomerados contendo apenas átomos de silício. ${ }^{6.12}$ Experimentalmente, podemos citar o trabalho de Rantala et al., ${ }^{6}$ onde foram obtidos espectros de absorção de vários isômeros de $\mathrm{Si}_{9}, \mathrm{Si}_{10}$ e $\mathrm{Si}_{11}$. Do ponto de vista teórico, existem estudos que vão de um cálculo rigoroso para o $\mathrm{Si}_{2}{ }^{7}$ com a utilização da metodologia $M R C l$ e a descrição de alguns estados eletrônicos, até metodologias com maior grau de aproximação para sistemas com um número maior de átomos de silício. Krack e $\mathrm{Jug}^{8}$ estudaram a reatividade dos aglomerados $\mathrm{Si}_{5}$ e $\mathrm{Si}_{10}$ com amônia, enquanto Ramakrishna e Bahel ${ }^{9}$ estudaram várias estruturas para a espécie $\mathrm{Si}_{12}$, procurando encontrar um padrāo para o crescimento do aglomerado de silício. Aglomerados com até 10 átomos foram estudados por Raghavachari e Rohifing, io Fournier et al. ${ }^{11}$ e Hartke, ${ }^{12}$ com metodologias variando do Hartree-Fock, MP2, MP4 ao Funcional da Densidade.

Ao lado dos aglomerados contendo apenas um tipo de elemento químico, várias pesquisas têm sido realizadas em sistemas contendo ao menos dois elementos diferentes. A importância desses estudos é muito grande, pois podem ajudar na compreensão de processos químicos que ocorrem no meio interestelar, fornecer informaçōes sobre estruturas, ligaçōes químicas e ajudar no entendimeńto de processos complexos como as reações que ocorrem na deposição química de vapor (chemical vapor deposition - CVD). A técnica CVD tem sido muito utilizada para a síntese de materiais com grandes implicações tecnológicas.

Com relação aos sistemas contendo silício e oxigênio, podemos citar o trabalho de Wang et al., ${ }^{13}$ onde foram obtidos espectros fotoeletrônicos dos aglomerados $\mathrm{SiO}_{2}$, $\mathrm{Si}_{2} \mathrm{O}_{3}$ e $\mathrm{Si}_{2} \mathrm{O}_{4}$. Existe um trabalho teórico realizado por Boldyrev e Simon, ${ }^{14}$ onde foram estudadas várias estruturas com fórmula $\mathrm{Si}_{2} \mathrm{O}$ e $\mathrm{Si}_{3} \mathrm{O}$ com as metodologias Hartree-Fock, MP2, MP4 e QCISD(T). Kishi et al. ${ }^{15}$ estudaram diversos sistemas com fórmula $\mathrm{Si}_{n} \mathrm{Na}$, com $n$ variando de 1 a 7 . Eles otimizaram várias espécies, fornecendo valores de parâmetros 
geométricos, energias de adsorção e ionização. Kaya e Nakajima ${ }^{16}$ realizaram experimentos nas espécies $\mathrm{Si}_{n} \mathrm{Na}_{m}, \mathrm{Si}_{n} \mathrm{C}_{m}$ e $\mathrm{Si}_{n} \mathrm{~F}$ utilizando a técnica de espectroscopia fotoeletrônica, do mesmo modo como feito por Kawamata et al. ${ }^{17}$ no estudo das espécies aniônicas $\mathrm{Si}_{n} \mathrm{~F}_{m}$. Os compostos de silício e carbono são mais estudados, tanto experimentalmente quanto teoricamente, por serem precursores de uma cerâmica bastante conhecida, o carbeto de silício. Michalopoulos et al. ${ }^{18}$ estudaram a espécie $\mathrm{SiC}_{2}$ e, através da análise rotacional do jato esfriado (jet cooled), observaram que a molécula apresenta uma geometria angular. Presilla-Márquez e Graham ${ }^{19,20}$ obtiveram o espectro vibracional das espécies $\mathrm{Si}_{3} \mathrm{C}$ e $\mathrm{Si}_{2} \mathrm{C}_{3}$, ambas aprisionadas em matrizes a baixas temperaturas, sendo que Rittby ${ }^{21,22}$ realizou cálculos ab initio de ambas estruturas, obtendo resultados concordantes. Outros trabalhos foram realizados para as espécies $\mathrm{Si}_{2} \mathrm{C}_{4}, \mathrm{Si}_{3} \mathrm{C}_{3}, \mathrm{Si}_{4} \mathrm{C}_{2}{ }^{23}$ e $\mathrm{Si}_{2} \mathrm{C}_{2}{ }^{24} \mathrm{Um}$ estudo da estabilidade dos ânions de fórmula $\mathrm{Si}_{x} \mathrm{C}_{y}{ }^{2-}$, com $x$ variando de 1 a 3 e y de 4 a 9, foi realizado por Dreuw ef al. ${ }^{25}$ enquanto Kishi ef al. ${ }^{26}$ estudaram a afinidade eletrônica das espécies $\mathrm{Si}_{n} \mathrm{C}, \mathrm{com} n$ variando de 2 a 5 .

O estudo de aglomerados de átomos de silício e nitrogênio é uma área não muito explorada teoricamente. $O$ conhecimento da estabilidade e das propriedades estruturais das várias espécies possíveis é certamente um passo importante que pode ajudar a determinar a composição e as possíveis reações que ocorrem em fase gasosa e que levam à formação do nitreto de silício, $\mathrm{Si}_{3} \mathrm{~N}_{4}$, uma cerâmica de grande importância tecnológica. O pequeno número de estudos contrasta com os já realizados sobre os aglomerados de silício e de silício com carbono.

A respeito dos compostos de silício e nitrogênio, a espécie mais simples SiN foi investigada experimentalmente por lto ef al. ${ }^{27}$ Elhanine et $a ._{0}{ }^{28}$ e Naulin ef al.,${ }^{29} \mathrm{e}$

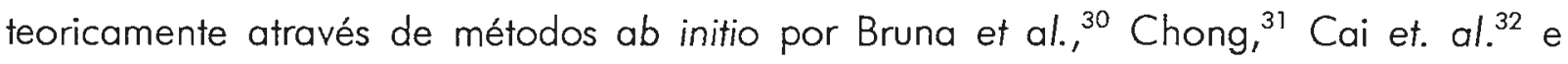
Borin. $^{33}$

A molécula SiNN foi investigada pela primeira vez por Lembke ef al..$^{34}$ em 1977, sendo o produto da colisão de átomos de silício com moléculas de nitrogênio armazenado em várias matrizes a $4 \mathrm{~K}$. Neste trabalho, os espectros obtidos utilizando a técnica de ressonância de spin eletrônico em matrizes de neônio, argônio e nitrogênio mostraram resultados bastante distintos, que, de acordo com os autores, dão evidências 
de uma estrutura linear ${ }^{3} \Sigma^{-}$SiNN na matriz de argônio e uma estrutura angular na matriz de nitrogênio. Sinais muito distintos apareceram também no espectro infravermelho obtido nas matrizes de nitrogênio e de argônio. As diferenças entre esses dois espectros infravermelhos, tanto em relação à atribuição das bandas quanto à intensidade, foi discutido brevemente e a justificativa para essas diferenças foi atribuída aos "efeifos de matrizes".

O primeiro trabalho teórico do SiNN apareceu somente em 1988 e foram empregadas metodologias tradicionais como Hartree-Fock (HF-SCF), interação de configuraçōes com excitaçōes simples e duplas a partir da configuração Hartree-Fock (CISD), e teoria do campo autoconsistente com um espaço ativo completo (CASSCF). ${ }^{35}$ Contrários às expectativas dos autores, os resultados obtidos com esses métodos apresentaram-se em completo desacordo com as evidências experimentais existentes. De fato, esses métodos levaram à existência de uma estrutura fracamente ligada, com o átomo de silício ligado à molécula de nitrogênio por uma interaçāo do tipo van der Waals. O cálculo CISD com a base tripla-zeta mais duas funçōes de polarização $(T Z P+2 P)$ colocou o átomos de silício 2,819 $\AA$ distante dos nitrogênios, em uma orientação colinear, e com a metodologia CASSCF/DZ $+\mathrm{P}$ essa distância aumentou para $3,175 \AA$.

A falta de sucesso dos métodos ab initio tradicionais levaram Dixon e DeKock ${ }^{36}$ a explorar a molécula SiNN com a então emergente metodologia do Funcional da Densidade Local (LDFT). Os cálculos utilizando os programas DMol e DGauss resultaram em uma distância internuclear SiN de 1,749 e 1,737 $\AA$, respectivamente, que são valores típicos de uma ligação simples entre os átomos silício e nitrogênio; a distância NN de 1,164 e 1,167 $\AA$, respectivamente, são cerca de $6 \%$ maior que a presente no $N_{2}$. Além de predizer a existência de uma estrutura ligada, as freqüências harmônicas calculadas com DMol e DGauss estão em boa concordância com os resultados experimentais, se levarmos em conta o não sucesso dos métodos $a b$ initio tradicionais. Os resultados DMol e DGauss para as freqüências vibracionais foram 1821 e $1823 \mathrm{~cm}^{-1}$ para $\omega_{1}, 569$ e 605 $\mathrm{cm}^{-1}$ para $\omega_{3}$, e 321 e $338 \mathrm{~cm}^{-1}$. para a freqüência bending $\omega_{2}$, respectivamente, enquanto que experimentalmente 1731 e $485 \mathrm{~cm}^{-1}$ foram atribuídos aos modos $\omega_{1}$ e $\omega_{3}$, respectivamente. 
Os bons resultados obtidos com a aproximação LDF motivaram lgnatyev e Schaefer ${ }^{37}$ a utilizarem níveis mais sofisticados de tratamento de correlação eletrônica. Eles serviram-se das metodologias coupled cluster com excitaçōes simples e duplas CCSD e CCSD(T), sendo que no último caso há a inclusão de excitações triplas conectadas para a energia de correlação, juntamente com a base dupla-zeta mais uma polarização (DZP). Eles obtiveram estruturas ligadas e estáveis com ambas metodologias. Em nível CCSD, o valor obtido para $\omega_{1}$ de $1825 \mathrm{~cm}^{-1}$ é praticamente idêntico aos resultados $L D F$, mas a inclusão de correções com as triplas conectadas causou uma diminuição considerável, passando a $1726 \mathrm{~cm}^{-1}$.

Embora não tenha sido enfatizado adequadamente nos trabalhos anteriores, é do nosso entendimento que as mudanças nas freqüências de estiramento $\operatorname{SiN}\left(\omega_{3}\right)$ são bastante significativas. Os resultados CCSD e CCSD(T) de 393 e $467 \mathrm{~cm}^{-1}$, respectivamente, apresentam diferenças maiores que $100 \mathrm{~cm}^{-1}$ se comparados com os resultados $L D F\left(569\right.$ e $\left.605 \mathrm{~cm}^{-1}\right)$. A concordância para a freqüência do modo bending é muito melhor entre as duas metodologias. Com relaçāo à geometria molecular, a distância SiN aumentou para 1,788 (CCSD) e 1,770 [CCSD(T)] Å, quando comparado com os resultados $L D F$ de 1,749 (DMol) e 1,737 (DGauss) $\AA$. A distância NN apresentou uma diminuição para 1,155 $\AA$ em nível CCSD e um pequeno aumento para 1,168 $\AA$ em CCSD(T), se comparados com os valores 1,164 e 1,167 $\AA$ obtidos com DMol e DGauss, respectivamente. Baseados em suas experiências prévias, Ignatyev e Schaefer ${ }^{37}$ sugeriram $^{2}$ que o uso de bases atômicas maiores levaria somente a uma melhor concordância dos resultados CCSD(T) com a experiência. Esse estudo aparentemente concluiu o problema de descrever corretamente a estrutura e freqüência do SiNN. Um trabalho posterior foi realizado por Murray et al., ${ }^{38}$ e eles investigaram a eficiência do uso do Funcional da Densidade não local em comparação com o funcional local em predizer adequadamente as freqüências do SiNN, enquanto que Wang et al..$^{39}$ procuraram realizar um estudo comparativo da distribuição eletrônica obtidas com as metodologias Hartree-Fock, teoria de perturbação Møller-Plesset de segunda ordem (MP2) e Funcional da Densidade. Este último trabalho ${ }^{39}$ mostrou que a grande contaminação de spin no Hartree-Fock não restrito e MP2 não causa um significativo efeito nas previsōes da estrutura de equilíbrio do SiNN. 
O uso de funcionais da densidade não locais é considerado um progresso sobre os funcionais locais. ${ }^{38}$ Cálculos com o formalismo Kohn-Sham restrito e não restrito para camadas abertas [(ROKS) e (UKS), respectivamente] com a base atômica dupla zeta mais polarização (DZP) resultou em valores de freqüência de 1754 e $1725 \mathrm{~cm}^{-1}$ para $\omega_{1}$, em excelente concordância com lgnatyev e Schaefer CCSD(T)/DZP, cujo valor é de 1726 $\mathrm{cm}^{-1}$. Para $\omega_{3}$ os resultados desses estudos mostram maiores diferenças, 534 (ROKS), 547 (UKS) e 467 (Ref. 37) $\mathrm{cm}^{-1}$. Cálculos realizados com a base mais extensa TZ2P $+2 f$ resultaram em um aumento nos valores das freqüências. Os valores ROKS para $\omega_{1}$ e $\omega_{3}$ passaram a 1793 e $517 \mathrm{~cm}^{-1}$, respectivamente, enquanto usando UKS os valores passaram a 1766 e $529 \mathrm{~cm}^{-1}$, respectivamente. É interessante notar que todos os resultados utilizando funcionais locais e CCSD predisseram freqüências $\omega_{1}$ próximas de $1825 \mathrm{~cm}^{-1}$. Por outro lado, todos os métodos com funcionais não locais e CCSD/T)/DZP estimaram valores entre 1726 e $1775 \mathrm{~cm}^{-1}$. Surpreendentemente, e em contraste com esses resultados, o estudo utilizando a metodologia interação de configurações com múltiplas referências (MRCI) e base DZP realizado por Cai et al. ${ }^{40}$ produziu um valor de $2038 \mathrm{~cm}^{-1}$ para a freqüência de estiramento $N N\left(\omega_{1}\right)$, sendo esse valor muito distinto dos obtidos nos demais trabalhos. A distância $\mathrm{SiN}$ obtida também mostrou-se bastante elevada, 1,899 $\AA$, onde poderia se esperar uma melhor concordância com o resultado CCSD/T).

A partir dos resultados apresentados a respeito do SiNN acreditamos que a correta elucidação da estrutura e das freqüências da molécula SiNN é uma questão em aberto. Do ponto de vista experimental, resultados mais convincentes são necessários para caracterizar sem dúvidas a molécula, e do ponto de vista teórico, alguns pontos ainda merecem um estudo mais rigoroso. Claramente a base DZP utilizada por Ignatyev e Schaefer ${ }^{37}$ em seus cálculos coupled cluster é relativamente pequena e não fornece um resultado final preciso para os parâmetros geométricos e espectroscópicos para esta molécula. A dependência da base no cálculo $\operatorname{CSSD}(7)$ não foi descrita adequadamente nos trabalhos apresentados. Como a contaminação de spin não tem um significativo efeito na estrutura e freqüências, conforme mostrado por Wang et. al., ${ }^{39}$ não seria de se esperar uma melhor concordância nos resultados $M R C /$ e CCSD(T)? Qual seria a razão para a grande diferença entre os resultados do estudo realizado por Cai et al.40 e as 
demais investigaçōes teóricas? Quais poderiam ser os resultados para a estrutura e freqüências com um cálculo $\mathrm{MRCl}$ com a inclusão de mais configurações e com uma base muito mais extensa que a utilizada por Cai et al.? Finalmente, teriam os resultados experimentais sido corretamente interpretados? Deixando clara essas questões, o maior objetivo desse trabalho é obter as respostas utilizando um nível muito maior de tratamento dos efeitos de correlação, e, desse modo, poder fornecer respostas que possam ajudar a elucidar com clareza e precisão os parâmetros geométricos e as freqüências do SiNN.

A primeira evidência experimental da existência da espécie triatômica $\mathrm{Si}_{2} \mathrm{~N}$ foi obtida por Iraqi ef al. ${ }^{2}$ usando a técnica de espectrometria de massa de neutralizaçãoreionização. A sugestão de que a forma mais estável dessa molécula deveria apresentar uma geometria cíclica também foi proposta. O primeiro cálculo teórico das geometrias e freqüências de algumas possíveis estruturas do $\mathrm{Si}_{2} \mathrm{~N}$ foi realizado por Goldberg et $a l_{.}{ }^{3} \mathrm{em}$ nível Hartree-Fock e MP2, com a base $6-311+G^{*}$. Um estudo mais completo foi realizado por Ornellas e $\mid$ wata $^{41}$ onde vários isômeros foram analisados utilizando diferentes níveis de teoria (HF, MP2, MP4 e CCSD(T)), e bases atômicas (DZP, cc-pVTZ-f e cc-pVTZ). Nesse trabalho, três estruturas termodinamicamente estáveis foram encontradas, com o mínimo global correspondendo a uma estrutura linear simétrica (SiNSi). O efeito Rennet-Teller foi utilizado para explicar a prediçāo teórica do espectro infravermelho da estrutura mais estável, sendo estimado o valor do parâmetro de Renner.

A molécula $\mathrm{Si}_{3} \mathrm{~N}$ foi estudada pela primeira vez por Goldberg ef al.. ${ }^{3} \mathrm{~A}$ espectrometria de massa de colisão-ativação e neutralização-reionização, além de métodos teóricos foram usados para descrever as espécies neutras, catiônicas e aniônicas do $\mathrm{Si}_{3} \mathrm{~N}$. As metodologias utilizadas para otimizar as geometrias foram restritas ao Hartree-Fock e MP2 com a base 6-311+G*. Em um trabalho mais recente, Gingerich ef al. ${ }^{42}$ determinaram os parâmetros térmicos do $\mathrm{Si}_{3} \mathrm{~N}$ usando a espectrometria de massa de efusão Knudsen.

A espécie de silício análoga ao cianogênio, $\mathrm{Si}_{2} \mathrm{~N}_{2}$, é experimentalmente desconhecida. Essa molécula foi estudada extensivamente do ponto de vista teórico pelo nosso grupo, onde vários pontos estacionários foram analisados com um aumento do 
nível de tratamento dos efeitos de correlação $(H F, M P 2, M P 4$ e CCSD $(T)) .{ }^{43}$ Foi prevista a existência de isômeros termodinamicamente estáveis, sendo que o mínimo global corresponde à estrutura linear simétrica SiNNSi. Uma comparação dos efeitos de cada metodologia foi realizada sobre os parâmetros geométricos, freqüências vibracionais e energias relativas.

Em seguida estendemos essa série de investigações de aglomerados de silício e nitrogênio para a molécula de fórmula $\mathrm{Si}_{3} \mathrm{~N}_{2}$. Essa espécie é desconhecida experimentalmente, e caracterizamos as propriedades das possíveis estruturas pela primeira vez. Junto com os resultados dos trabalhos anteriores, nós esperamos que, além dos dados estruturais e energéticos sobre as novas espécies, possa fornecer uma idéia do processo de formação e crescimento de aglomerados de silício e nitrogênio. Além disso, é nosso desejo que os resultados apresentados nesse trabalho motivem a identificação experimental desses novos compostos no espaço intereste!ar, bem como em lcboratórios. 


\section{I.2 ABORDAGENS TEÓRICAS}

O problema da correlação no SiNN foi investigado com o uso de duas técnicas de alto nível, o coupled cluster com excitaçōes simples e duplas (CCSD) e com contribuiçōes de triplas conectadas [CCSD(T)], $]^{44,45}$ conforme implementado no programa Gaussian92, ${ }^{46}$ e interação de configurações com múltiplas referências (MRC/) conforme implementado no programa MELD ${ }^{47}$ e MOLPRO94. ${ }^{48}$

Várias bases atômicas foram utilizadas nesse estudo. Elas variaram desde as simples 6-31G*, 6-311G* de Pople, ${ }^{49,50}$ e a dupla-zeta de Dunning-Huzinaga (DH) mais uma série de funções de polarização do tipo $d_{1}^{51}$ até as mais extensas do tipo correlated consistent polarized valence triple-zeta (cc-pVTZ) e valence quadruple-zeta (cc-pVQZ), desenvolvidas por Dunning e colaboradores. ${ }^{52,53}$ Uma versão mais restrita da base $c c$ pVTZ sem o uso da funçāo do tipo $f$, representada por cc-pVIZ-f, toi também utilizada. Com relaçāo à base $\mathrm{DH}$, nós utilizamos duas bases ligeircmente diferentes. A base denominada D95, que está armazenada no programa GAUSSIAN 92, é idêntica à base original exceto por uma pequena diferença no valor do expoente da função $d$ no átomo de silício. Na base atômica original o valor desse expoente é de 0,50, enquanto que no programa Gaussian 92 esse valor é igual a 0,3247. Essa aparente pequena diferença . teve importantes conseqüências nos resultados, e foi um dos motivos que nos levaram a estudar esse sistema com a utilização de metodologias ab initio mais sofisticadas.

No caso de compostos com fórmula molecular $\mathrm{Si}_{3} \mathrm{~N}_{2}$, várias estruturas foram analisadas em nível Hartree-Fock utilizando o formalismo restrito (RHF) para as espécies com camada fechada e não-restrito (UHF) para as de camada aberta. Parâmetros geométricos e freqüências vibracionais, dentro da aproximação do oscilador harmônico, foram também determinados. Os valores dessas freqüências permitem a caracterização da natureza do estado estacionário da estrutura obtida na otimização geométrica, isto é, saber se correspondem um mínimo na superfície de energia potencial, um estado de transição ou pontos de sela de ordem superior. A importância dos efeitos de correlação eletrônica nas estruturas, estabilidades relativas e freqüências foi investigada utilizando a 
teoria de perturbação de segunda ordem de Møller-Plesset (MP2), com os elétrons do caroço "congelados" durante os cálculos.

Os orbitais moleculares foram construídos usando a série de primitivas gaussianas de Mclean e Chandler ${ }^{54}$ (13s, 9p) contraída para [6s, 5p], e aumentado com duas séries de funçōes de polarização do tipo d com expoentes 0,553 e 0,158 no silício, e a série de Krishnan et al. ${ }^{55} 6-311 G^{*}\left(\alpha_{d}=0,913\right)$ para o nitrogênio. Essa base pode ser simbolizada como $(13 s, 9 p, 2 d) /[6 s, 5 p, 2 d]$ para o silício e $(11 s, 5 p, 1 d) /[4 s, 3 p, 1 d]$ para o nitrogênio, correspondendo a um total de 137 funções gaussianas contraídas para - $\mathrm{Si}_{3} \mathrm{~N}_{2}$. Com relação à função de onda UHF, vale a pena lembrar que esta não descreve um estado de spin puro, e usualmente contém contribuições de multiplicidades superiores. A quantidade de contaminação de spin pode ser usualmente avaliada a partir do valor esperado do operados $S^{2},\left\langle S^{2}\right\rangle$. Por incluir uma certa quantidade de correlação estática, a energia UHF é geralmente mais baixa que a corresponciente ROHF. Em nível MP2, como grande parte da correlação eletrônica é recuperada, o efeito de um cálculo MP2 não restrito (UMP2) é um aumento da energia devido à contaminação de spin. ${ }^{56}$ Todos os cálculos realizados neste sistema foram feitos com a utilização do programa Gaussian $94 .^{57}$ 


\section{I.3 O SISTEMA SiNN}

Antes de entrar em detalhes sobre os resultados obtidos é interessante deixar claro alguns aspectos relacionados aos dados experimentais da molécula SiNN. Inicialmente, dados sugerindo uma estrutura linear foram deduzidos a partir do espectro obtido em apenas uma das matrizes, especificamente da matriz de argônio. Conforme mencionado na introdução, os autores sugeriram uma estrutura angular a partir dos dados da matriz de nitrogênio. Na Figura 7 da referência 34 podem ser vistos três picos obtidos a partir da matriz de argônio, a 1731, 1737 e $1752 \mathrm{~cm}^{-1}$, com intensidades decrescentes. Esses valores sugerem que a freqüência de estiramento NN está ocorrendo em três pontos diferentes na matriz. A comparação com o espectro da matriz de nitrogênio leva ao surgimento de algumas dúvidas. O pico mais intenso na matriz de nitrogênio, que segundo os autores está relacionado com uma molécula angular, corresponde a uma transição a $1754,5 \mathrm{~cm}^{-1}$. Qual a relaçāo entre essa freqüência e a de $1752 \mathrm{~cm}^{-1}$, que supõe-se corresponder ao estiramento NN da estrutura linear? Observa-se adicionalmente a presença de um pico intenso a $1739 \mathrm{~cm}^{-1}$ e um outro menos intenso, mas com um perfil bastante claro, a $1774,5 \mathrm{~cm}^{-1}$. No entanto, se a molécula torna-se angular, não seria de se esperar uma diminuição da freqüência de estiramento NN? Como podemos notar, é observada uma tendência oposta. Se o grupo NN está interagindo com átomos do cluster, não seria de se esperar um enfraquecimento da ligação NN e, conseqüentemente, uma diminuição no valor da freqüência? Se a resposta for afirmativa, o valor da freqüência obtida teoricamente deve apresentar um valor mais alto, por representar a molécula numa situação em que há uma menor perturbação externa. Essas questōes levam a sérias dúvidas sobre a real geometria da molécula e também qual dado experimental deve ser utilizado quando comparado com os resultados de cálculos teóricos. Certamente, experimentos e resultados teóricos mais conclusivos são necessários para resolver qualquer dúvida na interpretação dos dados.

Nesse contexto, para evitar confusões futuras na comparação das freqüências, é importante ressaltar que os valores experimentais apresentados nos vários trabalhos da literatura referem-se às freqüências fundamentais $(v)$, enquanto os trabalhos teóricos referem-se às freqüências harmônicas $(\omega)$ de uma molécula isolada. Essa diferença não 
tem sido enfatizada em vários trabalhos teóricos, podendo levar a comparações não realistas. Se supusermos que os efeitos anarmônicos são da ordem de $3 \%$ das freqüências fundamentais, então as freqüências harmônicas associadas como as transições vibracionais menos e mais energéticas apresentadas na Figura 7 da referência 34 devem ser 1785 e $1830 \mathrm{~cm}^{-1}$, respectivamente. Para o estiramento SiN esses valores devem ser de 476 e $500 \mathrm{~cm}^{-1}$.

\section{Resultados CCSD(T)}

Os parâmetros estruturais e freqüências vibracionais harmônicas obtidas com o uso de várias bases e metodologias estão apresentados na Tabela 1.

O primeiro ponto a observar, e que chamou a nossa atenção nas primeiras etapas do trabalho, foi a significativa variação nas freqüências e ncs distâncias internucleares com as duas bases dupla-zeta. A base armazenada no programa Gaussian 92 utiliza um valor de expoente igual a 0,3247, enquanto que na base utilizada na referência 37 o valor é de 0,50 . Realizamos as otimizações com as duas bases e podemos observar que as freqüências de estiramento $\mathrm{SiN} \omega_{3}(\sigma)$ diferem em cerca de $95 \mathrm{~cm}^{-1}$, e essa diferença é considerável, levando em conta que as freqüências possuem valores relativamente baixos (474 e $\left.379 \mathrm{~cm}^{-1}\right)$. Para a freqüência de estiramento $N N \omega_{1}(\sigma)$, essa diferença é de cerca de $80 \mathrm{~cm}^{-1}$ (1827 e $\left.1747 \mathrm{~cm}^{-1}\right)$. Depois de relacionar essa diferença com os valores dos expoentes da função $d$ do silício, obtivemos uma concordância com os resultados de Ignatiev e Schaefer nos resultados utilizando $\alpha_{d}(\mathrm{Si})=0,50$. Se uma base atômica diferente tivesse sido utilizada por esses autores, o histórico da molécula SiNN discutido na introdução seria certamente diferente. É interessante notar que na Tabela 1 apenas um cálculo ab initio leva a um valor de $\omega_{1}$ abaixo de $1800 \mathrm{~cm}^{-1}$, e corresponde ao trabalho realizado por Ignatiev e Schaefer com a base DZP e $\alpha_{d}\left(S_{i}\right)=0,50$. A conclusão apresentada por eles, de que o aumento da base atômica levaria a uma maior concordância entre os resultados obtidos por eles e os experimentais, nāo foi verificada a partir dos resultados obtidos neste trabalho. A mudança na frequêencia de estiramento SiN foi ainda maior $\left(103 \mathrm{~cm}^{-1}\right)$ ao passar do cálculo utilizando a base $c c-p V T Z$-f para $c c$ - 
pVQZ; com relação à freqüência NN o resultado CCSD(T)/cc-pVQZ $\left(1859 \mathrm{~cm}^{-1}\right)$ difere em mais de $130 \mathrm{~cm}^{-1}$ do resultado $\operatorname{CCSD}(T) / D Z P$ de $1726 \mathrm{~cm}^{-1}$. Se atentarmos exclusivamente aos resultados com as bases correlacionadas, podemos observar um padrão de convergência, com uma diminuição no valor de $\omega_{1}$, e um aumento nos valores de $\omega_{2}$ e $\omega_{3}$ com o aumento da base atômica.

Tabela 1. Distâncias otimizadas (em $\AA$ ) e freqüências harmônicas $\left(e m \mathrm{~cm}^{-1}\right.$ ) da molécula SiNN calculadas com várias metodologias.

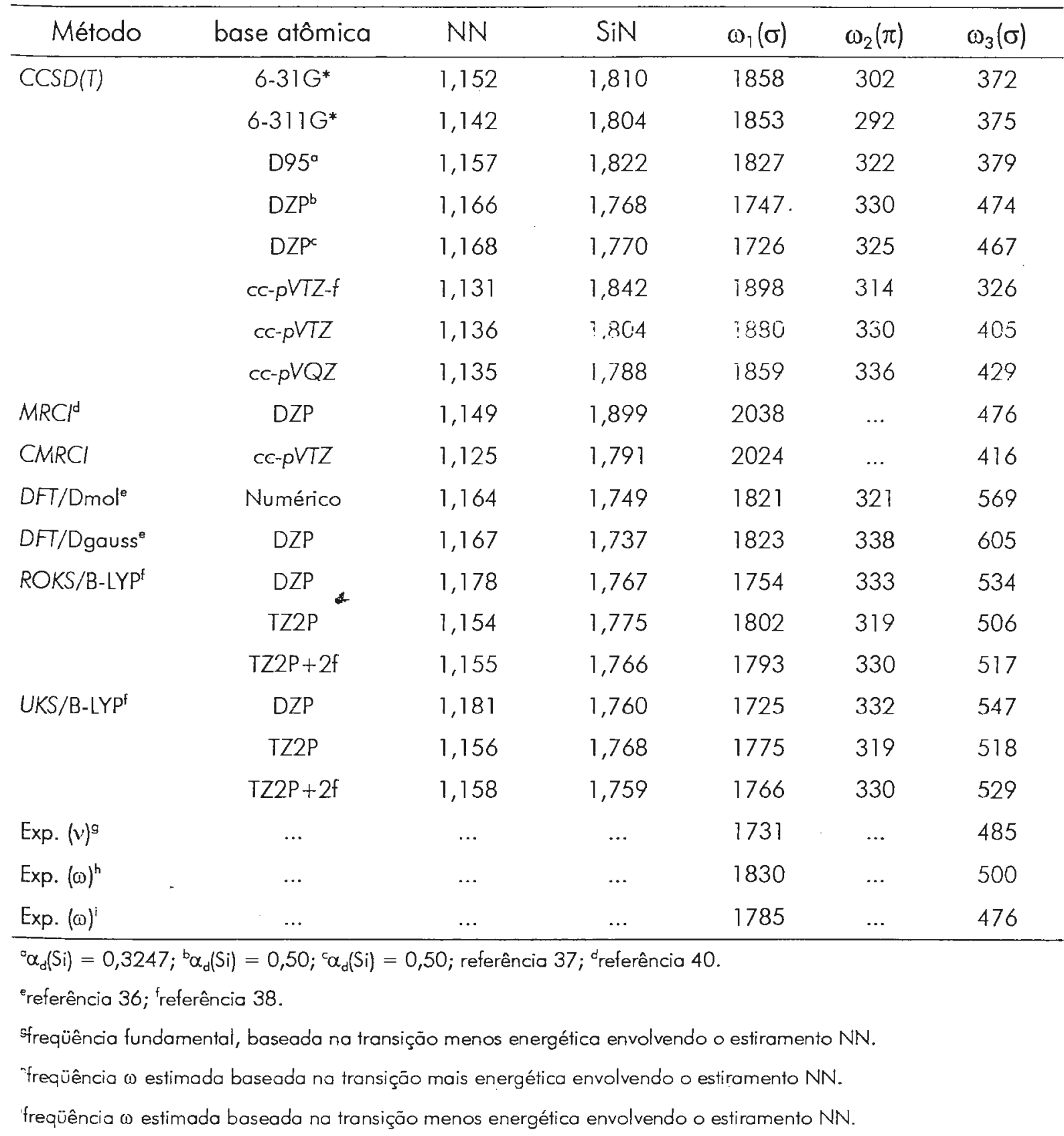


A experiência acumulada a partir de resultados utilizando a metodologia CCSD(T) com bases atômicas bastante extensas tem mostrado uma grande concordância com os valores experimentais, sendo que os nossos resultados mais sofisticados utilizando CCSD(T)/cc-pVQZ devem diferir em cerca de 1 a $2 \%$ do valor da freqüência harmônica da molécula SiNN isolada. Nosso melhor resultado de $1859 \mathrm{~cm}^{-1}$ para $\omega_{1}$ é muito próximo do valor estimado de $1830 \mathrm{~cm}^{-1}$ para a freqüência harmônica da transiçāo mais energética na Figura 7 da referência 34, mas essa diferença aumenta para $73 \mathrm{~cm}^{-1}$ se comparado com o pico menos energético $\left(v_{1}\right)$ a $1731 \mathrm{~cm}^{-1}\left(\omega_{1}=1786 \mathrm{~cm}^{-1}\right)$, sendo esse valor utilizado como experimental. Como $73 \mathrm{~cm}^{-1}$ é um valor de erro muito grande para esse nível de cálculo, ${ }^{58}$ estamos inclinados a aceitar o valor de $1830 \mathrm{~cm}^{-1}$ como o dado experimental mais realista para a freqüência harmônica do estiramento NN da molécula SiNN. Em nível $\operatorname{CCSD}(T) / c c-p V T Z$, a energia de dissociação $\operatorname{SiNN}\left({ }^{3} \Sigma\right) \rightarrow \operatorname{Si}\left({ }^{3} \mathrm{P}\right)+$ $\mathrm{N}_{2}\left({ }^{\prime} \Sigma_{\mathrm{g}}{ }^{+}\right)$é de $26,01 \mathrm{kcal} / \mathrm{mol}$, incluindo a energia do ponto zero vibracional. Com base nesses resultados, se o nosso raciocínio estiver incorréo, isso implica que estamos dianté de uma molécula de comportamento "patológico", que merecerá uma atenção futura à medida que novas metodologias forem sendo desenvolvidas. Se o nosso pensamento estiver correto, então as evidências experimentais devem ser revistas e/ou novas experiências devem ser realizadas para fornecer resultados mais confiáveis. Importante notar também que o uso de bases correlacionadas causa uma diminuição de cerca de $3 \%$ na distância internuclear $N N$, relativa aos resultados com as demais bases, e que uma distância SiN maior e um menor valor para a freqüência de estiramento SiN são obtidas qụando as funçōes do tipo $f$ são removidas da base cc-pVTZ.

\section{Resultados $\mathrm{MRCI}$}

Depois de verificarmos a não ocorrência da previsão de lgnatiev e Schaefer de que uma melhor concordância com os resultados experimentais das freqüências com 0 aumento da base atômica, procuramos estudar a molécula SiNN utilizando a metodologia $\mathrm{MRCl}$ e tentar descobrir as razōes da grande diferença entre os resultados $\mathrm{MRCl}$ de Cai et al. ${ }^{40}$ e os demais trabalhos teóricos. 
Inicialmente procuramos reproduzir a abordagem metodológica de Cai et al. usando orbitais do tipo $K^{59}$ e a técnica $M R C$ implementada no programa MELD. Nosso cálculo difere, entretanto, no uso de uma base mais extensa, cc-pVTZ, e um menor limite (threshold) de energia $(0,5 \mu \mathrm{H})$ para a seleção das configurações por meio de teoria de perturbação. O espaço de referência consiste de 11 funçōes de configurações escolhidos por base no valor dos coeficientes $(>0,05)$ gerados na primeira fase do cálculo. Várias varreduras da superfície de energia potencial nas regiões mais importantes da molécula deram resultados frustrantes. A superfície final obtida indica que a molécula apresenta uma estrutura repulsiva, levando a um canal de dissociação com os produtos Si e $\mathrm{N}_{2}$. Isso pode ser visto a partir dos contornos mostrados na Figura 1, onde as linhas indicam uma diferença de $0,05 \mathrm{kcal} / \mathrm{mol}\left(8.10^{-5}\right.$ u.a.). A Figura 1 mostra que não existe um mínimo na região previamente indicada por Cai et al. ( $\mathrm{SiN}=1,899 \AA$ e $\mathrm{NN}=1,149 \AA$ ). Esses resultados sugerem que o limite relativamente alto de energia adotado por Cai et. al. $(15,8 \mu \mathrm{H})$ deve ter causado a exclusão de um grande número de configurações na função de onda final e que são importantes para a localização correta do mínimo global. Esse fato parece ser importante na regiāo onde a superfície de energia potencial é bastante rasa, em que mudanças da ordem de $0,005 \AA$ tanto na distância NN como na SiN levam a mudanças na energia da ordem de magnitude das contribuições deixadas de fora por Cai et al.

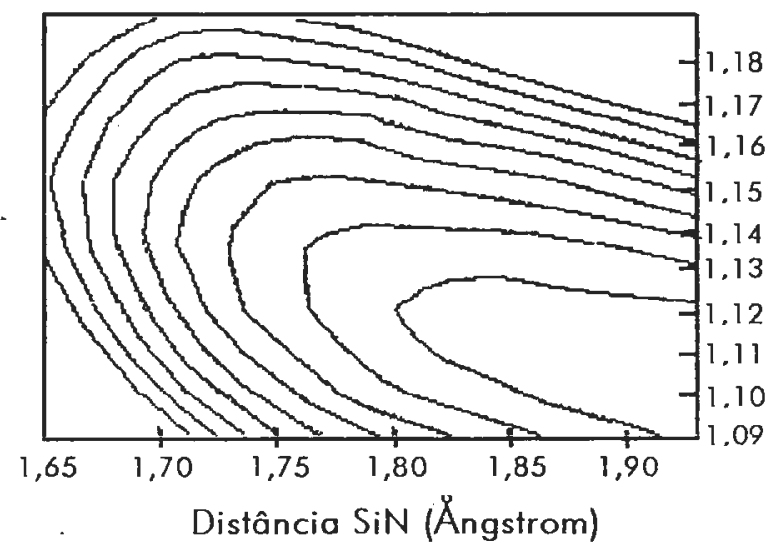

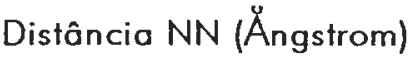

Figura 1. Contorno da superfície de energia potencial da molécula SiNN $\left({ }^{3} \Sigma\right.$ ) calculado em nível de teoria MRSDCI/cc-pVTZ. As linhas de contorno diferem em aproximadamente $0,05 \mathrm{kcal} / \mathrm{mol}$. 
Apesar do cálculo realizado significar uma melhora em relaçāo ao trabalho anterior, o resultado final foi desapontador. A não disponibilidade de um espaço em disco muito grande impediu a realização de um cálculo $C l$, com o programa MELD, utilizando uma função de onda mais extensa e um limite de energia menor para a seleção das configuraçōes. Essas limitaçōes fizeram com que utilizássemos um $\mathrm{Cl}$ direto, para obter a contribuição das funções de configuraçōes deixadas de fora na função de onda $\mathrm{MRCl}$ convencional.

Numa segunda etapa, realizamos um outro cálculo $M R C l$, mas com algumas mudanças em relação ao cálculo anterior. Inicialmente, os orbitais moleculares utilizados na construção das funções de configuração são os orbitais naturais obtidos através da diagonalização da matriz densidade gerada num cálculo CASSCF; o cálculo CASSCF realizado utilizou o espaço de valência cheio (full) com 14 elétrons distribuídos em 12 orbitais moleculares $\left(6,3,3,0 ; C_{2 v}\right)$, gerando um total de 70746 configuraçōes. $^{50,61} \mathrm{Em}$ seguida, o cálculo $M R C /$ foi do tipo contraído internamente, conforme implementado no programa $\mathrm{MOLPRO}{ }^{62,63}$ o espaço de referência inclui 21 funções de configurações e a função $C /$ final contém 490624 funções contraídas. As funções de configuração foram selecionadas baseadas na magnitude dos seus coeficientes $(>0,05)$ do vetor CASSCF-Cl, mais algumas especificaçōes escolhidas para incluir algumas configuraçōes com excitaçōes simples e duplas envolvendo alguñs orbitais internos do espaço ativo.

Após uma varredura inicial nas regiōes mais importantes da superfície de energia potencial, uma busca mais detalhada foi realizada, e um ponto de mínimo foi localizado e corresponde a uma geometria linear com distâncias internucleares de 1,791 e 1,125 para as ligações $\operatorname{SiN}$ e $N N$, respectivamente. Na região próxima do mínimo a busca foi feita envolvendo mudanças de 0,001 $\AA$ nas distôncias para ambas as ligações.

A partir dos resultados obtidos vemos que a estrutura de equilíbrio prevista pelo método $\mathrm{MRCl}$ mostra distâncias internucleares ligeiramente menores que as obtidas com a metodologia CCSD(7), ambas com a base cc-pVTZ: 1,804 $(\operatorname{SiN})$ e 1,136 $($ NN). Em seguida usamos uma expressão de diferenciação numérica com três pontos (separados por $0,005 \AA)$ para obter as duas constantes de força de estiramento. As freqüências harmônicas foram obtidas a partir da substituição dos valores das duas constantes de 
força na expressão apropriada para uma molécula linear assimétrica, conforme pode ser obtida no livro de Herzberg. ${ }^{64}$ Nossos resultados de 16,545 e 1,460 mdyn/Å, para as constantes de força das ligaçōes NN e SiN, respectivamente, forneceram valores de 2024 e $416 \mathrm{~cm}^{-1}$ para as freqüências harmônicas. Se compararmos com os resultados $\operatorname{CCSD}(T) / c c-p V T Z, 1880$ e $405 \mathrm{~cm}^{-1}$, vemos um grande diferença $\left(144 \mathrm{~cm}^{-1}\right)$ para o valor de $\omega_{1}$, apesar da boa concordância entre os parâmetros geométricos.

É importante mencionar que a configuração Hartree-Fock contribui em cerca de $85 \%$ da expansão $M R C$. Se a discrepância entre os resultados teóricos surge devido aos 15\% de caráter multiconfiguracional que não é incluído no cálculo $\operatorname{CCSD}(T)$, e/ou por causa da contribuição de um grande número de excitaçōes de ordem superior que não foram incluídas no cálculo $\mathrm{MRCl}$ são pontos que serāo certamente respondidos no futuro. No momento, entretanto, baseados na convergência dos resultados CCSD(T) com as bases correlacionadas, estamos inclinados a aceitar os resultados CCSD(T)/cc-jVQZ como os mais precisos e realistas para a molécula isolada. Nenhum desses resultados concordam com as freqüências harmônicas experimentais ou com os resultados CCSD(T)/DZP de lgnatyev e Schaefer.

\section{Resultados com o Funcional da Densidade}

A cronologia dos cálculos utilizando o funcional da densidade com uma breve descrição e comparação dos principais resultados das freqüências foi apresentada na introdução. Neste ponto o nosso interesse é enfatizar alguns aspectos para que torne a comparaçāo com os resultados ab initio mais clara. Nos limitaremos aos cálculos não locais utilizando o funcional B-LYP com orbitais restritos de camada aberta e os não restritos a partir das equaçōes de Kohn-Sham (ROKS e UKS), que são considerados como sendo superiores aos cálculos com funcionais locais.

Qual a precisão que se pode esperar desse tipo de cálculo? De acordo com Murray et al.," "uma super estimativa dos comprimentos de ligação e uma subestimativa dos valores de freqüência são típicos do funcional B-LYP". De fato, eles exemplificaram com um cálculo B-LYP/TZ2P na molécula $N_{2}$ mostrando que a freqüência é subestimada em 
$33 \mathrm{~cm}^{-1}$. Embora outros casos similares sobre a precisão desse tipo de cálculo sejam encontrados no artigo, eles não são coerentes, entretanto, em aplicar essa observação empírica na análise das freqüências da molécula SiNN. Eles concluem que os resultados "tendem a exceder mais do que poderia ser estimado pelas correçōes anarmônicas". Para ser consistente, eles deveriam concluir que a freqüência harmônica experimental $\left(\omega_{1}\right)$ deveria ser maior que $1810 \mathrm{~cm}^{-1}$, e, como conseqüência, seria de se esperar que eles questionassem a correta interpretaçāo dos resultados experimentais. Corrigindo os dados deles da freqüência pelo erro encontrado na molécula $\mathrm{N}_{2}$, nós chegamos a uma valor de $1808 \mathrm{~cm}^{-1}$ para o cálculo UKS e $1826 \mathrm{~cm}^{-1}$ para o resultado ROKS. Analisando esses dados dessa maneira nos dá um suporte adicional para os nossos cálculos CCSD(T), especialmente aqueles com o uso das bases correlacionadas, além da sugestão de que as freqüências harmônicas não foram interpretadas corretamente.

Com relação à comparação com experimentos, o pico a $1731 \mathrm{~cm}^{-1}$ é o ponto de partida para comparaçōes com os trabalhos teóricos, mas comparar esse valor sem levar em conta os efeitos de anarmonicidade e de matriz, além de considerar igual à freqüência harmônica de uma molécula isolada, são situações não recomendadas. Do ponto de vista teórico, alguns cuidados também são necessários. Com a exceção do trabalho de Cai et al., todos os trabalhos mais recentes têm feitos comparações com os resultados CCSD/T/DZP de Ignôtiev e Schaefer. Neste trabalho nós acreditamos ter mostrado de maneira convincente de que os resultados deles não são precisos.

\section{Outros Isômeros do $\mathrm{SiN}_{2}$}

Na interpretação do espectro infravermelho da molécula SiNN nas matrizes de argônio e nitrogênio, Lembke et $a /{ }^{34}$ atribuíram uma estrutura linear para a molécula na matriz de argônio, e uma angular na matriz de nitrogênio. Se a estrutura angular implica em uma distorção da linearidade imposta pela condições existentes na matriz ou se refere à uma estrutura realmente angular são itens não discutidos em qualquer dos trabalhos anteriores. Nós procuramos por uma eventual espécie angular localizada em um ponto de mínimo na superfície de energia potencial utilizando as metodologias MP2 e CCSD(T), 
mas não obtivemos resultados satisfatórios. Várias tentativas iniciais de uma estrutura angular assimétrica convergiram para a forma linear mais estável.

Em seguida, examinamos a possibilidade de existência de uma espécie angular simétrica e de uma linear simétrica em nível CCSD/7)/cc-pVTZ. Nenhuma dessas possibilidades foi analisada em qualquer dos trabalhos anteriores. Os dados obtidos estão apresentados na Tabela 2 e visualizados na Figura 2.

Tabela 2. Geometrias otimizadas (em $\AA$ e graus), estabilidades relativas (em $\mathrm{kcal} / \mathrm{mol}$ ), e freqüências harmônicas (em $\mathrm{cm}^{-1}$ ) dos isômeros do $\mathrm{SiN}_{2}$ calculados em nível CCSD/T// cc-pVTZ.

\begin{tabular}{ccccccccc}
\hline Molécula & Estado & $\Delta E$ & NSi & NN & NSiN & \multicolumn{3}{c}{ Freqüências } \\
\hline $1^{a}$ & ${ }^{3} \Sigma^{-}$ & 0,00 & 1,804 & 1,135 & $\ldots$ & $1880(\sigma)$ & $330(\pi)$ & $405(\sigma)$ \\
II & ${ }^{1} A_{1}$ & 6,09 & 1,847 & 1,247 & 39,5 & $1488\left(a_{i}\right)$ & $581\left(a_{1}\right)$ & $724\left(b_{2}\right)$ \\
III & ${ }^{1} \Sigma^{+}$ & 15,81 & 1,776 & 1,149 & $\ldots$ & $1850(\sigma)$ & $332(\pi)$ & $532(\sigma)$ \\
IV & ${ }^{3} \Sigma_{g}^{-}$ & 84,60 & 1,657 & $\ldots$ & 180,0 & $926\left(\sigma_{v}\right)$ & $622\left(\pi_{v}\right)$ & $824\left(\sigma_{s}\right)$ \\
V & ${ }^{1} A_{1}$ & 102,23 & 1,659 & 3,255 & 157,6 & $814\left(a_{1}\right)$ & $117\left(a_{1}\right)$ & $1135\left(b_{2}\right)$ \\
\hline
\end{tabular}

aenergia CCSD(T)/cc-pVTZ $=-398,315761$ u.a.

Todas as estruturas encontradas localizam-se em pontos de mínimo na superfície de energia potencial. $O$ isômero cíclico ' $A_{1}$ encontra-se muito baixo energeticamente, apenas 6,09 $\mathrm{kcal} / \mathrm{mol}$ acima do mínimo global, enquanto as estruturas angular ${ }^{~} A_{1}$ e a linear ${ }^{3} \Sigma_{g}^{-}$encontram-se relativamente altas energeticamente. Note que na molécula cíclica a distância de ligação NN e a freqüência de estiramento NN são típicas de uma ligação dupla, e que nenhuma das freqüências harmônicas calculadas caem na região de relevância do espectro experimental do SiNN. 

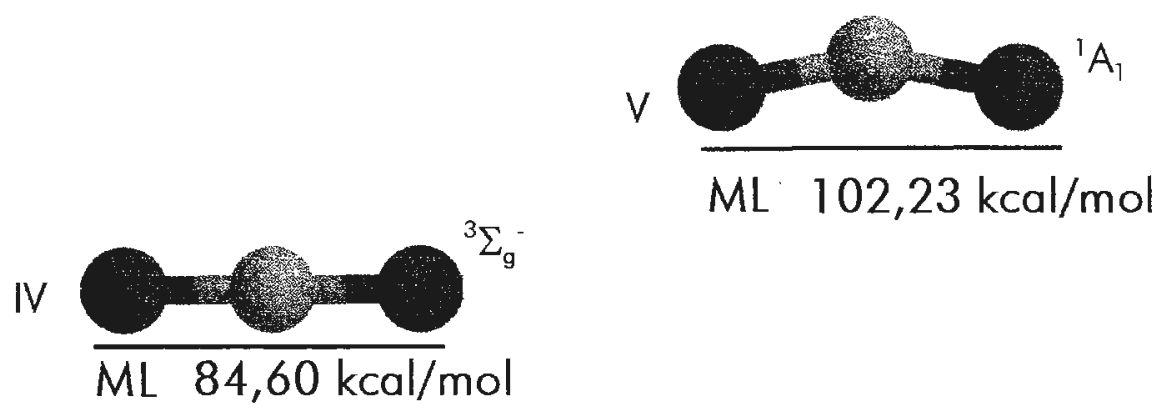
única diferença no espectro infravermelho entre essas duas espécies relaciona-se com a freqüência de estiramento $\mathrm{SiN}$, que é $102 \mathrm{~cm}^{-1}$ maior que a encontrada na espécie tripleto. É interessante notar que a diferença de energia $(\sim 16 \mathrm{kcal} / \mathrm{mol})$ entre as estruturas lineares assimétricas singleto e tripleto é muito próxima da separação ${ }^{~} \mathrm{D}-{ }^{3} \mathrm{P}$ no átomo de silício $(\sim 18 \mathrm{kcal} / \mathrm{mol})$, um fato que pode de algum modo refletir a natureza localizada do acoplamento entre os dois elétrons no átomo de silício na molécula SiNN. Considerando a alta temperatura envolvida na vaporização dos átomos de silício, a possibilidade de encontrar $\circ \mathrm{SiNN}\left({ }^{1} \Sigma^{+}\right)$aprisionada com as moléculas tripleto é bastante plausível, e deve ser levada em conta na interpretaçăo das bandas experimentais. De fato, a partir da Tabela 2, observa-se que as freqüências da espécie singleto mostram uma melhor concordância com os resultados experimentais estimados do que a espécie tripleto. É importante mencionar que os dados estruturais e energéticos apresentados nesse trabalho complementam os resultados anteriores realizados pelo nosso grupo envolvendo as espécies $\mathrm{Si}_{2} \mathrm{~N}^{41}$ e $\mathrm{Si}_{2} \mathrm{~N}_{2}{ }^{43}$ e que pode ajudar na compreensão do mecanismo de crescimento de aglomerados pequenos de silício e nitrogênio. Para todos os outros isômeros investigados, no caso $\mathrm{Si}_{2} \mathrm{~N}$ e $\mathrm{Si}_{2} \mathrm{~N}_{2}$, nenhum deles possui uma freqüência de estiramento $N N$ que caia na região de estudo do $\operatorname{SiNN}\left({ }^{3} \Sigma^{-}\right)$. 


\section{I.4 O SISTEMA $\mathrm{Si}_{3} \mathrm{~N}_{2}$}

\section{Estruturas e energias das espécies $\mathrm{Si}_{3} \mathrm{~N}_{2}$}

Inicialmente, utilizando a metodologia Hartree-Fock, analisamos a superfície de energia potencial de uma série de arranjos atômicos, com geometrias lineares, planares e tridimensionais para a busca de pontos estacionários. Muitas dessas possibilidades representam espécies muito instáveis e com energias muito elevadas. A série das estruturas mais representativas investigadas estão apresentadas nas Figuras 3 e 4, que também contém as energias relativas entre os pontos estacionários, os parâmetros geométricos em níveis HF e MP2, e a energia da estrutura mais estável determinada com ambas metodologias. Na Tabela 3 estão apresentadas as freqüências no infravermelho calculadas dentro da aproximação harmônica em ambos HF e MP2 niveis de teoria.

Para a discussão que se segue, é conveniente estabelecer uma padrão de referência para que possamos realizar comparações nas discussōes a respeito dos tipos de ligações químicas envolvidas nas várias estruturas. Neste trabalho, utilizaremos distâncias de ligações em compostos bem conhecidos como referências para inferir ligaçōes de caráter simples, duplas e triplas. No caso das ligações entre átomos de silício, temos o disilano como uma referência para uma ligação simples $\left(2,34 \AA \AA^{65}\right.$ e $\mathrm{Si}_{2}$ para uma dupla $(2,25 \AA) .{ }^{66}$ Entre silício e nitrogênio, $\mathrm{H}_{3} \mathrm{Si}-\mathrm{NH}_{2}$ ilustra uma típica ligação simples $(1,72 \AA)^{67,68}$ e $\mathrm{H}_{2} \mathrm{Si}=\mathrm{NH}$ é um modelo para uma ligação dupla $(1,58 \AA)^{; 9}$ finalmente, entre dois nitrogênios, $N_{2}$ é um padrão para uma ligação tripla $(1,098 \AA),{ }^{70}$ diazina $\mathrm{HN}=\mathrm{NH}$ para uma ligação dupla $(1,252 \AA){ }^{71-73}$ e $\mathrm{H}_{2} \mathrm{~N}-\mathrm{NH}_{2}$ para uma ligação simples $(1,414 \AA) \cdot{ }^{74}$

O isômero com a menor energia corresponde à estrutura I na Figura 3; em ambas metodologias corresponde ao mínimo global, como pode ser visto pelos valores positivos das freqüências na Tabela 3. Esta estrutura mostra apenas ligaçōes silício-nitrogênio, com as distâncias Si-N centrais típicas de uma ligação simples, enquanto que as distâncias mais externas são comparáveis às duplas. Como pode ser visto na Figura 3, a diferença 
entre os parâmetros geométricos SCF e MP2 é pequena, com as distâncias de ligação aumentando em cerca de 0,04 $\AA$ ao passar de SCF para MP2. É interessante mencionar que a análise populacional de Mulliken prediz uma estrutura relativamente iônica com os átomos de nitrogênio carregados negativamente com uma unidade de carga cada, e para compensar esse valor elevado de carga o silício central e os dois terminais adquirem uma carga positiva de cerca de 0,8 e 0,6 unidades de carga, respectivamente. Apesar dos valores positivos de todas as freqüências, podemos notar a existência de valores pequenos, de $59\left(a_{1}\right)$ e $94\left(b_{2}\right) \mathrm{cm}^{-1}$ para $\omega_{1}$ e $\omega_{2}$, respectivamente, o que implica no fato de apresentar um poço de potencial bastante raso, o que poderia levar a um rearranjo molecular ou dissociação se uma energia suficiente for concentrada nesses dois modos. Esta espécie é provável que seja encontrada a baixas temperaturas, aprisionada em matrizes; sua linha de absorção no infravermelho mais intensa $(708 \mathrm{~km} / \mathrm{mol})$ calculada em nível MP2 ocorre a $1285 \mathrm{~cm}^{-1}$ e corresponde a um estiramento SiN antissimétrico.

Próximo ao isômero I encontramos uma outra estrutura planar ('A $A_{1}$, II) que está associada a um estado de transição em ambas teorias SCF e MP2. Essa estrutura localiza-se a $16,61 \mathrm{kcal} / \mathrm{mol}$ (MP2) acima de l, e exibe uma distância SiN $(2,00 \AA)$ relativamente longa, e duas distância típicas de uma ligaçāo simples padrāo $(1,68$ e 1,61 Å). Uma análise dos modos normais mostra que os valores de freqüência de 416, 867 e $992 \mathrm{~cm}^{-1}$ podem relacionados com as vibrações SiNSi, enquanto $1152 \mathrm{~cm}^{-1}$ é próximo do estiramento do SiN. Uma avaliação da coordenada de reação interna (internal reaction coordinate - $(R C)$ mostrou, entretanto, que a estrutura II corresponde a um estado de transição conectando duas formas equivalentes de I. Uma possibilidade que existe é a de que uma matriz pode trazer uma estabilização a essa espécie, permitindo, a observação de algumas das freqüências vibracionais. 

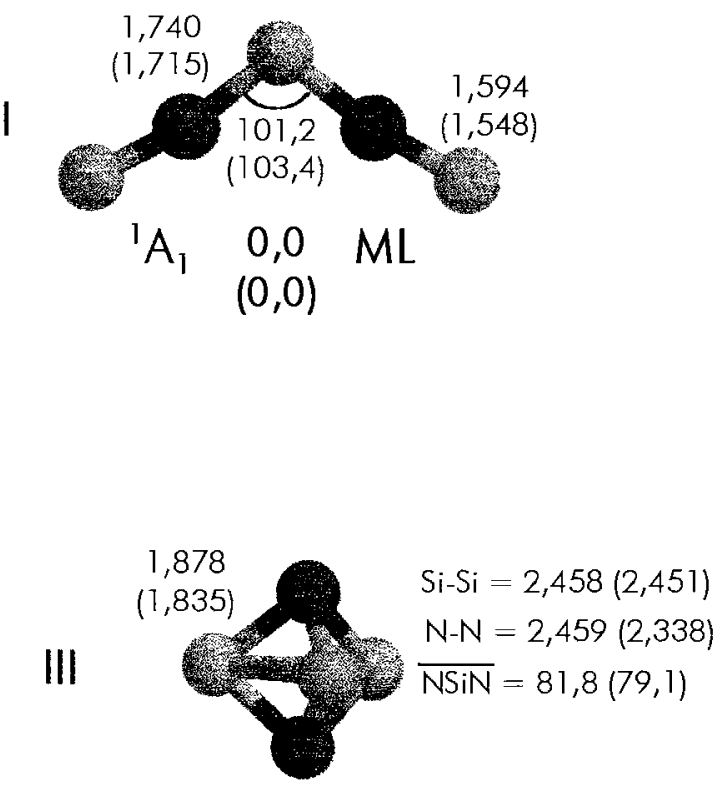

$\begin{array}{cc}{ }^{\prime} A_{1}^{\prime} & 40,96 \\ & (58,86)\end{array}$

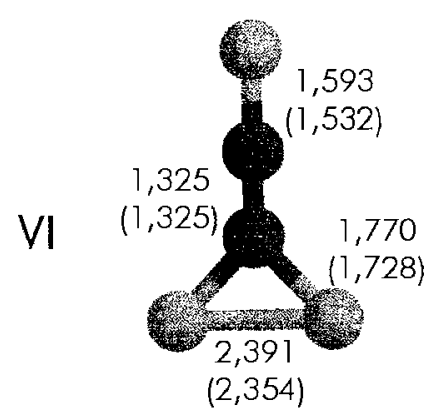

${ }^{\top} A_{1} \quad \underset{(68,85)}{58,19} \mathrm{ML}$

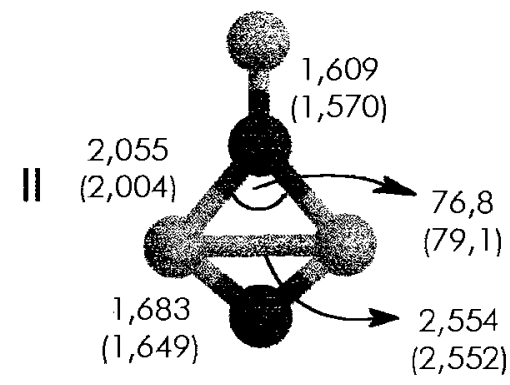

$\begin{array}{ccc}{ }^{1} \mathrm{~A}_{1} & 16,61 \\ & (18,53)\end{array}$

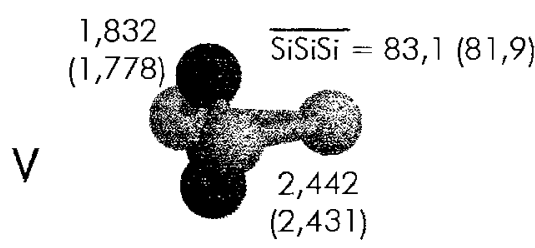

${ }^{1} \mathrm{~A}_{1} \underset{(73,91)}{45,05} \mathrm{ML}$

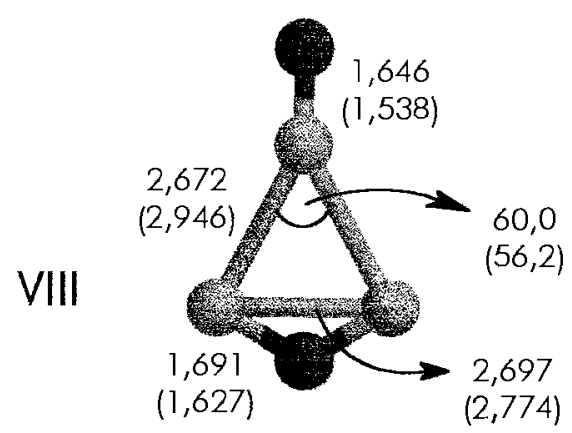

$\begin{array}{cc}{ }^{1} \mathrm{~A}_{1} & 64,15 \\ (104,55)\end{array}$

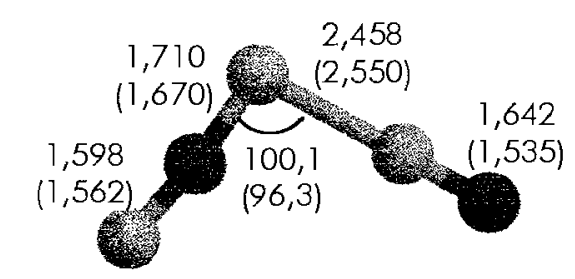

IX

$\begin{array}{ccc}{ }^{1} \mathrm{~A}^{\prime} & 66,91 \\ & (94,38)\end{array} \mathrm{ML}$

Figura 3. Geometrias dos pontos estacionários (em $\AA$ e graus) e energias relativas (em $\mathrm{kcal} / \mathrm{mol}$ ) para os estados singleto de espécies com fórmula $\mathrm{Si}_{3} \mathrm{~N}_{2}$. Os números entre parênteses referemse aos valores SCF.

$E(M P 2)=-976,342604$ u.a. e $E(S C F)=-975,744471$ u.a. para a estrutura I. 

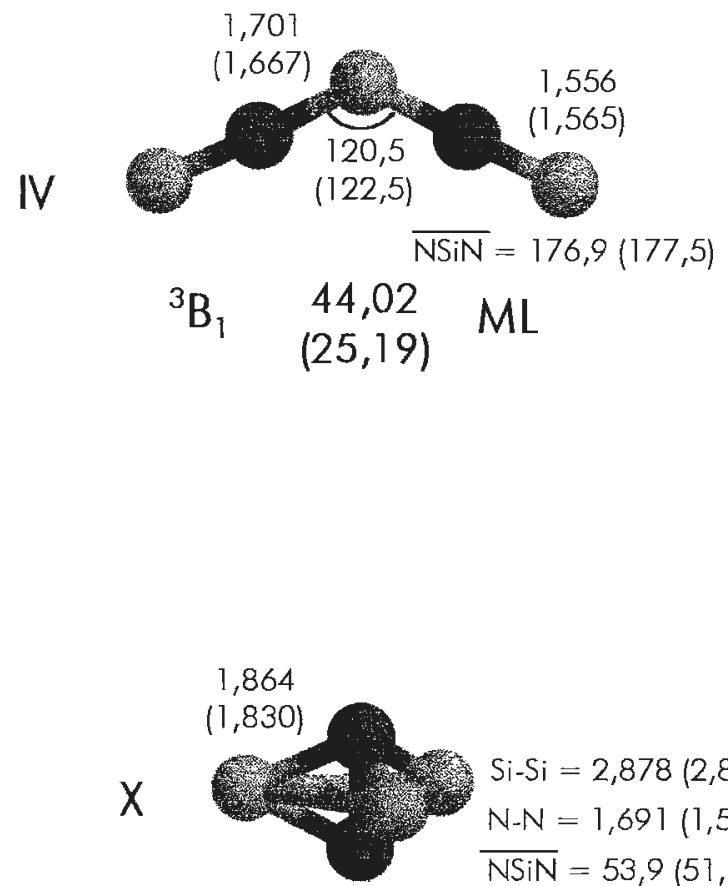

${ }^{3} A_{1}^{\prime}$

$$
\begin{gathered}
77,33 \\
(83,32)
\end{gathered} \quad \mathrm{ML}
$$

$\mathrm{Si}-\mathrm{Si}=2,878(2,853)$

$N-N=1,691(1,596)$

$\overline{\mathrm{NSiN}}=53,9(51,7)$

(2)

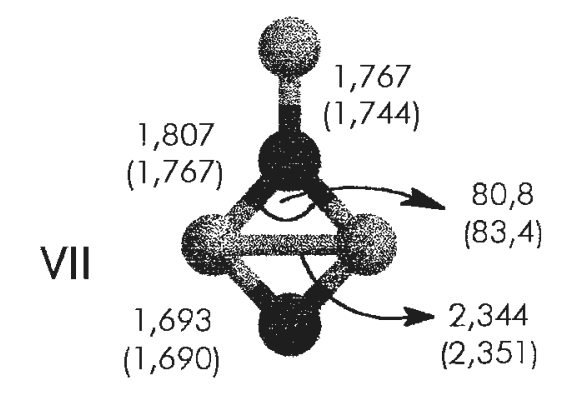

${ }^{3} \mathrm{~A}_{2} \underset{(51,69)}{60,31} \mathrm{ML}$

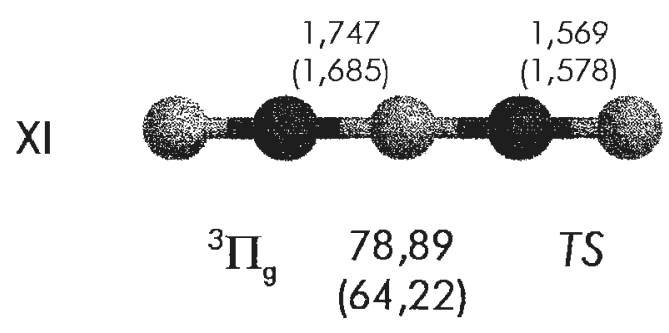

Figura 4. Geometrias dos pontos estacionánios (em $\AA$ e graus) e energias relativas (em $\mathrm{kcal} / \mathrm{mol}$ ) para os estados tripleto de espécies com fórmula $\mathrm{Si}_{3} \mathrm{~N}_{2}$. Os números entre parênteses referem-se aos valores SCF.

Temos que III corresponde à primeira estrutura tridimensional, e mostra uma geometria de uma bipirâmide trigonal. Em nível $S C F$, esta encontra-se a $58,86 \mathrm{kcal} / \mathrm{mol}$ acima de 1 , e corresponde ao terceiro isômero mais estável, enquanto que em MP2 corresponde à segunda em energia, localizado a 40,96 kcal/mol acima do mínimo global I. Ambas metodologias predizem que a estrutura otimizada corresponde a um mínimo local com geometrias praticamente idênticas, sendo a maior diferença a distância entre os dois nitrogênios, que aumentou $0,12 \AA$ ao passar de SCF $(2,32 \AA)$ para MP2 $(2,46 \AA)$. As distâncias $\mathrm{SiN}$ e SiSi são cerca de $0,1 \AA$ maiores que uma típica ligação simples. Essa estrutura interessante com formato de uma "gaiola" é similar à geometria do mínimo global do $\mathrm{Si}_{5}{ }^{4}$ e no estudo dos isômeros do $\mathrm{Si}_{3} \mathrm{C}_{2}$, Froudakis et al. ${ }^{75}$ também encontraram uma estrutura análoga, correspondendo ao segundo isômero mais estável. 
Tabela 3. Freqüências harmônicas vibracionais calculadas $\left(e \mathrm{~cm}^{-1}\right)$ e valores de $\hat{S}^{2}$ para vários aglomerados de $\mathrm{Si}_{3} \mathrm{~N}_{2}$ em níveis MP2 e SCF (entre parênteses). 1 cal = $4.18 \mathrm{~J}$

\begin{tabular}{|c|c|c|c|c|c|c|c|c|c|c|c|c|}
\hline \multicolumn{2}{|c|}{ Estrutura } & \multicolumn{11}{|c|}{ Freqüências vibracionais } \\
\hline & & $\hat{S}^{2}$ & \multicolumn{2}{|c|}{$\omega_{1}$} & \multicolumn{2}{|l|}{$\omega_{2}$} & \multicolumn{2}{|c|}{$\omega_{3}$} & \multicolumn{2}{|c|}{$\omega_{4}$} & \multicolumn{2}{|c|}{$\omega_{5}$} \\
\hline I & $\left({ }^{1} A_{1}\right)$ & 0,00 & $\begin{array}{c}59 \\
(73)\end{array}$ & $\sigma_{1}$ & $\begin{array}{c}94 \\
(155)\end{array}$ & & $\begin{array}{c}103 \\
(156)\end{array}$ & $a_{2}$ & $\begin{array}{c}155 \\
(179)\end{array}$ & $b_{2}$ & $\begin{array}{c}323 \\
(378)\end{array}$ & $a_{1}$ \\
\hline II & $\left({ }^{\prime} A_{1}\right)$ & 0,00 & $\begin{array}{l}171 i \\
(126 i)\end{array}$ & $b_{2}$ & $\begin{array}{c}74 \\
\text { (131) }\end{array}$ & $b_{1}$ & $\begin{array}{c}138 \\
(154)\end{array}$ & $b_{2}$ & $\begin{array}{l}225 \\
(275)\end{array}$ & $b_{1}$ & $\begin{array}{c}298 \\
(344)\end{array}$ & $a_{1}$ \\
\hline III & $\left({ }^{1} A_{1}^{\prime}\right)$ & 0,00 & $\begin{array}{l}262 \\
(251)\end{array}$ & $\mathrm{e}^{n}$ & $\begin{array}{l}262 \\
(251)\end{array}$ & $\mathrm{e}^{n}$ & $\begin{array}{l}406 \\
(433)\end{array}$ & $\mathbf{e}^{\prime}$ & $\begin{array}{l}406 \\
(433)\end{array}$ & $\mathrm{e}^{\prime}$ & $\begin{array}{c}590 \\
(631)\end{array}$ & $a_{1}^{\prime}$ \\
\hline IV & $\left({ }^{3} B_{2}\right)$ & $\begin{array}{l}2,16 \\
(2,17)\end{array}$ & $\begin{array}{c}57 \\
(66)\end{array}$ & $a_{1}$ & $\begin{array}{c}151 \\
(164)\end{array}$ & $b_{2}$ & $\begin{array}{c}184 \\
(234)\end{array}$ & $\overline{a_{2}}$ & $\begin{array}{c}191 \\
(243)\end{array}$ & $b_{1}$ & $\begin{array}{c}326 \\
(347)\end{array}$ & $a_{1}$ \\
\hline V & $\left({ }^{1} A_{1}\right)$ & 0,00 & $\begin{array}{c}255 \\
(280)\end{array}$ & $a_{1}$ & $\begin{array}{c}277 \\
(258)\end{array}$ & $b_{2}$ & $\begin{array}{l}374 \\
(275)\end{array}$ & $b_{1}$ & $\begin{array}{c}481 \\
(546)\end{array}$ & $a_{1}$ & $\begin{array}{c}526 \\
(527)\end{array}$ & $b_{2}$ \\
\hline VI & $\left({ }^{1} A_{1}\right)$ & 0,00 & $\begin{array}{c}122 \\
(138) \\
\end{array}$ & $b_{2}$ & $\begin{array}{c}151 \\
(179)\end{array}$ & $b_{1}$ & $\begin{array}{c}334 \\
(381)\end{array}$ & $a_{1}$ & $\begin{array}{c}391 \\
(422)\end{array}$ & $b_{2}$ & $\begin{array}{c}425 \\
(468)\end{array}$ & $b_{1}$ \\
\hline VII & $\left({ }^{3} A_{2}\right)$ & $\begin{array}{c}2,08 \\
(2,08)\end{array}$ & $\begin{array}{c}113 \\
(155)\end{array}$ & $b_{1}$ & $\begin{array}{c}126 \\
(162)\end{array}$ & $\mathrm{b}_{2}$ & $\begin{array}{c}259 \\
(317)\end{array}$ & $D_{1}$ & $\begin{array}{c}403 \\
(437)\end{array}$ & $a_{1}$ & $\begin{array}{c}463 \\
(313 \lambda\end{array}$ & $b_{2}$ \\
\hline VIII & $\left({ }^{1} A_{1}\right)$ & 0,00 & $\begin{array}{c}46 i \\
(65 i)\end{array}$ & $b_{2}$ & $\begin{array}{l}62 \\
(36)\end{array}$ & $b_{1}$ & $\begin{array}{c}203 \\
(153)\end{array}$ & $a_{1}$ & $\begin{array}{l}211 \\
(38)\end{array}$ & $\bar{b}_{2}$ & $\begin{array}{c}222 \\
(217)\end{array}$ & $b_{1}$ \\
\hline IX & $\left({ }^{1} A^{\prime}\right)$ & 0,00 & $\begin{array}{c}59 \\
(45)\end{array}$ & $\mathbf{a}^{\prime}$ & $\begin{array}{l}96 \\
(41)\end{array}$ & $a^{n}$ & $\begin{array}{l}170 \\
(140)\end{array}$ & $a^{\prime}$ & $\begin{array}{c}225 \\
(170)\end{array}$ & $\mathrm{a}^{\prime \prime}$ & $\begin{array}{c}301 \\
(219)\end{array}$ & $a^{\prime}$ \\
\hline $\mathrm{X}$ & $\left({ }^{3} A_{1}^{\prime}\right)$ & $\begin{array}{c}2,04 \\
(2,05)\end{array}$ & $\begin{array}{c}318 \\
(1961)\end{array}$ & $\mathrm{e}^{\prime}$ & $\begin{array}{c}318 \\
(196)\end{array}$ & $\mathrm{e}^{\prime}$ & $\begin{array}{l}459 \\
(456)\end{array}$ & $a_{2}$ & $\begin{array}{c}480 \\
(541)\end{array}$ & $21^{\prime}$ & $\begin{array}{c}524 \\
(508)\end{array}$ & $e^{\prime \prime}$ \\
\hline$X I$ & $\left({ }^{3} \Pi_{g}\right)$ & $\begin{array}{l}2,16 \\
(2,21)\end{array}$ & $\begin{array}{c}727 i \\
(890 i)\end{array}$ & $\pi_{v}$ & $\begin{array}{c}43 \\
(25)\end{array}$ & $\pi_{u}$ & $\begin{array}{c}52 \\
(63)\end{array}$ & $\pi_{u}$ & $\begin{array}{c}86 \\
(192)\end{array}$ & $\pi_{9}$ & $\begin{array}{l}157 \\
\text { (129) }\end{array}$ & $\pi_{9}$ \\
\hline
\end{tabular}

Tabela 3 (continuação).

\begin{tabular}{|c|c|c|c|c|c|c|c|c|c|c|c|}
\hline \multicolumn{2}{|c|}{ Estrutura } & \multicolumn{10}{|c|}{ Freqüências vibracionais } \\
\hline & & \multirow{2}{*}{$\frac{\hat{S}^{2}}{0,00}$} & \multicolumn{2}{|l|}{$\omega_{6}$} & \multicolumn{2}{|c|}{$\omega_{7}$} & \multicolumn{2}{|l|}{$\omega_{8}$} & \multicolumn{2}{|c|}{$\omega_{9}$} & $\omega_{10}$ \\
\hline 1 & $\left({ }^{1} A_{1}\right)$ & & $\begin{array}{c}556 \\
(621)\end{array}$ & $b_{2}$ & $\begin{array}{c}565 \\
(627)\end{array}$ & $a_{1}$ & $\begin{array}{l}1285 \\
(1443)\end{array}$ & & $\begin{array}{c}1303 \\
(1487)\end{array}$ & $a_{1}$ & \\
\hline II & $\left({ }^{1} A_{1}\right)$ & 0,00 & $\begin{array}{c}416 \\
(470)\end{array}$ & $a_{1}$ & $\begin{array}{l}867 \\
(965)\end{array}$ & $\overline{\sigma_{1}}$ & $\begin{array}{c}992 \\
(1098)\end{array}$ & & $\begin{array}{l}1152 \\
(1295)\end{array}$ & & \\
\hline III & $\left({ }^{1} A_{1}^{\prime}\right)$ & 0,00 & $\begin{array}{l}592 \\
(707)\end{array}$ & $a_{2}$ & $\begin{array}{l}593 \\
(697)\end{array}$ & $\mathrm{e}^{\prime}$ & $\begin{array}{l}593 \\
(697)\end{array}$ & $e^{\prime}$ & $\begin{array}{l}764 \\
(957)\end{array}$ & $a_{1}$ & \\
\hline IV & $\left({ }^{3} B_{2}\right)$ & $\begin{array}{r}2,16 \\
(2,17) \\
\end{array}$ & $\begin{array}{c}504 \\
(560) \\
\end{array}$ & $a_{1}$ & $\begin{array}{l}661 \\
(717) \\
\end{array}$ & $\overline{b_{2}}$ & $\begin{array}{l}1474 \\
(1253)\end{array}$ & & $\begin{array}{l}1948 \\
(925) \\
\end{array}$ & $\mathrm{b}_{2}$ & \\
\hline V & $\left({ }^{\prime} A_{1}\right)$ & 0,00 & $\begin{array}{c}535 \\
(602) \\
\end{array}$ & $a_{1}$ & $\begin{array}{l}703 \\
(689)\end{array}$ & $a_{2}$ & $\begin{array}{c}751 \\
(882)\end{array}$ & & $\begin{array}{c}808 \\
(856) \\
\end{array}$ & $b_{1}$ & \\
\hline VI & $\left({ }^{1} A_{1}\right)$ & 0,00 & $\begin{array}{c}505 \\
(568)\end{array}$ & $a_{1}$ & $\begin{array}{c}776 \\
(852)\end{array}$ & $b_{2}$ & $\begin{array}{c}942 \\
(1103)\end{array}$ & $a_{1}$ & $\begin{array}{c}1426 \\
(1663)\end{array}$ & $a_{1}$ & \\
\hline VII & $\left({ }^{3} A_{2}\right)$ & $\begin{array}{c}2,08 \\
(2,08)\end{array}$ & $\begin{array}{c}573 \\
(618) \\
\end{array}$ & $a_{1}$ & $\begin{array}{l}836 \\
(646) \\
\end{array}$ & $b_{2}$ & $\begin{array}{c}993 \\
(1096)\end{array}$ & $a_{1}$ & $\begin{array}{l}1037 \\
(864)\end{array}$ & $a_{1}$ & \\
\hline VIII & $\left({ }^{1} A_{1}\right)$ & 0,00 & $\begin{array}{c}393 \\
(305)\end{array}$ & $\sigma_{1}$ & $\begin{array}{l}801 \\
(900)\end{array}$ & $\overline{a_{1}}$ & $\begin{array}{c}967 \\
(1179)\end{array}$ & $\mathrm{b}_{2}$ & $\begin{array}{c}1137 \\
(1384)\end{array}$ & $a_{1}$ & \\
\hline IX & $\left({ }^{\prime} A^{\prime}\right)$ & 0,00 & $\begin{array}{c}502 \\
(358) \\
\end{array}$ & $a^{\prime}$ & $\begin{array}{c}613 \\
(650)\end{array}$ & $a^{\prime}$ & $\begin{array}{c}968 \\
(1393)\end{array}$ & $a^{\prime}$ & $\begin{array}{l}1304 \\
(1453)\end{array}$ & $\mathrm{o}^{\prime}$ & \\
\hline$x$ & $\left({ }^{3} A_{1}^{\prime}\right)$ & $\begin{array}{c}2,04 \\
(2,05)\end{array}$ & $\begin{array}{l}524 \\
(508)\end{array}$ & $\mathrm{e}^{n}$ & $\begin{array}{c}763 \\
(890)\end{array}$ & $\sigma_{1^{\prime}}$ & $\begin{array}{c}782 \\
(729)\end{array}$ & $\mathrm{e}^{\prime}$ & $\begin{array}{c}782 \\
(729)\end{array}$ & $\mathrm{e}^{\prime}$ & \\
\hline$X I$ & $\left({ }^{3} \Pi_{g}\right)$ & $\begin{array}{l}2,16 \\
(2,21)\end{array}$ & $\begin{array}{c}289 \\
(375)\end{array}$ & $\sigma_{9}$ & $\begin{array}{c}358 \\
(382)\end{array}$ & $\pi_{v}$ & $\begin{array}{c}530 \\
(4861)\end{array}$ & $\sigma_{u}$ & $\begin{array}{c}1504 \\
(1142)\end{array}$ & $\sigma_{9}$ & $\begin{array}{l}2449 \\
(718)\end{array}$ \\
\hline
\end{tabular}


A estrutura IV é o mais estável isômero tripleto $\left({ }^{3} \mathrm{~B}_{1}\right)$ encontrado e é um mínimo local tanto em SCF quanto em MP2, apresentando uma geometria semelhante a I. Em nível SCF, este corresponde ao segundo isômero mais estável $(25,19 \mathrm{kcal} / \mathrm{mol})$, mas em MP2 torna-se menos estável $(44,02 \mathrm{kcal} / \mathrm{mol})$, passando a ser o terceiro em estabilidade. As mudanças nos parâmetros geométricos foram pequenas ao passar de SCF para MP2. As distâncias SiN internas aumentaram em cerca de $0,03 \AA$, enquanto as ligações terminais e os ângulos permaneceram praticamente inalterados relativos aos resultados SCF. Comparado como a estrutura singleto I, ambas distâncias encolheram em $0,04 \AA$ (MP2). Do mesmo modo que 1 , a freqüência $\omega_{1}\left(a_{1}\right)$ apresenta um valor pequeno, enquanto que em $\omega_{2}\left(b_{1}\right)$ e $\omega_{3}\left(a_{2}\right)$ ocorreu um aumento de cerca de 100 e $80 \mathrm{~cm}^{-1}$, respectivamente. Para essa estrutura, entretanto, apesar dos valores positivos das freqüências, uma absorção de múltiplos fótons pelo modo $a_{1}\left(57 \mathrm{~cm}^{-1}\right)$ pode levar a um rearranjo molecular ou dissociação. A observação dessa espécie em uma matriz é também uma possibilidade em aberto. Se o isolamento dessa estrutura for viável, então uma freqüência elevada de $1948 \mathrm{~cm}^{-1}$ permitiria diferenciar o espectro de IV do análogo singleto I.

Como ponto de partida para a estrutura tridimensional $V$, iniciamos com a aproximação de um átomo de silício com uma estrutura similar à estrutura em forma de duas pontes, encontrada por Ornellas e Iwata ${ }^{43}$ no estudo da espécie $\mathrm{Si}_{2} \mathrm{~N}_{2}$. Em níveis SCF e MP2, o processo de otimização mostrou uma convergência em que essa estrutura iornou-se planar, com um pequeno aumento na ligação SiN, e a formaçāo de uma ligaçāo simples fraca entre os silícios do plano com o silício fora deste, e esse valor é cerca de 0,1 $\AA$ maior que uma ligação simples típica. Com ambas metodologias, a estrutura corresponde a um mínimo local, com o resultado MP2 indicando uma estrutura muito mais estável que a obtida com SCF. Energeticamente, a estrutura $V$ encontra-se a apenas $4,0 \mathrm{kcal} / \mathrm{mol}$ acima de III, e do mesmo modo que em III, os valores de freqüência são certamente indicativos de uma estrutura ligada. Interessante notar que as distâncias SiSi são praticamente as mesmas em V e III, e de fato elas diferem apenas no deslocamento dos átomos de nitrogênio da regiāo central do grupo formado pelos átomos de silício para uma região mais periférica. Nota-se, também, que a diferença de energia entre as estrufuras IV e $\mathrm{V}, 1,1 \mathrm{kcal} / \mathrm{mol}$, é muito pequena para permitir uma 
afirmação definitiva sobre a posição energética relativa entre esses dois isômeros, pois uma expansão na base atômica poderia reverter essa ordem. Entretanto, as duas séries de freqüências vibracionais são bem distintas e não deve haver problemas na identificação dessas espécies isoladas.

$\mathrm{O}$ isômero planar $\mathrm{VI}$ corresponde também a uma estrutura localizada em um mínimo local. As distâncias SiSi e SiN no anel são da ordem de magnitude de uma ligação simples típica, e a distância NN $(1,325 \AA)$ encontra-se entre uma ligação NN dupla como na diazina $(1,252 \AA)$ e uma simples, como na hidrazina $(1,414 \AA)$; a distância SiN terminal $(1,593 \AA$ ) é muito próxima de uma ligaçāo dupla padrão de 1,58 $\AA$ como encontrada no $\mathrm{H}_{2} \mathrm{Si}=\mathrm{NH}$. Com relação à energia relativa, o resultado $M P 2$ indica que a estrutura é cerca de $10 \mathrm{kcal} / \mathrm{mol}$ mais estável que se comparado com o $S C F$, e $58,2 \mathrm{kcal} / \mathrm{mol}$ acima do mínimo global.

O isômero VII corresponde a um estado tripleto $\left({ }^{3} A_{2}\right)$ e é um outro exemplo de uma estrutura cíclica planar estável. Em nível MP2, este encontra-se 2,1 kcal/mol acima de VI. Nós podemos notar que a ordem de estabilidade relativa de VI e VII é dependente do nível de cálculo adotado, pois em nível SCFVII corresponde a um estado de transição mais estável. Nesse caso, embora o cálculo HF seja variacional, a correlação estática presente na função de onda UHF causa uma maior estabilização de VII relativo a VI. Por outro lado, a contaminação de spin faz com que a expansão UMP2 tenha uma convergência muito mais lenta que no caso RMP2. Uma combinação desses fatores é certamente responsável para a estrutura VI ser mais estável que VII por apenas 2,1 $\mathrm{kcal} / \mathrm{mol}$, que é um valor muito pequeno para que esta ordem relativa seja definitiva. $A$ utilização de uma base atômica mais extensa e a inclusão de correlação estática e dinâmica pode levar a uma alteração nessa ordem de estabilidade. Com relação à geometria, a distância SiSi $(2,34 \AA$ A é típica de silícios apresentando uma ligação simples. As distâncias $\mathrm{SiN}$ no anel são ligeiramente mais curtas que uma típica ligação SiN simples $(1,72 \AA)$ para o nitrogênio com conectividade dupla e ligeiramente maiores para o nitrogênio com conectividade tripla. É importante ressaltar que não foi possível encontrar uma estrutura estável singleto análoga a VII. O mais próximo que conseguimos obter corresponde à estrutura II, que por sua vez corresponde a um estado de transição. 
No caso da estrutura VIII, a estabilização obtida ao ir de SCF para MP2 foi muito significativa. Em nivel SCF esta encontra-se a 104,55 kcal/mol acima do isômero mais estável, enquanto que em MP2 essa diferença diminui para 64,15 kcal/mol. Entretanto, em ambos os casos essa estrutura corresponde a um estado de transição, com as geometrias otimizadas correspondendo basicamente a uma interação entre um grupo SiNSi angular com um SiN através dos silícios. Note que quando o nitrogênio aproxima os silícios, como em II, um ponto estacionário muito mais estável é encontrado, que por sua vez também é associado com um estado de transição.

No caso da estrutura assimétrica IX, ambas metodologias predizem a existência de um mínimo local, sendo que em MP2 é $66,9 \mathrm{kcal} / \mathrm{mol}$ acima de 1 , comparado com os $94,4 \mathrm{kcal} / \mathrm{mol}$ obtido com o cálculo SCF. A distância SiSi $(2,45 \AA)$ é um pouco maior que uma ligação SiSi simples padrão $(2,34 \AA$ ). Do mesmo modo que em I, a estrutura IX apresenta uma freqüência muito baixa $\left[59 \mathrm{~cm}^{-1}-\omega_{1}\left(a^{\prime}\right)\right]$ que pode também levar a um rearranjo molecular ou uma dissociação se houver uma excitação apropriada.

Uma estrutura tridimensional em forma de gaiola $(X)$ semelhante a III, mas correspondendo a um estado tripleto foi encontrada; $O$ isômero $X$ é muito menos estável que III, com a estabilidade relativa de 83,32 e 77,33 kcal/mol em níveis SCF e MP2, respectivamente. Com relação à natureza do ponto estacionário, o resultado SCF leva a um ponto de sela de segunda ordem, enquanto que em MP2 corresponde a um mínimo local. Com relação a essa mudança, de SCF para MP2, vale a pena observar que os valores das freqüências imaginárias e as demais freqüências não são pequénos, e essa mudança na natureza do estado estacionário deve ser atribuída ao efeito de correlação dinâmica incluída no cálculo MP2. A distância SiN é aproximadamente a mesma que em III e é indicativa de uma ligação simples. Em X encontramos uma distância $N N(1,69 \AA)$ menor em cerca de 0,8 $\AA$ e uma SiSi $(2,87 \AA$ ) maior em cerca de 0,4 $\AA$ em comparação a III, resultando em uma estrutura mais compacta quando comparada a III.

Considerando as estruturas lineares, a mais estável encontrada (XI) envolve apenas ligações SiN, e corresponde a um estado tripleto. Em nível SCF, o estado estacionário é um ponto de sela de segunda ordem, enquanto que em MP2 corresponde a um estado de transição a 78,9 kcal/mol acima de I. Nas estruturas lineares não encontramos pontos 
estacionários singleto. Várias arranjos lineares possiveis foram testados, e, com exceção de XI, todos eles são muito instáveis, com energias acima de $100 \mathrm{kcal} / \mathrm{mol}$ relativo a l, e correspondendo a pontos de sela de primeira ou de ordens superiores.

A partir desses resultados podemos observar que os isômeros mais estáveis apresentam uma preferência para a formação de estruturas com o maior número possível de ligações SiN; a formação da ligação fraca SiSi é claramente evitada. O fato de que as estruturas com ligaçōes SiSi são menos estáveis que as envolvendo ligações NN ou SiN já foi apontado em trabalhos anteriores. ${ }^{41,43}$ No caso do $\mathrm{Si}_{2} \mathrm{~N}$, o mínimo global corresponde a uma geometria linear simétrica, e para $\circ \mathrm{Si}_{2} \mathrm{~N}_{2}$ corresponde a dois silícios terminais conectados aos nitrogênios em uma estrutura simétrica linear. No caso do $\mathrm{Si}_{3} \mathrm{~N}_{2}$, nós não encontramos qualquer estrutura linear bastante estável; o mínimo global corresponde a uma estrutura planar angular com apenas ligaçōes $\mathrm{SiN}$.

\section{Comparações com $\mathrm{Si}_{5}$ e $\mathrm{Si}_{3} \mathrm{C}_{2}$}

Considerando as estruturas tridimensionais, os resultados para o isômero em forma de "gaiola" III apresenta certas similaridades com o equivalente encontrado no estudo dos aglomerados de fórmula $\mathrm{Si}_{3} \mathrm{C}_{2}$ realizado por Froudakis et al.. ${ }^{75}$ Trabalhando em nível MP2/DZP, eles encontraram que o segundo isômero mais estável apresenta uma geometria em formato de "gaiola" similar a III. Para $\circ \mathrm{Si}_{3} \mathrm{C}_{2}$, esse isômero é 19,9 $\mathrm{kcal} / \mathrm{mol}$ acima da estrutura com menor energia, enquanto que em $\mathrm{Si}_{3} \mathrm{~N}_{2}$ essa diferença é cerca de duas vezes maior. Ligaçōes químicas entre os dois carbonos e entre os carbonos e silícios estão presentes no $\mathrm{Si}_{3} \mathrm{C}_{2}$, assim como a ausência de ligaçōes entre os silícios. No caso III, os átomos de nitrogênio estão mantidos muito afastados um do outro, com a distância entre os silícios somente um pouco maior que uma ligação simples padrão, e distâncias SiN típicas de ligações simples. A estrutura mais estável encontrada por Froudakis et al. corresponde a um pentágono planar, com um átomo de carbono adjacente a outro. A estabilidade dessa estrutura foi atribuída ao grande número de ligações $\mathrm{SiC}$ e a existência de uma ligação forte $\mathrm{CC}$, levando a uma grande estabilização, apesar da existência de duas ligaçōes SiSi. No caso do isômero III o mesmo 
raciocínio pode ser aplicado para justificar a estabilidade dessa estrutura. A busca de uma estrutura similar entre os isômeros do $\mathrm{Si}_{3} \mathrm{~N}_{2}$ resultou em espécies muito instáveis localizadas a mais de $110 \mathrm{kcal} / \mathrm{mol}$ (SCF) acima do mínimo global. Notamos também que III é similar ao isômero mais estável do $\mathrm{Si}_{5}$. Com base nos trabalhos anteriores ${ }^{41,43} \mathrm{e}$ também nas evidências discutidas acima, podemos concluir que o número de ligações SiSi nas moléculas de silício e nitrogênio é fator crítico que governa sua estabilidade, mais que no caso dos aglomerados de silício e carbono. Para as espécies estudadas neste trabalho as estruturas mais estáveis possuem o menor número possível de ligaçōes SiSi.

Tendências de estabilidade nas séries $\mathrm{Si}_{x} \mathrm{~N}_{y}$ e canais de dissociação

Conforme mencionado, para as moléculas $\mathrm{SiN}_{2}, \mathrm{Si}_{2} \mathrm{~N}$ e $\mathrm{Si}_{2} \mathrm{~N}_{2}$ a estrutura mais estável corresponde a uma geometria linear. No caso do $\mathrm{Si}_{3} \mathrm{~N}_{2}$, essa tendência linear é quebrada e $O$ isômero mais estável apresenta uma geometria planar angular. Esse comportamento não é inesperado, pois os silícios apresentam uma preferência para a formaçāo de ligaçōes tridimensionais, quando comparado ao carbono. A estrutura III, que encontra-se a $41 \mathrm{kcal} / \mathrm{mol}$ acima de l, pode ser visualizada como uma "semente" para ym crescimento tridimensional, especialmente a temperaturas elevadas. Baseado nessa tendência, espera-se que o aumento no número de átomos de silício leve à preferência para a formação de estruturas tridimensionais, como no caso do $\mathrm{Si}_{5}$.

Energeticamente próxima a III, a estrutura $V$ é também tridimensional, mas com os nitrogênios posicionados simetricamente sobre a borda do plano formado pelos silícios. As tentativas de encontrar um estado de transiçāo que correlacione III e V não deram resultados. As estruturas I, III e V, associadas com estados singletos, são todas energeticamente mais estáveis que o primeiro canal de dissociação $\mathrm{Si}_{3}\left({ }^{1} A_{1}\right)+N_{2}\left({ }^{l}{ }_{g}{ }^{+}\right)$ por 54,2, 13,2 e 9,1 kcal/mol, respectivamente, e a estrutura IV, associada com estado tripleto, encontra-se abaixo do primeiro canal de dissociação tripleto, $\mathrm{Si}_{3}\left({ }^{3} \mathrm{~B}_{2}\right)+\mathrm{N}_{2}\left({ }^{l}{ }_{\mathrm{g}}{ }^{+}\right)$, por $11,8 \mathrm{kcal} / \mathrm{mol}$. Também notamos que o primeiro estado tripleto localizado em um mínimo local (IV) correlaciona com o estado de transição linear (XI), conforme determinado através dos cálculos $I R C$. Como vários canais possíveis de dissociação 
apresentam uma energia muito elevada, conforme mostrado na Figura 5, podemos esperar que as estruturas mencionadas sejam termodinamicamente estáveis.

Com respeito à correlação dessas estruturas com os vários canais de dissociação, a busca de um estado de transição no hiperespaço 9-dimensional conectando as estruturas com os canais mostrou ser desapontador, pois a busca de um ponto de sela nessa superfície é muito difícil. Dos três estados de transição encontrados com energias abaixo de $80 \mathrm{kcal} / \mathrm{mol}$ em relação ao mínimo global, as estruturas II e XI, conforme mencionado, conectam duas estruturas equivalentes de I e IV, respectivamente. Várias tentativas foram feitas através de cálculos $I R C$ para encontrar os mínimos locais que correlacionam com a estrutura de transição VIII, mas devido à pouca profundidade da superfície de energia potencial na vizinhança do pondo de sela, refletido pelos baixos valores das freqüências vibracionais, a busca automática com vários valores de parâmetros de "passos" causou o retorno ao ponto estacionário original após algumas poucas etapas.

Essas dificuldades impediram que pudéssemos estimar as barreiras de energia para interconversões e energias de dissociação. Entretanto, energias de atomização podem ser facilmente estimadas a partir da Figura 5, sendo que para a estrutura I esse valor é de $420,6 \mathrm{kcal} / \mathrm{mol}$, incluindo a correção de energia do ponto zero. 


$\frac{\mathrm{Si}_{3}\left({ }^{1} \mathrm{~A}_{1}\right)+2 \mathrm{~N}\left({ }^{4} \mathrm{~S}\right) 271,8}{2 \mathrm{SiN}\left({ }^{2} \Sigma^{+}\right)+\operatorname{Si~}\left({ }^{3} \mathrm{P}\right) 268,8}$
$\frac{\mathrm{Si}_{2}\left({ }^{3} \Pi_{\mathrm{u}}\right)+\mathrm{SiN}_{2}\left({ }^{1} \mathrm{~A}_{1}\right)}{153,9}$

$\frac{3 \mathrm{Si}\left({ }^{3} \mathrm{P}\right)+2 \mathrm{~N}\left({ }^{4} \mathrm{~S}\right)}{426,9}$

$\frac{\operatorname{SiN}\left({ }^{2} \Sigma^{+}\right)+\operatorname{SiNSi}\left({ }^{2} \Pi_{\mathrm{g}}\right)}{138,3}$

$\frac{3 \mathrm{Si}\left({ }^{3} \mathrm{P}\right)+\mathrm{N}_{2}\left({ }^{1} \Sigma_{\mathrm{g}}^{+}\right)}{209,2}$
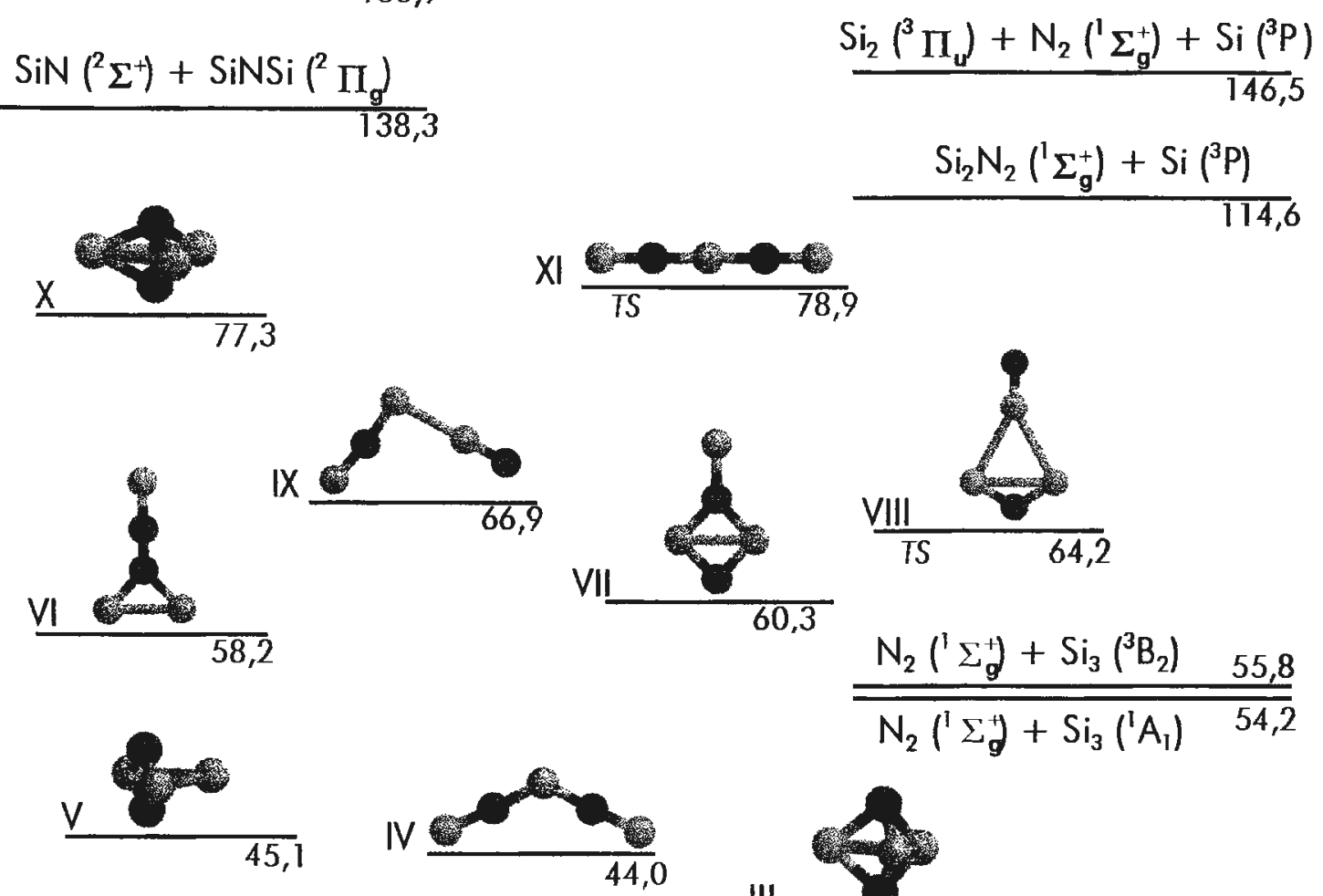

60,3

$\frac{\mathrm{N}_{2}\left({ }^{1} \Sigma_{g}^{+}\right)+\mathrm{Si}_{3}\left({ }^{3} \mathrm{~B}_{2}\right)}{55,8}$

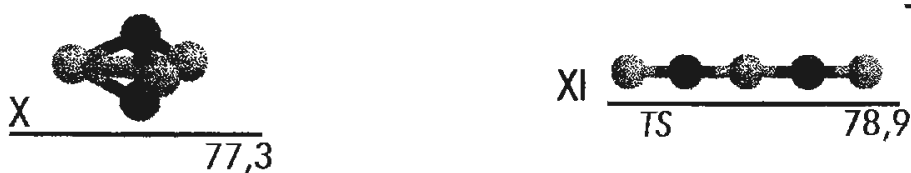

114,6 


\subsection{CONCLUSÕES}

Neste trabalho, um estudo detalhado da molécula $\operatorname{SiNN}\left({ }^{3} \Sigma^{-}\right)$, com ênfase em particular nas freqüências vibracionais, foi realizado utilizando metodologias com um tratamento do efeito de correlação eletrônica de alto nível. Apresentamos de modo convincente evidências de que a freqüência harmônica da ligaçāo NN deve cair numa regiāo próxima de $1830 \mathrm{~cm}^{-1}$. Com exceçāo da referência 38, os cálculos CCSD(T) apontam nessa direção. De fato, nosso cálculo de mais alto nível [CCSD(T)/cc-pVQZ] fornece um valor de $1859 \mathrm{~cm}^{-1}$ para o estiramento harmônico $N N$, em desacordo com o valor CCSD(T)/DZP de $1726 \mathrm{~cm}^{-1}$ da referência 37. Analisando o valor experimental, sugerimos que $1830 \mathrm{~cm}^{-1}$ deve ser um valor experimental mais realista para essa freqüência, daí acreditarmos na necessidade de se obter novos dados experimentais. Surpreendentemente, nosso cálculo CMRCl falhou em fornecer dados de acordo com $\operatorname{CCSD}(T)$. A freqüência obtida de $2024 \mathrm{~cm}^{-1}$ é $144 \mathrm{~cm}^{-1}$ maior que a esperada. A falta de excitações de ordem superior no CMRCl comparado com a aproximação CCSD(T) talvez seja a causa dessa diferença.

Ainda neste trabalho, quatro outros mínimos locais foram investigados com a metodologia $\operatorname{CCSD}(T)$ e a base cc-pVTZ. A espécie cíclica ${ }^{1} A_{1}$ encontr-se muito baixa energeticamente $(6,09 \mathrm{kcal} / \mathrm{mol})$ e é seguida por uma linear assimétrica singleto, a 15,81 $\mathrm{kcal} / \mathrm{mol}$ do mínimo global. Com exceção do estiramento SiN, as freqüências da estrutura linear assimétrica singleto são praticamente idênticas às da assimétrica tripleto, e isso deve ser levado em conta na discussão das freqüências experimentais. Dentro das condições de alta temperatura em que os átomos de silício sāo inicialmente gerados, a possibilidade de que espécies singleto sejam também aprisionadas nas matrizes deve ser levado em consideraçāo na análise espectral.

Com relação ao aglomerado de fórmula $\mathrm{Si}_{3} \mathrm{~N}_{2}$, neste estudo buscamos caracterizar as estruturas e estabelecer uma escala relativa de estabilidade entre as várias espécies e também relativa às diferentes possibilidades de dissociação das moléculas. Contrário às tendências observadas em outros trabalhos, uma estrutura angular foi encontrada como mínimo global; uma estrutura bipiramidal cerca de 41,0 kcal/mol 
acima do mínimo global é a próxima estrutura localizada em um ponto de mínimo e assemelha-se à estrutura tridimensional do $\mathrm{Si}_{5}$. Estruturas lineares são muito instáveis. Poucos estados de transição foram encontrados e correlacionados com mínimos locais, mas para outros foi difícil seguir o caminho para um mínimo local através de um cálculo IRC. Estados de transição correlacionando mínimos locais e canais de dissociação foram também difíceis de encontrar na superfície multidimensional, mas algumas espécies foram determinadas como sendo termodinamicamente estáveis, sendo a energia do canal de dissociaçāo mais baixo um limite inferior para a energia de dissociação. 


\section{I.6 REFERÊNCIAS}

1. J. M. Jasinski, B. S. Meyerson e B. A. Scott, Annu. Rev. Phys. Chem. 38, 109 (1987).

2. M. Iraqi, N. Goldberg e H. Schwarz, J. Phys. Chem. 97, 11371 (1993).

3. N. Goldberg, M. Iraqi, H. Schwarz, A. Boldyrev e J. Simons, J. Chem. Phys. 101, 2871 (1994).

4. K. Raghavachari e L. Curtiss, Quantum Mechanical Electronic Structure Calculations with Chemical Accuracy, S. R. Langhoff (Ed.), Kluwer Academic, Netherlands, 1995, p. 173.

5. S. K. Nayak, S. N. Khanna, B. K. Rao e P. Jena, J. Phys. Chem. A 101, 1072 (1997).

6. T.T. Rantala, D. A. Jelski e T. F. George, Chem. Phys. Lett. 232, 215 (1995).

7. F. L. Sefyani e J. Schamps, Chem. Phys. 191, 155 (1995).

8. M. Krack e K. Jug, Chem. Phys. 192, 127 (1995).

9. M. V. Ramakrishna e A. Bahel, J. Chem. Phys. 104, 9833 (1996).

10. K. Raghavachari e C. M. Rohlfing, Chem. Phys. Lett. 143, 428 (1988).

11. R. Fournier, S. B. Sinnott e A. E. DePristo, J. Chem. Phys. 97, 4149 (1992).

12. B. Hartke, Theor. Chem. Acc. 99, 241 (1998).

13. L.-S. Wang, H. Wu, S. R. Desai, J. Fan e S. D. Colson, J. Phys. Chem. 100, 8697 (1996).

14. A. I. Boldyrev e J. Simon, J. Phys. Chem. 97, 5875 (1993).

15. R. Kishi, A. Nakajima, S. Iwata e K. Kaya, Chem. Phys. Lett. 244, 200 (1994). 
16. K. Kaya e A. Nakajima, Mater. Sci. Eng. A 217/218, 7 (1996).

17. H. Kawamata, Y. Negishi, R. Kishi, S. Iwata, A. Nakajima e K. Kaya, J. Chem. Phys. 105, 5369 (1996).

18. D. L. Michalopoulos, M. E. Geusic, P. R. R. Langridge-Smith e R. E. Smalley, J. Chem. Phys. 80, 3556 (1984).

19. J. D. Presilla-Márquez e W. R. M. Graham, J. Chem. Phys. 96, 6509 (1992).

20. J. D. Presilla-Márquez e W. R. M. Graham, J. Chem. Phys. 100, 181 (1994).

21. C. M. L. Rittby, J. Chem. Phys. 96,6768 (1992).

22. C. M. L. Rittby, J. Chem. Phys. 100, 175 (1994).

23. G. Froudakis e A. Zdetsis, J. Chem. Phys. 101, 6790 (1994).

24. G. W. Trucks e R. J. Bartlett, J. Mol. Struct. (Theochem) 135, 423 (1986).

25. A. Dreuw, T. Sommerfeld e L. S. Cederbaum, J. Chem. Phys. 109, 2727 (1998).

26. R. Kishi, M. Gomei, A. Nakajima, S. Iwata e K. Kaya, J. Chem. Phys. 104, 8593 (1996).

27. H. Ito, K. Suzuki, T. Kondow e K. Kushitsu, Chem. Phys. Lett. 208, 328 (1993).

28. M. Elhanine, B. Hanoune, G. Guelachvili e C. Amiot, J. Phys. (Fr.) 2, 931 (1992).

29. C. Naulin, M. Costes, Z. Moudden, N. Ghanem e G. Dorthe, Chem. Phys. Lett. 202, 452 (1993).

30. P. J. Bruna, H. Dohmann e S. Peyerimhoff, Can. J. Phys. 62, 1508 (1984).

31. D. P. Chong, Chem. Phys. Lett. 220, 102 (1994). 
32. Z.-L. Cai, J. M. L. Martin, J. P. François e R. Gijbels, Chem. Phys. Lett. 252, 398 (1996).

33. A. C. Borin, Chem. Phys. Lett. 262, 80 (1996).

34. R. R. Lembke, R. F. Ferrante e W. Weltner, Jr., J. Am. Chem. Soc. 99, 416 (1977).

35. R. L. DeKock, R. S. Grev e H. F. Schaefer, J. Chem. Phys. 89, 3016 (1988).

36. D. A. Dixon e R. L. DeKock, J. Chem. Phys. 97, 1157 (1992).

37. I. S. Ignatyev e H. F. Schaefer, J. Phys. Chem. 96, 7632 (1992).

38. C. W. Murray, G. J. Laming, N. C. Handy e R. D. Amos, J. Phys. Chem. 97, 1868 (1993).

39. J. Wang, L. A. Erikson, R. J. Boyd, Z. Shi e B. G. Johnson, J. Phys. Chem. 98, 1844 (1994).

40. Z. L. Cai, Y. F. Wang e H. M. Xiao, J. Chem. Soc. Faraday Trans. 88, 1611 (1992).

41. F. R. Ornellas e S. Iwatg, J. Phys. Chem. 100, 10919 (1996).

42. K. A. Gingerich, R. Viswanathan e R. W. Schmude Jr., J. Chem. Phys. 106, 6016 (1997).

43. F. R. Ornellas e S. Iwata, J. Phys. Chem. 100, 16155 (1996).

44. K. Raghavachari, G. W. Trucks, J. A. Pople e M. Head-Gordon, Chem. Phys. Lett. 157,479 (1989).

45. G. E. Scuseria, Chem. Phys. Lett. 176, 27 (1991).

46. GAUSSIAN92, revisão C; M. J. Frisch, G. W. Trucks, M. Head-Gordon, P. M. W. Gill, M. W. Wong, J. B. Foresman, B. G. Johnson, H. B. Schlegel, M. A. Robb, E. S. Replogle, R. Gomperts, J. L. Andres, K. Raghavachari, J. S. Binkley, C. Gonzales, R. L 
Martin, D. J. Fox, D. J. Defrees, J. Baker, J. J. P. Stewart e J. A. Pople, Gaussian, Inc., Pittsburgh, PA, 1992.

47. O programa MELD foi desenvolvido originalmente por E. R. Davidson, S. R. Langhoff, S. T. Elbert e L. E. McMurchie com subsequentes modificações feitas por D. Feller e D. C. Rawlings. Para a descrição do código, veja E. R. Davidson, Modern Techniques in Computational Chemistry: MOTTEC-97, editado por E. Clementi (Escom, Leiden, 1991), p. 381.

48. MOLPRO é um pacote de programas $a b$ initio desenvolvido por H.-J. Werner e P. J. Knowles, com contribuições de J. Almlöf, R. D. Amos, M. J. O. Deegan, S. T. Elbert, C. Hampel, W. Meyer, K. Peterson, R. Pitzer, A. J. Stone, P. R. Taylor e R. Lindh.

49. P. C. Hariharan e J. A. Pople, Theor. Chim. Acta 28, 213 (1973).

50. M. M. Frand, W. J. Pietoro, W. J. Hehre, J. S. Binkley, M. S. Gordon, D. J. DeFrees e J. A. Pople, J. Chem. Phys. 77, 3654 (1982).

51. T. H. Dunning e P. J. Hay, em Modern Theoretical Chemistry, editado por H. F. Schaefer (Plenum, New York, 1977), Vol. 3, p. 1.

52. T. H. Dunning, J. Chem. Phys. 90,1007 (1989).

53. D. E. Woon e T. H. Dunning, J. Chem. Phys. 98, 1358 (1993).

54. A. D. McLean e G. S. Chandler, J. Chem. Phys. 72, 5639 (1980).

55. R. Krishnan, J. S. Binkley, R. Seeger e J. A. Pople, J. Chem. Phys. 72, 650 (1980).

56. F. Jensen, Introduction to Computational Quantum Chemistry, Wiley, Chichester, England, 1995; pp 112-117.

57. Gaussian 94, Revisão E.1; M. J. Frisch, G. W. Trucks, H. B. Schlegel, M. W. Gill, B. G. Johnson, M. A. Robb, J. R. Cheeseman, T. Keith, G. A. Petersson, J. A. Montgomery, K. Raghavachari, M. A. Al-Laham, V. G. Zakrzewski, J. V. Ortiz, J. B. Foresman, J. Cioslowski, B. B. Stefanov, A. Nanayakkara, M. Challacombe, C. Y. 
Peng, P. Y. Ayala, W. Chen, M. W. Wong, J. L. Andres, E. S. Replogle, R. Gomperts, R. L. Martin, D. J. Fox, J. S. Binkley, D. J. Defrees, J. Baker, J. P. Stewart, M. HeadGordon, C. Gonzalez e J. A. Pople, Gaussian, Inc., Pittsburgh, PA, 1995.

58. K. A. Peterson e T. H. Dunning, J. Phys. Chem. 99, 3988 (1995).

59. D. Feller e E. R. Davidson, J. Chem. Phys. 74, 3977 (1981).

60. H.-J. Werner e P. J. Knowles, J. Chem. Phys. 82, 5053 (1985).

61. P. J. Knowles e H.-J. Werner, Chem. Phys. Lett. 115, 259 (1985).

62. H.-J. Werner e P. J. Knowles, J. Chem. Phys. 89, 5883 (1988).

63. P. J. Knowles e H.-J. Werner, Chem. Phys. Lett. 145, 514 (1988).

64. G. Herzberg, Molecular Spectra and Molecular Structure: Infrared and Raman Spectra of Polyatomic Molecules (Van Nostrand Reinhold, New York, 1945), Vol. II, p. 173.

65. B. T. Luke, J. A. Pople, M. Krogh-Jespersen, Y. Apeloig, J. Chandrasekhar e P. v. R. Schleyer, J. Am. Chem. Soc. 108, 260 (1986).

66. R. D. Verma e P. A. Warsop, Can. J. Phys. 41, 152 (1963).

67. M. S. Gordon, Chem. Phys. Lett. 126, 451 (1986).

68. D. W. Rankin, A. G. Robiette, G. M. Sheldrick, W. S. Sheldrick, B. J. Aylett, I. A. Ellis e J. J. Monaghan, J. Chem. Soc. (London) A 1224 (1990).

69. T. N. Truong e M. S. Gordon, J. Am. Chem. Soc. 108, 1775 (1986).

70. K. P. Huber e G. Herzberg, Molecular Spectra and Molecular Structure: Constants of Diatomic Molecules; Van Nostrand Reinhold: New York, 1979; Vol. IV.

71. M. Carlotti, I. W. C. Johns e A. Trombetti, Can. J. Phys. 52, 340 (1974).

72. J. A. Pople e L. A. Curtiss, J. Chem. Phys. 95, 4385 (1991). 
73. N. Goldberg, M. C. Holthausen, J. Hrusák, W. Koch e H. Schwarz, Chem. Ber. 126, 2753 (1993).

74. T. Shimanouchi, J. Phys. Chem. Ref. Data 6, 993 (1977).

75. G. E. Froudakis, M. Mühlhäuser e A. D. Zdetsis, Chem. Phys. Lett. 233, 619 (1995). 


\section{SUPERFÍCIE E AGLOMERADOS DE SILÍCIO}




\section{II.1 ESTRUTURA DAS SUPERFÍCIES SÓLIDAS}

Em geral, dois tipos de estruturas de superfícies podem ser observados experimentalmente: periódicas e não-periódicas. Superfícies periódicas são aquelas onde as estruturas da superfície se repetem em intervalos regulares, enquanto as nāoperiódicas não apresentam essa repetiçāo, levando a formas amorfas.

A estrutura cristalina do interior de um material tem sido estudada com grande detalhe através da cristalografia, que desenvolveu uma notação específica para a descrição do interior (bulk) de cristais. De acordo com essa notação, a classificação da estrutura cristalina é feita em termos das posições dos átomos no cristal. Em um material cristalino, os átomos apresentam uma disposição periódica, e uma vez conhecida essa periodicidade e a estrutura mínima de reperiçāo é possível realizar essa classificaçāo.

Para a descrição de um retículo periódico, é conveniente que seja feito em termos de algo conhecido como célula unitária, que é definida como a unidade básica de repetiçāo do retículo. Se procedermos a uma repetição em todas as direçōes a partir de uma célula unitária obteremos o cristal inteiro. A escolha da célula unitária não é única, e na literatura é comum adotar a chamada célula unitária primitiva, que é a unidade repetitiva com a menor área ou volume possível.

A partir da escolha da célula unitária pode-se obter os vetores do retículo, vetores esses que apontam de um ponto de uma célula unitária para outro ponto equivalente da célula vizinha. Esses vetores não são necessariamente ortogonais, apesar da ortogonalidade facilitar a análise do cristal. Para um retículo em duas dimensōes, com somente um átomo em cada célula primitiva, pode-se especificar a periodicidade dos átomos em termos de dois vetores e de um ângulo entre eles, enquanto que para um em três dimensōes três vetores e três ângulos sāo necessários. Bravais considerou todas as possibilidades de combinaçôes de simetria entre esses vetores e ângulos e mostrou que existem cinco possibilidades para um retículo em duas dimensōes, correspondentes a cinco grupos de simetria diferentes, e quatorze em três dimensōes. Essas possibilidades são conhecidas como retículos primitivos de Bravais. Os mais conhecidos retículos de Bravais são o cúbico de face centrada (CFC) e cúbico de corpo centrado (CCC), sendo 
que nesse último caso podemos citar como exemplo o retículo do diamante, que é o mesmo do silício.

Uma superfície cristalina é obtida a partir do corte do interior (bulk) de um cristal. Essa superfície também apresenta uma regularidade, e para isso Miller ${ }^{\top}$ desenvolveu uma notação específica, conhecida como índices de Miller, que é adotada até o presente.

Existem dois tipos de índices: um para indicar uma determinada direçāo em um retículo e outra para indicar um plano no retículo. Por convenção, os índices apresentados entre parênteses, por exemplo (100), referem-se à notação do plano, enquanto que os índices entre colchetes, por exemplo [111], referem-se à orientação cristalográfica.

Para determinar os índices de Miller de um plano (i j k utiliza-se a relação:

$$
(i ; k)=\left(\frac{m}{b_{x}}, \frac{m}{b_{y}}, \frac{m}{b_{z}}\right)
$$

Os índices $b_{x}, b_{y}$ e $b_{z}$ correspondem aos pontos onde o plano intersecta os eixos $x$, y e $z$, respectivamente, conforme podemos ver no exemplo da Figura 6 . O valor de $m$ é uma constante, sendo igual ao menor denominador comum entre $1 /\left|b_{x}\right|, 1 /\left|b_{y}\right|$ e $1 /\left|b_{z}\right|$ e maior ou igual a 1 , ignorando valores infinitos de $b_{x}, b_{y}$ e $b_{z}$. No exemplo da Figura 6 temos um plano que intersecta os eixos $x$, y e z em 2,3 e 4 , respectivamente. Com isso o menor denominador é 12, de modo que o plano é representado por (643). Um plano que intersecta nos pontos 2,1 e $\infty(m=2)$ corresponde a (120). Normalmente, utiliza-se barras para designar valores negativos. Por exemplo, se o plano intersecta os eixo $x, y$ e $z$ nos pontos $2,-1$ e $\infty$ teremos a representação (1 $\overline{2} 0)$. 


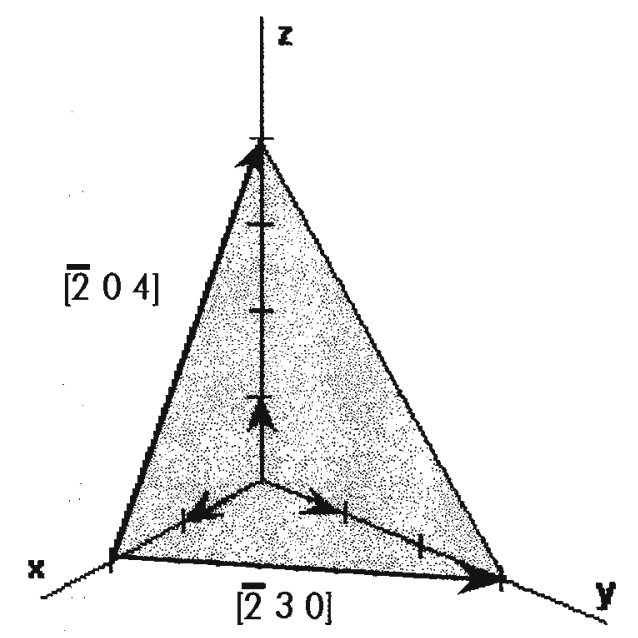

Figura 6. Representação do plano (643), de acordo com os índices de Miller.

Interessante observar que diferentes planos podem ter os mesmos índices de Miller, como nos casos dos planos paralelos que intersectam os eixos nos pontos $(2,2,2),(1,1,1)$ e $(3,3,3)$, pois nesses casos os planos correspondem a (111).

Para representar os índices de Miller de um vetor, utiliza-se a notação [iik]. No caso da direção [123], por exemplo, utiliza-se dois vetores do retículo na direção do eixo y e três na $z$, para cada vetor do retículo na direção $x$.

Em um cristal cúbico o plano (ijk) é perpendicular à direção [ijk], mas isso não ocorre necessariamente se considerarmos outro retículo cristalino.

\section{Relaxação e reconstrução da superfície}

Experimentalmente, a estrutura ideal raramente é observada. Quando uma superfície é formada, algumas ligações do material são quebradas, levando à formação de dangling bonds, ou seja, de átomos com elétrons desemparelhados. Essa estrutura é instável, e a estabilização é conseguida com a redução desses dangling bonds a partir da formação de novas ligações químicas. Esse fenômeno, conhecido como reconstrução da superfície, é responsável pela formação de uma nova variedade de estruturas e, 
conseqüentemente, todo um comportamento químico particular. Desse modo, temos que os átomos da superfície movem-se em relação aos átomos internos, levando a uma mudança na periodicidade da superfície. Além da reconstrução, um outro tipo de rearranjo muito comum é a relaxação. Este é um caso bastante comum, visto que praticamente todas as superfícies, no vácuo, apresentam esse fenômeno, que consiste no movimento de camadas inteiras de átomos na direção normal à superfície, sem que haja um rearranjo dos átomos dentro de cada camada. Experimentalmente, observa-se que a separação entre a primeira e a segunda camadas é menor que a observada no interior, e quanto menor o empacotamento ou a densidade, tanto maior é o efeito observado. Normalmente essa mudança nas distâncias se prolonga até a quinta ou sexta camada interna.

Notaçāo de superfícies reconstruídas

estudo com maiores detalhes da estrutura de superfícies teve início nos anos de 1950, e nessa época havia a dificuldade de não existir uma linguagem adequada para descrever a estrutura de superfícies reconstruídas. Mas Wood ${ }^{2}$ propôs uma notação simples para resolver esse problema. A idéig era, a partir de uma superfície ideal, achar os vetores do retículo da cela unitária primitiva, $\overrightarrow{b_{1}} \in \overrightarrow{b_{2}}$, onde por convenção adota-se o vetor $\overrightarrow{b_{1}}$ como sendo o menor dos dois vetores, conforme podemos ver na Figura 7, para - caso da estrutura da $\mathrm{Pt}(110)$. No caso da estrutura reconstruída temos dois outros vetores $\overline{\mathbf{b}_{1 a}}$ e $\overline{\mathbf{b}_{2 a}}$, onde:

$$
\begin{aligned}
& \overrightarrow{b_{1 a}}=\overrightarrow{b_{1}} \\
& \overrightarrow{b_{2 a}}=2 \overrightarrow{b_{2}}
\end{aligned}
$$




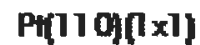

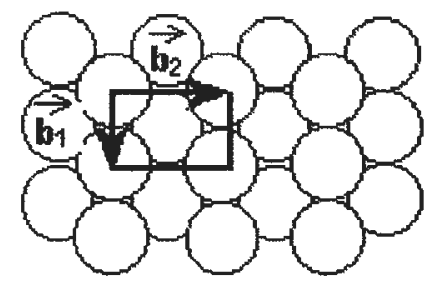

PH(110)(102)

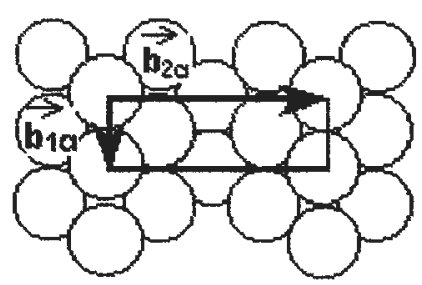

Figura 7. Vetores do retículo cristalino das superfícies $P+(110)(1 \times 1)$ e $P+(110)(1 \times 2)$.

Wood propôs chamar essa superfície reconstruída de $\mathrm{Pt}(110)$ (1×2), onde o valor 1 corresponde à razão entre os comprimentos dos vetores $\overrightarrow{b_{1 a}}$ e $\overrightarrow{b_{1}}$ e o valor 2 à razão entre $\overrightarrow{b_{2 a}}$ e $\overrightarrow{b_{2}}$. Nessa notação a superfície não reconstruída é chamada de $P+(110)(1 \times 1)$.

A notação de Wood tem sido adotada no estudo de superfícies a partir de então, mas muitas vezes as pessoas não seguem a notação de maneira exata. Por exemplo, a reconstrução (1x2) da Pt(1 10) é normalmente chamada de $(2 \times 1) \operatorname{Pt}(110)$ e não $\mathrm{Pt}(110)$ (1x2), como proposto por Wood. Do mesmo modo, a estrutura não reconstruída $(1 \times 1)$ é chamada de $(1 \times 1) \operatorname{Pt}(110)$.

Uma pequena dificuldade surge quando os vetores da estrutura reconstruída não seguem a mesma orientação que os vetores da superfície não reconstruída. Por exemplo, os vetores da cela unitária primitiva da estrutura mostrada na Figura 8 no caso da superfície reconstruída $W(100)$ formam um ângulo de $45^{\circ}$ em relação à cela unitária da superfície não reconstruída. A notação para esse caso é $(\sqrt{2} \times \sqrt{2})$ R45 $5^{\circ}$, onde o valor $\sqrt{2}$ indica que o vetor final é $\sqrt{2}$ vezes o comprimento do vetor da cela original, e $45^{\circ}$ indica que o retículo reconstruído apresenta uma rotação de $45^{\circ}$ em relação à cela original, ou seja, da superfície ideal. Entretanto, pode utilizar a cela unitária convencional, e nesse caso teremos uma estrutura do tipo $(2 \times 2)$. Nesse caso, as pessoas utilizam a notação $c(2 \times 2)$ onde a letra " $c$ " indica o uso da cela unitária convencional para descrever a superfície reconstruída. Normalmente, usa-se a cela unitária convencional ao invés da primitiva para descrever a estrutura da superfície. 
Park e Madden ${ }^{3}$ tiveram a idéia de representar uma reconstrução através do uso de matrizes. $O$ uso de matrizes tem a vantagem de poder descrever estruturas que não são descritas pelo modelo de Wood. Mas a notação de Wood continua sendo utilizada devido à sua simplicidade.

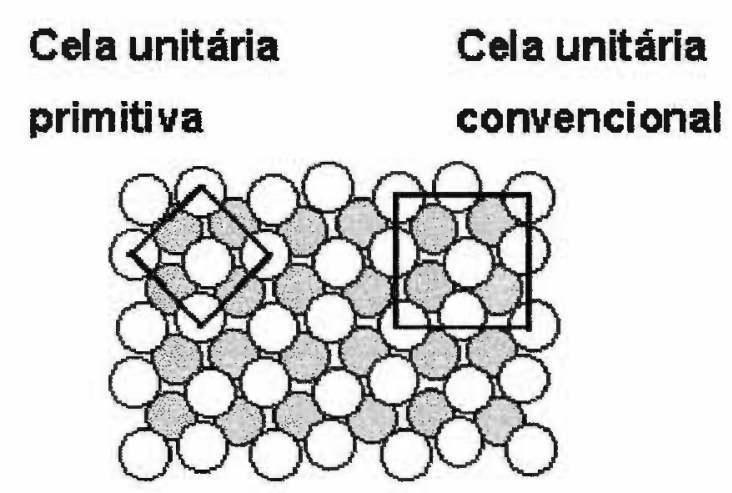

Figura 8. Celas unitárias primitiva e convencional para a superfície reconstruída do W(100). 


\section{II.2 A SUPERFÍCIE Si(100)}

O interesse no estudo da superfície do silício tem sido muito grande, principalmente com o desenvolvimento de novas técnicas experimentais de alta resolução, como difração de elétrons de baixa energia (low-energy electron diffraction - LEED), difraçāo de raio-X, microscopia de tunelamento de varredura (scanning tunneling microscope - STM), espectroscopia de fotoemissão ultravioleta com resolução angular (ARUPS), difração de hélio e experimentos de difração de fotoelétrons do caroço da superfície (surface core-level photoelectron diffraction experiments). Essas técnicas têm permitido uma melhor compreensão das características e propriedades da superfície, como a presença de irregularidades, o processo de reconstrução, além de auxiliar no entendimento dos mecanismos envolvidos na deposição química de vapor (chemical vapor deposition - CVD), tanto no crescimento de filmes de silício quanto nos processos de adsorção de substânicias químicus na superfície. A compreensão dos detalhes desses processos sāo importantes, por exemplo, para permitir um melhor controle na produção de materiais de interesse tecnológico, como no caso da indústria de microeletrônica. Esses materiais podem ser tanto o próprio silício semicondutor quanto outros obtidos a partir da adsorção de substâncias na estrutura cristalina do mesmo. É importante ressaltar, entretanto, que esses fenômenos que ocorrem nas superfícies são de natureza muito complexa, e os conhecimentos adquiridos até o momento são ainda bastante limitados. Como exemplo, podemos citar um dos casos mais estudados até o momento, que é a deposição de silício a partir do silano em uma superfície de silício, onde detalhes dos mecanismos envolvidos e a influência de defeitos na superfície são ainda motivos de discussão.

cristal de silício possui uma estrutura semelhante à do diamante, onde cada átomo encontra-se ligado covalentemente a outros quatro átomos numa disposição tetraédrica. Dependendo da forma como esse cristal é cortado, as superfícies resultantes apresentarão diferentes números de dangling bonds em diferentes disposições. A superfície que apresenta a forma mais simples e que também é a mais estudada é a (100) devido à sua importância tecnológica. Nela, cada átomo de silício encontra-se ligado a outros dois localizados num plano acima e a outros dois num abaixo. Na Figura 9 temos 
a representação da cela unitária convencional do silício, onde estão indicados os planos (100) e (001) e, conforme pode-se observar, esses planos são equivalentes. Na Figura 10 temos representada uma fração da superfície (100) do silício, destacando como a cela unitária se relaciona na mesma.

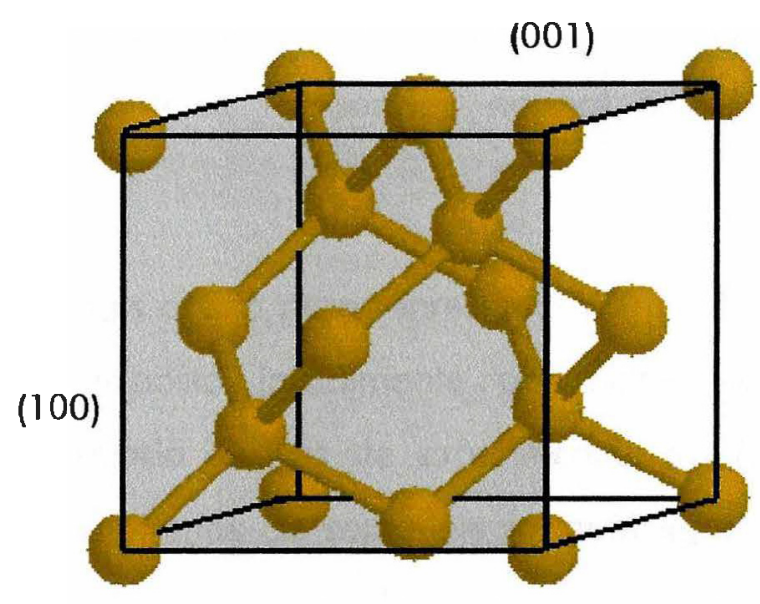

Figura 9. Planos (100) e (001) da cela unitária convencional do silício

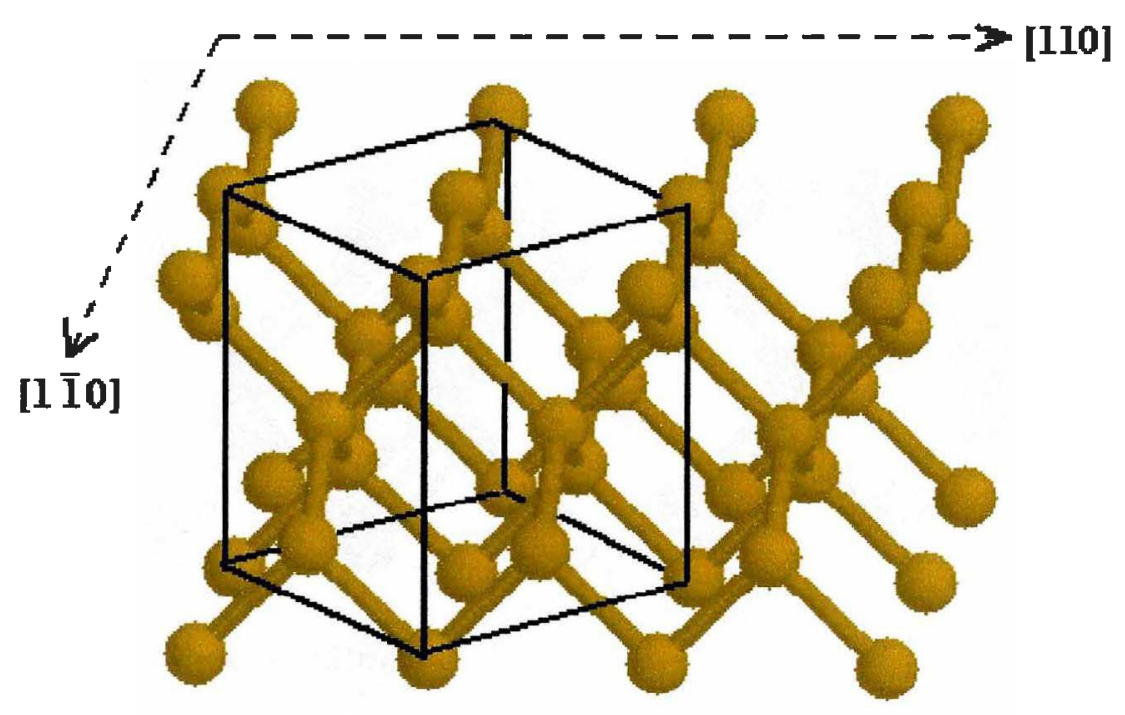

Figura 10. Fração da superfície do silício com a cela unitária convencional em destaque. 
Essa superfície, assim como as demais que podem ser criadas, é instável e sofre estabilização a partir da diminuição do número de dangling bonds com a formação de ligações químicas entre os átomos da superfície, fazendo com que esta apresente uma periodicidade distinta do interior do material. Essas dangling bonds são as responsáveis pela reatividade da superfície, e dependendo de como esses átomos se ligam temos a formação de diversos tipos de superfícies. Essa estabilização a partir de um movimento paralelo à superfície com a formação de novas ligações químicas corresponde à reconstrução já mencionada. O outro fenômeno correspondente à relaxação, consiste no deslocamento dos átomos no sentido normal à superfície e também contribui na estabilização.

O modelo mais aceito para representar a reconstrução do Si(100) é o modelo do dímero. Ele foi proposto inicialmente por Schlier e Farnsworth ${ }^{4}$ para explicar a periodicidade observada através de experimentos de $\angle E E D$. Segundo esse modelo, as dangling bonds nos átomos da superfície formam ligações químicas na direçã o [110], sendo que as ligações paralelas dos dímeros formam colunas na direção [1 10]. Na Figura 11 está ilustrado como ocorre o processo de reconstrução nessa superfície, que passa a ser representada por Si(001) $(2 \times 1)$.

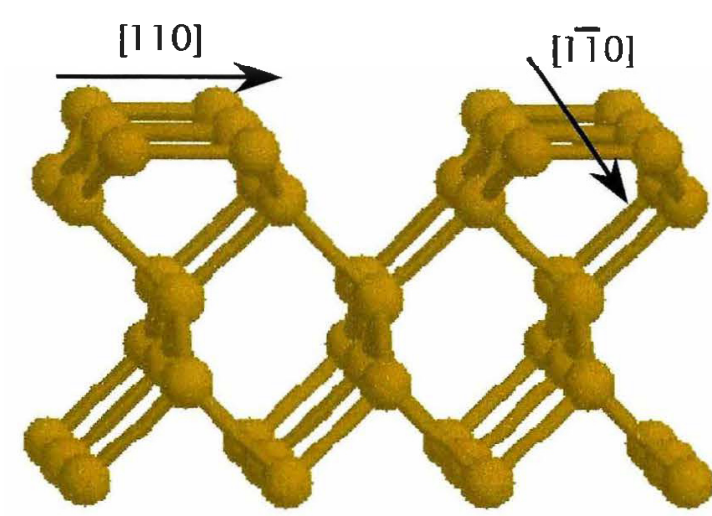

estrutura simétrica

(unbuckled)

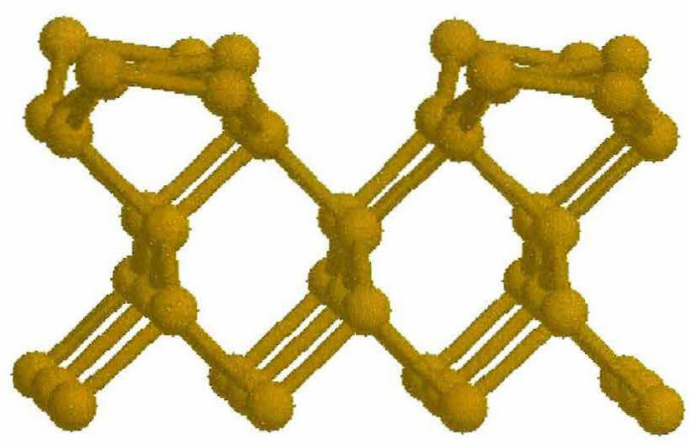

estrutura assimétrica (buckled)

Figura 11. Processo de reconstrução para a formação da superfície Si(001)(2x1). 
As superfícies $\mathrm{Si}(100)$ e Si(001), conforme mencionadas, são equivalentes, ou seja, ambas apresentam o mesmo processo de reconstrução, gerando estruturas idênticas. A diferença entre ambas reside na orientação dos vetores que indicam as direções na superfície. Como as superfícies são semelhantes, utilizaremos as notações $\operatorname{Si}(100)$ e $\mathrm{Si}(\mathrm{OO} 1)$ indistintamente.

À exceção dessa formação de ligaçōes químicas, existem ainda muitas controvérsias a respeito da estrutura da superfície Si(100), principalmente se esses dimeros apresentam uma forma simétrica ou assimétrica. Quanto ao dímero assimétrico, ele é obtido a partir do deslocamento de um dos silícios dímeros na direçāo normal à superfície. As formas simétricas e assimétricas podem levar à formação de quatro configurações para a superfície: dímero simétrico $(2 \times 1)$, assimétrico $(2 \times 1)$, onde os dímeros deslocados (buckled) estão todos na mesma direção, (2x2) e (4x2), onde os dímeros de uma mesma coluna estão deslocados de forma alternada e os das coluncs adjacentes estāo deslocados na mesma direção e em direçōes opostas, respectivamente.

Vários trabalhos tanto experimentais quanto teóricos foram realizados com a finalidade de descobrir se a configuração correspondente ao estado fundamental apresenta os dímeros simétricos ou assimétricos. Os resultados obtidos são os mais variados, dependendo da técnica experimental adotada e do tipo de cálculo teórico empregado.

Experimentos com difração de elétrons de baixa energia. (low-energy electron diffraction - LEED), ${ }^{5-8}$ difração de elétrons de alta energia refletidos (reflection high-energy electron diffraction - RHEED), difraçāo de raios-X $(X \text {-ray diffraction - XRD })^{0.12}$ e difração de átomos de $\mathrm{He}$ (atom or helium diffraction - $A D)^{13,14}$ sugeriram a presença de dímeros buckled. Uma transição de fase da configuração $(2 \times 1)$ para $c(4 \times 2)$ foi observada com $\angle E E D^{15}$ e $S_{T M}^{16}$ com o abaixamento da temperatura para menos de $200 \mathrm{~K}$. Resultados semelhantes foram obtidos por outras técnicas, como difração de raio- $X^{17,18}$ e surface core-level photoelectron diffraction, ${ }^{19}$ que mostraram a existência da forma assimétrica em temperaturas abaixo de $90 \mathrm{~K}$, indicando ser a forma buckled a mais estável a baixas temperaturas. Experimentos usando $S T M^{20.22}$ mostraram que a fraçāo de dímeros assimétricos, com as configurações $(2 \times 2)$ e $(4 \times 2)$, varia muito através da superfície, sendo 
que estes encontram-se mais presentes em regiões próximas a defeitos na superfície. Resultados STM sugerem a possibilidade de que a estrutura simétrica pode ser resultante de uma rápida alternância entre dímeros assimétricos nas regiões livres de defeitos, enquanto que próximo a estes defeitos os dímeros assimétricos encontram-se "congelados".

Vários estudos do ponto de vista teórico também foram realizados com a finalidade de auxiliar na compreensão do fenômeno de reconstrução. Os trabalhos confirmam a ocorrência da reconstruçāo como elemento fundamental para a estabilizaçāo da superfície, mas resultados conflitantes surgem quando a questāo se refere à preferência pela forma simétrica ou assimétrica dos dímeros. As conclusōes variam conforme a metodologia e o modelo químico adotados.

A dificuldade teórica surge na forma de descrição principalmente da ligação envolvendo os silícios dímeros. Utilizando a linguagem convencional de orbitais, temos que a estrutura "ideal" da superfície $\mathrm{Si}(100)$ apresenta os átomos de silício da superfície com os dois elétrons, cada um associado a um orbital do tipo $\mathrm{sp}^{3}$. Com o processo de reconstrução, temos a formação de ligaçōes químicas e, a partir disso, temos duas possibilidades de ligaçāo entre dois silícios. No primeiro caso, podemos ter uma ligação dupla, levando à formaçāo de uma camada fechada, enquanto que no outro caso podemos ter uma ligação simples e a existência de um elétron "livre" em cada silício dímero. A alta reatividade da superfície $\mathrm{Si}(100)$ é justificada no primeiro caso como o resultado da relativa instabilidade da ligaçāo dupla $\mathrm{Si}=\mathrm{Si}$, enquanto que no segundo caso os elétrons desemparelhados dos silícios dímeros seriam os responsáveis. A escolha adequada da metodologia a ser empregada será, portanto, fundamental para o modo de descrição da ligaçāo, pois os formalismos baseados em um único determinante permitem considerar apenas o primeiro caso, enquanto que os multideterminantais possibilitam também o segundo.

Vários estudos utilizando formalismos de um único determinante foram realizados para a superfície Si(100), como métodos semiempíricos, funcional da densidade e Hartree-Fock SCF. Em muitos desses trabalhos os autores utilizam clusters, ou seja, aglomerados com número restrito de átomos e uma estrutura que procura se assemelhar 
à da superfície. $\mathrm{O}$ aglomerado de fórmula $\mathrm{Si}_{9} \mathrm{H}_{12}$ é dos mais utilizados, por ser grande o suficiente para possuir dois silícios dímeros e pequeno bastante para ser modelado segundo as técnicas mais comuns em química quântica, podendo-se, nesse caso, incluir estudos dos efeitos de correlação eletrônica. Esse aglomerado apresenta algumas limitaçōes, como não apresentar muitas camadas internas, o que faz com que não se possa considerar os efeitos devidos aos átomos do interior da superfície. Por conter apenas um par de silícios dímeros, não é possível verificar os efeitos causados pelas interaçōes com dímeros adjacentes.

Os resultados semiempíricos obtidos por Chadii $^{23,24}$ levam à preferência pela estrutura assimétrica, com um deslocamento vertical (buckling) entre 0,45 e $0,65 \AA$. A Teoria do Funcional da Densidade tem tido uma utilização cada vez maior tanto para o estudo da superfície quanto para a interação e incorporação de compostos na mesma, mas os resultados muitas vezes variam conforme a escolha do funciona!. Estudo recente realizado por $\mathrm{Yang}^{25}$ com os aglomerados $\mathrm{Si}_{9} \mathrm{H}_{12}$ e $\mathrm{Si}_{15} \mathrm{H}_{16}$, utilizando as bases atômicas STO-3G, 3-21G e 6-31G e as metodologias SCF e funcional da densidade com o funcional híbrido B3LYP, mostra ser o aglomerado com um único dímero simétrico a forma mais estável, enquanto que para aquele com dois dímeros a estrutura final obtida é assimétrica. $O$ fato da estrutura com dois dímeros ser a assimétrica é atribuída por esses autores às condições de vínculo adofádas no processo de otimização, pois nesse caso elas são bem menos rígidas, e o relaxamento dos átomos da segunda e terceira camadas exerce uma grande influência na otimização da estrutura. Para a estrutura com um único dímero, com o funcional B3LYP e a base 6-31G, a energia de reconstrução obtida foi de 1,34 eV/dímero e a distância Si-Si-dímero foi de 2,268 $\AA$. $O$ aglomerado com dois dímeros assimétricos, com as mesmas condiçōes acima, mostra uma energia de reconstrução de 1,47 eV/dímero e uma distância Si-Si dímero de 2,329 ̊̊. Essa estrutura buckled é cerca de 0,13 eV/dímero mais estável que a simétrica. Essa diferença de energia é bastante pequena e resultados semelhantes têm sido observados em todos os trabalhos que fazem tal comparação. Essa pequena diferença de energia, que varia conforme o aglomerado utilizado, bem como com a base e a metodologia, tem dificultado a obtenção de uma conclusão mais definitiva sobre a estabilidade desses modelos. Outro trabaltio foi realizado por Hoshino et al. ${ }^{26} \mathrm{com}$ a finalidade de explicar o 
processo de formação de dímeros assimétricos com a incorporação de átomos de Li e H. Esses átomos induzem a formação de dímeros assimétricos que se propagam através da superfície. Para isso, eles utilizaram os aglomerados de fórmula $\mathrm{Si}_{27} \mathrm{H}_{24}$ e $\mathrm{Si}_{33} \mathrm{H}_{28}$, que simulam quatro e cinco dímeros paralelos, respectivamente. A metodologia adotada foi a Hartree-Fock SCF com a base atômica 3-21G. Para esses aglomerados, a estrutura mais estável é a simétrica, e a otimização geométrica com os átomos acima levou a uma deformação, com a criação e propagação de ligaçōes assimétricas alternadas. A justificativa para essa deformação foi a de que os átomos de $\mathrm{Li}$ e $\mathrm{H}$ induzem uma separação de cargas na ligação entre os silícios dímeros, de modo que os dímeros vizinhos tendem a compensar essa distribuição de cargas sofrendo uma distorção em sentido oposto.

Em um artigo mais recente, Markovits ef $a{ }^{27}{ }^{27}$ realizaram um cálculo Hartree-Fock para estudar a reconstrução da superfície Si(100) usando um pseudopotencial periódico. Duas camadas (slabs) foram utilizadas para representar a superfície, sendo a maior contendo quatro camadas e a menor duas. A estrutura simétrica singleto foi a mais estável encontrada por eles, apresentando um acoplamento antiferromagnético entre os elétrons não emparelhados dos silícios dímeros. A distância entre esses silícios é de 2,43 Å. A energia desse estado é muito próxima do estado tripleto, e cerca de $16 \mathrm{kcal} / \mathrm{mol}$ mais estável que a estrutura buckled. Essa diferença diminui para cerca de $5 \mathrm{kcal} / \mathrm{mol}$ quando o cálculo é realizado utilizando o Funcional da Densidade.

Na literatura, alguns cálculos utilizando um aglomerado para a représentação de um único dímero $\left(\mathrm{Si}_{9} \mathrm{H}_{12}\right)$ e as metodologias Hartree-Fock e Funcional da Densidade são apresentados como parte de trabalhos voltados ao estudo da interação de moléculas na superfície Si(100)..$^{28-38}$ Hoffmann e Liu ${ }^{39}$ utilizaram esse aglomerado para estudar os mecanismos envolvidos no processo de adsorção química do acetileno. Com a metodologia RHF e a base 6-31G** obtiveram uma energia de estabilização devido à reconstrução de $0,94 \mathrm{eV}$. Interessante observar que com a base STO-3G a estrutura simétrica passou a corresponder a um estado de transição, sendo que o mínimo passou a ser uma estrutura buckled, tanto com o método RHF quanto com UHF. Konecný e Doren $^{28,31,32,38}$ utilizaram a Teoria do Funcional da Densidade e o funcional híbrido B3LYP para o estudo do processo de adsorção da água e do borano, além das reações de 
cicloadição de compostos hidrocarbonetos insaturados, como no caso da reação do tipo Diels-Alder, com dienos conjugados. Com o funcional BLYP e a base TZ94P eles obtiveram uma estrutura assimétrica $0,05 \mathrm{kcal} / \mathrm{mol}$ mais estável que a simétrica, com uma distância entre os silícios da superfície (silícios dímeros) de 2,27 $\AA$. Bacalzo et a/. ${ }^{29}$ utilizaram o funcional B3LYP e várias bases atômicas para estudar os processos de interação da molécula CO na superfície Si(100). Servindo-se da forma simétrica e da base 6-31G*, eles obtiveram uma distância entre os silícios dímeros de 2,221 $\AA$. Por outro lado, Brown e Doren ${ }^{30}$ utilizando o funcional BLYP e várias bases atômicas observaram também que com a base TZ94P a forma assimétrica é menos que 0,3 $\mathrm{kcal} / \mathrm{mol}$ mais estável que a simétrica. Mas com um cálculo em um único ponto, com a base relativamente mais extensa 6-311G+t, viram que a ordem de estabilidade se inverte, de maneira que essa sensibilidade com a base adotada faz com que eles não tenham chegado a um resultado mais conclusivo. Os trabalhos de Raghavachari ef a/..$^{33,35,36}$ estavam mais voltados para a compreensāo dos processos inicicis de oxidaçāo da superfície $\mathrm{Si}(100)$. Para isso, enfocaram tanto as características do espectro vibracional obtido a partir da incorporação de uma molécula de água como a termodinâmica relacionada à introdução de átomos de oxigênio na estrutura do aglomerado.

Alguns estudos utilizando funçōes de onda multiconfiguracionais foram realizados com a finalidade de se obter uma dešcrição mais precisa acerca da natureza da ligação entre os silícios dímeros. O primeiro trabalho nesse sentido foi feito por Redondo e Goddard III, ${ }^{40}$ que utilizaram o aglomerado de fórmula $\mathrm{Si}_{9} \mathrm{H}_{12}$ e as metodologias HartreeFock e ligação de valência generalizada (generalized valence bond - GVB). Com o método $G V B$ e posterior cálculo do tipo interaçāo de configuraçōes, eles estudaram as possibilidades de estruturas singleto e tripleto. As geometrias obtidas foram distintas, sendo a singleto a mais estável e apresentando uma distância entre os silícios dímeros igual a $2,47 \AA$, enquanto que para o estado tripleto a distância foi de 2,66 $\AA$. Em ambas, a forma simétrica mostrou ser favorecida. Com a metodologia Hartree-Fock e utilizando orbitais restritos para a estrutura singleto simétrica, eles obtiveram que o estado tripleto é $1,33 \mathrm{eV}$ mais estável que o singleto restrito, pois este último tem os seus dois elétrons superficiais colocados em um mesmo orbital. A distorçāo do aglomerado singleto levou a uma estrutura buckled mais estável que a simétrica, com o silício dímero mais deslocado 
a 0,33 $\AA$ acima do outro silício, mas eles atribuíram isso a uma característica apenas da metodologia Hartree-Fock, pois com a inclusão de efeitos de correlação essa forma assimétrica deixou de ser a mais estável.

Jing e Whitten ${ }^{41}$ fizeram cálculos do tipo Interação de Configuraçōes com excitações simples e duplas a partir dos orbitais SCF (HF-SDCI) para os estados singleto e tripleto nos aglomerados de fórmula $\mathrm{Si}_{7} \mathrm{H}_{8}, \mathrm{Si}_{8} \mathrm{H}_{12}$ e $\mathrm{Si}_{12} \mathrm{H}_{20}$. Em nível SCF, o estado tripleto é consideravelmente mais estável que o singleto, mas esse resultado é invertido com a utilização do método HF-SDCl. Portanto, uma função de onda multideterminantal é essencial para a correta descrição do estado fundamental da superfície $\mathrm{Si}(100)$. O cálculo C/ para o estado singleto foi feito utilizando-se os orbitais SCF singleto e tripleto, a partir de dois determinantes de referência. A distância Si-Si dímero obtida dessa forma foi $2,40 \AA$ e a energia de reconstrução $1,98 \mathrm{eV} /$ dímero. A estrutura simétrica é mais estável que a assimétrica, mas a diferença de energia é muito pequena, de 0,02 eV.

Em estudo mais recente, Paulus ${ }^{42}$ realizou cálculos MCSCF com posterior inclusão de correlação dinâmica via $\mathrm{MRCl}$. Uma série de aglomerados, variando de $\mathrm{Si}_{9} \mathrm{H}_{12}$ a $\mathrm{Si}_{32} \mathrm{H}_{28}$ foram estudados e permitiram verificar a influência de fatores como o número de ligações Si-Si dímeros e o número de camadas do interior do aglomerado sobre a distância Si-Si dímero e a energia de reconstrução. O estado tripleto também é mais estável em nível SCF, mas em MCSCF é cerca de 0,3 eV menos estável que o singleto. Além disso, a ocupação dos orbitais, onde o primeiro orbital não ocupado em nível Hartree-Fock tem uma ocupaçāo apreciável, é mais um motivo para a necessidade de se utilizar uma funçāo de onda multideterminantal. Vários testes foram feitos para verificar a influência da base atômica, e observou-se que a inclusão de funções $d$ é importante para a obtenção de uma energia de reconstrução mais precisa. Com relação à influência das camadas do bulk para o valor da energia de reconstrução, foi observado que o aglomerado com três camadas não é suficiente para modelar adequadamente as propriedades da superfície, como a energia de reconstrução. Verificou-se que a interação dos dímeros não é apreciável em nível MCSCF, mas em MRClo abaixamento na energia de reconstrução com a adição de mais dímeros é mais acentuado. A energia obtida para o processo de reconstrução para a formaçāo do dímero simétrico foi de 1,75 eV, enquanto que a distância dessa ligação foi de $2,35 \AA$, que é semelhante à presente no 
bulk. $O$ estudo da distorção dos silícios dímeros foi feito removendo os vínculos de simetria e variando o ângulo de distorção dos silícios superficiais, mantendo fixa as distâncias entre esses átomos. Desse maneira, os resultados MCSCF e MRClapontaram a forma simétrica como a mais estável, enquanto que usando o Funcional da Densidade (DFT), os resultados $L D A$ e CGA previram a forma distorcida. Ela atribuiu que a utilização do DFT causa uma superestimativa da contribuiçāo eletrônica da forma distorcida e uma baixa estimativa da estrutura com a camada fechada (closed shell).

Schoemaker e Burggraf ${ }^{43}$ prosseguiram com os trabalhos de Goddard e Paulus, onde uma função de onda com uma única referência não é adequada para descrever a estrutura eletrônica dos silícios dímeros, sendo necessário utilizar funçōes com múltiplas referências. Desse modo, eles adotaram a base dupla zeta mais polarização (DZP) e funçōes de onda de ligaçāo de valência generalizada. Vários aglomerados cujos tamanhos variavam de 9 a 66 silícios foram estudados, com a intençāo de observar a validade desses aglomerados para representar as propriedades da superfície. Eles obtiveram que os silícios dímeros apresentam uma estrutura simétrica, e sugerem que outros estudos sāo necessários para explicar a forte evidência experimental da existência da estrutura buckled, como o uso de aglomerados maiores e o estudo da dinâmica desse processo. A partir da otimizaçāo das várias estruturas eles notaram que a adoção de vínculos na geometria do aglomerado leva a resultados fisicamente não realísticos. $O$ cálculo dos aglomerado maiores, sem a adoção de vínculos, mostrou que o efeito dos rearranjos superficiais são sentidos em várias camadas mais internas, o que vai de encontro com os resultados experimentais. Esses resultados sugerem que aglomerados pequenos, como $\mathrm{Si}_{9} \mathrm{H}_{12}$, não são adequados para representar o comportamento do interior do material. Resultados de análises vibracionais mostraram que os modos relativos aos silícios dímeros refletem a facilidade com que estes podem ser distorcidos e perturbados da sua estrutura de mínima energia. 


\section{II.3 ABORDAGENS TEÓRICAS}

Para o estudo da superfície Si(100) utilizamos uma abordagem que consiste no uso de aglomerados de silício com um número definido de átomos. Esses aglomerados são construídos de modo a permitir a representação de algumas características importantes dessa superfície, no caso, a existência dos silícios responsáveis pelo fenômeno da reconstrução. Essa estratégia tem sido muito utilizada no estudo teórico dessa superfície e das reações desta com átomos e moléculas, conforme mencionado nas seções 11.2 e III.1. O uso de aglomerados de átomos apresenta a desvantagem de não permitir a obtenção de propriedades de larga escala da superfície, como o fenômeno de bandas, por exemplo, mas permite estudar as reações químicas de um modo bastante localizado, facilitando o estudo das interações e formações de ligações químicas de um modo bastante claro.

A questão acerca do tamanho de aglomerado a ser usado depende do quanto se quer representar a superfície, da metodologia a ser utilizada e da disponibilidade computacional. O sistema mais simples que utilizamos foi o aglomerado de fórmula $\mathrm{Si}_{9} \mathrm{H}_{12}$, que permite a representação de pelo menos uma ligação entre os silícios dímeros, com os demais átomos formando três camadas iaternas. A representação desse aglomerado pode ser visto na Figura 12. Átomos de hidrogênio são adicionados de modo a saturar os átomos internos de silício, procurando manter a estrutura tetraédrica dos mesmos. A vantagem desse aglomerado é que, além de permitir o estudo da reconstrução, tem um tamanho suficiente que permite o uso de várias metodologias, sem uma grande necessidade computacional. Esse tem sido o motivo que tem levado ao uso do $\mathrm{Si}_{9} \mathrm{H}_{12}$ em estudos teóricos a respeito tanto da superfície quanto de reaçōes. No nosso trabalho procuramos estudar esse sistema não apenas a fim de comparar com os trabalhos realizados até então, mas com a finalidade de adquirir uma experiência que nos permitisse o uso de uma metodologia e uma base ideal para o nosso posterior estudo dos processos envolvidos na deposição de nitrogênio na superfície de silício. Com esse ponto em mente estudamos os efeitos da base atômica e das metodologias nas propriedades geométricas e nas freqüências desse aglomerado, principalmente 
relacionados aos silícios dímeros, onde existe muitas controvérsias se os mesmos apresentam uma estrutura simétrica ou distorcida (buckled).

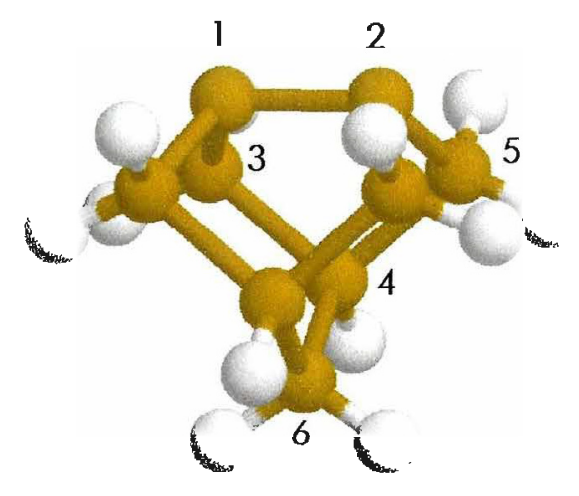

Figura 12. Aglomerado de fórmula $\mathrm{Si}_{9} \mathrm{H}_{12}$ com a numeração dos átomos de silício.

Durante o processo de otimização geométrica não adotamos qualquer forma de vínculo na geometria, excetuando os inerentes à simetria do sistema. Estudamos estruturas singleto e tripleto com as metodologias Hartree-Fock-SCF, do Funcional da Densidade, com a utilização do funcional híbrido B3LYP, que combina o funcional de troca com 3 parâmetros de Becke ${ }^{44}$ com o funcional de correlação de Lee, Yang e Parr, ${ }^{45}$ teoria de perturbação Møller-Plesset de segunda ordem (MP2) e teoria do campo autoconsistente com um espaço ativo completo (CASSCF).

Com a intenção de estudar os efeitos da interação entre os silícios dímeros, utilizamos o aglomerado de fórmula $\mathrm{Si}_{15} \mathrm{H}_{16}$, cuja estrutura pode ser vista na Figura 13. Esse aglomerado permite a simulação de dois dímeros vizinhos, sendo, portanto, de interesse para se poder estudar a eventual influência e interação entre esses dímeros tanto nas reações com substâncias presentes em fase gasosa como nos fenômenos que ocorrem tipicamente na superfície, como migração dos átomos, rearranjos, etc. 
Estudamos, do mesmo modo que realizado para $\circ \mathrm{Si}_{9} \mathrm{H}_{12}$, as propriedades geométricas e energéticas das estruturas simétricas e distorcidas.

Todos os cálculos foram todos realizados com os programas Gaussian $94^{46} \mathrm{e}$ $98,{ }^{47}$ que estão implementados no computador IBM RS6000 do Laboratório de Computação Científica Avançada (LCCA) da USP.

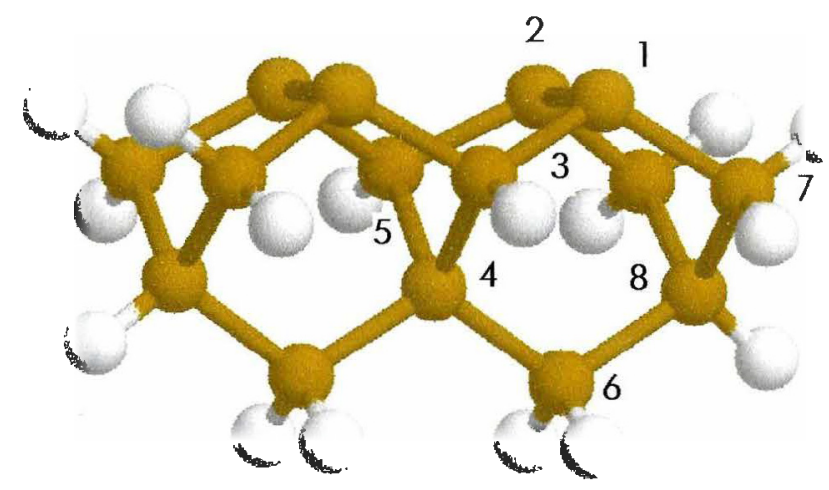

Figura 13. Aglomerado de fórmula $\mathrm{Si}_{15} \mathrm{H}_{16}$ com a numeração dos átomos de silício. 


\section{II.4 O SISTEMA $\mathrm{Si}_{9} \mathrm{H}_{12}$}

\section{Resultados Hartree-Fock}

Nas Tabelas 4, 5 e 6 encontramos os resultados obtidos com a metodologia Hartree-Fock para os estados singleto e tripleto. Para o estado singleto, testamos a utilização de orbitais restritos e não-restritos, enquanto que para o tripleto limitamos aos não-restritos. Na nossa notação, $\mathrm{H}(i-i)$ corresponde à distância entre as camadas $i$ e i, enquanto que $\mathrm{D}(i, j)$ corresponde à distância entre átomos de silício das camadas ie j. Os valores de $h(i, j)$ referem-se à distância entre as camadas relativas aos átomos $i$ e $i$ e d(i,i) à distância entre esses átomos, e a numeração adotada está apresentada na Figura 12.

Tabela 4. Parâmetros geométricos (em $\AA$ ) obtidos com orbitais restritos e a metodologia HartreeFock para o aglomerado singleto $\mathrm{Si}_{9} \mathrm{H}_{12}$.

\begin{tabular}{|c|c|c|c|c|c|c|c|}
\hline & & STO.3G & STO-3G & $3.21 G$ & $6.31 G$ & $6-31 G^{* *}$ & $6.31 G^{*}(5 d)$ \\
\hline Simetria & Bulk & $\begin{array}{c}\text { Unbuckled } \\
\mathrm{C}_{2 v}\end{array}$ & $\begin{array}{c}\text { Buckled } \\
C_{s}\end{array}$ & $\begin{array}{c}\text { Unbuckled } \\
C_{2 v}\end{array}$ & $\begin{array}{c}\text { Unbuckled } \\
\mathrm{C}_{2 v}\end{array}$ & $\begin{array}{c}\text { Unbuckled } \\
C_{2 v}\end{array}$ & $\begin{array}{c}\text { Unbuckled } \\
\mathrm{C}_{2 v}\end{array}$ \\
\hline$\Delta E(\mathrm{kcal} / \mathrm{mol})$ & & 0,00 & $-1,94$ & & & & \\
\hline$D(1-1)$ & $2,26 \pm 0,1$ & 2,081 & $d(1-2)=2,201$ & 2,198 & 2,212 & 2,885 & 2,185 \\
\hline$D(1-2)$ & 2,353 & 2,238 & $\begin{array}{l}d(1-3)=2,295 \\
d(2-5)=2,241\end{array}$ & 2,376 & 2,378 & 2,349 & 2,349 \\
\hline$D(2-3)$ & 2,353 & 2,264 & $\begin{array}{l}d(3-4)=2,265 \\
d(5-4)=2,260\end{array}$ & 2,418 & 2,416 & 2,380 & 2,380 \\
\hline$D(3-4)$ & 2,353 & 2,275 & $d(4-6)=2,267$ & 2,413 & 2,419 & 2,390 & 2,390 \\
\hline$H(1-1)$ & 1,360 & & $h(1-2)=0,668$ & & & & \\
\hline$H(1-2)$ & 1,360 & 1,066 & $\begin{array}{l}h(1-3)=1,399 \\
h(2-5)=1,023\end{array}$ & 1,081 & 1,060 & 1,023 & 1,023 \\
\hline$H(2-3)$ & 1,360 & 1,496 & $\begin{array}{l}h(3-4)=1,636 \\
h(5-4)=1,344\end{array}$ & 1,566 & 1,581 & 1,564 & 1,564 \\
\hline$H(3-4)$ & 1,360 & 1,197 & $h(4-6)=1,247$ & 1,246 & 1,256 & 1,242 & 1,241 \\
\hline
\end{tabular}


Tabela 5. Parâmetros geométricos (em $\AA$ ) obtidos com orbitais não-restritos e a metodologia Hartree-Fock para o aglomerado singleto $\mathrm{Si}_{9} \mathrm{H}_{12}$.

\begin{tabular}{cccccc}
\hline & & $3-21 \mathrm{G}$ & $6-31 \mathrm{G}$ & $6-31 \mathrm{G}^{* *}$ & $6-31 \mathrm{G}^{*}(5 \mathrm{~d})$ \\
\cline { 3 - 6 } Simetria & Bulk & Unbuckled & Buckled & Unbuckled & Unbuckled \\
& & $\mathrm{C}_{2 \mathrm{v}}$ & $\mathrm{C}_{2 \mathrm{v}}$ & $\mathrm{C}_{2 \mathrm{v}}$ & $\mathrm{C}_{2 \mathrm{v}}$ \\
\hline $\mathrm{D}(1-1)$ & $2,26 \pm 0,1$ & 2,383 & 2,387 & 2,351 & 2,351 \\
$\mathrm{D}(1-2)$ & 2,353 & 2,396 & 2,396 & 2,363 & 2,363 \\
$\mathrm{D}(2-3)$ & 2,353 & 2,400 & 2,401 & 2,371 & 2,371 \\
$\mathrm{D}(3-4)$ & 2,353 & 2,399 & 2,406 & 2,381 & 2,381 \\
$\mathrm{H}(1-2)$ & 1,360 & 1,284 & 1,253 & 1,212 & 1,213 \\
$\mathrm{H}(2-3)$ & 1,360 & 1,534 & 1,549 & 1,540 & 1,541 \\
$\mathrm{H}(3-4)$ & 1,360 & 1,309 & 1,314 & 1,295 & 1,294 \\
\hline
\end{tabular}

Tabela 6. Parâmetros geométricos (em $\AA$ ) obtidos com orbitais não-restritos e a metodologia Hartree-Fock para o aglomerado tripleto $\mathrm{Si}_{9} \mathrm{H}_{12}$.

\begin{tabular}{|c|c|c|c|c|c|}
\hline & & STO-3G & $3-21 G$ & $031 G$ & $6-315^{* * *}$ \\
\hline & Bulk & Unóuckled & Buckled & Unbuckled & Unbuckled \\
\hline Simetria & & $C_{2 v}$ & $C_{2 v}$ & $C_{2 v}$ & $C_{2 v}$ \\
\hline$D(1-1)$ & $2,26 \pm 0,1$ & 2,292 & 2,447 & 2,448 & 2,404 \\
\hline$D(1-2)$ & 2,353 & 2,258 & 2,405 & 2,404 & 2,370 \\
\hline$D(2-3)$ & 2,353 & 2,252 & 2,398 & 2,399 & 2,37 ו \\
\hline$D(3-4)$ & 2,353 & 2,260 & 2,395 & 2,401 & 2,377 \\
\hline$H(1-2)$ & 1,360 & 1,275 & 1,353 & 1,321 & 1,282 \\
\hline$H(2-3)$ & 1,360 & 1,451 & 1,521 & 1,535 & 1,525 \\
\hline$H(3-4)$ & 1,360 & 1,275 & 1,338 & 1,340 & 1,325 \\
\hline
\end{tabular}

Nas tabelas apresentadas, a distância entre os silícios dímeros é representada por $D(1-1)$. Os valores relativos ao bulk $(2,353 \AA$ e 1,360 $\AA)$ correspondem aos dados experimentais, enquanto que $D(1-1)$ igual a $2,26 \pm 0,1 \AA$ corresponde ao valor experimental obtido por Wang. ${ }^{48}$

Com a metodologia Hartree-Fock, temos que os resultados obtidos com a base STO-3G para o caso singleto e orbitais restritos são bem diferentes dos obtidos com as demais bases, e essas diferenças sāo conseqüências do fato de ser uma base bastante limitada e inadequada para o estudo desse sistema. Um exemplo dessa diferença foi que 
apenas com essa base foi possível obter uma estrutura assimétrica, no caso, para o estado singleto com a utilização de orbitais restritos. Seus parâmetros geométricos estão apresentados na Tabela 4. Energeticamente, esta forma é apenas 1,94 kcal/mol mais estável que a correspondente simétrica, enquanto que com relação à natureza do estado estacionário, a forma simétrica corresponde a um estado de transição e a distorcida (buckled) a uma estrutura localizada em um ponto de mínimo na superfície de energia potencial. Com a exceção desse único caso, não obtivemos com a metodologia HartreeFock uma outra estrutura assimétrica, tanto mudando a base atômica quanto a escolha dos orbitais. Além disso, todas as demais possibilidades estudadas com a metodologia Hartree-Fock correspondem a estruturas localizadas em pontos de mínimo na superfície de energia potencial.

Pelos resultados obtidos com as diferentes metodologias, temos que os valores de $H(i-j)$ mostram o seguinte comportamento: $H(1-2)$ possui um valor pequeno devido aos processos de reconstrução e relaxação dos silícios superficiais; $H(2-3)$ possui um valor grande e $H(3-4)$ um pequeno, se comparados ao valor típico do bulk (1,360 $\AA$ ). Essas diferenças nas distâncias entre camadas são de caráter geral, pois esse comportamento aparece dentro de todas as metodologias e bases utilizadas nesse trabalho. Essas contrações e expansões são movimentos compensadores do aumento da tensão causada pela relaxaçāo e reconstrução (formação de ligação química) dos silícios da superfície, e, experimentalmente, observa-se que esses efeitos se propagam por várias camadas internas. Um modelo com mais camadas seria necessário tanto para que possamos obter um valor de $H(i-j)$ que corresponda ao valor do bulk dentro da base atômica adotada quanto para se ter uma idéia da extensão dos efeitos causados pelos processos de reconstrução e relaxação. O sistema adotado $\left(\mathrm{Si}_{9} \mathrm{H}_{12}\right)$, com o pequeno número de camadas internas, não é suficiente para que possamos obter resultados definitivos para o problema acima.

nosso interesse inicial foi centrado na influência da base atômica nos parâmetros geométricos e na natureza do estado estacionário. Como seria de se esperar, a mudança da base de 3-21G para 6-31G nos três casos acima, não acarretou mudanças substanciais. nos parâmetros geométricos. Mas o mesmo não se pode dizer quando passamos a adicionar funções de polarizaçāo nos átomós de silício, onde vemos 
uma diminuição em todos os parâmetros geométricos, conforme podemos observar nas Tabelas 4 a 6 . Para o caso da estrutura singleto restrito, temos que $\mathrm{H}(1-2)$ diminuiu cerca de $0,027 \AA$, enquanto que em $H(2-3)$ e $H(3-4)$ a diminuição foi de cerca de $0,016 \AA$. Com relação à distância entre os silícios, houve uma diminuição da ordem de $0,03 \AA$. Essas diminuições fizeram com que o aglomerado descrito com a base 6-31 G* ficasse mais "achatado" em cerca de 0,07 $\AA$ em relação aos resultados com a base 6-31G. Mesmo com as diminuições observadas nas distâncias entre os silícios, temos que para os átomos mais internos os valores ainda são cerca de 0,03 a 0,04 $\AA$ maiores que o valor aceito experimentalmente para uma distância típica no bulk, que é de $2,353 \AA$. Interessante notar que a mudança de $6-31 G^{* *}$ para $6-31 G^{*}$ não levou a mudanças nos parâmetros geométricos, que demonstra que os átomos de hidrogênio têm pouca influência para a geometria final do aglomerado. Com a base 6-31G, o valor de $D(1-1)$ $(2,212 \AA)$ é bem próximo do obtido por Yang et al. ${ }^{25}(2,226 \AA)$. Também, devido à diferença nos vínculos adotados por esses autores, pequenas alterações foram observadas com essa base, sendo as maiores diferenças nas distâncias entre as camadas $H(i-i)$. O valor final para a distância entre os silícios dímeros é $2,185 \AA$, com a base 6 $31 G^{*}$, e esse valor é conseqüência da adoção de orbitais restritos, que faz com que os elétrons dos silícios dímeros estejam todos compartilhados em orbitais duplamente ocupados. Essa distância é consideravelmente menor que a de uma ligação dupla padrāo, no caso, do $\mathrm{Si}_{2}$, cujo valor é de $2,25 \AA \AA^{49} \mathrm{Na}$ Figura 14 podemos ver a forma do orbital $H O M O$, que mostra maior concentração eletrônica justamente sobre a ligação entre os silícios dímeros, fazendo com que a ligação entre esses silícios tenha realmente um caráter de uma ligação dupla. A adoçāo desses orbitais não permite a existência das dangling bonds nos silícios dímeros, ou seja, com um elétron desemparelhado em cada um desses átomos. Com isso fica clara a inadequação do uso de orbitais restritos para a caracterização correta da superfície.

Com esse problema em mente, realizamos a otimização geométrica da mesma estrutura com spin singleto, mas com a utilização de orbitais não-restritos. Os parâmetros geométricos obtidos estão na Tabela 5. A inclusão de funções de polarização nos átomos de silício levou também a uma diminuição de todas as distâncias, sendo essas variações aproximadamente da mesma ordem que as observadas no caso RHF. No caso da 
distância entre os silícios dímeros, a diminuição foi de $0,036 \AA$, enquanto para o silícios mais internos a diminuição foi menor, da ordem de 0,025 $\AA$. Comparativamente, temos que as maiores diferenças observadas entre as geometrias UHF e RHF se referem aos silícios dímeros. No caso UHF, a distância entre esses silícios obtida com a base 6-31G* $(2,351 \AA)$ é bem maior que no caso $R H F$, sendo a diferença de 0,166 $\AA$. A maior distância de ligação, que está relacionada a um menor grau de reconstrução, levou também a um aumento no parâmetro $H(1-2)$, cujo valor final $(1,213 \AA)$ é $0,190 \AA$ maior que o correspondente resultado em RHF. Essa distância de 2,351 $\AA$ é da ordem de uma ligação simples típica, como no caso do disilano, ${ }^{50}$ cuja distância é de cerca de $2,34 \AA$. Na Figura 15 podemos ver a forma de um orbital unicamente ocupado, onde temos que a densidade eletrônica apresenta uma maior concentração sobre um dos silícios do dímero simétrico, e o orbital correspondente com spin oposto apresenta uma maior concentração sobre o outro silício dímero. Dessa maneira, com a utilização desses orbitais pode-se obter uma descrição mais adequada das dangling bonds. $\bigcirc$ uso da metodologia Hartree-Fock com orbitas não-restritos tem a vantagem de permitir o estudo de sistemas biradicais, como no sistema em estudo, com um elétron localizado em cada silício dímero. Tal fato não acontece no caso de orbitais restritos, onde todos os elétrons são "forçados" a compartilhar orbitais duplamente ocupados, não permitindo a existência de estruturas radicais.

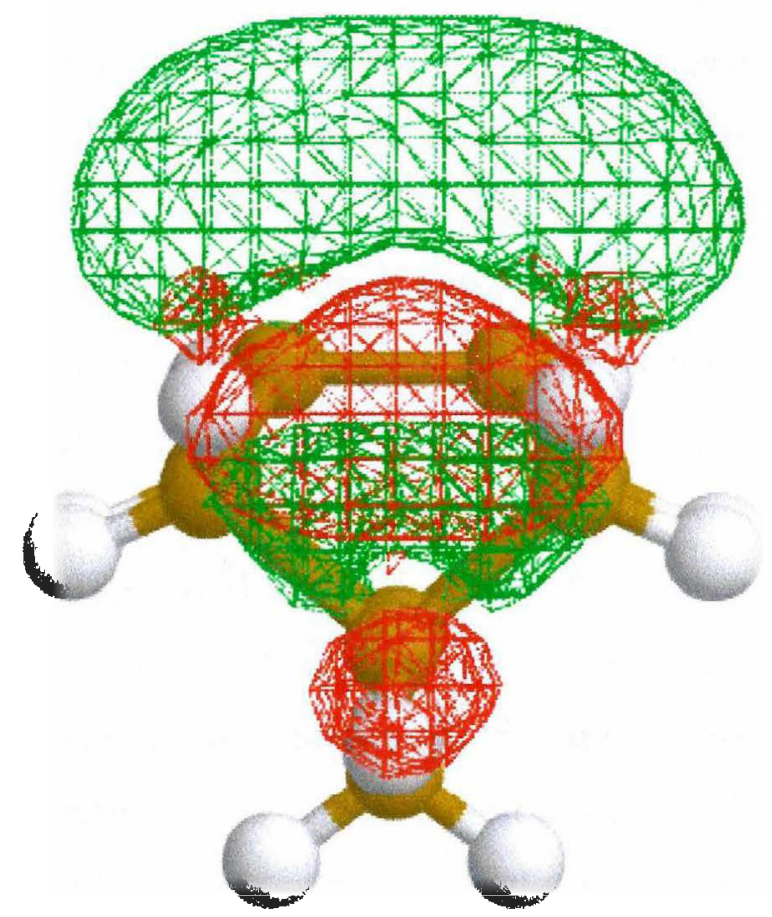

Figura 14. Representação do orbital $\mathrm{HOMO}$ da estrutura $\mathrm{Si}_{9} \mathrm{H}_{12}$ singleto obtida com a utilização de orbitais restritos. 


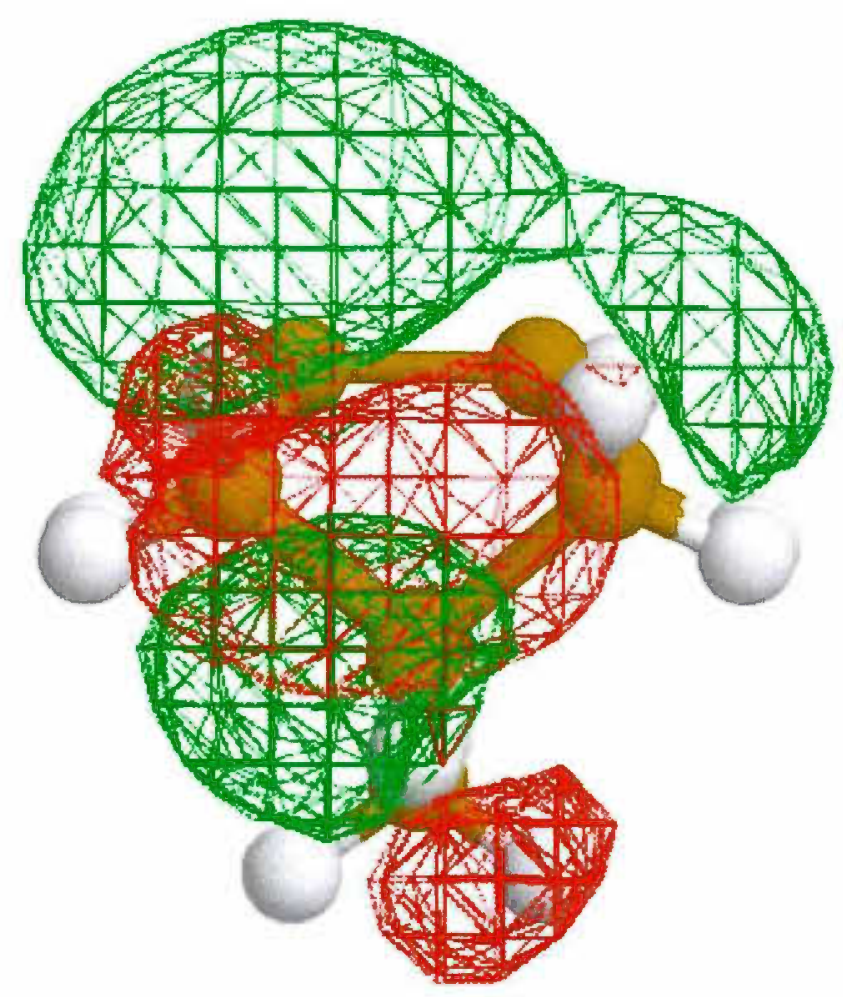

Figura 15. Representação do orbital $H O M O$ da estrutura $\mathrm{Si}_{9} \mathrm{H}_{12}$ singleto obtida com a utilização de orbitais não-restritos.

A viabilidade da existência de uma estrutura tripleto foi também investigada. Os resultados obtidos com a utilização de orbitais não-restritos estão na Tabela 6 . Não foi encontrada qualquer estrutura buckled com as bases atômicas utilizadas, e todos os pontos estacionários obtidos com as várias bases atômicas se relacionam com pontos de mínimo na superfície de energia potencial. Com relação aos parâmetros geométricos, a introdução de funções de polarização levou também a uma diminuição em todos os valores, sendo que $H(1-2)$ e $D(1-1)$ sofreram as maiores variaçōes, de $0,038 \AA$ e 0,043 $\AA$, respectivamente. Temos ainda que a distância entre os silícios dímeros $D(1-1)$ da estrutura tripleto é maior que a correspondente na singleto RHF em cerca de 0,22 $\AA$, sendo que o valor obtido $(2,404 \AA)$ ainda é $0,054 \AA$ maior que no singleto UHF. A distância de 2,404 $\AA$ é cerca de 0,06 $\AA$ maior que a de uma ligação simples Si-Si do disilano, e através dos valores da densidade de spin obtivemos que os elétrons desemparelhados estão centrados nos silícios dímeros, com cada elétron localizado em um dos silícios. O menor grau de reconstrução reflete-se no maior valor de $H(1-2)$ e no menor de $H(2-3)$, se comparados com os dois casos singleto. As distâncias entre os 
silicios nas camadas mais internas apresentam valores aproximadamente constantes da ordem de 2,37 $\AA$, ao contrário das estruturas singleto, que mostraram distâncias crescentes à medida que avançaram para camadas mais internas.

Com relação à estabilidade relativa das estruturas estudadas, temos que com a base $6-31 \mathrm{G}^{*}$ a tripleto UHF é cerca de $15,76 \mathrm{kcal} / \mathrm{mol}$ mais estável que a singleto $R H F$. Desse modo a metodologia Hartree-Fock prevê o favorecimento de uma estrutura com os elétrons desemparelhados na superfície, o que não é observado experimentalmente. Esse resultado foi obtido apenas com a metodologia Hartree-Fock, pois tanto com a Teoria do Funcional da Densidade quanto com a Teoria de Perturbação de segunda ordem há uma inversão dessa situação, sendo a estrutura singleto RHF bem mais favorável energeticamente que a tripleto. Mas dentre as três possibilidades estudadas, a singleto UHF é a mais estável, sendo a diferença de energia de $17,77 \mathrm{kcal} / \mathrm{mol}$ em relação ao singleto RHF e apenas $2,01 \mathrm{kcal} / \mathrm{mol}$ em relaçço ao tripleto.

A partir dos resultados acima, torna-se claro que na metodologia Hartree-Fock com a utilização de orbitais não-restritos para a estrutura singleto temos melhores resultados para os parâmetros geométricos, energias relativas e a descrição da ligação envolvendo os silícios dímeros.

Para se ter uma noção da estabilização devida aos processos de reconstrução e de relaxaçāo, calculamos a energia da estrutura com a geometria ideal, ou seja, sem rearranjos dos silícios superficiais e com todas as distâncias entre os silícios fixas no valor experimental de 2,35 $\AA$. A estabilização observada foi de cerca de 42,12 kcal/mol (1,83 eV com relaçāo à estrutura singleto $R H F$ e de $59,88 \mathrm{kcal} / \mathrm{mol}(2,60 \mathrm{eV}$ com a singleto UHF.

Markovitz et al. ${ }^{27}$ estudaram o processo de reconstrução utilizando a metodologia Hartree-Fock. Com o aglomerado de fórmula $\mathrm{Si}_{8} \mathrm{H}_{12}$, cuja estrutura permite a representação de uma ligação entre silícios dímeros, eles obtiveram que a estrutura simétrica obtida com o RHF singleto é $25,6 \mathrm{kcal} / \mathrm{mol}$ menos estável que a UHF tripleto. Esse valor é bastante diferente da obtida por nós $(15,76 \mathrm{kcal} / \mathrm{mol})$, e tal diferença provavelmente é devido às diferenças de vínculos adotados no processo de otimização, onde no nosso caso nenhum foi adotado, exceto a simetrica $C_{2 v}$ e no caso de Markovitz 
apenas os silícios dímeros e os da primeira camada interna foram otimizados. Nessas condições eles obtiveram uma estrutura distorcida para o aglomerado, o que não ocorreu conosco, sendo que energeticamente é idêntica à estrutura simétrica. Eles estudaram a estrutura UHF singleto, que não é a mais estável, como no nosso caso, mas está a cerca de $7 \mathrm{kcal} / \mathrm{mol}$ acima da estrutura tripleto $U H F$. Com relação à geometria, as distâncias entre os silícios dímeros obtidas por Markovitz sāo semelhantes às nossas. No caso RHF singleto a distância é de $2,20 \AA$, um pouco maior que a obtida por nós $(1,185 \AA$ ), enquanto que na estrutura $U H F$ tripleto o valor é $1,43 \AA$, que é cerca de $0,03 \AA$ maior do que obtivemos.

Num trabalho mais antigo realizado por Redondo e Goddard ${ }^{40}$ foi utilizado o aglomerado $\mathrm{Si}_{9} \mathrm{H}_{12}$, e eles obtiveram, com o uso de pseudopotencial e a metodologia Hartree-Fock, que a estrutura tripleto também é mais estável que a singleto em 1,33 eV $(30,67 \mathrm{kcal} / \mathrm{mol})$, levando a um estado fundamental que corresponde a uma forma ferromagnética. Esse valor é quase o dobro da obtida por riós, o que evidericia a influência que a adoção de vínculos pode causar nas propriedades, como a energia, pois eles permitiram o deslocamento apenas de alguns átomos. Na busca de uma estrutura buckled eles obtiveram uma estrutura singleto distorcida um pouco mais estável que a simétrica, mas ainda menos estável que a tripleto. Eles atribuíram a existência da forma assimétrica à falta da inclusão de correlação efetrônica, pois nenhuma estrutura distorcida foi obtida com o uso das metodologias $G V B$ e $C$.

Yang et $a ._{0}^{25}$ utilizaram as metodologias Hartree-Fock e do Funcional da Densidade para estudar as estruturas dos aglomerados de fórmula $\mathrm{Si}_{9} \mathrm{H}_{12}$ e $\mathrm{Si}_{15} \mathrm{H}_{16}$. Eles utilizaram bases atômicas bastante limitadas, no caso, STO-3G, 3-21G e 6-31G e restringiram o estudo ao estado singleto. Com essas bases eles obtiveram somente estruturas simétricas, sendo que o mesmo foi verificado a partir dos nossos resultados, ao utilizar as bases acima. Com a metodologia RHF e a base 6-31G obtivemos resultados semelhantes com relação aos parâmetros geométricos. Pequenas diferenças ocorreram, principalmente na distância entre as camadas de silício, e tal fato deve-se à diferença nos vínculos adotados durante o processo de otimização. Apesar de fornecer várias informações sobre a estrutura do aglomerado, o trabalho de Yang peca por não adotar uma base mais extensa, principalmente com a adição de funções de polarização, pois a 
presença destas causa uma grande mudança nos parâmetros geométricos, bem como uma discussão mais extensa a respeito das metodologias mais adequadas para a simulação da superfície, pois a partir do trabalho de Redondo sabe-se da necessidade do uso de funçōes de onda multiconfiguracionais para a correta descrição da superfície. Isso porque sabe-se que o uso de metodologias com um único determinante e com a adoção de orbitais restritos nāo fornece as melhores interpretaçōes para o problema.

Schoemaker e Burggraf ${ }^{43}$ retomam o estudo da superfície utilizando as metodologias HF-SCF, GVB e TCSCF (cálculo SCF com duas configurações). Eles utilizaram uma série de aglomerados, com um número variando de 9 a 66 silícios. $\bigcirc$ aglomerado $\mathrm{Si}_{9} \mathrm{H}_{12}$ foi otimizado com a metodologia $\mathrm{RHF}$ para o estado singleto, e os resultados obtidos para os parâmetros geométricos são muito semelhantes aos nossos, como seria de se esperar, pois os cálculos foram realizados de modo análogo, sem a adoção de vínculos na geometria. Eles adotaram o aglornerado $\mathrm{Si}_{66} \mathrm{H}_{52}$ prara verificar o quanto $\circ \mathrm{Si}_{9} \mathrm{H}_{12}$ reproduz as caracierísticas de um bulk. Eles verificaram que a influência da reconstrução, com a formação dos dímeros, propaga-se até oito camadas internas. Desse modo fica clara a limitação do $\mathrm{Si}_{9} \mathrm{H}_{12}$ para a reprodução das características do interior do silício.

\section{Resultados Funcional da Densidade}

Os parâmetros geométricos obtidos com a Teoria do Funcional da Densidade e o funcional híbrido B3LYP para os estados singleto e tripleto estão nas Tabelas 7 a 9. Do mesmo modo como no caso Hartree-Fock, utilizamos orbitais restritos e nāo-restritos para o estado singleto e somente não-restritos para o tripleto. 
Tabela 7. Parâmetros geométricos (em $\AA$ ) obtidos com orbitais restritos e a metodologia do Funcional da Densidade com o funcional B3LYP para o aglomerado singleto $\mathrm{Si}_{9} \mathrm{H}_{12}$.

\begin{tabular}{|c|c|c|c|c|c|c|c|}
\hline \multirow[b]{3}{*}{ Simetria } & \multirow{3}{*}{ Bulk } & $3-21 G$ & $6.31 G$ & $6-31 G^{=*}$ & $6-31 G^{* *}$ & $6-31 G^{*}$ & $6-31 G^{*}$ \\
\hline & & Unbuckled & Unbuckled & Unbuckled & Buckled & Unbuckled & Buckled \\
\hline & & $C_{2 v}$ & $C_{2 v}$ & $C_{2 v}$ & $C_{s}$ & $C_{2 v}$ & $C_{s}$ \\
\hline$D(1-1)$ & $2,45-2,54$ & 2,236 & 2,252 & 2,221 & $d(1-2)=2,225$ & 2,222 & $d(1-2)=2,225$ \\
\hline \multirow[t]{2}{*}{$D(1-2)$} & 2,353 & 2,372 & 2,381 & 2,347 & $d(1-3)=2,354$ & 2,347 & $d(1-3)=2,354$ \\
\hline & & & & & $d(2-5)=2,342$ & & $d(2-5)=2,342$ \\
\hline \multirow[t]{2}{*}{$D(2-3)$} & 2,353 & 2,406 & 2,414 & 2,376 & $d(3-4)=2,375$ & 2,376 & $d(3-4)=2,375$ \\
\hline & & & & & $d(5-4)=2,377$ & & $d(5-4)=2,377$ \\
\hline$D(3-4)$ & 2,353 & 2,396 & 2,411 & 2,380 & $d(4-6)=2,381$ & 2,380 & $d(4-6)=2,381$ \\
\hline$H(1-1)$ & & & & & $h(1-2)=0,196$ & & $h(1-2)=0,196$ \\
\hline \multirow[t]{2}{*}{$H(1-2)$} & 1,360 & 1,114 & 1,095 & 1,051 & $h(1-3)=1,136$ & 1,052 & $h(1-3)=1,136$ \\
\hline & & & & & $h(2-5)=0,985$ & & $h(2-5)=0,985$ \\
\hline \multirow[t]{2}{*}{$H(2-3)$} & 1,360 & 1,569 & 1,589 & 1,574 & $h(3-4)=1,597$ & 1,574 & $h(3-4)=1,597$ \\
\hline & & & & & $h(5-4)=1,553$ & & $h(5-4)=1,553$ \\
\hline$H(3-4)$ & 1,360 & 1,233 & 1,252 & 1,232 & $h(4-6)=1,230$ & 1,232 & $h(4-6)=1,236$ \\
\hline
\end{tabular}

Tabela 8. Parâmetros geométricos (em Å) obtidos com orbitais nāo-restritos e a metodologia do Funcional da Densidade com o funcional B3LYP para o aglomerado singleto $\mathrm{Si}_{9} \mathrm{H}_{12}$.

\begin{tabular}{ccccc}
\hline & & 3-21G & 6-31G & 6-31G** \\
\cline { 3 - 5 } & Bulk & Unbuckled & Unbuckled & Unbuckled \\
Simetria & & $C_{2 v}$ & $C_{2 v}$ & $C_{2 v}$ \\
\hline$D(1-1)$ & $2,45-2,54$ & 2,280 & 2,299 & 2,239 \\
$D(1-2)$ & 2,353 & 2,379 & 2,388 & 2,348 \\
$D(2-3)$ & 2,353 & 2,401 & 2,409 & 2,374 \\
$D(3-4)$ & 2,353 & 2,392 & 2,407 & 2,379 \\
$H(1-2)$ & 1,360 & 1,176 & 1,156 & 1,075 \\
$H(2-3)$ & 1,360 & 1,555 & 1,577 & 1,569 \\
$H(3-4)$ & 1,360 & 1,254 & 1,271 & 1,239 \\
\hline
\end{tabular}


Tabela 9. Parâmetros geométricos (em $\AA$ ) obtidos com orbitais não-restritos e a metodologia do Funcional da Densidade com o funcional B3LYP para o aglomerado tripleto $\mathrm{Si}_{9} \mathrm{H}_{12}$.

\begin{tabular}{cccccc}
\hline & \multirow{2}{*}{ Bulk } & 3-21G & $6-31 G$ & $6-31 G^{* *}$ & $6-31 G^{*}$ \\
\cline { 3 - 6 } Simetrio & & $\begin{array}{c}\text { Unbuckled } \\
C_{2 v}\end{array}$ & $\begin{array}{c}\text { Unbuckled } \\
C_{2 v}\end{array}$ & $\begin{array}{c}\text { Unbuckled } \\
C_{2 v}\end{array}$ & $\begin{array}{c}\text { Unbuckled } \\
C_{2 v}\end{array}$ \\
\hline$D(1-1)$ & $2,45-2,54$ & 2,461 & 2,472 & 2,419 & 2,419 \\
$D(1-2)$ & 2,353 & 2,402 & 2,410 & 2,369 & 2,368 \\
$D(2-3)$ & 2,353 & 2,392 & 2,401 & 2,369 & 2,369 \\
$D(3-4)$ & 2,353 & 2,380 & 2,395 & 2,368 & 2,368 \\
$H(1-2)$ & 1,360 & 1,367 & 1,341 & 1,302 & 1,303 \\
$H(2-3)$ & 1,360 & 1,516 & 1,535 & 1,521 & 1,521 \\
$H(3-4)$ & 1,360 & 1,337 & 1,346 & 1,332 & 1,331 \\
\hline
\end{tabular}

Considerando a estrutura singleto simétrica (unbuckled), com orbitais restritos, temos que os efeitos observados com a inclusão de funçōes c'e polarização nos átomos de silício são semelhantes aos obtidos com a metodologia Hartree-Fock. A distância entre os silícios dímeros diminuiu cerca de $0,03 \AA$ com a inclusão de funçōes de polarização, sendo dessa mesma ordem a diminuição observada com os demais silícios. Com a base 6-31G*, ambas geometrias (HF e DFT) são bem semelhantes, excetuando os silícios dímeros, que com a Teoria do Funcional da Densidade mostra uma distância de ligação igual a $2,222 \AA$, que é $0,037 \AA$ maior que a obtida com o método Hartree-Fock. Essa distância é da ordem de uma ligação dupla $(2,25 \AA)$, como no caso do $\mathrm{Si}_{2}{ }^{49}$

$O$ ponto importante a ser destacado é que com a base 6-31G a estrutura simétrica encontra-se localizada em um ponto de mínimo, mas com a inclusāo de funções de polarização passou a corresponder a um estado de transição. Buscando descobrir um ponto de mínimo, permitimos uma quebra na simetria do aglomerado, introduzindo deslocamentos normais à superfície pelos silícios dímeros. Obtivemos com isso a convergência para uma estrutura ligeiramente distorcida, de simetria Cs, que se encontra em um ponto de mínimo. Essa estrutura é apenas $0,081 \mathrm{kcal} / \mathrm{mol}$ mais estável que a simétrica, sendo esse valor muito pequeno e passível de variaçōes com a adoção de outros funcionais. A geometria final está na Tabela 7 , onde vemos que não apenas sāo energeticamente próximas mas apresentam também geometrias semelhantes. As maiores diferenças observadas foram na distância entre os silícios dímeros e entre estes e os da 
primeira camada interna. Na estrutura simétrica, o aglomerado apresenta uma "altura" apenas $0,028 \AA$ maior que a obtida com o método Hartree-Fock com a base $6-31 \mathrm{G}^{*} \mathrm{e}$ orbitais restritos, enquanto que com relação aos parâmetros geométricos apenas a distância entre os silícios dímeros $(2,222 \AA)$ é maior que a correspondente obtida com Hartree-Fock, sendo as demais ligaçōes ligeiramente menores. Com relaçāo à estrutura buckled, temos que a distorção sofrida pelos silícios dímeros é pequena, sendo o ângulo formado entre os silícios e um plano horizontal da ordem de $5^{\circ}$. $O$ deslocamento desses dois átomos fez com que o silício dímero mais deslocado ficasse 0,200 $\AA$ acima do outro, e os silícios da camada seguinte também se deslocassem de maneira semelhante mas em menor grau, ou seja, os silícios ligados ao silício mais externo estão acima dos ligados ao mais interno em cerca de 0,07 $\AA$.

Na Tabela 8 temos os resultados obtidos para a estrutura singleto com a utilização de orbitais não-restritos. Ao contrário do caso restrito, nōo tervamas a existêricia de uma estrutura buckled. Interessante observar que com a base j-31G* a geometria não difere tanto se comparada com o caso restrito, ao contrário do observado com a metodologia Hartree-Fock. A distância entre os silícios dímeros é apenas 0,017 $\AA$ maior que o valor com os orbitais restritos, enquanto que essa variação chegou a $0,166 \AA$ no Hartree-Fock. Enquanto que com o uso de orbitais restritos houve um aumento de 0,037 $\AA$ ao passar de Hartree-Fock para DFT, com a base 6-31 G*, no casó dos orbitais nãorestritos ocorreu uma diminuição considerável de $0,112 \AA$, e a distância final $(2,239 \AA)$ é da ordem de um típica ligação dupla $(2,25 \AA$ ) . Na Tabela 8 vemos que a inclusão de funções de polarização causou uma diminuição de $0,060 \AA$ na distância entre os silícios dímeros. As demais ligaçōes diminuíram de 0,040 $\AA$ a $0,028 \AA$, no caso dos silícios mais externos e dos mais internos, respectivamente. Energeticamente, com a utilização de orbitais não-restritos temos uma estrutura praticamente idêntica à observada no caso buckled com orbitais restritos.

Também nãó conseguimos a convergência de uma estrutura tripleto distorcida. Os resulíados obtidos para a forma simétrica estão apresentados na Tabela 9. Nela vemos que a adição de funções de polarização diminuiu a distância entre os silícios dímeros em $0,053 \AA$, e a diminuiçạo foi menor entre os silícios mais internos, da ordem de 0,027 Essas variações sāo ligeiramente maiores que as observadas no caso tripleto nāo-restrito 
Hartree-Fock $(0,042 \AA$ e $0,024 \AA$, respectivamente). Com a base 6-31G* temos a maior distância encontrada entre os silícios dímeros, que é de 2,419 $\AA$. Esse valor é 0,194 maior que o correspondente singleto distorcido DFT com orbitais restritos e $0,014 \AA$ maior que a obtida com a metodologia Hartree-Fock para o estado tripleto. Essa maior distância de ligação reflete na maior "altura" do aglomerado, se comparado com as estruturas singleto obtidas com a metodologia DFT.

Energeticamente, temos que, diferentemente do observado no resultado HartreeFock, a estrutura tripleto é cerca de $7,04 \mathrm{kcal} / \mathrm{mol}$ menos estável que a singleto restrito. buckled. Para as estruturas simétricas, a correspondente com orbitais não-restritos continuou a sendo a mais estável, mas esta é energeticamente quase idêntica à estrutura buckled com orbitais restritos. Comparando com os resultados obtidos no Hartree-Fock, observamos um aumento na diferença de energia entre a estrutura singleto com orbitais não-restritos e a tripleto ( $2 \mathrm{kcal} / \mathrm{mol}$ para $7 \mathrm{kcal} / \mathrm{mol}$ ) e uma diminuição com o singleto restrito simétrico $(17,76 \mathrm{kcal} / \mathrm{mol}$ para cerca de $0,8 \mathrm{kcal} / \mathrm{mol})$. A inversũo da ordem de estabilidade da estrutura tripleto em relação ao singleto restrito foi bastante acentuada, se comparada ao resultado análogo Hartree-Fock. Nesse caso, o resultado tripleto é 15,76 $\mathrm{kcal} / \mathrm{mol}$ mais estável que o singleto, enquanto que com o DFT passou a ser 7,04 $\mathrm{kcal} / \mathrm{mol}$ menos estável. Esse é mais um fator que mostra a inadequação da metodologia Hartree-Fock para a descrição da superfície com o uso do aglomerado $\mathrm{Si}_{9} \mathrm{H}_{12}$.

Para o cálculo da energia de estabilizaçāo, que obtivemos do mesmo modo como descrito para o caso Hartree-Fock, temos que o valor é de $51,94 \mathrm{kcal} / \mathrm{mol}(2,25 \mathrm{eV})$ para a estrutura singleto restrito buckled. Esse valor é maior que o correspondente obtido com o Hartree-Fock $(42,12 \mathrm{kcal} / \mathrm{mol})$.

Muitos trabalhos foram realizados utilizando a metodologia do Funcional da Densidade para o estudo da reação da superfície Si(100) com átomos e moléculas. A grande aceitação dessa metodologia deve-se ao seu baixo custo computacional e o fornecimento de resultados muitas vezes em grande concordância com os valores experimentais. Devido ao grande número de trabalhos utilizando o Funcional da Densidade, não estamos aqui com a intenção de apresentar uma revisão geral dos trabalhos e resultados da literatura, mas sim mencionar alguns dados representativos 
onde essa metodologia foi utilizada e as conseqüências nos parâmetros geométricos e energéticos do aglomerado $\mathrm{Si}_{9} \mathrm{H}_{12}$.

Yang et $a / .^{25}$ realizaram um estudo com o aglomerado $\mathrm{Si}_{9} \mathrm{H}_{12}$ utilizando o funcional híbrido B3LYP, nas mesmas condições do cálculo Hartree-Fock, conforme mencionado no item anterior. Eles utilizaram as bases STO-3G, 3-21G e 6-31G, e com elas não encontraram uma estrutura buckled com a metodologia DFT. De acordo com os nossos resultados, isso ocorreu devido ao fato de não terem utilizado funções de polarização no silício, já que somente com a introdução destes num cálculo singleto restrito levou a uma forma ligeiramente distorcida. Os parâmetros geométricos obtidos por eles são qualitativamente parecidos com os nossos, mas pequenas diferenças aparecem como resultado da adoção de vínculos por Yang.

Bacalzo et al. ${ }^{29,51}$ estudaram a interação e adsorção da molécula CO na superfície $\mathrm{Si}(100)$, simulada pelo aglomerado $\mathrm{Si}_{9} \mathrm{H}_{12}$. Eles utilizaram o funcionai 333 l.YP, a base ó$31 G^{*}$ e não utilizaram vínculos durante o processo de otimização. Eles não se preocuparam com a questão da estabilidade entre as formas buckled e unbuckled, mas adotaram a forma simétrica para o estudo. Desse modo, o valor da distância entre os silícios dímeros foi de 2,221 $\AA$, valor esse idêntico ao obtido no nosso trabalho, o que seria de se esperar pelas condições semelhantes adotadas.

Para o estudo da interação de hidretos de silício, Brown e Doren ${ }^{30,52}$ utilizaram o aglomerado $\mathrm{Si}_{9} \mathrm{H}_{12}$, os programas DGAUSS, DMOL e Gaussian 94, e o funcional BLYP. As otimizaçōes foram realizadas sem vínculos, e os cálculos DGAUSS e DMOL forneceram a estrutura assimétrica como a mais estável. A sensibilidade do problema pode ser percebida pelo resultado DGAUSS/TZ94P, onde a estrutura simétrica é um estado de transição e a buckled é mínimo, enquanto que com o DMOL/DNP, onde DNP corresponde a uma base atômica numérica dupla-zeta com funçōes de polarização, ambas correspondem a estruturas localizadas em pontos de mínimo. O cálculo realizado com Gaussian 94 e uma base extensa $(6-31 G++(2 d f, 2 p))$ indicaram que a estrutura simétrica é ligeiramente mais estável que a assimétrica. Tais fatos não levaram os autores a uma conclusão a respeito da estabilidade relativa entre o aglomerado buckled e 
unbuckled. As distâncias entre os silícios dímeros foi de 2,29 e 2,25 , para os cálculos DGAUSS e DMOL, respectivamente.

Penev et al. ${ }^{53}$ também observaram a mudança na estabilidade do aglomerado em função da escolha do funcional. Eles estudaram o processo de desorção e adsorção dissociativa do $\mathrm{H}_{2}$ em $\mathrm{Si}(100)$. Com o uso de pseudopotenciais, os funcionais BP e BLYP forneceram a estrutura simétrica como a mais estável, enquanto a ordem se inverteu com os cálculos LDA e PW91. Importante lembrar que eles utilizaram vínculos, como a fixação dos átomos internos, deixando apenas os silícios dímeros e os da primeira camada livres para otimizar.

Esses são apenas alguns exemplos encontrados na literatura onde podemos ver a dificuldade em se definir a estabilidade relativa entre as formas simétricas e assimétricas do $\mathrm{Si}_{9} \mathrm{H}_{12}$, mesmo levando em conta a metodologia do Funcional da Densidade, que é a única que leva ù obtenção de uma formo buckled sem grandes necessidades de vínculos e limitaçōes. Apesar de experimentalmente haver a indicação da preferência pela forma simétrica, talvez a limitação imposta pela dimensão do aglomerado impeça a obtenção de um resultado mais confiável, visto que efeitos como a influência de outros dímeros e do bulk sāo deixados de lado no estudo do $\mathrm{Si}_{9} \mathrm{H}_{12}$. Apesar da metodologia do Funcional da Densidade estar tendo uma aceitação cada vez maior no cálculo de estruturas moleculares, não parece capaz de fornecer um resultado mais conclusivo a respeito da estabilidade da superfície $\mathrm{Si}(100)$ simulada pelo $\mathrm{Si}_{9} \mathrm{H}_{12}$.

\section{Resultados MP2}

Os resultados obtidos com a metodologia Teoria de Perturbação de segunda ordem (MP2) e a base 6-31G* para os estados singleto e tripleto estão na Tabela 10. Diferentemente do obtido com a metodologia do Funcional da Densidade, não encontramos uma estrutura assimétrica com a base acima. No estudo utilizondo MP2 nos restringimos apenas à base 6-31G*. 
Tabela 10. Parâmetros geométricos (em $\AA$ ) obtidos com a metodologia Teoria de Perturbação de segunda ordem e a base 6-31 $\mathrm{G}^{*}$ para o aglomerado singleto e tripleto $\mathrm{Si}_{9} \mathrm{H}_{12}$.

\begin{tabular}{|c|c|c|c|c|}
\hline & \multirow{3}{*}{ Bulk } & $\begin{array}{l}\text { singleto } \\
\text { restrito }\end{array}$ & $\begin{array}{l}\text { singleto } \\
\text { näo-restrito }\end{array}$ & $\begin{array}{c}\text { tripleto } \\
\text { näo-restrito }\end{array}$ \\
\hline & & Unbuckled & Unbuckled & Unbuckled \\
\hline Simetria & & $C_{2 v}$ & $C_{2 v}$ & $C_{2 v}$ \\
\hline$D(1-1)$ & $2,45-2,54$ & 2,227 & 2,275 & 2,386 \\
\hline$D(1-2)$ & 2,353 & 2,329 & 2,338 & 2,350 \\
\hline$D(2-3)$ & 2,353 & 2,360 & 2,354 & 2,352 \\
\hline$D(3-4)$ & 2,353 & 2,361 & 2,360 & 2,353 \\
\hline$H(1-2)$ & 1,360 & 1,027 & 1,123 & 1,278 \\
\hline$H(2-3)$ & 1,360 & 1,554 & 1,524 & 1,498 \\
\hline$H(3-4)$ & 1,360 & 1,214 & 1,249 & 1,319 \\
\hline
\end{tabular}

Com relação ao estado singleto, temos que a mudança na utilização de orbitais restritos para não-restritos levou a uma pequena variação nos parâmetros geométricos, de maneira semelhante ao observado com o Funcional da Densidade, excetuando os parâmetros relativos aos silícios mais superficiais. A distância entre os silícios dímeros aumentou de $0,048 \AA$, enquanto que a diferença entre esses silicios e a próxima camada aumentou em cerca de $0,1 \AA$. Com orbitais restritos temos que a distância entre os silícios dímeros é de 2,227 $\AA$, sendo esse valor praticamente idêntico ao obtido com Teoria do Funcional da Densidade $(2,222 \AA)$, mas essa diferença aumenta com os orbitais nãorestritos, sendo o aumento de 0,036 $\AA$. Esse último valor mostra o menor grau de reconstrução, que gera como conseqüência um maior valor de $\mathrm{H}(1-2)$ e com isso uma menor perturbação nos silícios mais internos, levando a um menor valor de $\mathrm{H}(2-3)(1,524$ A) se comparado com o resultado DFT $(1,569 \AA$ A). Esse efeito é mais acentuado se compararmos o resultado MP2 com Hartree-Fock singleto não-restrito, pois neste último caso a separação entre os silícios dímeros é de $2,351 \AA$, que é $0,076 \AA$ maior que o MP2. Esse menor grau de reconstrução no resultado $H F$ reflete no maior valor de $H(1-2)$ $(1,213 \AA$ contra 1,123 $)$.

Com relação à estrutura tripleto, temos que a distância entre os silícios dímeros $(2,386 \AA)$ é a menor se comparada com as obtidas com as metodologias Hartree-Fock e a Teoria do Funcional da Densidade, sendo as diferenças iguais a $0,020 \AA$ e $0,033 \AA$, 
respectivamente. $\bigcirc$ valor de 2,386 $\AA$ é bastante próximo do correspondente a uma ligação simples típica, cujo valor é $2,34 \AA$.

Energeticamente, temos que o estado tripleto é cerca de $13,05 \mathrm{kcal} / \mathrm{mol}$ menos estável que o singleto restrito e esse valor é praticamente o dobro do obtido com a Teoria do Funcional da Densidade. A estrutura singleto com orbitais nāo-restritos é também a mais estável, sendo $1,88 \mathrm{kcal} / \mathrm{mol}$ e $14,93 \mathrm{kcal} / \mathrm{mol}$ mais estável que o singleto restrito e o tripleto não-restrito, respectivamente. Essa ordem energética é qualitativamente semelhante ao obtido com DFT, sendo que as diferenças ocorrem apenas com os valores das energias. A variação de energia entre as estruturas singleto restrito e nāo restrito aumentou de 0,08 para $1,88 \mathrm{kcal} / \mathrm{mol}$ e entra a singleto não-restrito e tripleto aumentou de 7,04 para 14,93 $\mathrm{kcal} / \mathrm{mol}$. O resultado MP2 para as estabilidades relativas torna mais clara a ordem energética, se levarmos em conta os resultados Hartree-Fock e DFT. Desse modo, corcluímos que a estrutura tripleto, com orbitais não-restritos, é a menos estável, enquanto que a singleto com orbitais não-restritos é a mais estável.

A energia de estabilização calculada para o processo de reconstrução e relaxação foi de $69,53 \mathrm{kcal} / \mathrm{mol}(3,02 \mathrm{eV})$ para a estrutura singleto restrito, e esse valor é o maior obtido dentre as metodologias vistas até agora. Esse valor mostra uma tendência de aumento do valor da estabilização com o aumento da correção na função de onda Hartree-Fock.

Poucos trabalhos são realizados atualmente com a metodologia MP2, principalmente com o crescente interesse por outras como o funcional da densidade. Não temos conhecimento de um estudo específico da superfície $\mathrm{Si}(100)$ com o aglomerado $\mathrm{Si}_{9} \mathrm{H}_{12}$ utilizanda $M P 2$.

\section{Resultados CASSCF}

Para o estudo do aglomerado singleto $\mathrm{Si}_{9} \mathrm{H}_{12}$ utilizando a metodologia CASSCF, realizamos inicialmente um cálculo Hartree-Fock-SCF para a seleção dos orbitais a serem incluídos no espaço ativo. Para a escolha dos orbitais necessários ao cálculo CASSCF 
realizamos três testes, utilizando os orbitais restritos obtidos a partir de cálculos HartreeFock das estruturas otimizadas singleto, tripleto e quinteto, sendo todos os cálculos feitos com a base 6-31G*. Nossa preocupaçāo foi tentar descobrir a menor quantidade de orbitais necessários para descrever corretamente a estrutura eletrônica do aglomerado.

Inicialmente utilizamos os orbitais obtidos de um cálculo singleto com orbitais restritos. A configuração eletrônica correspondente aos 69 orbitais ocupados foi: $25 a_{1}$, $17 b_{1}, 16 b_{2}$ e $11 a_{2}$. A partir da análise da estrutura dos orbitais, selecionamos três, que apresentam uma maior localização na região dos silícios dímeros. Os orbitais selecionados foram: $24 a_{1}, 25 a_{1}$ e $17 b_{2}$, sendo o 25a, HOMO e $17 b_{2}$ LUMO. Com isso temos, segundo a notação do programa Gaussian 94, um cálculo do tipo $\operatorname{CAS}(4,3)$, ou seja, quatro elétrons envolvidos no processo de excitação entre os três orbitais selecionados para o espaço ativo. Feito isso, realizamos a otimizaçāo geométrica da estrutura, deixando todos os átomos livres, sendo a simetria do sistema $\left(C_{2 v}\right)$ o único vínculo existente. Tivemos a formação de 6 configurações, e a função de onda da estrutura otimizada apresentou um caráter multiconfiguracional:

$$
|\Psi>\sim 0,915| \Psi_{1}>-0,403 \mid \Psi_{2}>
$$

onde $\left|\Psi_{1}\right\rangle$ corresponde à configuração de referência Hertree-Fock, ou seja, $\ldots\left(24 a_{1}\right)^{2}\left(25 a_{1}\right)^{2}$ e $\left|\Psi_{2}\right\rangle$ corresponde a ...(24a $)^{\prime}\left(17 b_{2}\right)^{2}$, com os dois elétrons do HOMO $\left(25 a_{1}\right)$ excitados para o LUMO $\left(17 b_{2}\right)$. A partir da matriz densidade de um elétron temos a seguinte ocupação orbital:

\begin{tabular}{cccc}
\hline orbital & $24 a_{1}$ & $25 a_{1}$ & $17 b_{2}$ \\
\hline ocupação & 2,000 & 1,675 & 0,325 \\
\hline
\end{tabular}

A partir desse primeiro resultado vemos claramente que uma função de onda multiconfiguracional é necessária para descrever corretamente a estrutura eletrônica desse aglomerado. Com isso, resultados obtidos com metodologias que utilizam um único determinante, como o Hartree-Fock, fornecem resultados incorretos, mesmo que a configuração de referência represente cerca de $90 \%$ da função de onda final. Portanto é necessário levar em conta o primeiro orbital virtual na função de onda eletrônica, e uma 
melhor idéia da participação deste pode ser vista pelo valor da ocupação orbital, onde o valor de 0,325 é grande o suficiente para que a configuração com esse orbital não seja desconsiderada.

Os parâmetros geométricos podem ser vistos na Tabela 11, e nela vemos que a distância entre os silícios dímeros é de $2,276 \AA$, e vemos aqui também o mesmo comportamento observado no MP2, ou seja, o aumento da distância entre os silícios dímeros com o a inclusāo de correlação eletrônica. Esse valor de 2,276 Å é o maior obtido até então, sendo 0,091, 0,055 e 0,049 ^ maior que os resultados Hartree-Fock, DFT e MP2, respectivamente, para o estado singleto com orbitais restritos. Os demais valores de $D(i-j)$ apresentam uma diferença bem menor, sendo no máximo de $0,028 \AA$. Esse menor grau de reconstrução nesse cálculo CASSCF faz com que H(1-2) também seja maior que as demais estruturas singleto estudadas, sendo essa diferença da ordem de 0,1 $\AA$. Esse maior valor de $H(1-2)$ torna o aglomerado nessa inetodologia o mais "alto" obtido até entāo, sendo 0,152 $\AA$ maior que o equivolente em MP2.

Para a obtenção da energia de reconstrução, realizamos um cálculo $\operatorname{CAS}(4,3)$ sobre a estrutura ideal, não-reconstruída, sem a realização de otimização geométrica. Os orbitais selecionados para constituírem o espaço ativo foram aqueles que correlacionam com os orbitais escolhidos na estrutura reconstruída. Desse modo obtivemos uma energia de reconstrução de $57,46 \mathrm{kcal} / \mathrm{mol}(2,49 \mathrm{eV})$, sendo esse valor intermediário entre o obtido com as metodologias DFT/B3LYP $(2,26 \mathrm{eV})$ e MP2 $(3,02 \mathrm{eV})$.

Com o intuito de facilitar a comparação dos resultados, temos na Tabela 10-A as energias de estabilização obtidas durante $O$ processo de reconstrução com as metodologias HF, DFT/B3LYP, MP2 e CAS(4,3).

Tabela 10-A. Energias de estabilização (em eV) obtidas para o aglomerado $\mathrm{Si}_{9} \mathrm{H}_{12}$ com várias metodologias e com a base 6-31G*.

\begin{tabular}{ccccc}
\hline & HF-SCF & DFT/B3LYP & MP2 & CAS(4,3) \\
\hline singleto RHF simétrico & 1,83 & 2,24 & 3,02 & 2,49 \\
singleto RHF buckled & & 2,25 & & \\
singleto UHF simétrico & 2,60 & 2,25 & 3,10 & \\
tripleto UHF simétrico & 2,51 & 1,94 & 2,45 & \\
\hline
\end{tabular}


Tabela 11. Parâmetros geométricos (em $\AA$ ) obtidos com testes para a escolha dos orbitais ativos com a metodologia CASSCF e a base $6-31 \mathrm{G}^{*}$ para o aglomerado singleto $\mathrm{Si}_{9} \mathrm{H}_{12}$.

\begin{tabular}{ccccc}
\hline & & CAS(4,3) & CAS(4,5) & CAS(6,6) \\
\cline { 3 - 5 } Simetria & Bulk & $\begin{array}{c}\text { Unbuckled } \\
\mathrm{C}_{2 v}\end{array}$ & $\begin{array}{c}\text { Unbuckled } \\
\mathrm{C}_{2 v}\end{array}$ & $\begin{array}{c}\text { Unbuckled } \\
\mathrm{C}_{2 v}\end{array}$ \\
\hline $\mathrm{D}(1-1)$ & $2,45-2,54$ & 2,276 & 2,294 & 2,286 \\
$\mathrm{D}(1-2)$ & 2,353 & 2,357 & 2,355 & 2,354 \\
$\mathrm{D}(2-3)$ & 2,353 & 2,373 & 2,373 & 2,373 \\
$\mathrm{D}(3-4)$ & 2,353 & 2,386 & 2,386 & 2,386 \\
$\mathrm{H}(1-2)$ & 1,360 & 1,130 & 1,118 & 1,116 \\
$\mathrm{H}(2-3)$ & 1,360 & 1,555 & 1,555 & 1,558 \\
$\mathrm{H}(3-4)$ & 1,360 & 1,262 & 1,258 & 1,257 \\
\hline
\end{tabular}

Em seguida, continuando os testes para a escolha adequada dos orbitais, utilizamos orbitais de um cálculo tripleto restrito. Para a escolha dos orbitais, utilizamos os dois unicamente ocupados, que correspondem a $25 a_{1}$ e $17 b_{2}$, além do $24 a_{1}$ e mais dois orbitais virtuais, $26 a_{1}$ e $18 b_{2}$. Com isso iemos quatro elétrons podendo sofrer excitaçōes entre cinco orbitais, sendo um cálculo do tipo CAS(4,5). Importante observar que os três orbitais ocupados selecionados no cálculo Hartree-Fock têm a mesma forma que os três orbitais selecionados para o cálculo $\operatorname{CAS}(4,3)$ acima. Com isso, ao fazermos o CAS $(4,5)$ estaremos utilizando os mesmos orbitais, acrescidos de mais dois orbitais virtuais ausentes no cálculo anterior. Com isso, temos a formação de cinqüenta configuraçōes e a função de onda final, da geometria otimizada, é:

$$
|\Psi>\sim 0,926| \Psi_{1}>-0,356\left|\Psi_{2}>+0,086\right| \Psi_{3}>-0,070 \mid \Psi_{4}>
$$

As configurações acima correspondem a:

$$
\begin{aligned}
& \mid \Psi_{1}>=\ldots\left(24 a_{1}\right)^{2}\left(25 a_{1}\right)^{2} \\
& \mid \Psi_{2}>=\ldots\left(24 a_{1}\right)^{2}\left(17 b_{2}\right)^{2} \\
& \mid \Psi_{3}>=\ldots\left(24 a_{1}\right)^{\prime}\left(25 a_{1}\right)^{\prime}\left(17 b_{2}\right)^{\prime}\left(18 b_{2}\right)^{\prime} \\
& \mid \Psi_{4}>=\ldots\left(24 a_{1}\right)^{2}\left(18 b_{2}\right)^{2}
\end{aligned}
$$


A partir da matriz densidade de um elétron temos a seguinte ocupação orbital:

\begin{tabular}{cccccc}
\hline orbital & $24 a_{1}$ & $25 a_{1}$ & $17 b_{2}$ & $18 b_{2}$ & $26 a_{1}$ \\
\hline ocupação & 1,977 & 1,733 & 0,266 & 0,020 & 0,000 \\
\hline
\end{tabular}

Temos que a função de onda apresenta duas configurações com maior peso, semelhante ao que obtivemos no caso anterior, com o uso de orbitais singleto. Além disso, aparecem duas outras configuraçōes com um peso na função de onda bem menor, mas não desprezível. Com relação à ocupação orbital, temos também resultados semelhantes aos obtidos com o CAS(4,3), mas com uma pequena ocupação do orbital $18 b_{2}$, da ordem de 0,020 , dez vezes menor que o do orbital $17 b_{2}$, além de uma ocupação nula do orbital $26 a_{1}$, que mostra claramente ser este irrelevante na inclusão no espaço ativo para o cálculo CASSCF.

Comparando os resultados dos parâmetros geométricos com os obtidos com orbitais singletos, vemos que diferem muito pouco, sendo observada apenas uma ligeira diferença nos valores relativos aos silícios mais externos, onde a distância entre os silícios dímeros aumentou em $0,018 \AA$.

Como um último teste para a escolha e determinação dos orbitais de interesse, utilizamos orbitais gerados de um cálculo Hartree-Fock quinteto restrito. A configuraçāo Hartree-Fock é $25 a_{1}, 18 b_{1}, 17 b_{2}$ e $11 a_{2}$, sendo os orbitais $25 a_{1}, 18 b_{1}, 17 b_{2}$ e $11 a_{2}$ unicamente ocupados. Para a construção do espaço ativo utilizamos esses quatro orbitais unicamente ocupados, o último orbital duplamente ocupado $\left(24 a_{1}\right)$ e o primeiro virtual $\left(26 a_{1}\right)$. Com isso, temos a utilização de seis orbitais e seis elétrons no espaço ativo, que corresponde à notação CAS $(6,6)$. Um total de 175 configurações foram obtidas, sendo que a função de onda final foi:

$$
|\Psi>\sim 0,925| \Psi_{1}>-0,353\left|\Psi_{2}>-0,086\right| \Psi_{3}>-0,067 \mid \Psi_{4}>
$$


As configurações acima correspondem a:

$$
\begin{aligned}
& \left|\Psi_{1}\right\rangle=\ldots\left(24 a_{1}\right)^{2}\left(11 a_{2}\right)^{2}\left(25 a_{1}\right)^{2} \\
& \left|\Psi_{2}\right\rangle=\ldots\left(24 a_{1}\right)^{2}\left(11 a_{2}\right)^{2}\left(17 b_{2}\right)^{2} \\
& \left|\Psi_{3}\right\rangle=\ldots\left(24 a_{1}\right)^{\prime}\left(11 a_{2}\right)^{2}\left(25 a_{1}\right)^{\prime}\left(17 b_{2}\right)^{\prime}\left(18 b_{2}\right)^{1} \\
& \left|\Psi_{4}\right\rangle=\ldots\left(11 a_{2}\right)^{2}\left(25 a_{1}\right)^{2}\left(18 b_{2}\right)^{2} .
\end{aligned}
$$

A ocupação orbital passou a ser:

\begin{tabular}{ccccccc}
\hline orbital & $11 a_{2}$ & $24 a_{1}$ & $25 a_{1}$ & $17 b_{2}$ & $26 a_{1}$ & $18 b_{1}$ \\
\hline ocupaçāo & 2,000 & 1,971 & $i, 736$ & 0,263 & 0,008 & 0,022
\end{tabular}

Observamos que os valores para as ocupaçōes são semelhantes aos obtidos com - $\operatorname{CAS}(4,5)$. O orbital $11 a_{2}$ permanece sempre duplamente ocupado, de modo que a excitação dos elétrons desse orbital está relacionado com configurações eletrônicas pouco importantes. De maneira semelhante, os orbitais $26 a_{1}$ e $18 b_{2}$ têm pequena ocupação, e a excitação para esses orbitais virtuais tem uma pequena importância.

Os resultados acima, além de mostrarem a necessidade do uso de funçōes de onda multiconfiguracionais, indicam que a configuração obtida com a excitação dos elétrons do HOMO $\left(25 a_{1}\right)$ para o LUMO $\left(17 b_{2}\right)$ é a mais importante, além da configuração fundamental, sendo as demais de importância muito pequena.

Com relação aos parâmetros geométricos, estes pouco variaram nos três casos estudados com o CASSCF. Os valores relacionados aos silícios mais internos permaneceram idênticos, enquanto pequenas alteraçōes ocorreram apenas com os silícios superficiais. $O$ valor de $D(1-1)$ para o $\operatorname{CAS}(4,3)(2,276 \AA)$ aumentou $0,018 \AA$ ao passar para $\operatorname{CAS}(4,5)$ e $0,010 \AA$ para $\operatorname{CAS}(6,6)$.

Realizamos também um cálculo CAS(4,3) a partir da geometria buckled obtida com o funcional B3LYP, a base $6-31 \mathrm{G}^{*}$ e orbitais restritos. Conforme mencionado, esse 
foi o único caso em que uma estrutura distorcida foi obtida. Selecionamos para o espaço ativo os orbitais concentrados nos silícios dímeros, a partir dos orbitais gerados num cálculo DFT-B3LYP singleto restrito, que correspondem aos mesmos escolhidos no estudo da estrutura simétrica, ou seja, os dois orbitais duplamente ocupados mais energéticos e - primeiro virtual (LUMO). A otimização foi realizada na simetria $C_{s}$ sem a adoção de vínculos na geometria, e a estrutura otimizada convergiu para a forma simétrica, idêntica à obtida no cálculo $\mathrm{C}_{2 v}$ acima. Desse modo, podemos ver que todas as metodologias levam à forma simétrica, excetuando o funcional da densidade, que, do mesmo modo como obtida em outros trabalhos, apresenta uma preferência para uma estrutura distorcida. Experimentalmente, acredita-se que a forma buckled é a mais estável, mas a partir dos cálculos realizados com o aglomerado $\mathrm{Si}_{9} \mathrm{H}_{12}$ obtemos a preferência para a forma simétrica. A questão que surge é saber se esse resultado deve-se ao tamanho limitado do aglomerado, pois não leva em consideração efeitos de camadas mais internus $\varepsilon$ a influência de cutros dímeros, un se existe realmente uma discrepância entre o resultado teórico e a observação experimental, já que os cálculos realizados são adequados por incluir uma função de onda multiconfiguracional. A preferência para a forma simétrica, a partir dos resultados do aglomerado $\mathrm{Si}_{9} \mathrm{H}_{12}$, parece indicar a interpretação experimental de que a superfície Si(100) sem perturbação apresenta uma estrutura unbuckled, enquanto a forma distorcida surgiria em locais com presença de perturbações, que levariam a essa mudança na geometria.

Para o aglomerado $\mathrm{Si}_{9} \mathrm{H}_{12}$ também realizamos a otimização geométrica utilizando a metodologia CASSCF com a base CEP-31G*. Esse base com pseudopotencial tem sido muito utilizada por apresentar resultados bastante confiáveis com relação à descrição de estruturas, não apenas do ponto de vista geométrico, mas também eletrônico. Com essa base, temos que os cálculos passam a ser feitos não sobre os 138 elétrons do sistema, mas com o número bem menor de 48 elétrons, que correspondem aos elétrons presentes na camada de valência dos átomos. A utilizaçāo desta base serve a dois propósitos, que são: comparar os resultados obtidos com os realizados por outros pesquisadores e também para servir como referência para comparaçāo no estudo de aglomerados maiores, onde nos limitaremos à utilização dessa base pois a $6-31 \mathrm{G}^{*}$ passa a ser de uso 
impraticável em aglomerados muito maiores. Os resultados obtidos com $\circ \operatorname{CAS}(4,3)$ e CAS(4,5) estão na Tabela 12.

Tabela 12. Parâmetros geométricos (em $\AA$ ) obtidos com testes para a escolha dos orbitais ativos com a metodologia CASSCF e a base CEP-31G* para o aglomerado singleto $\mathrm{Si}_{9} \mathrm{H}_{12}$.

\begin{tabular}{cccc}
\hline & & CAS(4,3) & CAS(4,5) \\
\cline { 3 - 4 } Simetria & Bulk & $\begin{array}{c}\text { Unbuckled } \\
C_{2 v}\end{array}$ & $\begin{array}{c}\text { Unbuckled } \\
C_{2 v}\end{array}$ \\
\hline$D(1-1)$ & $2,45-2,54$ & 2,290 & 2,308 \\
$D(1-2)$ & 2,353 & 2,371 & 2,368 \\
$D(2-3)$ & 2,353 & 2,385 & 2,386 \\
$D(3-4)$ & 2,353 & 2,399 & 2,400 \\
$H(1-2)$ & 1,360 & 1,142 & 1,127 \\
$H(2-3)$ & 1,360 & 1,565 & 1,565 \\
$H(3-4)$ & 1,360 & 1,270 & 1,266 \\
\hline
\end{tabular}

Para o cálculo CAS(4,3) selecionamos os orbitais para o espaço ativo de maneira semelhante ao feito com a base $6-31 G^{*}$. A função de onda da estrutura otimizada é aproximadamente:

$$
|\Psi>\sim 0,911| \Psi_{1}>-0,412 \mid \Psi_{2}>
$$

onde $\left|\Psi_{1}\right\rangle$ corresponde à configuração Hartree-Fock $\left(8 a_{1}\right)^{2}\left(9 a_{1}\right)^{2}\left(6 b_{2}\right)^{0}$ e $\left|\Psi_{2}\right\rangle$ corresponde à $\left(8 a_{1}\right)^{2}\left(9 a_{1}\right)^{0}\left(6 b_{2}\right)^{2}$. O orbital $9 a_{1}$ corresponde nesse caso ao HOMO e o $6 \mathrm{~b}_{2}$ ao LUMO. Com relação à ocupação orbital, temos os seguintes valores:

\begin{tabular}{cccc}
\hline orbital & $8 a_{1}$ & $9 a_{1}$ & $6 b_{2}$ \\
\hline ocupação & 2,000 & 1,666 & 0,339 \\
\hline
\end{tabular}

A função de onda do $\operatorname{CAS}(4,5)$ é:

$$
|\Psi>\sim 0,922| \Psi_{1}>-0,364\left|\Psi_{2}>+0,088\right| \Psi_{3}>-0,075 \mid \Psi_{4}>
$$

sendo as configuraçōes eletrônicas acima semelhantes às obtidas com a base 6-31G*. 
A ocupação orbital passou a ser:

\begin{tabular}{cccccc}
\hline orbital & $8 a_{1}$ & $9 a_{1}$ & $6 b_{2}$ & $7 b_{2}$ & $10 a_{1}$ \\
\hline ocupação & 1,970 & 1,720 & 0,278 & 0,020 & 0,001 \\
\hline
\end{tabular}

Os resultados obtidos com a base CEP-31G* mostram muita semelhança com os obtidos com a base 6-31G*, tanto em relação aos parâmetros geométricos quanto à descrição da estrutura eletrônica. As funçōes de onda e as ocupaçōes dos orbitais apresentam valores muito próximos, indicando que essa base fornece também parâmetros corretos e que 0 uso dela nos aglomerados maiores deve ser bastante aceitável. Com relação às distâncias internucleares, observamos um ligeiro aumento ao passarmos de 6-31G* para CEP-31G*, sendo esse aumento da ordem de 0,1 $\AA$. Essa pequena diferença permite que tenhamos uma maior confiança na utilização dessa base para os estudos posteriores nos aglomerados maicres.

O primeiro trabalho utilizando uma metodologia multiconfiguracional para $\circ$ estudo da superfície $\mathrm{Si}(100)$ foi realizado em 1982 por Redondo e Goddard III. ${ }^{40}$ Eles utilizaram o aglomerado $\mathrm{Si}_{9} \mathrm{H}_{12}$ e a metodologia $G V B$, com o uso de pseudopotencial nos átomos. Com a metodologia $\mathrm{HF}$ e a adoçāo de vários vínculos no processo de otimização eles obtiveram uma estrutura assimétrica, que fói atribuída à ausência de inclusão de efeitos de correlação. Para resolver isso eles utilizaram a metodologia GVB, que levou à uma estrutura simétrica com uma distância entre os silícios dímeros igual a $2,47 \AA$.

Jing e Whitten ${ }^{41}$ utilizaram os aglomerados de fórmula $\mathrm{Si}_{7} \mathrm{H}_{8}, \mathrm{Si}_{8} \mathrm{H}_{12}$ e $\mathrm{Si}_{12} \mathrm{H}_{20}$ e adotaram vínculos durnte o processo de otimização geométrica. Eles adotaram o aglomerado $\mathrm{Si}_{12} \mathrm{H}_{20}$ e a metodologia interaçāo de configuraçōes, sendo duas as configuraçōes de referência, uma correspondendo à configuração Hartree-Fock e a outra obtida a partir da excitaçāo dos elétrons do HOMO para o LUMO. A partir dessas configurações realizaram uma expansão $\mathrm{Cl}$, mas não apresentaram detalhes relativos a esse cálculo. Importante mencionar que as duas configuraçōes adotadas por eles como referências correspondem às mais importantes, como foi observado também a partir dos nossos resultados. A distância entre os silícios dímeros otimizada obtida por eles foi de 
2,40 $\AA$, enquanto que a energia de reconstrução foi de 1,98 eV. Com a mesma metodologia $\mathrm{Cl}$, eles procuraram uma estrutura buckled e obtiveram uma ligeiramente menos estável que a simétrica, apenas $0,02 \mathrm{eV}$, com a distância entre os silícios dímeros igual a $2,45 \AA$.

Um trabalho mais consistente acerca do problema da estrutura mutideterminantal da superfície de silício foi realizado por Paulus. ${ }^{42}$ Ela estudou uma série de aglomerados, que variavam do $\mathrm{Si}_{9} \mathrm{H}_{12}$ ao $\mathrm{Si}_{32} \mathrm{H}_{28}$, sendo que durante o processo de otimizaçāo dessas estruturas as distâncias entre os silícios internos e entre os silícios e hidrogênios foram mantidas constantes, ou seja, apenas os silícios dímeros e os da primeira camada interna estavam sem vínculos. A base atômica adotada para a maioria dos cálculos foi a valência dupla-zeta com pseudopotencial e funções de polarização nos silícios e base mínima nos hidrogênios. Os resultados dos cálculos MCSCF indicaram que existem pelo menos 10 configuraçōes com coeficientes maiores que 0,1 , mostrando claramente a natureza multideterminantal da superfície. Para a escolha dos orbitais a serem utilizados no cálculo MCSCF, ele partiu dos orbitais tripletos obtidos de um cálculo HF. Com isso, obteve uma ocupaçāo dos orbitais semelhante à obtida por nós, ou seja, o orbital HOMO com ocupaçāo igual a 1,63 e o LUMO com 0,37, mostrando que a estrutura eletrônica com camada fechada não é adequada para a correta representação da superfície. Para o aglomerado $\mathrm{Si}_{9} \mathrm{H}_{12}$, o cálculo MCSCF forneceu uma distâncía entre os silícios dímeros de $2,41 \AA$ e energia de reconstrução de $1,17 \mathrm{eV}$. Ela realizou a busca de uma estrutura assimétrica, mantendo fixa a distância entre os silícios dímeros e variando o ângulo destes com o restante do aglomerado. $\bigcirc$ resultado mostrou que a estrutura simétrica corresponde à forma mais estável, levando a concluir que a forma unbuckled é a preferida, e que os resultados de cálculos DFT, que mostram a preferência pela buckled, sāo devidos a uma superestimaçāo da contribuiçāo eletrônica da forma distorcida, e que tal fato não corresponde à forma correta da estrutura eletrônica. Ela realizou uma diminuição dos vínculos para verificar se tal fato faz com que a estrutura distorcida tornese a mais estável, mas observou que o relaxamento da estrutura nāo foi é responsável por uma eventual existência de uma forma buckled. No nosso trabalho, não utilizamos qualquer vínculo durante a otimização e obtivemos os mesmos resultados que Paulus, ou seja, aparentemente a causa da existência de uma forma distorcida não está relacionada 
com o relaxamento dos átomos do interior do aglomerado (bulk), apesar do sistema $\mathrm{Si}_{9} \mathrm{H}_{12}$ não possuir muitas camadas internas, o que dificulta a extrapolação desse resultado para sistemas maiores.

Schoemaker e Burggraf ${ }^{43}$ realizaram cálculos HF, GVB e TCSCF (cálculo SCF com duas configuraçōes) para vários aglomerados, utilizando as bases $6-31 \mathrm{G}^{*}$ e pseudopotenciais. Para o cálculo GVB eles selecionaram um par de orbitais ligantes e antiligantes para cada ligaçāo entre os silícios dímeros. Desse modo, eles obtiveram para o aglomerado $\mathrm{Si}_{9} \mathrm{H}_{12}$ e a base 6-31G* uma distância entre os silícios dímeros de 2,280 Å. No processo de otimização eles não adotaram qualquer forma de vínculo, do mesmo modo como realizado por nós. A distância final de 2,280 $\AA$ é muito próxima da obtida por nós, que foi de $2,276 \AA$ para o cálculo CAS(4,3), e esses valores são bem menores que os obtidos nos trabalhos de Redondo e Goddard III $(2,47 \AA$ - GVB), Jing e Whitten $(2,45 \AA-C)$ e Paulus $(2,41 \AA$ - MCSCF $)$ e, aparentemente, essa diferença é devida às diferentes formas de vínculos na geometria adotados nas otimizações. A presença de vínculos limita a movimentação dos átomos impedindo que ocorram relaxamentos que levam a uma maior aproximação entre os silícios dímeros.

Os resultados obtidos com a inclusão de efeitos de correlação eletrônica mostram claramente a preferência pela forma simétrica. Excetuando os resultades DFT, todos os cálculos mostram a não preferência pela estrutura buckled. Segundo Schoemaker, a forma distorcida observada experimentalmente é devida à excitação de um modo vibracional da estrutura simétrica, e esse processo é muito favorecido pois a energia necessária para que ocorra a excitação é muito pequena, indicando a facilidade de se observar esse modo experimentalmente. 


\section{II.5 O SISTEMA $\mathrm{Si}_{15} \mathrm{H}_{16}$}

\section{Resultados HF-SCF}

$\mathrm{O}$ aglomerado de fórmula $\mathrm{Si}_{15} \mathrm{H}_{16}$ permite a simulaçāo de dois dímeros vizinhos, sendo, portanto, de interesse para se poder estudar a eventual influência e interação entre esses dímeros tanto nas reações com substâncias presentes em fase gasosa como nos fenômenos que ocorrem tipicamente na superfície, como migração dos átomos, rearranjos, etc. Na Figura 13, temos a representação desse aglomerado, juntamente com a numeração dos átomos de silício, sendo essa numeração utilizada nas tabelas contendo os parâmetros geométricos obtidos com as várias metodologias. Nessas tabelas, $\mathrm{H}(i-i)$ e $D(i-i)$ possuem o mesmo significado ciracir. no caso do $\mathrm{Si}_{9} \mathrm{H}_{12}$, enquanto que $h(k-i)$ e d $(k-1)$ correspondem à distância entre as camadas onde se encontram os átomos $k \mathrm{e} / \mathrm{e}$ a distância entre esses mesmos átomos, respectivamente.

Com esse aglomerado podemos calcular a estabilidade tanto da estrutura simétrica como da assimétrica, que pode nesse caso apresentar duas formas, uma com os silícios dímeros deslocados de maneira equivalente e outra com os átomos deslocados de maneira alternada. No primeiro caso, temos a representação da estrutura assimétrica $(2 \times 1)$, enquanto que no segundo temos as possibilidades $(2 \times 2)$ e $(4 \times 2)$, sendo que a diferença entre ambos depende se os átomos da coluna vizinha de dímeros encontram-se deslocados na mesma direção ou oposta, respectivamente.

Nas Tabelas 13 a 17 temos os resultados obtidos com a metodologia HartreeFock e diversas bases atômicas para os três casos citados acima. Para o caso da estrutura simétrica com o uso de orbitais restritos, temos que a mudança de 3-21G para 6-31G acarretou em pequenas alteraçōes, sendo que dentre estas, as maiores foram com os parâmetros relacionados com os silícios internos localizados entre os dímeros (átomos 3, 4 e 5). Os demais variaram de maneira semelhante ao observado no caso do $\mathrm{Si}_{9} \mathrm{H}_{12}$. $\mathrm{Na}$ mudança de $6-31 \mathrm{G}$ para $6-31 \mathrm{G}^{* *}$ temos que todos os parâmetros diminuíram de 
maneira semelhante ao $\mathrm{Si}_{9} \mathrm{H}_{12}$. O valor da distância entre os silícios dímeros com a base $6-31 G^{*}(2,181 \AA)$ é praticamente idêntico ao verificado no aglomerado menor $(2,185 \AA)$, como seria de se esperar pelo uso de orbitais restritos, mas as demais distâncias são ligeiramente maiores, de modo que a estrutura resultante é 0,124 $\AA$ mais "alta" que o $\mathrm{Si}_{9} \mathrm{H}_{12}$.

Tabela 13. Parâmetros geométricos (em $\AA$ ) obtidos com orbitais restritos e a metodologia HartreeFock para o aglomerado singleto simétrico $\mathrm{Si}_{15} \mathrm{H}_{16}$.

\begin{tabular}{ccccccc}
\hline & & & $3-21 G$ & $6-31 G$ & $6-31 G^{* *}$ & 6-31G** \\
\cline { 3 - 7 } & & Bulk & Unbuckled & Unbuckled & Unbuckled & Unbuckled \\
& & Simetria & $C_{2 v}$ & $C_{2 v}$ & $C_{2 v}$ & $C_{2 v}$ \\
\hline$D(1-1)$ & $d(1-1)$ & $2,45-2,54$ & 2,197 & 2,209 & 2,181 & 2,181 \\
$D(1-2)$ & $d(1-7)$ & 2,353 & 2,380 & 2,381 & 2,352 & 2,352 \\
& $d(1-3)$ & & 2,306 & 2,370 & 2,344 & 2,344 \\
$D(2-3)$ & $d(7-8)$ & 2,353 & 2,418 & 2,417 & 2,382 & 2,382 \\
& $d(3-4)$ & & 2,444 & 2,459 & 2,407 & 2,407 \\
$D(3-4)$ & $d(8-6)$ & 2,353 & 2,419 & 2,422 & 2,395 & 2,395 \\
& $d(4-6)$ & & 2,410 & 2,422 & 2,395 & 2,395 \\
$H(1-2)$ & $h(1-7)$ & 1,360 & 1,151 & 1,129 & 1,086 & 1,086 \\
& $h(1-3)$ & & 1,029 & 1,002 & 1,006 & 1,006 \\
$H(2-3)$ & $h(7-8)$ & 1,360 & 1,549 & 1,563 & 1,555 & 1,555 \\
& $h(3-4)$ & & 1,698 & 1,726 & 1,686 & 1,687 \\
$H(3-4)$ & $h(8-6)$ & 1,360 & 1,309 & 1,314 & 1,312 & 1,312 \\
& $h(4-6)$ & & 1,212 & 1,279 & 1,261 & 1,260 \\
\hline
\end{tabular}

Diferentemente do aglomerado $\mathrm{Si}_{9} \mathrm{H}_{12}$, obtém-se uma estrutura assimétrica mesmo em nível Hartree-Fock, o que mostra que a interação entre os dímeros favorece a distorção e a conseqüente separação de cargas entre os silícios dímeros. A observação das cargas entre esses silícios, de acordo com a definição de Mulliken, para as estruturas distorcidas mostra claramente que o silício mais deslocado apresenta uma carga negativa, enquanto que o outro silício dímero apresenta uma positiva. Para a estrutura assimétrica com os dímeros alternados, a mudança de 3-21G para 6-31G fez com que a distância entre os silíciọs dímeros e as demais sofressem também uma pequena variação. Os valores de $h(k-l)$ que sofreram as maiores alteraçōes, no caso, diminuiçōes, são os 
relativos ao silício mais deslocado (átomo 1), e essa mesma tendência de diminuição também foi observada com a adição de funções de polarização. Nesse caso, os valores mais internos de $h(k-1)$ praticamente não se alteraram. Com relação às distâncias entre os átomos de silício, todas sofreram uma razoável diminuição, da ordem de $0,03 \AA$, exceto com as ligaçōes relacionadas ao átomo 1, que diminuíram bem mais, inclusive se comparadas com o observado no caso simétrico. Do mesmo modo que para $\circ \mathrm{Si}_{9} \mathrm{H}_{12}, \mathrm{a}$ mudança de $6-31 G^{* *}$ para $6-31 G^{*}$ fez com que não houvesse mudança nos parâmetros geométricos. A maior diferença entre essa estrutura e a simétrica reside na distância entre os silícios dímeros, pois o caso buckled apresenta um valor de 2,263 $\AA$, bem maior que o $2,181 \AA ̊$ do caso simétrico. Esse valor de 2,263 $\AA$ é da ordem de uma ligaçāo dupla $(2,25 \AA)$.

Tabela 14. Parâmetros geométricos (em Å) obiidos com orbitais restritos e a metólólogia HartireeFock para o aglomerado $\mathrm{Si}_{15} \mathrm{H}_{16}$ singleto assimétrico com os silícios dímeros alternados.

\begin{tabular}{|c|c|c|c|c|c|c|}
\hline & & & $3.21 G$ & $6.31 G$ & $6-31 G^{* *}$ & $6-31 G^{*}$ \\
\hline & & Bulk & Buckled & Buckled & Buckled & Buckled \\
\hline & & Simetria & $C_{2 v}$ & $C_{2 v}$ & $C_{2 v}$ & $C_{2 v}$ \\
\hline$D(1-1)$ & $d(1-2)$ & $2,45-2,54$ & 2,363 & 2,346 & 2,263 & 2,263 \\
\hline \multirow[t]{4}{*}{$D(1-2)$} & $d(1-7)$ & 2,353 & 2,478 & 2,458 & 2,393 & 2,394 \\
\hline & $d(1-3)$ & & 2,459 & 2,447 & 2,379 & 2,380 \\
\hline & $d(2-9)$ & & 2,386 & 2,385 & 2,355 & 2,355 \\
\hline & $d(2-5)$ & & 2,363 & 2,370 & 2,342 & 2,342 \\
\hline \multirow[t]{3}{*}{$D(2-3)$} & $d(7-8)$ & 2,353 & 2,409 & 2,406 & 2,375 & 2,375 \\
\hline & $d(3-4)$ & & 2,450 & 2,462 & 2,416 & 2,417 \\
\hline & $d(9-8)$ & & 2,415 & 2,416 & 2,381 & 2,381 \\
\hline \multirow[t]{2}{*}{$D(3-4)$} & $d(8-6)$ & 2,353 & 2,404 & 2,410 & 2,386 & 2,386 \\
\hline & $d(4-6)$ & & 2,396 & 2,409 & 2,385 & 2,385 \\
\hline \multirow[t]{4}{*}{$H(1-2)$} & $h(1-7)$ & 1,360 & 1,658 & 1,577 & 1,476 & 1,478 \\
\hline & $h(1-3)$ & & 1,476 & 1,413 & 1,355 & 1,356 \\
\hline & $h(2-9)$ & & 1.013 & 1,007 & 0,959 & 0,959 \\
\hline & $h(2-5)$ & & 0,844 & 0,842 & 0,833 & 0,833 \\
\hline \multirow[t]{3}{*}{$H(2-3)$} & $h(7-8)$ & 1,360 & 1,538 & 1,556 & 1,556 & 1,557 \\
\hline & $h(3-4)$ & & 1,697 & 1,728 & 1,711 & 1,712 \\
\hline & $h(9.8)$ & & 1,550 & 1,555 & 1,553 & 1,552 \\
\hline \multirow[t]{2}{*}{$H(3-4)$} & $h(8-6)$ & 1,360 & 1,322 & 1,335 & 1,333 & 1,333 \\
\hline & $h(4-6)$ & & 1,345 & 1,327 & 1,300 & 1,300 \\
\hline
\end{tabular}


No caso da estrutura assimétrica com os dímeros paralelos, cujos parâmetros geométricos podemos ver na Tabela 17, temos que o aglomerado otimizado com a base 6-31G* é 0,264 $\AA$ mais "achatado" que o correspondente com os dímeros alternados. Além disso, o grau de distorção dos silícios dímeros é menor no caso paralelo, onde a diferença na altura entre eles é de 0,235 $\AA$, enquanto que nos dímeros alternados é de $0,523 \AA$. Com relação d̀ distância entre os silícios dímeros, temos o valor de $2,196 \AA$,

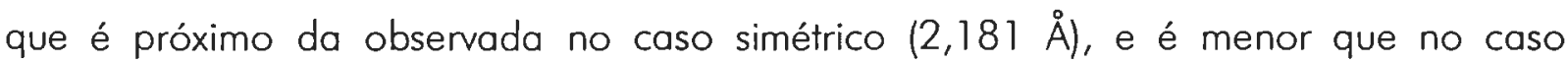
assimétrico alternado, sendo a diferença de $0,067 \AA$.

Energeticamente, temos que a estrutura com os dímeros alternados é o mais estável, mas a diferença de energia entre essas estruturas é pequena, de aproximadamente $1,84 \mathrm{kcal} / \mathrm{mol}$.dímero em relaçāo à estrutura com os dímeros paralelos e de 1,88 kcal/mol.dímero em relação ao não distorcido. Essas diferenças são muito pequenas para podermos assegurar uma preferêricia por uma estrutura ou outra, pois essa ordem pode alterar com a mudança de base e de metodologia.

Com relação à energia de reconstrução, temos os valores de 1,80, 1,88 e 1,81 eV/dímero, para as estruturas simétricas, buckled alternado e buckled paralelo, respectivamente. Esses valores são próximos do obtido para o aglomerado $\mathrm{Si}_{q} \mathrm{H}_{12}$, que é de 1,83 eV, mostrando que o processo de reconstrução-aparentemente é pouco dependente de uma eventual interação entre os silícios relacionados com o processo de reconstrução.

Nas Tabelas 15 a 17, temos os resultados Hartree-Fock com a base CEP-31 G*. A estrutura com os silícios dímeros distorcidos paralelos é também mais "achatada" em cerca de 0,104 $\AA$ que a alternada. Comparado com o resultado obtido com a base 631G*, a distância entre os silícios dímeros apresentou pequena diferença no caso da estrutura simétrica, mas no caso das estruturas alternadas essas diferenças foram bem maiores. Com a base CEP-31G*, a estrutura assimétrica com dímeros alternados mostrou uma distância de $2,287 \AA$, que é $0,024 \AA$ maior que com a base $6-31 G^{*}$, enquanto que no caso com dímeros paralelos a distância obtida $(2,241 \AA)$ é 0,045 $\AA$ maior. Com relaçāo às diferenças de energia, os aglomerados apresentaram a mesma ordem de estabilidade das estruturas verificadas com a base 6-31 $\mathrm{G}^{*}$, mas quantitativamente 
observamos uma maior diferença de energia entre elas, pois a estrutura com dímeros alternados é 2,54 kcal/mol.dímero mais estável que a com os dímeros paralelos, além de ser 3,27 kcal/mol.dímero mais estável que a reconstruída simétrica.

Tabela 15. Parâmetros geométricos (em $\AA$ ) obtidos com orbitais restritos, a metodologia HartreeFock e a base CEP-31G* para o aglomerado singleło simétrico $\mathrm{Si}_{15} \mathrm{H}_{16}$.

\begin{tabular}{|c|c|c|c|}
\hline & & \multirow[b]{2}{*}{ Bulk } & CEP-31G* \\
\hline & & & Unbuckled \\
\hline & & Simetrio & $C_{2 v}$ \\
\hline$D(1-1)$ & $d(1-1)$ & $2,45-2,54$ & 2,191 \\
\hline \multirow[t]{2}{*}{$D(1-2)$} & $d(1-7)$ & 2,353 & 2,365 \\
\hline & $d(1-3)$ & & 2,357 \\
\hline \multirow[t]{2}{*}{$D(2-3)$} & $d(7-8)$ & 2,353 & 2,395 \\
\hline & $d(3-4)$ & & 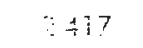 \\
\hline \multirow[t]{2}{*}{$D(3-4)$} & $d(8-6)$ & $2,353^{\circ}$ & $\therefore$ \\
\hline & $d(4-6)$ & & 470 \\
\hline \multirow[t]{2}{*}{$H(1-2)$} & $h(1-7)$ & 1,360 & $:, 097$ \\
\hline & $h(1-3)$ & & 1,016 \\
\hline \multirow[t]{2}{*}{$H(2-3)$} & $h(7-8)$ & 1,360 & 1,571 \\
\hline & $h(3-4)$ & & 1,691 \\
\hline \multirow[t]{2}{*}{$H(3-4)$} & $h(8-6)$ & 1,360 & 1,320 \\
\hline & $h(4-6)$ & & 1,281 \\
\hline
\end{tabular}


Tabela 16. Parâmetros geométricos (em $\AA$ ) obtidos com orbitais restritos, a metodologia HartreeFock e a base CEP-31G* para o aglomerado $\mathrm{Si}_{15} \mathrm{H}_{16}$ singleto assimétrico com os silícios dímeros alternados.

\begin{tabular}{cccc}
\hline & & & CEP-31G* \\
\cline { 3 - 4 } & & $\begin{array}{c}\text { Bulk } \\
\text { Simetrio }\end{array}$ & $\begin{array}{c}\text { Buckled } \\
C_{2 v}\end{array}$ \\
\hline$D(1-1)$ & $d(1-2)$ & $2,45-2,54$ & 2,287 \\
$D(1-2)$ & $d(1-7)$ & 2,353 & 2,409 \\
& $d(1-3)$ & & 2,398 \\
& $d(2-9)$ & & 2,373 \\
& $d(2-5)$ & & 2,357 \\
$D(2-3)$ & $d(7-8)$ & 2,353 & 2,389 \\
& $d(3-4)$ & & 2,427 \\
& $d(9-8)$ & & 2,391 \\
$D(3-4)$ & $d(8-6)$ & 2,353 & 2,396 \\
& $d(4-6)$ & & 2,399 \\
$H(1-2)$ & $h(1-7)$ & 1,350 & 1,523 \\
& $h(1-3)$ & & 1,399 \\
& $h(2-9)$ & & 0,975 \\
& $h(2-5)$ & & 0,082 \\
$H(2-3)$ & $h(7-8)$ & 1,360 & 0,731 \\
& $h(3-4)$ & & 1,718 \\
& $h(9-8)$ & & 1,554 \\
$H(3-4)$ & $h(8-6)$ & 1,360 & 1,338 \\
& $h(4-6)$ & & 1,327 \\
\hline
\end{tabular}


Tabela 17. Parâmetros geométricos (em $\AA$ ) obtidos com orbitais restritos, a metodologia HartreeFock e as bases CEP-31G* e 6-31 $\mathrm{G}^{*}$ para o aglomerado $\mathrm{Si}_{15} \mathrm{H}_{16}$ singleto assimétrico com os silícios dímeros paralelos.

\begin{tabular}{ccccc}
\hline & & & CEP-31G* & 6-31G* \\
\cline { 3 - 5 } & & Bulk & Buckled & Buckled \\
& & Simetria & $C_{s}$ & $C_{s}$ \\
\hline$D(1-1)$ & $d(1-2)$ & $2,45-2,54$ & 2,241 & 2,196 \\
$D(1-2)$ & $d(1-7)$ & 2,353 & 2,399 & 2,364 \\
& $d(1-3)$ & & 2,398 & 2,359 \\
& $d(2-9)$ & & 2,369 & 2,349 \\
& $d(2-5)$ & & 2,347 & 2,336 \\
$D(2-3)$ & $d(7-8)$ & 2,353 & 2,391 & 2,378 \\
& $d(3-4)$ & & 2,415 & 2,402 \\
& $d(9-8)$ & & 2,394 & 2,383 \\
& $d(5-4)$ & & 2,435 & 2,417 \\
$D(3-4)$ & $d(8-6)$ & 2,353 & 2,402 & 2,393 \\
& $d(4-6)$ & & 2,404 & $2,39.3$ \\
$H(1-2)$ & $h(1-7)$ & 1,360 & 1,434 & $i, 240$ \\
& $h(1-3)$ & & 1,264 & 1,131 \\
& $h(2-9)$ & & 0,985 & 0,990 \\
& $h(2-5)$ & & 0,792 & 0,914 \\
$H(2-3)$ & $h(7-8)$ & 1,360 & 1,582 & 1,545 \\
& $h(3-4)$ & & 1,759 & 1,703 \\
& $h(9-8)$ & & 1,558 & 1,566 \\
& $h(5-4)$ & & 1,670 & 1,685 \\
& $h(8-6)$ & 1,360 & 1,323 & 1,313 \\
& $h(4-6)$ & & 1,315 & 1,270 \\
\hline & & & &
\end{tabular}

Alguns trabalhos foram realizados com a finalidade de obter propriedades do aglomerado $\mathrm{Si}_{15} \mathrm{H}_{16}$. Yang et al. ${ }^{25}$ estudaram esse sistema, do mesmo modo que no $\mathrm{Si}_{9} \mathrm{H}_{22}$, e o resultado $\mathrm{HF}$ indicou a existência das estruturas simétrica e buckled alternada, não sendo encontrada a buckled paralela. Com a base 6-31G a estrułura alternada é $5,75 \mathrm{kcal} / \mathrm{mol}$.dímero $(0,25 \mathrm{eV} /$ dímero) mais estável que a simétrica, e esse valor é bem maior que a obtida por nós com a base 6-31 $\mathrm{G}^{*}(1,88 \mathrm{kcal} / \mathrm{mol}$.dímero). A distância entre os silícios dímeros obtida foi de 2,239 $\AA$ para a estrutura simétrica e de $2,384 \AA$ para a assimétrica alternada. Os valores obtidos por nós com essa base, 6-31G, foram $2,209 \AA$ e $2,346 \AA$, para o caso simétrico e para o buckled alternado, respectivamente. Os valores menores obtidos por nós são devidos aos vínculos adotados por Yang et al. 
Markovitz et al. ${ }^{27}$ utilizaram o aglomerado $\mathrm{Si}_{13} \mathrm{H}_{16}$ para a representação de dois dímeros. Com esse sistema eles obtiveram com a metodologia Hartree-Fock e com o uso de orbitais restritos que a estrutura buckled é a mais estável, sendo a distância entre os

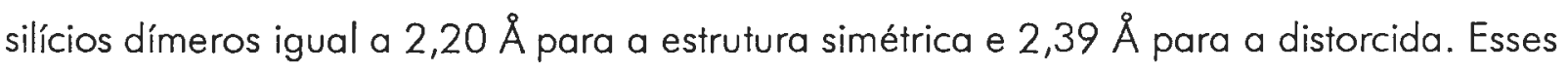
valores são mais próximos dos obtidos por nós, apesar da diferença da base atômica e dos vínculos adotados por eles, onde apenas os silícios dímeros e os da primeira camada interna foram otimizados.

Portanto, com a metodologia Hartree-Fock obtemos uma estrutura distorcida como a forma mais estável para o sistema $\mathrm{Si}_{15} \mathrm{H}_{16}$. Tal fato não foi observado com o sistema $\mathrm{Si}_{9} \mathrm{H}_{12}$, onde a forma buckled nem mesmo chegou a ser obtida. Se tal diferença ocorre, acreditamos que seja porque com essa metodologia existe uma grande interação entre os silícios dímeros, fazendo com que ocorra uma distorção e, com isso, a separação entre as cargas desses silícios. Essa interação entre os átomos címieros com cargas é preferida à estrutura simétrica.

\section{Resultados Funcional da Densidade}

Realizamos a otimização da estrutura simétrica e da assimétrica com os dímeros alternados utilizando a Teoria do Funcional da Densidade e o funcional híbrido B3LYP. Os resultados estão apresentados nas Tabelas 18 e 19. Para a estrutura simétrica, a mudança de base de 3-21G para 6-31G praticamente não mudou os parâmetros geométricos e as variações observadas foram semelhantes às obtidas com o método Hartree-Fock. Com a mudança da base 6-31G para 6-31G* houve uma diminuiçāo de todos os parâmetros. As variações foram praticamente semelhantes às observadas no Hartree-Fock, mas as diminuições da distância entre os silícios dímeros e o valor de H(12) foram ligeiramente maiores no caso DFT. A distância entre os silícios dímeros, 2,218 $\AA$, é ligeiramente menor que a observada no aglomerado $\mathrm{Si}_{9} \mathrm{H}_{12}$, mas ainda cerca de $0,036 \AA$ maior que o valor obtido com o Hartree-Fock com o $\mathrm{Si}_{9} \mathrm{H}_{12}$ simétrico. De modo geral, os parâmetros geométricos são próximos aos obtidos com o $\mathrm{Si}_{9} \mathrm{H}_{12}$, mas, de modo semethante ao verificado com a metodologia Hartree-Fock, o aglomerado $\mathrm{Si}_{15} \mathrm{H}_{16}$ é mais 
"alto" que o $\mathrm{Si}_{9} \mathrm{H}_{12}$ em cerca de $0,131 \AA$.

No caso da estrutura buckled com os dímeros alternados, temos que as distâncias entre os silícios variaram pouco com a mudança de base de 3-21G para 6-31G. 0 mesmo não aconteceu com as distâncias entre camadas, cujos valores sofreram uma diminuição semelhante ao observado com o Hartree-Fock, mas em valores um pouco maiores, como no caso dos parâmetros relativos ao átomo 1. Com a inclusāo de funções de polarização, temos que as distâncias entre os átomos de silício sofreram uma diminuição. Os silícios mais internos variaram de modo semelhante ao visto com o Hartree-Fock, mas diferentemente do observado até então, as distâncias relacionadas com os silícios dímeros diminuíram menos, como no caso do valor de $D(1-1)$, que variou em cerca de $0,02 \AA$. O valor final de $D(1-1)(2,266 \AA)$ é praticamente idêntico ao obtido com Hartree-Fock. Para as separações entre as camadas, observamos que houve um maior deslocamento do átomo $I$, e com isso os valores de $h(T-7)$ e $h(1-3)$ apresentaram um aumento, sendo esse comportamento distinto do obtido até então com qualquer aglomerado e metodologia.

Energeticamente, a estrutura buckled é apenas 1,30 kcal/mol.dímero mais estável que a simétrica. Esse valor é bem menor que o obtido com a metodologia Hartree-Fock $(1,88 \mathrm{kcal} / \mathrm{mol}$.dímero $)$ mas é muito maior que a observada no aglomerado $\mathrm{Si}_{9} \mathrm{H}_{12} \mathrm{com} \mathrm{a}$ Teoria do Funcional da Densidade $(0,081 \mathrm{kcal} / \mathrm{mol}$.dímero $)$.

Yang et a/. ${ }^{25}$ utilizaram o funcional B3LYP para o estudo do $\mathrm{Si}_{15} \mathrm{H}_{16}$. Eles obtiveram que a estrutura com os dímeros alternados é $3,22 \mathrm{kcal} / \mathrm{mol}$.dímero mais estável que o simétrico. Esse valor foi obtido com a base 6-31G, o que explica a diferença do dado obtido por nós, 1,30 kcal/mol.dímero, que foi com a base 6-31G*. Com relação à distância entre os silícios dímeros, Yang et al. obtiveram 2,283 $\AA$ e 2,329 $\AA$ para as estruturas simétricas e buckled alternados, respectivamente. Para essas mesmas estruturas, obtivemos os valores $2,249 \AA$ e 2,286 $\AA$, também com a base 6-31G. Interessante observar que os valores obtidos por Yang et al. são $0,034 \AA$ e $0,043 \AA$ maiores que os obtidos por nós, para os casos simétrico e alternados, e essa diferença de valores é maior que a verificada com o aglomerado $\mathrm{Si}_{9} \mathrm{H}_{12}$, onde a diferença considerando a estrutura simétrica foi de apenas $0,016 \AA$. Relembrando, apenas que com o aglomerado $\mathrm{Si}_{q} \mathrm{H}_{12}$ 
não obtivemos uma estrutura distorcida com a base 6-31G. Essa diferença observada com o aglomerado maior é um indicativo da influência que a adoção de vínculos pode causar, o que faz com que seja necessário tomar um certo cuidado no estudo de sistemas maiores, para que não ocorra um aumento no erro de certas propriedades, como os parâmetros geométricos. Resultado semelhante foi observado com a metodologia Hartree-Fock.

Tabela 18. Parâmetros geométricos (em $\AA$ ) obtidos com orbitais restritos e a metodologia do Funcional da Densidade com o funcional B3LYP para o aglomerado singleto simétrico $\mathrm{Si}_{15} \mathrm{H}_{16}$.

\begin{tabular}{ccccccc}
\hline & & & $3-21 G$ & $6-31 G$ & $6-31 G^{* *}$ & 6-31G* \\
\cline { 3 - 6 } & & Bulk & Unbuckled & Unbuckled & Unbuckled & Unbuckled \\
\hline$D(1-1)$ & & Simetria & $C_{2 v}$ & $C_{2 v}$ & $C_{2 v}$ & $C_{2 v}$ \\
\hline$D(1-2)$ & $d(1-1)$ & $2,45-2,54$ & 2,235 & 2,249 & 2,217 & 2,218 \\
& $d(1-7)$ & 2,353 & 2,377 & 2,385 & 2,350 & 2,349 \\
$D(2-3)$ & $d(1-3)$ & & 2,365 & 2,377 & 2,344 & 2,344 \\
& $d(7-8)$ & 2,353 & 2,406 & 2,414 & 2,378 & 2,378 \\
$D(3-4)$ & $d(3-4)$ & & 2,435 & 2,458 & 2,404 & 2,404 \\
& $d(8-6)$ & 2,353 & 2,401 & 2,414 & 2,386 & 2,386 \\
$H(1-2)$ & $d(4-6)$ & & 2,398 & 2,421 & 2,392 & 2,392 \\
& $h(1-7)$ & 1,360 & 1,197 & 1,174 & 1,123 & 1,123 \\
$H(2-3)$ & $h(1-3)$ & & 1,055 & 1,029 & 1,028 & 1,029 \\
& $h(7-8)$ & 1,360 & 1,551 & 1,570 & 1,560 & 1,560 \\
$H(3-4)$ & $h(3-4)$ & & 1,700 & 1,735 & 1,695 & 1,696 \\
& $h(8-6)$ & 1,360 & 1,293 & 1,307 & 1,305 & 1,305 \\
& $h(4-6)$ & & 1,286 & 1,287 & 1,264 & 1,264 \\
\hline
\end{tabular}


Tabela 19. Parâmetros geométricos (em $\AA$ ) obtidos com orbitais restritos e a metodologia do Funcional da Densidade com o funcional B3LYP para o aglomerado $\mathrm{Si}_{15} \mathrm{H}_{16}$ singleto assimétrico com os silícios dímeros alternados.

\begin{tabular}{|c|c|c|c|c|c|c|}
\hline & & & $3.21 G$ & $6-31 G$ & $6-31 G^{* *}$ & $6.31 G^{*}$ \\
\hline & & Bulk & Unbuckled & Unbuckled & Unbuckled & Unbuckled \\
\hline & & Simetria & $C_{2 v}$ & $C_{2 v}$ & $C_{2 v}$ & $C_{2 v}$ \\
\hline$D(1-1)$ & $d(1-2)$ & $2,45-2,54$ & 2,294 & 2,286 & 2,267 & 2,266 \\
\hline \multirow[t]{4}{*}{$D(1.2)$} & $d(1-7)$ & 2,353 & 2,434 & 2,422 & 2,390 & 2,389 \\
\hline & $d(1-3)$ & & 2,410 & 2,406 & 2,371 & 2,371 \\
\hline & $d(2-9)$ & & 2,371 & 2,379 & 2,350 & 2,350 \\
\hline & $d(2-5)$ & & 2,357 & 2,372 & 2,340 & 2,340 \\
\hline \multirow[t]{3}{*}{$D(2.3)$} & $d(7-8)$ & 2,353 & 2,401 & 2,408 & 2,371 & 2,371 \\
\hline & $d(3-4)$ & & 2,446 & 2,464 & 2,415 & 2,415 \\
\hline & $d(9-8)$ & & 2,408 & 2,416 & 2,376 & 2,376 \\
\hline \multirow[t]{2}{*}{$D(3.4)$} & $d(8-6)$ & 2,353 & 2,396 & 2,410 & 2,379 & 2,379 \\
\hline & $d(4-6)$ & & 2,394 & 2,418 & 2,385 & 2,385 \\
\hline \multirow[t]{4}{*}{$H(1-2)$} & $h(1-7)$ & 1,360 & 1,527 & 1,420 & 1,467 & 1,466 \\
\hline & $h(1-3)$ & & 1,341 & 1,252 & 1,324 & 1,324 \\
\hline & $h(2-9)$ & & 1,015 & 1,027 & 0,968 & 0,969 \\
\hline & $h(2-5)$ & & 0,852 & 0,872 & 0,818 & 0,820 \\
\hline \multirow[t]{3}{*}{$H(2-3)$} & $h(7-8)$ & 1,360 & 1,540 & 1,562 & 1,563 & 1,563 \\
\hline & $h(3-4)$ & & 1,712 & 1,742 & 1,716 & 1,717 \\
\hline & $h(9-8)$ & 4 & 1,563 & 1,575 & 1,556 & 1,556 \\
\hline \multirow[t]{2}{*}{$H(3-4)$} & $h(8-6)$ & 1,360 & 1,302 & 1,315 & 1,315 & 1,315 \\
\hline & $h(4-6)$ & & 1,315 & 1,305 & 1,304 & 1,303 \\
\hline
\end{tabular}

$\mathrm{O}$ aglomerado $\mathrm{Si}_{15} \mathrm{H}_{16}$ tem sido utilizado em alguns trabalhos como modelo para estudar a interação e incorporação de substâncias com a superfície de silício e para a observação da influência de dois dímeros, ${ }^{51,54}$ normalmente como uma extensão do estudo da reaçāo com o sistema de um único dímero, onde normalmente é utilizado o aglomerado $\mathrm{Si}_{9} \mathrm{H}_{12}$. 


\section{Resultados CASSCF}

Para a realização de um cálculo CASSCF na estrutura simétrica, conduzimos alguns testes iniciais para a escolha dos orbitais ativos. Primeiramente, fizemos um cálculo num único ponto sobre a geometria otimizada com HF/6-31G*. Utilizamos a base CEP-31G* e selecionamos sete orbitais a partir dos orbitais restritos do cálculo singleto Hartree-Fock. As configurações foram obtidas com excitações de dez elétrons CAS(10,7), segundo a notação adotada no programa Gaussian94. Dessa maneira, um total de 196 configurações de referência foram geradas, sendo que sete delas apresentam coeficientes maiores que 0,1 com a configuração Hartree-Fock apresentando um coeficiente de 0,877. A partir da análise das configuraçōes mais importantes e das ocupações dos orbitais, temos que pelo menos os dois orbitais mais internos do espaço ativo têm muita pouca participaçāo, mantendo-se sempre duplamente ocupados nas configuraçōes mais importantes. Com a eliminação desses dois orbitais do espaço ctivo, realizamos uma otimização geométrica sem a adoção de vínculos, com o CAS(6,5) e a base CEP-31G*. Os resultados obtidos estão na Tabela 20. Nela podemos ver que os valores de geometria são bem semelhantes ao observado no cálculo CAS $(4,3)$ realizado no aglomerado $\mathrm{Si}_{9} \mathrm{H}_{12}$. Inclusive a distância entre os silícios dímeros é idêntica. $\bigcirc$ valor final obtido de $2,291 \AA$ é o maior que observamos até o momento para estruturas simétricas. Interessante observar as conseqüências causadas pela inclusão de efeitos de correlação com a metodologia CASSCF, onde vemos que o valor para a distância $D(1-1)$ sofreu um aumento considerável, de cerca de $0,1 \AA$ se comparada com o cálculo Hartree-Fock. 
Tabela 20. Parâmetros geométricos (em $\AA$ ) obtidos com orbitais restritos, a metodologia CASSCF - CAS $(6,5)$ - e a base CEP-31 G* para o aglomerado singleto simétrico $\mathrm{Si}_{15} \mathrm{H}_{16}$.

\begin{tabular}{cccc}
\hline & & & CEP-31G* \\
\cline { 4 - 4 } & & Bulk & $\begin{array}{c}\text { Unbuckled } \\
C_{2 v}\end{array}$ \\
\hline$D(1-1)$ & $d(1-1)$ & $2,45-2,54$ & 2,291 \\
$D(1-2)$ & $d(1-7)$ & 2,353 & 2,373 \\
& $d(1-3)$ & & 2,367 \\
$D(2-3)$ & $d(7-8)$ & 2,353 & 2,387 \\
& $d(3-4)$ & & 2,406 \\
$D(3-4)$ & $d(8-6)$ & 2,353 & 2,400 \\
& $d(4-6)$ & & 2,398 \\
$H(1-2)$ & $h(1-7)$ & 1,360 & 1,212 \\
& $h(1-3)$ & & 1,116 \\
$H(2-3)$ & $h(7-8)$ & 1,360 & 1,557 \\
& $h(3-4)$ & & 1,679 \\
$H(3-4)$ & $h(8-6)$ & 1,360 & 1,329 \\
& $h(4-6)$ & & 1,302 \\
\hline
\end{tabular}

Realizamos o mesmo procedimento para a estrutura assimétrica com os silícios dímeros deslocados de forma alternada. A otimização do CAS(6,5) com a base CEP. 31G* acabou convergindo para uma forma simétrica, do mesmo modo como foi observado para o caso do $\mathrm{Si}_{9} \mathrm{H}_{12}$. Portanto, vemos que a adoção de uma metodologia multideterminantal, como o CASSCF, leva à preferência da forma unbuckled, sendo que esse resultado entra em conflito com os dados experimentais, que sugerem ser a forma buckled a mais estável. Essa diferença é mais acentuada se levarmos em conta que a estrutura eletrônica da superfície é claramente multideterminantal, sendo, portanto, corretamente descrita pela metodologia CASSCF. A razão dessa discrepância pode ser a limitação no tamanho do aglomerado, onde talvez sistemas maiores, com uma estrutura mais próxima de uma superfície real, possa influenciar no sentido de favorecer uma estrutura distorcida, ou a limitação pode estar no próprio cálculo CASSCF. Mas, nesse caso, começam a aparecer outras limitaçōes, pois o aumento do espaço ativo, para incluir orbitais que porventura são importantes e que foram deixados de fora, pode tornar - cálculo muito dispendioso, e, possivelmente, impraticável. Portanto, consideramos o estudo da superfície Si(100) como um assunto ainda em aberto, pois, apesar de cálculos 
como o do tipo Funcional da Densidade favorecer a forma distorcida, o uso de uma metodologia multideterminantal, que é mais adequada do ponto de vista teórico, leva a um resultado diferente.

Paulus $^{42}$ calculou a energia de reconstrução com a metodologia MCSCF e obteve o valor de 1,15 eV. Ela estudou a variação da energia de reconstrução com o uso de vários aglomerados e observou que essa propriedade varia muito pouco com essas mudanças, concluindo, portanto, que a interaçāo entre os dímeros é fraca em nível MCSCF. Do mesmo modo como obtido por nós, a estrutura simétrica é a mais estável, levando-o a concluir que a interação entre os dímeros nāo é suficiente para estabilizar a estrutura buckled em MCSCF. 


\subsection{CONCLUSÕES}

Nesse trabalho estudamos os aglomerados de fórmula $\mathrm{Si}_{9} \mathrm{H}_{12}$ e $\mathrm{Si}_{15} \mathrm{H}_{16}$, modelos esses usados para simular uma superfície $\mathrm{Si}(100)$ com um e dois dímeros, respectivamente. Procuramos observar os efeitos da metodologia e da base atômica sobre as propriedades desses sistemas.

Com relação ao aglomerado $\mathrm{Si}_{9} \mathrm{H}_{12}$, as metodologias, com exceção do Funcional da Densidade, levaram a uma preferência para uma estrutura singleto simétrica. Com o funcional B3LYP obtivemos uma forma buckled ligeiramente mais estável que a unbuckled, mas essa diferença de energia é muito pequena para permitir afirmar a preferência de uma ou de outra. A metodologia Hartree-Fock com o uso de orbitais restritos mostrou ser inadequada para a correta descriçāo da superfície, pois não permite a existência das dangling bonds. $O$ uso de orbitais não-restritos corrige essa deficiência, permitindo uma maior concentração eletrônica sobre cada silício dímero. A metodologia CASSCF mostrou ser adequada para o estudo desse sistema pois a descrição correta da superfície exige uma função de onda multideterminantal. Duas configurações são importantes: Hartree-Fock e a obtida com a excitação dos elétrons do HOMO para o LUMO.

sistema $\mathrm{Si}_{15} \mathrm{H}_{16}$ permitiu o estudo das formas simétrica, buckled alternada e paralela. Diferentemente do aglomerado $\mathrm{Si}_{9} \mathrm{H}_{12}$, obtém-se uma estrutura buckled com a metodologia Hartree-Fock; nesses caso, os resultados indicaram ser a estrutura com os dímeros alternados a forma mais estável, apesar da pequena diferença de energia com relaçāo às outras estruturas. Resultados semelhantes foram obtidos com a metodologia do Funcional da Densidade. A metodologia CASSCF, por sua vez, indicou ser a forma simétrica a mais estável, do mesmo modo que com o aglomerado $\mathrm{Si}_{9} \mathrm{H}_{12}$. Esse resultado nos faz questionar as limitaçōes dos aglomerados adotados e a possibilidade de uma restriçāo no cálculo CASSCF utilizado. 


\section{II.7 REFERÊNCIAS}

1. E. A. Wood, Crystals and Light: an Introduction to Optical Crystallography, Dover Publications, Inc., N. Y., 1977.

2. E. Wood, J. Appl. Phys. 35, 1306 (1983).

3. R. L. Park e H. H. Madden, Surf. Sci. 11, (1968).

4. R. E. Schlier e H. E. Farnsworth, J. Chem. Phys. 30, 917 (1959).

5. J. J. Lander e J. Morrison, J. Chem. Phys. 37, 729 (1962).

6. J. C. Fernandez, W. S. Ying, H. D. Shih, F. Jona, D. Jepsen e P. M. Marcus, J. Phys. C $14,: 55(1981)$.

7. W. S. Yang, F. Jona e P. M. Marcus, Solid State Commun. 43, 847 (1982).

8. B. W. Holland, C. B. Duke e A. Paton, Surf. Sci. 140, L269 (1984).

9. G. Jayaram, P. Xu e L.D. Marks, Lhys. Rev. Lett. 71, 3489 (1993).

10. R. Rossmann, H. L. Meyerheim, V. Jahns, J. Wever, W. Moritz, D. Wolf, D. Dornich e H. Schulz, Surf. Sci. 279, 199 (1992).

11. E. Fontes, J. R. Patel e F. Comin, Phys. Rev. Lett. 70, 2790 (1993).

12. C. A. Lucas, C. S. Dower, D. F. McMorrow, G. C. L. Wong, F. J. Lamelas e P. H. Fuoss, Phys. Rev. B 47, 10375 (1993).

13. M. J. Cardillo e W. R. Lambert, Surf. Sci. 168, 724 (1986).

14. W. R. Lambert, P. L. Trevor, M. J. Cardillo, A. Sakai e D. R. Hamann, Phys. Rev. B 35, 8055 (1987).

15. T. Tabata, T. Aruga e Y. Murata, Surf. Sci. 179, L63 (1987). 
16. R. A. Wolkow, Phys. Rev. Lett. 68, 2636 (1992).

17. N. Jedrecy, M. Sauvage-Simkim, R. Pinchaux, J. Massies, N. Greiser e V. H. Etgens, Surf. Sci. 230, 197 (1990).

18. R. Felici, I. K. Robinson, C. Otaviani, P. Inperatori, P. Eng e P. Perfetti, Surf. Sci. 375, 55 (1997).

19. E. L. Bullock, R. Gunnella, L. Patthey, T. Abukawa, S. Kono, C. R. Natoli e L. S. O. Johansson, Phys. Rev. Lett. 74, 2756 (1995).

20. R. J. Hamers, R. M. Tromp e J. E. Demuth, Phys. Rev. B 34, 5343 (1986).

21. R. Wiesendanger, D. Bürgler, G. Tarrach e H. -J. Güntherod, Surf. Sci. 232, 1 (1990).

22. R. Wiesendanger, D. Bürgler, G. Tarrach, H. -J. Güntherod, L. V. Shvets e J. M. D. Coey, Surf. Sci. 274, 93 (1992).

23. D. J. Chadi, Phys. Rev. Lett. 43, 43 (1979).

24. D. J. Chadi, J. Vac. Sci. Technol. 16, 1290 (1979).

25. C. Yang, S. Y. Lee e H. C. Kang, J. Chem. Phys. 107, 3295 (1997).

26. T. Hoshino, M. Hata, S. Oikawa e M. Tsuda, Phys. Rev. B54, 16 (1996).

27. A. Markovits, L. Favaro e C. Minot, J. Mol. Struct. (Theochem) 458171 (1999).

28. R. Konecny e D. J. Doren, J. Phys. Chem. B 101, 10983 (1997).

29. F. T. Bacalzo, D. G. Musaev e M. C. Lin, J. Phys. Chem. B 102, 2221 (1998).

30. A. R. Brown e D. J. Doren, J. Chem. Phys. 109, 2442 (1998).

31. R. Konecny e D. J. Doren, J. Am. Chem. Soc. 119, 11098 (1997). 
32. R. Konecny e D. J. Doren, J. Chem. Phys. 106, 2426 (1997).

33. K. Raghavachari, Y. J. Chabal e L. M. Struck, Chem. Phys. Lett. 252, 230 (1996).

34. S. Pai e D. Doren, J. Chem. Phys. 103, 1232 (1995).

35. B. Stefanov e K. Raghavachari, Surf. Sci. 389, L1 159 (1997).

36. M. K. Weldon, B. Stefanov, K. Raghavachari e Y. J. Chabal, Phys. Rev. Lett. 79, 2851 (1997).

37. W. Pan, T. Zhu e W. Yang, J. Chem. Phys. 107, 3981 (1997).

38. R. Konecny e D. Doren, Surf. Sci. 417, 169 (1998).

39. Q. Liv e R. Hoffman, J. Am. Chem. Soc. 117, 4082 (1995).

40. A. Redondo e W. A. Goddard III, J. Vac. Sci. Technol. 21, 344 (1982).

41. Z. Jing e J. L. Whitten, Surf. Sci. 274, 106 (1992).

42. B. Paulus, Surf. Sci. 408, 195 (1998).

43. J. Schoemaker e L.W. Burggraf, J. Chem. Phys. 112, 2994 (2000).

44. A. D. Becke, J. Chem. Phys. 98, 5648 (1993).

45. C. Lee, W. Yang e R. G. Parr, Phys. Rev. B37, 785 (1988).

46. Gaussian 94, Revisão E.1; M. J. Frisch, G. W. Trucks, H. B. Schlegel, M. W. Gill, B. G. Johnson, M. A. Robb, J. R. Cheeseman, T. Keith, G. A. Petersson, J. A. Montgomery, K. Raghavachari, M. A. Al-Laham, V. G. Zakrzewski, J. V. Ortiz, J. B. Foresman, J. Cioslowski, B. B. Stefanov, A. Nanayakkara, M. Challacombe, C. Y. Peng, P. Y. Ayala, W. Chen, M. W. Wong, J. L. Andres, E. S. Replogle, R. Gomperts, R. L. Martin, D. J. Fox, J. S. Binkley, D. J. Defrees, J. Baker, J. P. Stewart, M. HeadGordon, C. Gonzalez e J. A. Pople, Gaussian, Inc., Pittsburgh, PA, 1995. 
47. Gaussian 98, Revisão A.6; M. J. Frisch, G. W. Trucks, H. B. Schlegel, G. E. Scuseria, M. A. Robb, J. R. Cheeseman, V. G. Zakrzewski, J. A. Montgomery Jr., R. E. Stratmann, J. C. Burant, S. Dapprich, J. M. Millam, A. D. Daniels, K. N. Kudin, M. C. Strain, O. Farkas, J. Tomasi, V. Barone, M. Cossi, R. Cammi, B. Mennucci, C. Pomelli, C. Adamo, S. Clifford, J. Ochterski, G. A. Petersson, P. Y. Ayala, Q. Cui, K. Morokuma, D. K. Malick, A. D. Rabuck, K. Raghavachari, J. B. Foresman, J. Cioslowski, J. V. Ortiz, B. B. Stefanov, G. Liu, A. Liashenko, P. Piskorz, I. Komaromi, R. Gomperts, R. L. Martin, D. J. Fox, T. Keith, M. A. Al-Laham, C. Y. Peng, A. Nanayakkara, C. Gonzalez, M. Challacombe, P. M. W. Gill, B. Johnson, W. Chen, M. W. Wong, J. L. Andres, C. Gonzalez, M. Head-Gordon, E. S. Replogle e J. A. Pople, Gaussian, Inc., Pittsburgh, PA, 1998.

48. Y. Wang, M. Shi e J. W. Rabalais, Phys. Rev. B 48, 1689 (1993).

49. R. D. Verna e P. A. Warsop, Can. J. Phys. 41, 152 (1963).

50. B. T. Luke, J. A. Pople, M. Krogh-Jespersen, Y. Apeloig, J. Chandrasekhar, P. v. R. Schleyer, J. Am. Chem. Soc. 108, 260 (1986).

51. F. Bacalzo-Gladden e M. C. Lin, J. Phys. Chem. B 103, 7270 (1999).

52. A. R. Brown e D. J. Doren, J. Chem. Phys. 110,2643 (1999).

53. E. Penev, P. Kratzer e M. Scheffler, J. Chem. Phys. 110,3986 (1999).

54. F. Bacalzo-Gladden, X. Lu e M. C. Lin, J. Phys. Chem. B 105, 4368 (2001). 
III. ADSORÇÃO DE ÁTOMOS DE NITROGÊNIO NA SUPERFÍCIE Si(100) 


\section{1 INTRODUÇÃO}

Reaçōes em superfícies têm uma grande importância do ponto de vista tecnológico. Vários produtos químicos de interesse são obtidos através de processos de catálise heterogênea, onde reaçōes ocorrem na superfície de um catalisador. Como outro exemplo podemos citar os circuitos integrados, que são produzidos a partir da deposição de filmes na superfície de um semicondutor.

Devido à sua grande importância e utilidade, há muito tempo se tem conhecimento de processos envolvendo reações em superfícies. Esse interesse existe desde a época dos gregos antigos e dos romanos, que desenvolveram técnicas para inibir a perda de brilho dos metais.

Atualmente, existem três grandes áreas onde processos catalíticos sāo utilizados: indústria automotiva, refinamento de combustíveis fósseis e produçāo de substâncias químicas. A indústria automotiva utiliza principalmente metais nobres (platina, ródio e paládio) para o controle catalítico da emissão dos carros, principalmente hidrocarbonetos não consumidos completamente, $\mathrm{CO}$ e NO. Esses materiais são preparados para serem ativos com a alta velocidade de emissão dos polventes e com uma grande escala de variação da temperatura. No refino do petróleo, zeólitos são utilizados para o craqueamento de hidrocarbonetos na presença de hidrogênio. As reações para a produção de moléculas cíclicas e aromáticas a partir de alcanos para aumentar o número de octanos ocorrem sobre platina ou platina contendo catalisadores bimetálicos, como Pt-Re e Pt-Sn. Na indústria química, vários sāo os exemplos do uso de catalisadores. Em muitos casos utiliza-se ferro, como a produção do metanol a partir do $\mathrm{CO}$ e $\mathrm{H}_{2}$ e da amônia a partir de $\mathrm{H}_{2}$ e $\mathrm{N}_{2}$. Hidrogenação catalítica é um processo onde muitas vezes se usa níquel e paládio como catalisador. A hidrogenação de grupos nitrila gerando aminas e de olefinas são alguns exemplos de reações. Dentre o grande número de reações de oxidação, a oxidação da amônia formando óxido nítrico, e em seguida, ácido nítrico utiliza metais nobres, como Pt, Pt-Rh e Pt-Pd-Rh. A oxidação do $\mathrm{SO}_{2}$ para $\mathrm{SO}_{3}$ e ácido sulfúrico usa normalmente óxido de vanádio como catalisador. Muitos dos processos catalíticos usados na indústria química são heterogêneos, ou seja, a reação química 
ocorre sobre uma superfície e os reagentes são introduzidos como líquidos ou gases. Catálise homogênea, que usa freqüentemente moléculas organometálicas ou aglomerados moleculares, também são importantes do ponto de vista industrial. Como exemplo podemos citar o uso de íons de cobalto, cobre e paládio para a oxidação do acetileno para acetaldeído e ácido acético.

Por volta de 1960 houve o surgimento da indústria de circuitos integrados. Esses circuitos sāo obtidos através da deposiçāo de filmes sobre substratos semicondutores. $O$ controle preciso das propriedades desse filmes é essencial para o melhor funcionamento do circuito. Com isso, novas técnicas de análise de superfícies foram desenvolvidas para responder às necessidades da indústria. Essas novas técnicas têm permitido obter maiores detalhes da estrutura e da composição da superfície, bem como ter uma melhor compreensão dos fenômenos envolvidos ao nível molecular.

\section{Adsorção - Ligação de moléculas à superfície}

Adsorção é o processo onde moléculas na fase gasosa ou em uma soluçāo ligamse a uma camada condensada de uma superfície sólida ou líquida. A molécula que se liga à superfície é chamada de adsorbato, enquanto que a superfície onde o adsorbato se liga é chamado de adsorvente. $O$ processo em que as moléculas se ligam ao adsorvente é conhecido como adsorção, enquanto que a remoção das mesmas chama-se desorção.

Com relação à natureza da ligação existente entre o adsorbato e a superfície, existem dois tipos diferentes de adsorção: adsorção química, onde ocorre uma ligação química direta entre o adsorbato e a superfície e a adsorção física, onde não há a formação de uma ligação direta. Nesse último caso, o adsorbato é aprisionado devido a forças, como, por exemplo, de van de Waals. No caso de uma molécula ser adsorvida quimicamente, os elétrons passam a ser compartilhados entre a molécula e a superfície, de modo que a estrutura eletrônica do adsorbato sofre uma grande alteração. No caso da adsorção física, as interaçōes ocorrem devido às forças de polarização, de modo que 
não há a existência de elétrons compartilhados. Com isso a estrutura eletrônica do adsorbato sofre uma perturbação muito menor.

Para se ter uma noção das energias envolvidas nesses dois tipos de interações, a adsorção química envolve energias da ordem de $15-100 \mathrm{kcal} / \mathrm{mol}$ enquanto que este valor é da ordem de $2-10 \mathrm{kcal} / \mathrm{mol}$ para adsorção física.

As moléculas são adsorvidas quimicamente quando há a ocorrência de quebras de ligaçōes, sendo os demais casos adsorções físicas. Modernamente aceita-se que uma molécula é adsorvida quimicamente se a estrutura eletrônica do adsorbato é significativamente diferente da molécula presente na fase gasosa.

Muitas vezes a diferença entre uma adsorção física e uma química é uma questão delicada. Assume-se que um gás adsorvido o faz através de um processo químico se a snergia de ligação com a superfície é maior que $10 \mathrm{kcal} / \mathrm{mol}$, enquanto que para valores menores refere-se ao processo como físico. Mas uma distinção precisa entre esses dois processos é algo arbitrário. Muitas vezes a molécula pode apresentar uma adsorção física e química na mesma superfície. Freqüentemente a molécula sofre primeiramente uma adsorção física e depois sofre uma conversão para um estado adsorvido quimicamente. Com isso tem-se sempre moléculas presentes nessas duas formas durante um processo de incorporação de um adsorbato.

Moléculas adsorvidas e que formam ligações químicas com os átomos em uma superfície vibram a partir da sua posição de equilíbrio. Essas vibraçōes pode ser detectadas facilmente usando a técnica de espectroscopia vibracional. Normalmente, as freqüências vibracionais observadas ocorrem entre 300 e $800 \mathrm{~cm}^{-1}$, e esses valores são fáceis de serem distinguidos do espectro vibracional da superfície sólida sem substâncias adsorvidas, pois nesse caso apresentam valores menores.

No interior de um semicondutor as ligações entre os átomos são semelhantes às de uma molécula, onde híbridos s-p-d formam ligações locais. E na superfície há a presença de dangling bonds, que acabam sofrendo ligações, causando o que conhecemos como reconstrução da superfície. Geralmente, a química da superfície de 
um semicondutor é controlada pelas propriedades das dangling bonds e dos dímeros que são formados a partir das ligações entre essas dangling bonds.

modo mais simples de entender uma ligação em uma superfície semicondutora é considerar as ligaçōes que surgirem como sendo semelhantes às de uma molécula orgânica. Como exemplo temos que o hidrogênio forma uma ligação com o silício da superfície que se assemelha a uma ligação do tipo $\sigma$ em um silano. Na realidade, existem algumas complicações extras em um semicondutor, mas como uma primeira aproximação pode-se imaginar a ligação entre o adsorbato e a superfície como ligaçōes do tipo $\sigma$, como em moléculas orgânicas e inorgânicas.

Reaçōes de inserção são bastante comuns na superfície do silício, e freqüentemente ocorre um rearranjo quando gases sāo adsorvidos. A mudança mais comum é o relaxamento para uma estrutura semelhante à do interior (bulk) do semicondutor, mas observa-se também o relaxamento para estruturas muis complexas.

Outro processo que ocorre na superfície do silício é a reação de deslocamento direto, ou seja, um átomo correspondente a um adsorbato substitui um átomo de silício e este átomo de silício interage com um segundo átomo do adsorbato, formando uma sobrecamada. Esse tipo de reaçāo tem sido observado em adsorção de oxigênio, germânio e alumínio em silício.

No processo de colisão de moléculas com uma superfície alguns processos podem ocorrer: espalhamento, aprisionamento e formação de ligação. Uma dessas possibilidades é quando a molécula colide com uma superfície deformável, de modo que pode perder energia translacional suficiente para permanecer na proximidade de uma superfície. Nesse caso, a molécula está aprisionada, e esse processo é chamado de trapping. A melhor evidência experimental desse processo vem de experiências de feixe molecular, onde um feixe de moléculas energéticas é dirigido para uma superfície. Desse modo, pode-se detectar um pequeno número de moléculas que gastam algumas centenas de microssegundos na superfície. Esse tempo é relativamente grande se comparado com tempos envolvidos em processos normais de colisão, e essas moléculas são consideradas como estando aprisionadas. Nesse processo de aprisionamento, a 
molécula perde boa parte da energia translacional, de modo que esta não deixa a superfície imediatamente por nāo ter energia suficiente, ficando em um estado móvel fracamente ligado à superfície. Nessa situação, o movimento térmico dos átomos da superfície podem fazer com que a molécula sofra uma desorção. Com isso, a molécula precisa ser convertida em um estado mais fortemente ligado se quiser permanecer na superfície por mais tempo. Quando uma molécula colide com uma superfície, perde energia e é convertida em um estado onde a molécula permanece na superfície por um tempo razoável, dizemos que esta molécula está ligada, e esse processo é chamado de sticking.

É importante dizer que trapping e sticking são processos bem diferentes. A velocidade de aprisionamento é determinada pela taxa com que a energia é transferida pela molécula incidente para a superfície, enquanto que a velocidade com que a molécula passa a estar ligada relaciona-se com a velocidade com que a molécula localiza locais onde pode ser adsorvida fisicamente ou quimicamente. Experimentalmente, o aprisionamento é importante no caso de espécies fracamente ligadas, como no caso dos gases nobres, enquanto que sticking é mais importante com espécies que apresentam ligações mais fortes. Entretanto, espécies que se ligam fortemente normalmente adsorvem inicialmente em um estado fracamente ligado, para daí se converterem para um estado fortemente ligado. Portanto, trapping é importante também no casto de espécies fortemente ligadas. Em particular, este processo é importante pois participa na formação e crescimento de filmes semicondutores.

Com relação aos mecanismos de reações em superfície, aceita-se que esta modifica as reaçōes por atuar como um meio colisional efetivo para o início de reações, por estabilizar os intermediários reativos e por colocar os reagentes em uma configuração que é favorável à reação.

Atualmente aceita-se que a superfície atua de modo a estabilizar os intermediários reativos de uma reação. Um processo catalítico envolve a formação e destruição seqüencial de ligações entre o adsorbato e a superfície. Se a ligação adsorbato/superfície for muito fraca, não haverá a formação de complexos reativos, de modo que a reação torna-se muito lenta. Por outro lado, se a ligação for muito forte, torna-se difícil quebrar a 
ligação adsorbato/superfície, fazendo com que a reação fique lenta também. Com isso, os melhores catalisadores são substâncias que formam ligaçōes intermediárias entre os dois casos acima para a interação adsorbato/superfície. Essa idéia de que os melhores catalisadores possuem força de ligação intermediária é conhecido como Princípio de Sabatier.

Experimentalmente, as barreiras intrínsecas para uma reação em uma superfície variam com o tipo de reação, a composição e a estrutura da superfície, fazendo com que o estudo dos mecanismos envolvidos seja muito complexo.

\section{Cerâmicas: conceitos básicos}

Cerômicas são basicamente materiais inorgânicos não metálicos. Eles são conhecidos e utilizados há muito tempo, sendo os primeiros materiais produzidos artificialmente pelo homem. Mais recentemente, uma classe conhecida como cerâmica de alto desempenho (high performance) tem atraído um grande interesse, pelo fato de possuírem características e propriedades muito particulares.' Entre essas propriedades podemos citar a resistência mecânica e a corrosão a altas temperaturas, elevado ponto de fusão ou decomposição, durabilidade e dureza muito elevadas, baixa densidade e uma grande estabilidade térmica e química à corrosão e oxidação.

Essas cerâmicas são classificadas de acordo com a sua função, que pode ser: elétrica, magnética, ótica, química, térmica, biológica, nuclear e mecânica. ${ }^{2}$ Muitas dessas cerâmicas são isolantes elétricos e térmicos, mas algumas apresentam ao mesmo tempo uma alta resistência elétrica e uma alta condutividade térmica, como $\circ \mathrm{Al}_{2} \mathrm{O}_{3}$, $\mathrm{Si}_{3} \mathrm{~N}_{4}, \mathrm{AIN}, \mathrm{SiC}$ e $\mathrm{BeO}$. Outras apresentam características semicondutoras, como o $\mathrm{SiC}$, condutividade iônica, como a zircônia $\left(\mathrm{ZrO}_{2}\right)$, ferromagnéticas (ferrita), dielétricas $\left(\mathrm{BaTiO}_{3}\right)$ e podem ser opticamente translúcidas sob certas circunstâncias, como no caso da alumina $\left(\mathrm{Al}_{2} \mathrm{O}_{3}\right)$. A maioria desses compostos cerâmicos estão restritos aos boretos, carbetos, nitretos e óxidos de elementos do terceiro e quarto períodos (Al, B e Si) bem como metais de transição (Mo, Ti, W e Zr). Dependendo da combinação entre os 
elementos acima, a cerâmica resultante pode mostrar um caráter metálico, iônico ou covalente. Essas combinações de propriedades permitem que esses materiais sejam utilizados em processos industriais que envolvam temperaturas muito elevadas, acima de $1000^{\circ} \mathrm{C}$, bem como atuar como componente de máquinas de combustão interna.

A variedade de aplicação dessas cerâmicas é extensa, e o interesse tem crescido juntamente com o desenvolvimento da indústria de alta tecnologia como, por exemplo, da microeletrônica, onde esses materiais têm sido muito utilizados como componentes de circuitos integrados.

As principais desvantagens desses materiais cerâmicos sāo a sua característica quebradiça e a insuficiente reprodutibilidade de suas propriedades. No último caso, a dificuldade surge devido ao complexo processo industrial de fabricação que envolve a síntese da cerâmica.

Com essa crescente evolução tecnológica, há uma necessidade cada vez maior de materiais de alta qualidade, exigindo dessa maneira um controle cada vez mais rigoroso durante todo o processo de preparação dos mesmos. Esse controle visa a obtenção de materiais de elevada pureza e composição absolutamente definida, assim como livres de quaisquer imperfeições na sua estrutura, que comprometem muito o desempenho do material. Além disso, qualquer falha em alguma etapa desse processo induz a erros que dificilmente podem ser remediados nas etapas seguintes, levando à formação de produtos de qualidade inferior, ou seja, com falhas estruturais, como poros, micro-rachaduras e inclus.ōes, que estão relacionados com a falta de homogeneidade química ou física. Isso pode levar a conseqüências diversas quando o material é submetido a uma tensão mecânica. Como muitos dos processos de obtenção do material são baseados em reações químicas, o conhecimento dos detalhes envolvidos em cada etapa é muito importante para que se possa obter materiais de melhor qualidade e a um custo menor.

De um modo geral, a produção das cerâmicas segue a seqüência: síntese do pó a ser utilizado como matéria prima; processamento, com a adiçāo de substâncias sinterizantes; espalhamento do pó em uma superfície; sinterização; aplicação e testes da cerâmica obtida. A obtenção de uma cerâmica de alta qualidade depende, portanto, do 
processo químico utilizado para a síntese do pó a ser utilizado como matéria prima e de todo o processo subseqüente de tratamento até chegar à cerâmica desejada. Um pó de alta qualidade tem que apresentar as seguintes características: partículas de tamanho pequeno; ausência de aglomeração das partículas; uma distribuição homogênea das partículas de tamanhos semelhantes; formato esférico para melhorar o empacotamento; composição bem definida para uma determinada fase, como no caso da forma $\alpha$ do $\mathrm{Si}_{3} \mathrm{~N}_{4}$, e alta pureza química.

No caso das cerâmicas, a síntese da matéria prima ocorre unicamente utilizando processos químicos, que varia conforme o produto final de interesse. Várias possibilidades de síntese são conhecidas, como a síntese convencional de pós cerâmicos, que consiste numa reação no estado sólido entre óxidos e/ou carbonatos, como no caso do $\mathrm{BaTiO}_{3}$, que é produzido a partir da mistura, moagem e calcinação do $\mathrm{BaCO}_{3}$ e $\mathrm{TiO}_{2}$. Para o caso de pós que não sejam óxidos, a síntese convencional inclui a reação direta de um metal com um gás, como no caso do TiN, que é produzido através da nitretação do Ti a partir do $\mathrm{N}_{2}$ a $1500^{\circ} \mathrm{C}$. A necessidade de produção de novas cerâmicas, com propriedades diferentes, tem levado a uma grande pesquisa no sentido de criar e desenvolver novas técnicas de síntese. No caso da co-precipitação, temos a preparação de óxidos cerâmicos através da formação de precipitados intermediários, normalmente oxalatos, de modo que uma mistura dos componentes é formada durante o processo de precipitação. Isso resulta em um produto bastante homogêneo, o que favorece o processo de calcinação que se faz em seguida. Esse método tem sido utilizado para a produção de pó de $\mathrm{BaTiO}_{3}$ a partir da adição de ácido oxálico em uma mistura de cloretos de bário e de titânio, sob condiçōes controladas de $\mathrm{pH}$, temperatura e concentração dos reagentes. Uma outra técnica envolve o uso de sais fundidos, que se refere à utilização de compostos que se fundem produzindo líquidos com propriedades iônicas. Como substâncias de partida normalmente se utilizam sulfatos e cloretos, que são misturados com nitratos ou nitritos de metais alcalinos, sendo a mistura aquecida até a temperatura de reação. Esse método ainda não tem sido muito utilizado devido a problemas como nucleação e a formação de agregados, que impedem a formação de pós cerâmicos de boa qualidade. A utilização de colóides tem tido grande aceitação, pois a preparação de pó enivolve a nucleação e crescimento de partículas de tamanho menor 
que $l \mu \mathrm{m}$, ou seja, de dimensōes coloidais. Além disso, os pós são muitas vezes manuseados na forma de dispersōes coloidais e, nesse caso, se utiliza o processo conhecido como sol-gel. Aqui, o material de partida, um sal, por exemplo, é transformado em uma dispersão coloidal através de processos químicos, como a adição de ácidos diluídos ou água. A posterior remoção da água ou dos íons presentes no gel e a calcinaçāo acaba gerando um óxido como produto final. Uma vantagem desse método reside na versatilidade para a produção de cerâmicas com formas mais variadas, como, por exemplo, filmes de $1 \mu \mathrm{m}$. Uma outra técnica que tem recebido muita atenção é a pirólise polimérica, que se refere à síntese de um composto polimérico, também chamado de polímero pré-cerâmico, que em seguida sofre uma pirólise produzindo a cerâmica, como, por exemplo, na produçāo do $\beta-S i C$. Além das técnicas de síntese química de materiais cerâmicos descritas acima, existem outras que podem ser vistas nos artigos de Riedel $^{3}$ e de Segal. ${ }^{4}$ Alguns detalhes das várias etapas desde a síntese até a sinterização do material podem ser obtidos no trabalho de Aldinger e Kalz. ${ }^{1}$

\section{Nitreto de silício: propriedades e técnicas de síntese}

Dentre as várias espécies de cerâmicas de alłæ desempenho existentes, há um grande interesse no nitreto de silício $\left(\mathrm{Si}_{3} \mathrm{~N}_{4}\right)$. A sua grande resistência mecânica, dureza e estabilidade é conseqüência de sua estrutura bastante rígida e das fortes ligaçōes covalentes entre os átomos de silício e nitrogênio. Essas características fazem dele um material ideal para a utilização em sistemas que operam a temperaturas elevadas. Comparado com outros materiais de uso similar, $0 \mathrm{Si}_{3} \mathrm{~N}_{4}$ apresenta algumas vantagens, como o baixo coeficiente de expansão térmica e a elevada resistência à oxidação. Do ponto de vista estrutural, um filme de $\mathrm{Si}_{3} \mathrm{~N}_{4}$ pode se apresentar sob duas formas polimórficas: $\alpha-\mathrm{Si}_{3} \mathrm{~N}_{4}$ e $\beta-\mathrm{Si}_{3} \mathrm{~N}_{4}$, sendo que a forma que apresenta interesse tecnológico é a $\alpha-\mathrm{Si}_{3} \mathrm{~N}_{4}$. Nas figuras $15-\mathrm{A}$ e 15-B podemos ver a representaçāo dessas duas estruturas. A forma alfa é a mais estável a baixas temperaturas, sendo que a transformação de $\alpha$ para a $\beta$ ocorre somente a temperaturas acima de $1650^{\circ} \mathrm{C}$. Não foi ainda observada a transformaçāo no sentido inverso, provavelmente por razōes de ordem cinética. ${ }^{5}$ 


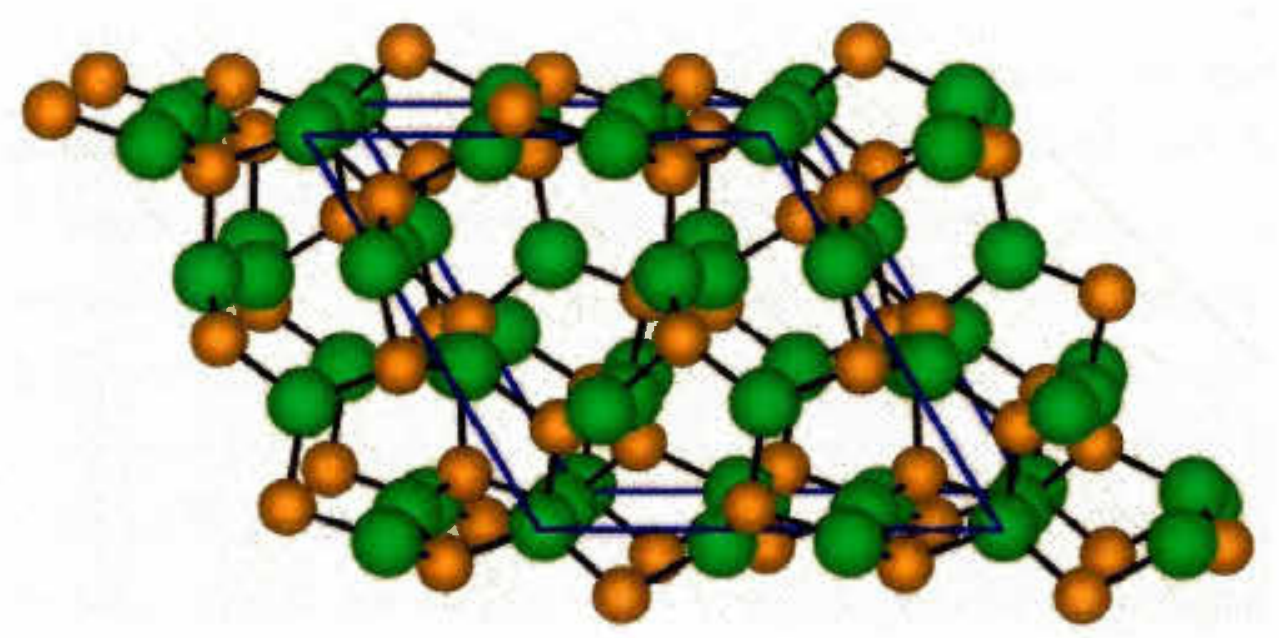

Figura 15-A. Estrutura da forma polimórfica $\alpha-\mathrm{Si}_{3} \mathrm{~N}_{4}$ com a indicação da cela unitária.

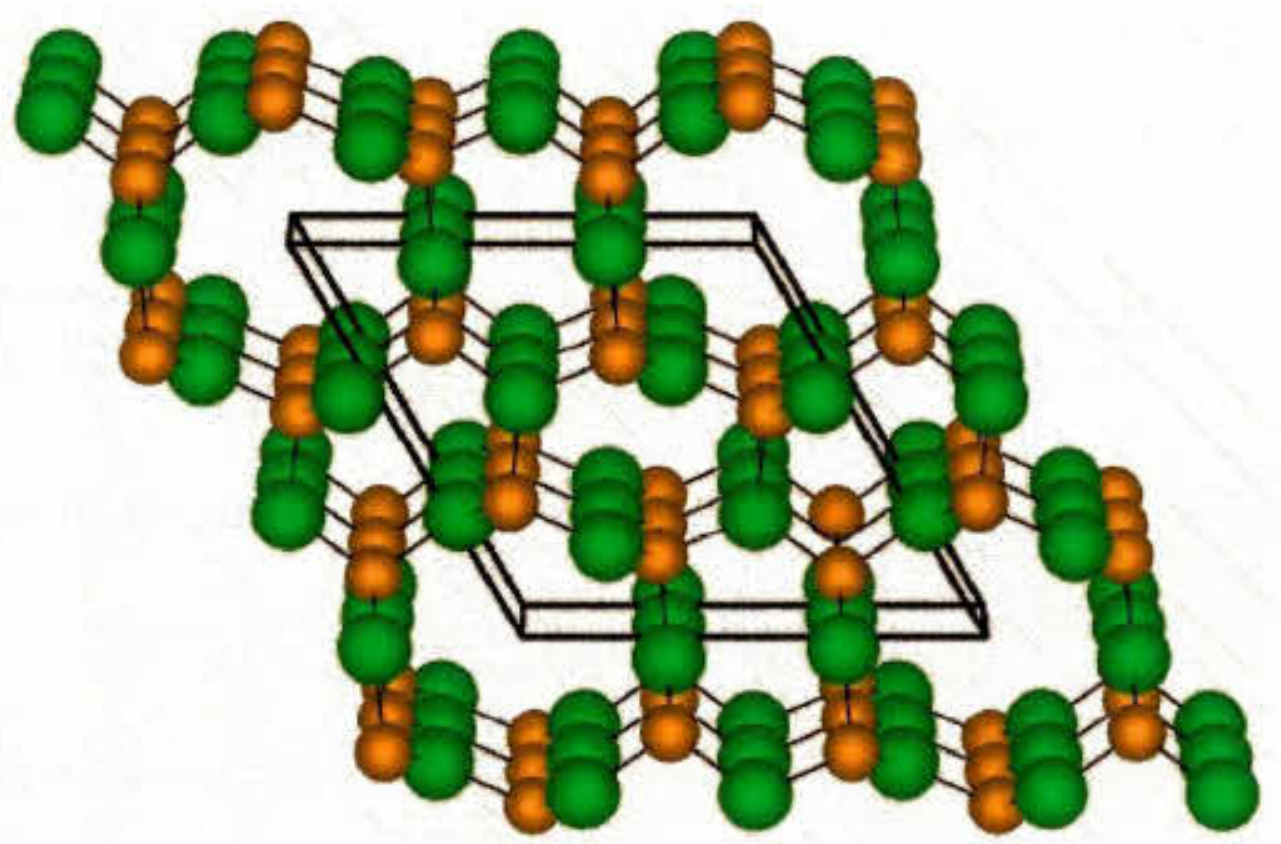

Figura 15-B. Estrutura da forma polimórfica $\beta-\mathrm{Si}_{3} \mathrm{~N}_{4}$ com a indicação da cela unitária. 
Com relação à estrutura cristalina, a forma $\beta-\mathrm{Si}_{3} \mathrm{~N}_{4}$ apresenta uma cela unitária com a fórmula $\mathrm{Si}_{\sigma} \mathrm{N}_{8}$ e "canais" com diâmetros da ordem de 0,15 nm, que pelas dimensões permitem a difusāo de átomos na estrutura do material. A forma $\alpha-\mathrm{Si}_{3} \mathrm{~N}_{4}$ é constituída de uma cela unitária com a fórmula $\operatorname{Si}_{12} N_{16}$ e, neste caso, não existe a presença de "canais", de modo que o processo de difusāo toma-se muito mais difícil. Com relação à estrutura $\beta-S_{3} N_{4}$, alguns trabalhos foram realizados para estudar o espectro dessa cerâmica, como, por exemplo, o feito por Honda ef al.. ${ }^{6}$ Eles estudaram a relação entre o espectro infravermelho com a tensão aplicada sobre o material, em especial com o modo de vibração de $1020 \mathrm{~cm}^{-1}$. Foram observadas três bandas, com freqüências de 1020,930 e $580 \mathrm{~cm}^{-1}$, que foram atribuídas ao $\beta-\mathrm{Si}_{3} \mathrm{~N}_{4}$. Eles utilizaram duas amostras de $\beta-\mathrm{Si}_{3} N_{4}$, sendo que uma foi obtida através da sinterizaçāo e a outra por pressão a altas temperaturas. Em ambos os casos eles observaram um deslocamento do pico para freqüências mais baixas à medida que aumentou a intensidade da tensāo sobre o material.

A obtençāo industrial do pó de $\mathrm{Si}_{3} \mathrm{~N}_{4}$ de alta qualidade é realizada seguindo uma das três rotas abaixo: ${ }^{5}$

a) nitretação do silício:

$$
3 \mathrm{Si}+2 \mathrm{~N}_{2} \rightarrow \mathrm{Si}_{3} \mathrm{~N}_{4}
$$

b) redução carbotérmica do $\mathrm{SiO}_{2}$ na presença de nitrogênio:

$$
3 \mathrm{SiO}_{2}+6 \mathrm{C}+2 \mathrm{~N}_{2} \rightarrow \mathrm{Si}_{3} \mathrm{~N}_{4}+6 \mathrm{CO}
$$

c) amonólise de compostos reativos de silício:

$$
\begin{aligned}
& 3 \mathrm{SiCl}_{4}+4 \mathrm{NH}_{3} \rightarrow \mathrm{Si}_{3} \mathrm{~N}_{4}+12 \mathrm{HCl} \\
& 3 \mathrm{SiH}_{4}+4 \mathrm{NH}_{3} \rightarrow \mathrm{Si}_{3} \mathrm{~N}_{4}+12 \mathrm{H}_{2}
\end{aligned}
$$

Outras rotas de síntese são conhecidas mas não têm atraído interesse por motivos tecnológicos ou econômicos, devido ao elevado custo de produção, cinética da reação muito lenta ou a formação de produtos indesejáveis: 


$$
\begin{aligned}
& 3 \mathrm{SiS}_{2}+4 \mathrm{NH}_{3} \rightarrow \mathrm{Si}_{3} \mathrm{~N}_{4}+6 \mathrm{H}_{2} \mathrm{~S} \\
& 3 \mathrm{SiC}+4 \mathrm{NH}_{3} \rightarrow \mathrm{Si}_{3} \mathrm{~N}_{4}+3 \mathrm{CH}_{4} \\
& 3 \mathrm{SiO}_{2}+4 \mathrm{NH}_{3} \rightarrow \mathrm{Si}_{3} \mathrm{~N}_{4}+6 \mathrm{H}_{2} \mathrm{O}
\end{aligned}
$$

O pó de $\mathrm{Si}_{3} \mathrm{~N}_{4}$ obtido a partir de qualquer um dos métodos acima deve obedecer a certos critérios para que possa vir a ser utilizado para a síntese de uma cerâmica de alta qualidade, como pureza, cristalinidade, forma e tamanho das partículas, grau de aglomeração das partículas e razão $\alpha / \beta$. As propriedades físicas e químicas dessa cerâmica são fortemente influenciadas pelas características do pó utilizado como reagente.

Dos métodos citados acima, a nitretação direta do silício é a forma dominante de síntese industrial. $O$ processo consiste na utilização de pó de silício de alta pureza para reagir com $\mathrm{N}_{2}$ a uma temperatura entre 1100 e $1400^{\circ} \mathrm{C}$. A seleção de pós de silício influencia fortemente a qualidade da cerâmica de $\mathrm{Si}_{3} \mathrm{~N}_{4}$, sendo que para a obtenção de materiais de alta pureza pode-se utilizar silício semicondutor como material de partida. $\bigcirc$ material obtido é triturado, tratado com ácido e finalmente secado, produzindo o pó de $\alpha-\mathrm{Si}_{3} \mathrm{~N}_{4}$. Experimentalmente, é necessário manter um grande controle durante toda a reação pelo fato desta ser bastante exotérmica $(\Delta \mathrm{H}=-750 \mathrm{~kJ} / \mathrm{mol})$, podendo causar uma grande elevação da temperatura e conduzir também à formação de $\beta-\mathrm{Si}_{3} \mathrm{~N}_{4}$, que é um produto indesejado. Existe também o risco da temperatura tornar-se elevada ao ponto de fundir o pó de silício presente no local da reação. Uma maneira de controlar a temperatura da reação é diminuindo a concentração de nitrogênio na atmosfera reativa. Geralmente, temperaturas baixas e a presença de hidrogênio no gás durante o processo de nitretação favorecem a formação do material na fase $\alpha$. A reaçāo depende muito do tamanho das partículas formadas e da pureza química do pó de silício. Ishizaki et al. ${ }^{7}$ realizaram a nitretação à temperatura de $1373 \mathrm{~K}$ sobre uma amostra de pós de silício finamente divididos, com diâmetros entre 20 e $50 \mathrm{~nm}$. A presença de ar na reação aumentou a temperatura de nitretaçāo de 1373 para $1473 \mathrm{~K}$. A temperatura de $1373 \mathrm{~K}$ é mais baixa que os valores utilizados até então, e eles atribuíram isso ao pequeno diâmetro do pó de silício utilizado. 
Várias pesquisas têm sido realizadas na tentativa de encontrar outras formas de síntese de filmes de $\mathrm{Si}_{3} \mathrm{~N}_{4}$. As reaçōes em fase gasosa induzidas por laser e por plasma têm suscitado um grande interesse por evitar a necessidade de manter o sistema a temperaturas muito elevadas, além de permitir uma maior localização da região de interação, sendo, portanto, de interesse para a fabricação de componentes de pequenas dimensões. A reação induzida por laser mais conhecida é a da mistura $\mathrm{SiH}_{4} / \mathrm{NH}_{3}$ com a utilização de um laser de ArF (193 nm). ${ }^{8}$ Uma reação menos estudada é a da mistura $\mathrm{Si}_{2} \mathrm{H}_{6} / \mathrm{NH}_{3}$ com o mesmo laser de ArF. O maior problema da síntese induzida por laser é o pequeno tamanho do feixe do laser, que permite a formação de produtos a uma velocidade de apenas alguns gramas por hora. Com relação à reação induzida por plasma, a reação mais comum é entre $\mathrm{SiCl}_{4}$ e $\mathrm{NH}_{3}$, mas existe também a possibilidade de uma reação de deposição de uma mistura de metano e nitrogênio sobre o substrato de silício. ${ }^{9}$ O produto final obtido é uma estrutura cristalina, composto principalmente por $\alpha$ $\mathrm{Si}_{3} \mathrm{~N}_{4}$. Liu et al. ${ }^{10}$ realizaram a caracterizaçõo de filmes de SiN! cubtidos através da deposiçāo utilizando plasma com ressonância ciclotrônica de elétrons. $O$ material foi obtido a partir da deposição de uma mistura de $\mathrm{N}_{2} / \operatorname{Ar}$ sobre uma superfície Si(100), sendo a identificação realizada usando a técnica de espectroscopia de absorção no infravermelho. A partir do espectro, eles identificaram picos com 800,840 e $970 \mathrm{~cm}^{-1}$. $O$ - modo mais intenso, de $840 \mathrm{~cm}^{-1}$ foi atribuído ao modo de estiramento assimétrico do grupo $\mathrm{NSi}_{3}$, o modo a $800 \mathrm{~cm}^{-1}$, à vibração da ligação $\mathrm{Si}-\mathrm{N}$ da configuração $\mathrm{SiN}_{\mathrm{x}}$ enquanto que o modo de freqüência mais elevada, de $970 \mathrm{~cm}^{-1}$, foi relacionado com o grupo $\mathrm{NSi}_{3}$ com configuraçāo planar. Eles observaram que os átomos de nitrogênio estāo predominantemente incorporados nos grupos $\mathrm{NSi}_{3}$. A dificuldade desses métodos que utilizam plasmas surge por causa da formação de diversos radicais, que podem se recombinar de várias maneiras, acabando por dificultar o controle da reaçāo. De qualquer forma, ambos os métodos (laser e plasma) não são normalmente utilizados para a produção de $\mathrm{Si}_{3} \mathrm{~N}_{4}$ por levarem à formação de um produto com uma composição indefinida, muitas vezes amorfa, além de não permitirem a produção de grandes quantidades do material, o que inviabiliza a sua utilização sob o ponto de vista industrial. No caso específico das reações induzidas por plasmas, a elevada temperatura causa a formação de diversos radicais a partir da quebra dos reagentes, que podem se recombinar sob diversas formas. Com isso, perde-se o controle do fluxo de partículas 
reagentes interagindo com a superfície de silício, dificultando o controle da reação. Essas duas formas de síntese permitem a obtenção de pós extremamente finos, da ordem de 10 a $30 \mathrm{~nm}$, mas os produtos normalmente não apresentam uma estequiometria correta, sendo normalmente amorfas. Devido às dificuldades acima, as reaçōes induzidas por laser ou por plasma não têm sido utilizadas para a produção em larga escala de $\mathrm{Si}_{3} \mathrm{~N}_{4}$, apesar das intensas pesquisas realizadas.

Entre outras alternativas, estudos também têm sido realizados para a obtenção de filmes de $\mathrm{Si}_{3} \mathrm{~N}_{4}$ a partir de polímeros orgânicos contendo átomos de silício. "Uma outra técnica de síntese envolve a reação entre silício e $\mathrm{NaN}_{3}$, com a adição de $\mathrm{NH}_{4} \mathrm{Cl}$ como agente catalítico. ${ }^{12} \bigcirc$ material é formado com a adição de agentes como titânio e carbono, que em seguida sofre combustão, sendo o produto obtido principalmente na forma alfa. Um mecanismo foi proposto, sendo que a reação se processa em fase gasosa, com o silício reagindo inicialmerite com $\circ \mathrm{NH}_{4} \mathrm{Cl}$, formando compostos do tipo $\mathrm{SiCl}_{x}$ que em seguida reagem com moléculas nitrogenadas, formando pós finos de nitreto de silício.

conhecimento dos processos químicos envolvidos na síntese do $\mathrm{Si}_{3} \mathrm{~N}_{4}$ é de grande interesse não apenas do ponto de vista puramente acadêmico, pois a química dos compostos de silício e nitrogênio é uma área ainda relativamente pouco estudada, mas também como uma ferramenta capaz de auxiliar tanto a obtenção de um produto de maior qualidade quanto otimizar os processos de produção, tornando-os mais econômicos. O desenvolvimento tecnológico, principalmente da eletrônica, no caso dos circuitos integrados, tem exigido a obtenção de filmes muito finos, da ordem de dezenas de átomos de espessura. Tal grau de exigência faz com que seja necessária uma maior compreensão dos mecanismos da nitretação, o que servirá como auxílio para a obtençāo de filmes cada vez mais finos e de alta qualidade. Com isso em mente, um dos objetivos deste trabalho é justamente procurar compreender como se processa a interação e a incorporacão dos átomos de nitrogênio nos átomos de silício. Vários estudos experimentais foram realizados com essa finalidade. $O$ primeiro trabalho de nitretaçāo térmica de uma superfície de silício foi feito em 1973, ${ }^{13}$ onde filmes de Si(100), Si(1 1 1) e Si(311) foram expostos à amônia e $N_{2}$ a elevadas temperaturas (1073 - 1373 K), levando à formação de $\mathrm{Si}_{3} \mathrm{~N}_{4}$. A maior reatividade da amônia em relação ao $N_{2}$ acabou 
motivando várias pesquisas, buscando compreender os mecanismos de adsorçāo, dissociação e incorporação do $\mathrm{NH}_{3}$ em diversas superfícies do silício. ${ }^{14-18} \mathrm{~A}$ vantagem de se utilizar amônia é que o crescimento do material pode ocorrer a temperaturas abaixo de $800^{\circ} \mathrm{C}$, enquanto que temperaturas acima de $1200^{\circ} \mathrm{C}$ são necessárias quando se utiliza $\mathrm{N}_{2}$. Vários resultados levaram à conclusāo de que a estrutura dessas superfícies não é alterada com a incorporação do $\mathrm{NH}_{3}$, e o modelo mais aceito é que o estágio inicial se caracteriza pela dissociação em $\mathrm{NH}_{2}$ e $\mathrm{H}$. As etapas posteriores de dissociação variam conforme a superfície em questão.

No trabalho de to et al., ${ }^{19}$ realizado em 1978, eles produziram filmes da ordem de $100 \AA ̊$ a partir da reação direta do silício com moléculas de nitrogênio a temperaturas variando entre 1200 e $1300^{\circ} \mathrm{C}$. Limitando a quantidade de oxigênio e água no ambiente de reaçāo, eles obtiveram um filme uniforme de nitreto de silício amorfo. A eliminaçāo de traços de oxigênio é importante pois o processo de oxidação do silício é termodinamicamente mais favorável que a nitreiação. Entre as técnicas utilizadas para a análise dos filmes obtidos, eles utilizaram a espectroscopia de absorção no infravermelho. Picos correspondentes a comprimentos de onda de 9 e 16,4 $\mu \mathrm{m}\left(1111\right.$ e $610 \mathrm{~cm}^{-1}$, respectivamente) foram atribuídos ao substrato, pois não apresentaram mudanças tanto antes quanto depois da reação ocorrer. Um pico correspondente a 11,8 $\mu \mathrm{m}\left(847 \mathrm{~cm}^{-1}\right)$ foi atribuído ao estiramento da ligação $\mathrm{Si}-\mathrm{N}$ e associado à formação do nitreto de silício cristalino, pois a intensidade do pico aumenta com o aumento da cristalizaçāo do material. Reação de nitretação a temperaturas mais baixas foi realizada por Watanabe et al. ${ }^{20}$ Eles reagiram $\mathrm{Si}(100) \mathrm{com} \mathrm{NH}_{3}$ a temperaturas entre 300 e $650^{\circ} \mathrm{C}$ e pressōes entre 124 e 1400 Pa. A partir dos resultados, utilizando a espectroscopia de absorção/reflexão no infravermelho com transformada de Fourier (FTIR/RAS), eles sugeriram que a reação com $\mathrm{NH}_{3}$ ocorre com a desorção dos hidrogênios ligados aos silícios superficiais, com a incorporação dos átomos de nitrogênio nesses silícios. $O$ mecanismo de incorporação ocorre com a dissociação do $\mathrm{NH}_{3}$ na superfície em $\mathrm{NH}_{\mathrm{x}}(\mathrm{x}=0,1,2)$ e átomos de $\mathrm{H}$. Estágios posteriores ocorrem com a desorção desses hidrogênios. Com relaçāo aos mecanismos envolvidos no crescimento térmico de filmes de $\mathrm{Si}_{3} \mathrm{~N}_{4}$ através da reação do silício com $\mathrm{NH}_{3}$, algumas controvérsias ainda existem. Alguns autores sugerem que as espécies contendo nitrógênio sofrem difusão através do filme de nitreto que está sendo 
formado e reage com o silício presente na interface silício/nitreto. Outro mecanismo proposto é que o silício presente no substrato difunde através do filme de nitreto de silício até atingir a superfície, onde reage com $\circ \mathrm{NH}_{3}$. Este último modelo é consistente com o fato de que a cinética de nitretaçāo depende muito pouco da pressāo da amônia. Com relação à estrutura da superfície do $\mathrm{Si}_{3} \mathrm{~N}_{4}$, existem também dois modelos propostos. Num deles, os silícios da superfície formam uma monocamada distinta quimicamente das demais, e encontram-se ligados a átomos de nitrogênio em uma camada logo abaixo da superfície, e os silícios superficiais apresentam dangling bonds. No outro modelo, os silícios encontram-se ligados a grupos $\mathrm{NH}_{2}$ na superfície do nitreto. Baumvol e Stedile ${ }^{21}$ estudaram os mecanismos envolvidos no crescimento térmico de filmes ultrafinos de $\mathrm{Si}_{3} \mathrm{~N}_{4}$, a partir da reação do $\mathrm{NH}_{3}$ com $\mathrm{Si}(100)$. Eles propuseram que o crescimento se inicia com a dissociação da amônia na superfície do silício e a reação dos fragmentos contendo átomos de nitrogênio com os átomos de silício. A partir do momento em que uma ou duas camadas forem formadas, o posterior crescimiento ocorrerá devido ao transporte de radicais nitrogenados $\left(\mathrm{NH}_{\mathrm{x}} \mathrm{x}<3\right)$ a partir da superfície em direção à interface do nitreto/silício. À medida que a camada de nitreto formada vai aumentando, menos nitrogênio atingirá a interface e reagirá com o silício, de modo que o crescimento térmico faz com que o filme atinja uma espessura limite. Portanto, com o mecanismo proposto tem-se a molécula de amônia atingindo a superfície, sofrendo uma dissociação e os fragmentos penetrando no substrato para reagir com os silícios internos. Com essa difusão os silícios superficiais tornam-se livres novamente, apresentando as dangling bonds, para reagir e incorporar outras moléculas de $\mathrm{NH}_{3}$. Outra reação de nitretação a baixas temperaturas foi realizado por Izumi e Matsumura. ${ }^{22}$ Eles reagiram espécies nitrogenadas, obtidas a partir da decomposição catalítica da amônia utilizando um filamento aquecido de tungstênio, com uma superfície $\mathrm{Si}(100)$. A temperatura do substrato foi mantida em cerca de $200^{\circ} \mathrm{C}$, e eles obtiveram um filme de $3,4 \mathrm{~nm}$ de oxinitreto de silício. A presença de oxigênio não era esperada, e eles especularam que isso poderia ocorrer devido à presença de água no gás $\mathrm{NH}_{3}$, mesmo utilizando um gás com altíssimo grau de pureza. As características da superfície foram acompanhadas através da técnica de espectroscopia fotoeletrônica de raio-X (XPS), e foi observada a presença de picos relacionados com a energia de ligação do $\mathrm{SiO}_{2}$ e do $\mathrm{Si}_{3} \mathrm{~N}_{4}$, e de acordo com isso 
estimaram que a estequiometria do filme deveria ser aproximadamente $\mathrm{Si}: \mathrm{N}: \mathrm{O}=$ $1: 0,9: 0,3$.

Estudos mais recentes têm procurado investigar a incorporação de nitrogênio a partir de outras moléculas, como $\mathrm{N}_{2} \mathrm{O},{ }^{23} \mathrm{NO}_{1}{ }^{24} \mathrm{~N}_{2} \mathrm{H}_{4}{ }^{25,26}$ e $\mathrm{HN}_{3} \cdot{ }^{27}$

Reaçōes em fase gasosa, como a amonólise de compostos reativos de silício, têm sido estudadas, sendo que a reação entre $\mathrm{SiCl}_{4}$ e $\mathrm{NH}_{3}$ produz um filme fino de $\mathrm{Si}_{3} \mathrm{~N}_{4}$. Esse processo não é adequado para a produçāo de grandes quantidades da cerâmica. Jong et $a l^{28}$ estudaram esta reação para temperaturas entre 950 e $1050^{\circ} \mathrm{C}$ e utilizaram vapores de magnésio, que aparentemente tem a função de facilitar a ocorrência da reação, substituindo o uso de laser ou plasma. O magnésio reage com $\circ \mathrm{SiCl}_{4}$, formando $\mathrm{MgCl}_{2}$ (g) e pó de silício, sendo que este último é formado e reage com $\circ \mathrm{NH}_{3}$, produzindo $\mathrm{Si}_{3} \mathrm{~N}_{4}$. Essa reação se processa facilmente a $1050^{\circ} \mathrm{C}$, formando principalmente $\alpha-\mathrm{Si}_{3} \mathrm{~N}_{4}$.

A utilização de altas temperaturas nas técnica de nitretação térmica e na de deposição química de vapor traz conseqüências indesejadas, como, por exemplo, processos de difusão. Nos ṕrocessos onde há a utilização de compostos hidrogenaidos observa-se a presença de uma grande quantidade de átomos de hidrogênio que permanecem presentes no produto final, acarretando uma menor qualidade do material num processo de fabricação de componentes de microeletrônica. Por causa desses inconvenientes, muita atenção tem sido dada ao processo de deposição direta por bombardeamento de íons (direct ion beam deposition) como uma alternativa na obtenção de filmes de nitreto de silício. Essa técnica de bombardeamento apresenta a vantagem de permitir a obtenção de filmes a temperaturas bem mais baixas que nos processos de deposição térmica. Além disso, existem outras vantagens, como a ausência de impurezas indesejáveis e um maior controle na composiçāo do filme e da espessura do mesmo. Esse controle na espessura é importante para a obtenção de filmes ultrafinos.

Com relação à deposição através do bombardeamento com o uso de íons, estudos têm sido realizados com a intenção de compreender o processo de interação desses íons reativos com a superfície. Esse interesse existe porque a natureza do processo 
de deposição é bastante complexa, e por isso as reações são realizadas dentro condições muito bem definidas, para ajudar na compreensão dos mecanismos envolvidos. $O$ entendimento que se tem atualmente dos fenômenos em nível microscópico deve-se em muito ao desenvolvimento de várias técnicas analíticas para o estudo de superfícies, como, por exemplo, a espectroscopia de fotoemissão de raios-X (X-ray photoemission spectroscopy - XPS), espectroscopia de elétrons Auger (Auger electron spectroscopy AES), espectrometria de massa de íons secundários (secondary ion mass spectrometry SIMS).

Para a deposição de filmes de nitreto de silício, alguns trabalhos foram realizados utilizando o bombardeamento de íons $\mathrm{N}_{2}^{+}$e $\mathrm{N}^{+}$com elevada energia, da ordem de keV, sobre uma superfície de silício. ${ }^{29,30}$ Nessas condições, os íons penetram no substrato abaixo da superfície e, com essa energia, são capazes de quebrar as ligações desses silícios internos através de colisões, de modo que os átomos de nitrogênio reagem e se rearranjam formando estruturas estáveis de nitreto de silício. Nesse sentido, podemos citcir o trabalho de Pan et al., ${ }^{29}$ onde eles realizaram reações através do bombardeamento de íns $\mathrm{N}^{+}$e $\mathrm{N}_{2}^{+}$com a superfície $\mathrm{Si}(100)$, sendo que os íons apresentavam energia cinética de $10 \mathrm{keV}$. Eles acompanharam a evolução da reação através da técnica de espectroscopia de elétrons Auger, para verificar a influência da dosagem de íons incidentes e do ângulo de incidência. Os resultados mostraram que a exposição contínua do jato incidente com a superfície leva facilmente à ausência de átomos de silício que não reagiram: Eles não observaram uma grande diferença nos resultados obtidos com $\mathrm{N}^{+}$ e $\mathrm{N}_{2}^{+}$, sendo que a concentração inicial de nitrogênio aumenta rapidamente com o aumento da quantidade de íons incidentes, e a saturação ocorre com a dosagem de $5.10^{16} \mathrm{~N}_{2}^{+} / \mathrm{cm}^{2}$. A partir desse valor, a relação da concentração entre $\mathrm{N}$ e Si da superfície é próxima a 1,25 , indicando uma estequiometria próxima do $\mathrm{Si}_{3} \mathrm{~N}_{4}$, onde a relaçāo é de 1,33. Uma nitretação completa, com a formação de $\mathrm{Si}_{3} \mathrm{~N}_{4}$, foi observada para ângulos incidentes entre $0^{\circ}$ e $30^{\circ}$ em relação à normal da superfície. Para ângulos maiores que $30^{\circ}$ há uma diminuiçāo do grau de nitretação da superfície e para valores maiores que $60^{\circ}$ praticamente não há a formação de nitreto de silício. Esses dados estão em concordância com os resultados teóricos que predizem que a incidência normal 
proporciona a máxima eficiência para a incorporaçāo dos íons. Em todas essas condiçōes, eles não notaram diferenças nos resultados entre o bombardeamento de $\mathrm{N}^{+}$e de $\mathrm{N}_{2}^{+}$

Uma outra experiência de bombardeamento foi realizada por Bachurin et al.. ${ }^{30}$ Neste caso, o $\mathrm{Si}(100)$ foi bombardeado por $\mathrm{N}_{2}^{+}$com energias entre 3 e $9 \mathrm{keV}$ em um sistema de ultra-alto vácuo, com pressões da ordem de $10^{-10}$ torr. Eles estudaram os efeitos da energia dos íons incidentes, do ângulo de incidência e da temperatura utilizando técnicas de espectroscopia de elétrons Auger, espectrometria de massa de íons secundários e espectroscopia no infravermelho com transformada de Fourier. No caso de bombardeamento com ângulos próximos da direção normal à superfície, eles observaram a formaçāo de uma camada superficial amorfa de $\mathrm{Si}_{3} \mathrm{~N}_{4}$. Para ângulos maiores que $37^{\circ}$ a concentração de nitrogênio é menor que a estequiometria do $\mathrm{Si}_{3} \mathrm{~N}_{4}$. À medida que o ânguio de incidência aumenta, há uma diminuição da espessura da camada formada e da concentração de nitrogênio, pois começa a aumentar a eliminação de nitrogênio através da superfície. Através da técnica de espectroscopia no infravermelho com transformada de Fourier eles observaram que o bombardeamento com ângulos próximos à direção normal à superfície produz uma camada superficial amorfa de $\mathrm{Si}_{3} \mathrm{~N}_{4}$, e a principal freqüência de absorção observada desta camada é de $820 \mathrm{~cm}^{-1}$.

Estudos de bombardeamento com íons $\mathrm{N}^{+}$e $\mathrm{N}_{2}^{+}$menos energéticos foram feitos por Park et al... ${ }^{31,32}$ Inicialmente, eles estudaram as reações com íons de baixa energia, entre 1 e 300 eV, com a superfície Si(100) e verificaram a influência da energia cinética e da dosagem de íons incidentes na superfície, sendo as espécies resultantes caracterizadas por espectroscopia de elétrons Auger e espectroscopia fotoeletrônica no ultravioleta. A partir do espectro ultravioleta e comparando com resultados de cálculos da densidade de estado da estrutura cristalina do $\mathrm{Si}_{3} \mathrm{~N}_{4}$, obtiveram que $\circ$ silício encontra-se tetraedricamente ligado a quatro nitrogênios e cada nitrogênio apresenta uma estrutura planar, ligado a três silícios. A probabilidade absoluta de reação, $P_{r}$ que é a relação entre a quantidade de íons que reagiram de modo efetivo pela quantidade de íons incidentes, apresenta resultados diferentes para os íons $\mathrm{N}^{+}$e $\mathrm{N}_{2}^{+}$. $\mathrm{O}$ valor dessa probabilidade para o ion $\mathrm{N}^{+}$é de aproximadamente 0,25 e permanece constante parg 
energias entre 1 e $25 \mathrm{eV}$, enquanto que no caso do ín $\mathrm{N}_{2}^{+}$o valor aumenta de zero até 0,25 nessa mesma faixa de variação de energia. A partir dos resultados da espectroscopia Auger, eles observaram que filmes com composição estequiométrica muito mais próxima do $\mathrm{Si}_{3} \mathrm{~N}_{4}$ podem ser obtidos com íons de baixa energia, se comparados com íons com energia da ordem de keV. A partir dos espectros obtidos eles puderam observar a ausência de átomos de silício na superfície que não reagiram. Além disso, estimaram a espessura da camada de nitreto de silício formada. Para bombardeamento de $\mathrm{N}_{2}^{+}$com energias entre 20 e $100 \mathrm{eV}$, estimaram um valor de 3,6 a $5,9 \AA$, enquanto que para energias da ordem de $200 \mathrm{eV}$ a camada deve ser maior que $5,9 \AA$, já que sinais do $\mathrm{Si}$ do substrato não foram mais observados no espectro Auger. A partir dos resultados do estudo da formação do filme como uma função da dosagem de $\mathrm{N}_{2}^{+}$incidente, eles observaram que a concentração superficial de nitrogênio aumenta rapidamente com pequenas dosagens de íons, diminui e finalmente atinge a saturarsõo para altas doses de $\mathrm{N}_{2}^{+}$. A dosagem necessária para atingir a saturação aumenta de 1 $2.10^{15}$ ions $/ \mathrm{cm}^{2}$, para energias dos íons de $5-10 \mathrm{eV}$, para $5.10^{15}$ íns $/ \mathrm{cm}^{2}$, para $50-100$ eV. Com relação às etapas do mecanismo de nitrełação, consideraram que ocorre em duas etapas. Primeiramente, os íons incidentes sofrem neutralização quando aproximamse a poucos $\AA$ da superfície, através de ressonância ou de processos eletrônicos Auger. Estima-se que essa neutralização ocorre com grande eficiência para íons incidentes com baixa energia (< $100 \mathrm{eV}$ ), de modo que praticamente pode-se considerar que são moléculas neutras que reagem com a superfície de silício. As espécies neutras incidentes mantêm a energia cinética inicial e colidem com a superfície, sendo que a partir daí muitas possibilidades de reações passam a existir. Pode ocorrer a dissociação do nitrogênio molecular com a conseqüente incorporação dos átomos de nitrogênio para formar a superfície de nitreto de silício, assim como acontecer um espalhamento da molécula ou dos átomos de nitrogênio formados na dissociação do $\mathrm{N}_{2}$. A formação do nitreto de silício é termodinamicamente favorável, sendo o processo exotérmico por 3,86 $\mathrm{eV}$, com a formaçāo de $\mathrm{Si}_{3} \mathrm{~N}_{4}$. A interação da superfície com $\mathrm{N}_{2}$ ocorre de maneira eficiente se os íons incidirem com energia cinética pelo menos suficiente para poder romper com a forte ligạçāo $\mathrm{N}-\mathrm{N}(9,76 \mathrm{eV})$, já que à temperatura ambiente as moléculas nõo possuem energia suficiente para ultrapassar essa alta energia de ativação. Após o $N_{2}$ 
sofrer dissociação, os fragmentos apresentam uma reatividade semelhante à do $\mathrm{N}^{+}$ incidente. Aparentemente, há a possibilidade de que estados excitados do $\mathrm{N}_{2}$ tomem parte da reação, pois a banda de valência do Si apresenta uma sobreposição com vários estados excitados do $\mathrm{N}_{2}$, de modo que uma eficiente neutralização por ressonância pode ocorrer nesses estados excitados. Diferentemente do $\mathrm{N}_{2}^{+}$, quando trata-se do íon $\mathrm{N}^{+}$, observa-se que este apresenta um $P_{r}$ praticamente independente da energia cinética. Essa diferença é atribuída ao fato da colisão do $\mathrm{N}^{+}$levar a apenas duas conseqüências, a incorporação na superfície levando à nitretação do silício ou sofrer um espalhamento. Quando uma forte ligação química é formada (a energia de ligação Si-N é aproximadamente $6,8 \mathrm{eV}$ entre $\circ$ ín incidente e a superfície, a trajetória dessas partículas de baixa energia torna-se fortemente influenciada pelo potencial atrativo próximo à superfície. A energia cinética remanescente após a colisāo torna-se relativamente insignificante comparada com o potencial e, freqüentemente, não é suficiente para permitir o escape da superfície. Isso pode levar a valores altos de $P_{r}$ mas experimentalmente observou-se que o valor não é unitário, e os autores atribuem isso a possíveis fatores, como os silícios dímeros não estarem densamente povoados na superfície ou os possíveis rearranios necessários no $\mathrm{Si}(100)$ durante o processo de nitretação. Um resultado importante obtido por eles é que o bombardeamento com íons de baixa energia leva a umałcomposição e a uma geometria muito próxima do $\mathrm{Si}_{3} \mathrm{~N}_{4}$, apresentando uma distância $\mathrm{N}-\mathrm{N}$ e o átomo de nitrogênio localizado no plano $\mathrm{N}-\mathrm{Si}_{3}$ típicos de uma estrutura cristalina do $\mathrm{Si}_{3} \mathrm{~N}_{4}$. Esse fato não se verifica quando utilizam-se íons com elevada energia, da ordem de keV, pois nesse caso ocorrem fenômenos como sputtering de átomos de nitrogênio e danos provocados na superfície pelos íons incidentes. Com isso há a formação de nitretos de silício com composição subestequiométrica: Ao utilizar íons com energias menores ocorre uma diminuição desses sputfering e dos danos causados na superfície, de modo que a composição da superficial tende termodinamicamente para a formação do produto estável $\mathrm{Si}_{3} \mathrm{~N}_{4}$.

O papel de átomos de sódio pré-adsorvidos na superfície do silício no processo de nitretação usando jatos moleculares de $\mathrm{N}_{2}$ com energia cinética entre 119 e 659 meV foi estudado por Bush et al.. ${ }^{33,34} \mathrm{~A}$ vantagem do uso de metais alcalinos é que a remoção dos mesmos por desorção térmica ocorre a temperaturas relativamente baixas, da ordem 
de $900 \mathrm{~K}$. A reação entre $\mathrm{N}_{2}$ e a superfície começa a ocorrer em quantidade perceptível somente a temperaturas acima de $450 \mathrm{~K}$, mas na presença de sódio a mesma se processa muito mais facilmente, ocorrendo à temperatura de $300 \mathrm{~K}$ e com moléculas incidentes de baixa energia (119 meV). Essa reação sugere um mecanismo local, onde o nitrogênio interage diretamente com os átomos de sódio. $O$ nitreto de silício começa a ser formado a $300 \mathrm{~K}$, mas esse processo aumenta com a remoçāo do sódio a 873 K, sugerindo que é inicialmente aprisionado em um estado intermediário na vizinhança do sódio adsorvido. Um mecanismo proposto consiste na formação de um estado molecular adsorvido $\left(\mathrm{N}_{2}^{-}\right)$. Essa espécie adsorvida é formada pela transferência direta de elétrons do sódio para a molécula $\mathrm{N}_{2}$, e a espécie iônica resultante liga-se diretamente com o silício próximo ao sódio. $O$ aquecimento pode levar a uma dissociação nos átomos de nitrogênio ou sofrer desorçāo como $\mathrm{N}_{2}$ para a fase gasosa. $O$ primeiro processo parece ser o preferencial, levando à formação de nitreto de silício.

Li et $a /^{35}$ estudaram a implantação de nitrogênio no silício, formando filmes amorfos com composição de nitrogênio superior e inferior à do $\mathrm{Si}_{3} \mathrm{~N}_{4}$, para em seguida introduzir átomos de ferro e examinar o seu efeito no processo de cristalização para formar $\alpha-\mathrm{Si}_{3} \mathrm{~N}_{4}$. Eles observaram que a presença do ferro diminui em muito a temperatura de cristalização para menos de $1000^{\circ} \mathrm{C}$, enquanto que nas amostras sem ferro essa temperatura tem que ser superior a $1250^{\circ} \mathrm{C}$. Nos casos estudados, o ferro foi expelido da fase contendo o nitrogênio durante a cristalização. A presença de oxigênio dificulta o processo de cristalizaçāo, mesmo na presença de ferro.

Lakshminarasimham e Gopalakrishnan ${ }^{36}$ estudaram a presença de oxigênio no $\alpha$ $\mathrm{Si}_{3} \mathrm{~N}_{4}$ e a influência no espectro infravermelho. Amostras de nitreto de silício foram preparadas por diferentes procedimentos: (a) amonólise do pó de silício; (b) nitretação de uma mistura equimolar de silício e sílica e (c) redução carbotérmica da sílica. Os padrōes obtidos a partir da difração de raio $X$ das quatro amostras mostraram a maior presença da fase $\alpha$, estando a fase $\beta$ presente em quantidade muito pequena. Maiores diferenças puderam ser observadas a partir do espectro infravermelho. As amostras dos métodos (a) e (b) não apresentaram sinais de absorçāo em cerca de $950 \mathrm{~cm}^{-1}$, que corresponde ao modo de estiramento antissimétrico do $\mathrm{Si}-\mathrm{N}-\mathrm{Si}$, mostrando a menor quantidade de 
nitrogênio que o valor teórico de 39,93 \%. Essa diminuição da intensidade também foi atribuída à presença de oxigênio no interior do material, cuja existência foi comprovada experimentalmente.

\section{Estudos teóricos da interação de substâncias com a superfície Si(100)}

O desenvolvimento cada vez maior de métodos teóricos e computacionais para o estudo de estruturas atômicas e moleculares tem gerado um interesse no estudo de materiais e suas propriedades. Muitas dessas pesquisas têm sido realizadas utilizando o método do Funcional da Densidade, e como exemplo das várias aplicaçōes podemos citar o artigo de Wimmer, ${ }^{37}$ onde apresenta resultados da adsorçāo química do silano na superfície nāo reconstruída Si(001), a adesão do $\mathrm{NH}_{3}$ em uma superfície de $\mathrm{CuO}(111)$, propriedades estruturais do $\mathrm{LaNi}_{5}$, propriedades ópticas do rubi entire outros. $\mathrm{O}$ interesse no estudo dos mecanismos e propriedades em nível atômico e molecular desses materiais tem sido motivado pela contínua miniaturização dos componentes, principalmente da indústria de semicondutores, e esse processo faz com que os fenômenos quânticos tenham importância cada vez maior. Nesse sentido, muitos esforços têm sido feitos na utilização de métodos de química teórica para o estudo dos processos de adsorção em superfícies, visando compreender fenômenos como, por exemplo, a incorporação de átomos e moléculas na superfície do silício. A compreensão dos mecanismos envolvidos nesses processos é de grande importância tecnológica, pois muitos materiais são sintetizados a partir dessas reações de incorporação. O número de trabalhos nesse sentido é, hoje em dia, enorme, e não é nosso interesse fazer aqui uma revisão geral de todos os casos, mas apenas mencionar alguns sistemas estudados e, com isso, mostrar o que se faz atualmente em matéria de simulação de reações com superfícies.

Como exemplo das primeiras tentativas podemos citar o trabalho de Ru-Hong et al., ${ }^{38}$ onde é estudado pela primeira vez, sob o ponto de vista teórico, a adsorção da amônia nas superfícies $\operatorname{Si}(100)$ e Si(1 11) não reconstruídas. Eles utilizaram o método DV$X_{\alpha}$ (método $X_{\alpha}$ variacional discreto) para obtenção de geometrias, densidade de estados e transferência de cargas entre adsorbato e substrato. Os resultados mostraram que a 
reatividade das duas superficies são diferentes, sendo que na $\mathrm{Si}(100)$ a amônia sofre uma adsorção dissociativa nos dangling bonds, sem barreira de ativaçāo, formando $\mathrm{NH}_{2}(\mathrm{a})$ e $H(a)$, enquanto que na superfície $\mathrm{Si}(111)$ ela é adsorvida molecularmente, sem dissociação. Um trabalho mais recente de adsorçāo da amônia foi realizado por Fattal et al., ${ }^{39}$ onde foram estudadas as estruturas e energias envolvidas na adsorção em $\mathrm{Si}(100)$. O nível de teoria adotado foi MRSDCl (Interação de Configuraçōes com excitaçōes simples e duplas a partir de múltiplas referências). Eles adotaram o aglomerado de fórmula $\mathrm{Si}_{9} \mathrm{H}_{12}$ para a representação da superfície e a metodologia CASSCF para a obtenção das geometrias de equilíbrio. Foi observada que a adsorção ocorre em duas etapas, sendo que inicialmente há a adsorçāo química molecular e sem barreira do $\mathrm{NH}_{3}$, seguida de uma dissociação formando $\mathrm{NH}_{2}(\mathrm{a})$ e $\mathrm{H}(\mathrm{a})$.

Uma reação muito estudada é a oxidação da superfície de silício. Raghavachari et $a .^{40-42}$ estudaram as estruturas, freqüências vibracionais e enerģias de vários canais de inserção de oxigênio. Essas possibilidades represeritam os primeiros passos da reação entre a superfície, representada pelo aglomerado $\mathrm{Si}_{9} \mathrm{H}_{12}$, com molécula de água. Okamoto $^{43}$ propôs e examinou alguns caminhos de reação entre $\mathrm{H}_{2} \mathrm{O}$ e $\mathrm{Si}(100)$, utilizando o método do Funcional da Densidade. Oito etapas foram estudadas, levando em conta a reação com duas moléculas de água, sendo que no final cada silício dímero apresenttou um grupo hidroxila ligado a ele.

A reação de adsorção e/ou desorção de $\mathrm{H}_{2}$ é muito estudada tanto experimentalmente quanto teoricamente, devido à sua importância e relativa simplicidade. Pai e Doren ${ }^{44}$ estudaram o mecanismo de desorção de $\mathrm{H}_{2}$ a partir de um processo de recombinação dos átomos de hidrogênio e obtiveram valores razoáveis para a energia de ativação para a desorção utilizando a metodologia do funcional da densidade. Carter et $a / .^{45,46}$ estudaram três mecanismos de desorção do $\mathrm{H}_{2}$ utilizando cálculos CASSCF e MRCI. A partir dos resultados da cinética e dinâmica sugeriram que o mecanismo que fornece resultados comparáveis com o experimental é o dihidreto (dihydride) isolado, diferente do mecanismo de pré-emparelhamento (prepairing).

Muitos trabalhos foram também realizados com a intenção de compreender os processos envolvidos na incorporaçāo de átomos na superfície do silício. Podemos 
mencionar os estudos feitos com cloro, ${ }^{47-49}$ carbono, $^{50}$ cobre e ferro, $^{51}$ arsênio $^{52}$ e bismuto, ${ }^{53}$ com metodologias variando do semiempírico e Hartree-Fock ao Funcional da Densidade.

O estudo de reações em superfícies é uma área de pesquisa de grande potencial tecnológico e cujas propriedades químicas em diversas reaçōes têm sido estudadas com muito interesse nesses últimos anos. Isso pode ser observado pelo grande número de trabalhos voltados aos processos de interação com as mais diversas moléculas, como $\mathrm{CO},{ }^{54,55} \mathrm{BH}_{3}{ }^{56} \mathrm{SiH}_{4}$ e seus fragmentos, ${ }^{57,58} \mathrm{SiCl}_{4}{ }^{59}$ moléculas orgânicas como etileno, ${ }^{60}$ acetileno, ${ }^{61}$ e reações do tipo Diels-Alder, ${ }^{62}$ com substâncias orgânicas contendo ligações duplas conjugadas, até complexos organometálicos. ${ }^{63} \mathrm{Em}$ todos esses estudos foram utilizados aglomerados de silício para a representação da superfície e os cálculos foram feitos utilizando a teoria do Funcional da Densidade, principalmente com o funcional híbrido B3LYP. Nesses exemplos, procuramos apenas dor uma idéia da variedade de sistemas estudados e da riqueza da química envolvida em processos superficicis. 


\section{III.2 ABORDAGENS TEÓRICAS}

Para o estudo das diversas estruturas possíveis obtidas através da incorporação de um átomo de nitrogênio numa superfície Si(100), utilizamos o aglomerado de fórmula $\mathrm{Si}_{9} \mathrm{H}_{12}$ para a simulação desta superfície. Esse aglomerado está representado na Figura 12, na seção II.3, e podemos ver que este consiste basicamente de quatro camadas de átomos de silício. A primeira contém dois átomos, representando os silícios dímeros superficiais, que estão conectados aos quatro átomos da segunda camada. A terceira e quarta camada apresentam dois e um átomos de silício, respectivamente. A valência dos silícios internos são saturadas com átomos de hidrogênio. Esse aglomerado apresenta apenas dois silícios na superficie, de modo que o estudo fica restrito apenas à interação entre o átomo de nitrogênio e os dois silícios dímeros.

A base atômica adotada foi a ó-31G para os átomos de hidrogênio e os três silícios mais internos e $6-31 G^{*}$, com cinco componentes para a função $d$, para o átomo de nitrogênio ${ }^{64}$ e os seis silícios ${ }^{65}$ restantes, que correspondem aos dois dímeros e aos quatro silícios da primeira camada. Essa diferenciação na base adotada foi feita com a finalidade de diminuir o tempo de computação, pois testes realizados com o aglomerado $\mathrm{Si}_{9} \mathrm{H}_{12}$ mostraram que as distâncias entre os átomos de silício variam muito pouco nas camadas mais internas utilizando as duas bases.

Para o estudo das estruturas utilizamos a metodologia do Funcional da Densidade, com o funcional híbrido B3LYP, que combina o funcional de troca com três parâmetros de Becke com o funcional de correlação de Lee, Yang e Parr. ${ }^{66,67}$ As otimizaçōes geométricas foram realizadas utilizando técnicas analíticas de gradiente, disponível no programa Gaussian 98..$^{68}$ Esse programa está implementado nos computadores CRAY J90 e IBM-RS6000, localizados no Laboratório de Computaçāo Científica Avançada (LCCA), da Universidade de São Paulo. 


\section{III.3 O SISTEMA $\mathrm{Si}_{9} \mathrm{H}_{12}+1 \mathrm{~N}-$ QUARTETO}

Inicialmente, estudamos uma série de possibilidades de interação de um átomo de nitrogênio com o aglomerado $\mathrm{Si}_{9} \mathrm{H}_{12}$, que usamos como modelo para representar a superfície Si(100). Restringimo-nos inicialmente às estruturas com simetria de spin quarteto considerando a adição de momento angular do átomo de nitrogênio no estado fundamental $\left({ }^{4} \mathrm{~S}\right)$ interagindo com o aglomerado $\mathrm{Si}_{9} \mathrm{H}_{12}$ singleto $\left({ }^{1} \mathrm{~A}_{1}\right)$. Diversas estruturas quarteto foram testadas, com o nitrogênio ligado a um, dois e três átomos de silício. As estruturas dupleto serão discutidas na próxima seção, sendo que as estruturas com essa simetria de spin podem ser obtidas a partir da neutralização de íons de nitrogênio, durante um processo de deposição com feixes de íons, em átomos neutros excitados.

Na maioria dos casos obtivemos estruturas quarteto localizadas em pontos de sela de segunda ordem ou ordens superiores; a convergência para estruturas localizadas em pontos de mínimo na superfície de energia potencial ocorreu em apenas três casos. Estas podem ser vistas na Figura 16, correspondendo às estruturas I, II e IV, onde mostramos as energias relativas das mesmas. No processo de otimização geométrica, é importante ressaltar que realizamos alguns vínculos na geometria, mantendo fixas as posições dos hidrogênios e permitindo a livre movimentação dos silícios e do nitrogênio. Essa adoção de vínculos foi feita tanto para diminuir o número de variáveis a serem otimizadas quanto para procurar simular de maneira aproximada a rigidez da estrutura cristalina do silício, pelo menos para os átomos não diretamente envolvidos no processo de adsorção. A natureza dos pontos estacionários obtidos foram analisadas através do cálculo das freqüências vibracionais dentro da aproximação do oscilador harmônico. 


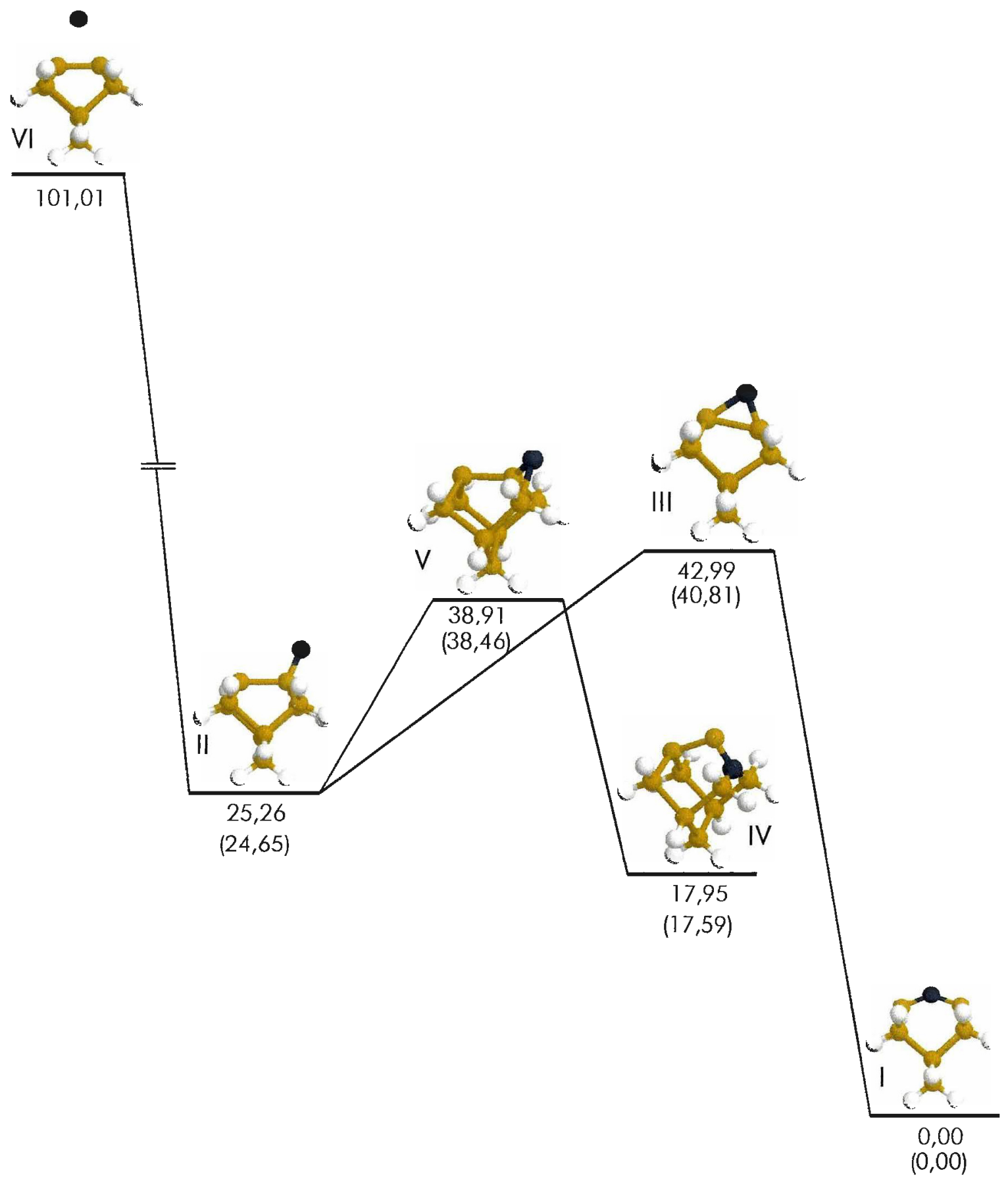

Figura 16. Energia relativa e energia livre de Gibbs (entre parênteses, calculada a 298,15 K), em $\mathrm{kcal} / \mathrm{mol}$, para as estruturas quarteto representativas ao longo do caminho de reação da adsorção de $\mathrm{N}$ na superfície $\mathrm{Si}(100)$ modelada pelo aglomerado $\mathrm{Si}_{9} \mathrm{H}_{12}$. 
A estrutura mais estável corresponde a l, e podemos ver na Figura 17 os parâmetros geométricos relevantes, sendo os valores de cargas atômicas e densidade de spin apresentados na Figura 18. Na Figura 17 podemos ver o nitrogênio ligado simetricamente aos dois silícios dímeros, sendo o ângulo SiNSi obtido de $139,1^{\circ}$ e a distância de ligaçāo $\operatorname{SiN}(1,712 \AA)$ ligeiramente menor que a de uma típica ligação simples, como no caso do $\mathrm{H}_{3} \mathrm{Si}-\mathrm{NH}_{2}{ }^{69,70}(1,72 \AA)$. Os silícios dímeros estão bastante afastados $(3,209 \AA)$, indicando uma interaçāo muito fraca entre esses dois átomos. Essa distância é apenas cerca de 15\% menor que a distância entre os silícios superficiais em uma superfície não reconstruída $(3,84 \AA)$. $\bigcirc$ cálculo das freqüências indica ser essa uma estrutura localizada em um ponto de mínimo. A partir da análise dos modos vibracionais temos dois que estão relacionados com os silícios superficiais e o nitrogênio, e na Figura 19 podemos ver a representação desses modos e os valores das intensidades relativas. A freqüência de $566 \mathrm{~cm}^{-1}$ praticamente não aparece no espectro e a de $1015 \mathrm{~cm}^{-1}$ tem intensidade muito baixa, o que leva a concluir a dificuldade de se identificar esse tipo do estrutura num experimento de espectroscopia no infravermelho.

No caso da estrutura II temos o nitrogênio ligado a apenas um dos silícios dímeros, sendo a distância $(1,773 \AA)$ também típica de uma ligação simples. Ela está representada na Figura 17, onde podemos ver os silícios dímeros apresentando uma ligação química, sendo a separação $(2,397 \AA)$ também da ordem de uma ligaçāo simples e ligeiramente maior que a distância obtida no aglomerado $\mathrm{Si}_{9} \mathrm{H}_{12}$ isolado, onde a separação era cerca de 2,22 $\AA$. Interessante observar que a incorporação do nitrogênio não altera a reconstrução entre os silícios dímeros, e que estes apresentam uma estrutura simétrica com a incorporação do nitrogênio, independente se a geometria de partida do aglomerado $\mathrm{Si}_{9} \mathrm{H}_{12}$ para a otimização era simétrica ou assimétrica (buckled). Essa estrutura é $25,26 \mathrm{kcal} / \mathrm{mol}$ menos estável que l, e do mesmo modo encontra-se em um ponto de mínimo. Na Figura 19 vemos que os modos associados aos silícios dímeros e o nitrogênio apresentam intensidade muito fraca, o que deve, do mesmo modo que em I, dificultar a identificação. Conforme veremos a seguir, essa estrutura localiza-se em um ponto de mínimo, mas é um estado intermediário que sofre estabilização ao sofrer uma conversão para duas outras possíveis estruturas. 

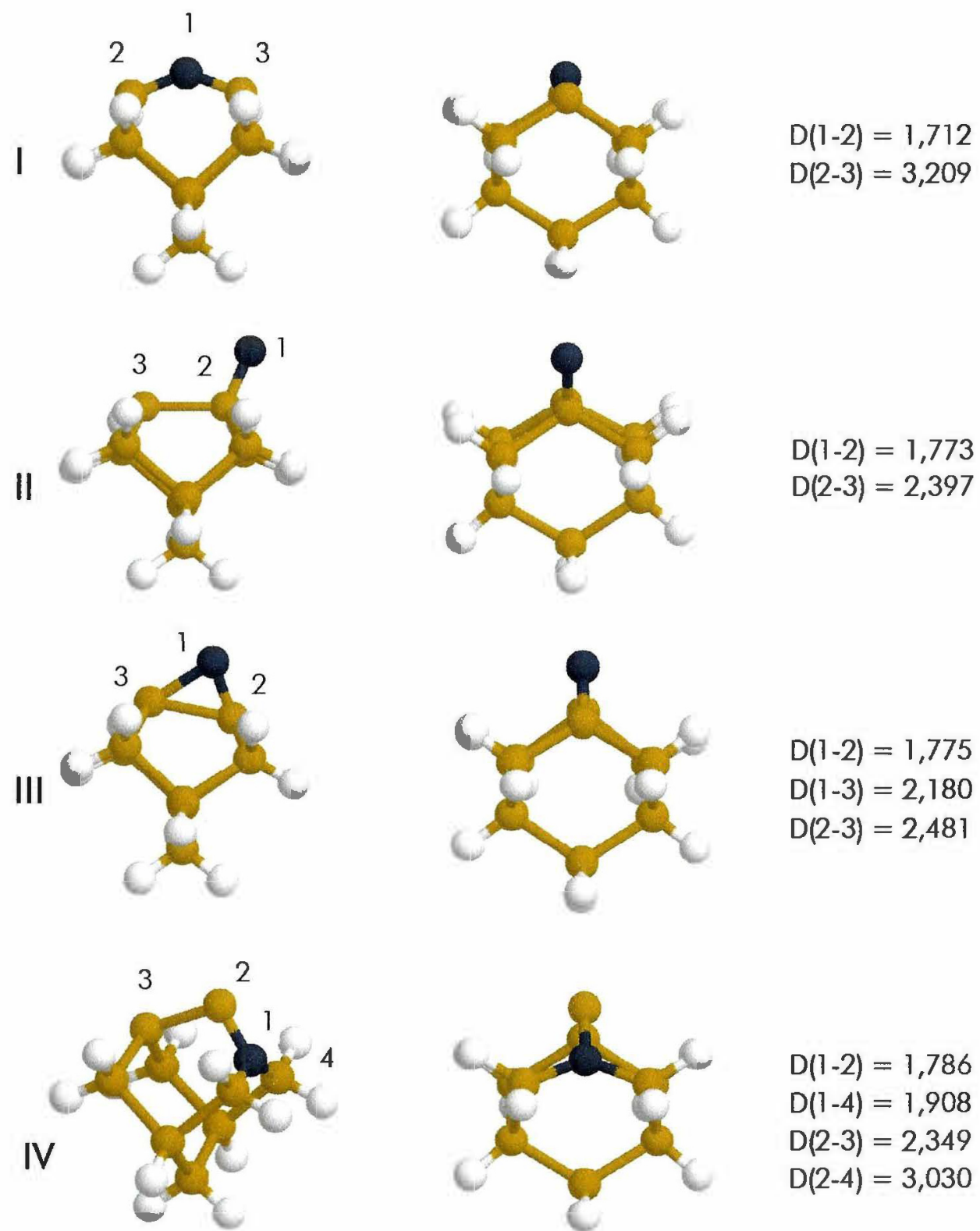

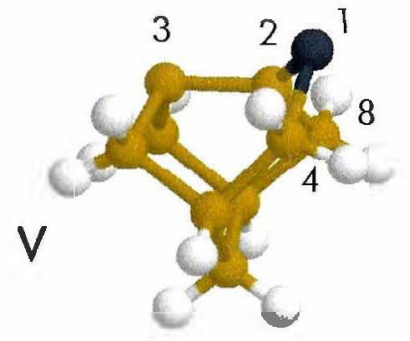

a

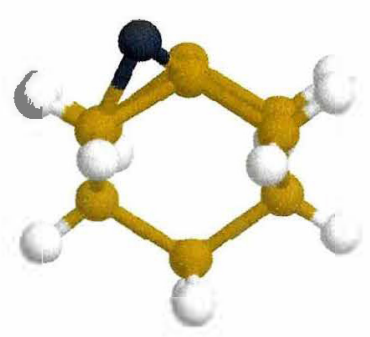

b

Figura 17. Parâmetros geométricos calculados para as estruturas quarteto representativas ao longo do caminho de reação da adsorção de $\mathrm{N}$ na superfície $\mathrm{Si}(100)$ modelada pelo aglomerado $\mathrm{Si}_{\mathrm{i}} \mathrm{H}_{12}$. A visão a é perpendicular aos silícios dímeros, e b é ao longo dos dímeros. As distâncias são dadas em Ångstrom. 

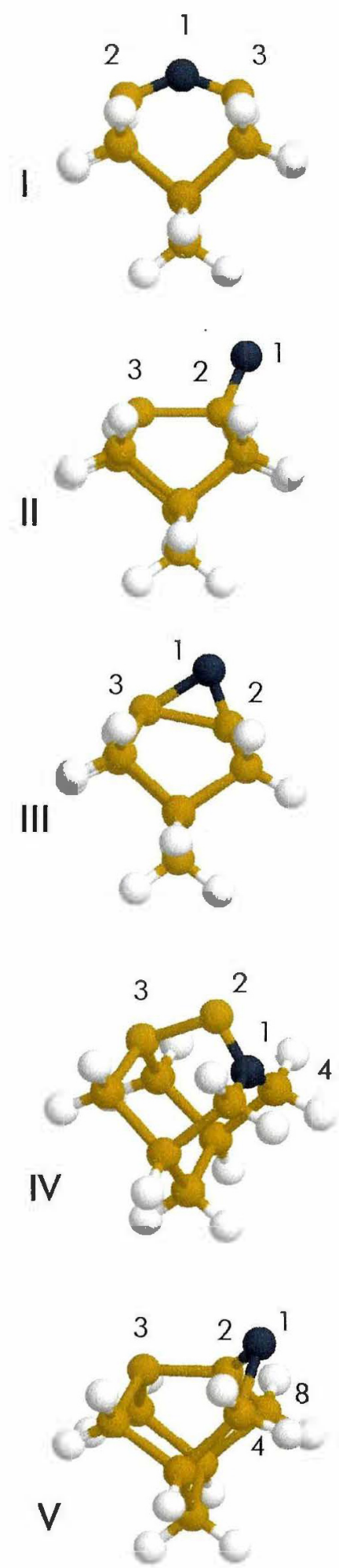

CARGAS ATÔMICAS:

$$
\begin{aligned}
& 1=-0,505 \\
& 2=0,301 \\
& 3=0,301
\end{aligned}
$$

$$
1=-0,299
$$$$
2=0,252
$$$$
3=-0,011
$$

$1=-0,388$

$2=0,184$

$3=0,171$

$1=-0,819$

$2=0,150$

$3=0,000$

$4=0,437$

$1=-0,383$

$2=0,186$

$3=0,023$

$4=0,207$

$8=0,112$
DENSIDADE DE SPIN

ATÔMICO TOTAL:

$$
\begin{aligned}
& 1=0,918 \\
& 2=0,639 \\
& 3=0,639
\end{aligned}
$$

$$
\begin{aligned}
& 1=1,794 \\
& 2=-0,151 \\
& 3=0,998
\end{aligned}
$$

$$
\begin{aligned}
& 1=1,398 \\
& 2=0,316 \\
& 3=0,743
\end{aligned}
$$

$1=0,217$

$2=1,453$

$3=1,064$

$4=-0,007$

$1=1,406$

$2=0,190$

$3=0,953$

$4=-0,002$

$8=0,092$

Figura 18. Cargas atômicas e densidade de spin calculadas para as estruturas quarteto representativas ao longo do caminho de reação da adsorção de $\mathrm{N}$ na superfície $\mathrm{Si}(100)$ modelada pelo aglomerado $\mathrm{Si}_{9} \mathrm{H}_{12}$. 


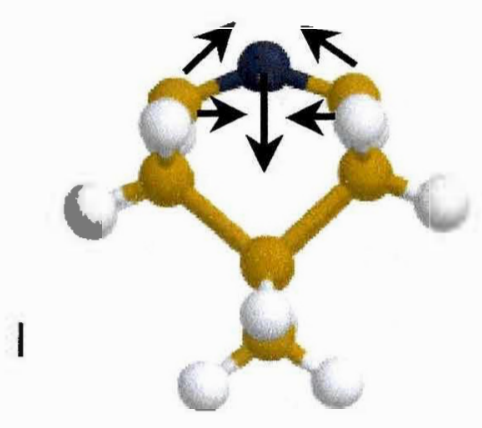

$$
v=566 \mathrm{~cm}^{-1}
$$

(1)

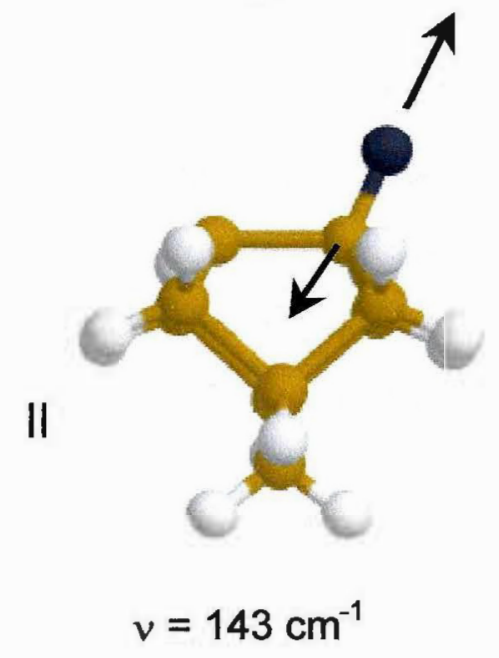

(8)

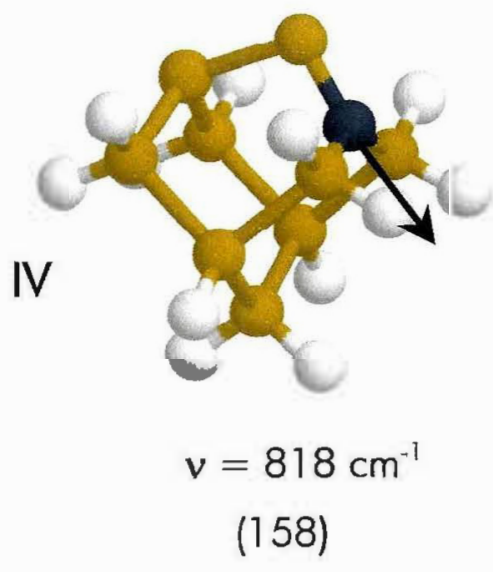

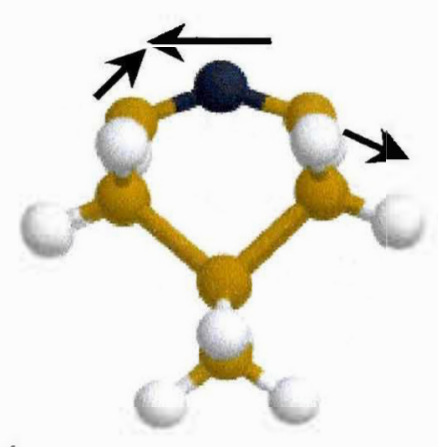

$$
v=1015 \mathrm{~cm}^{-1}
$$

(53)

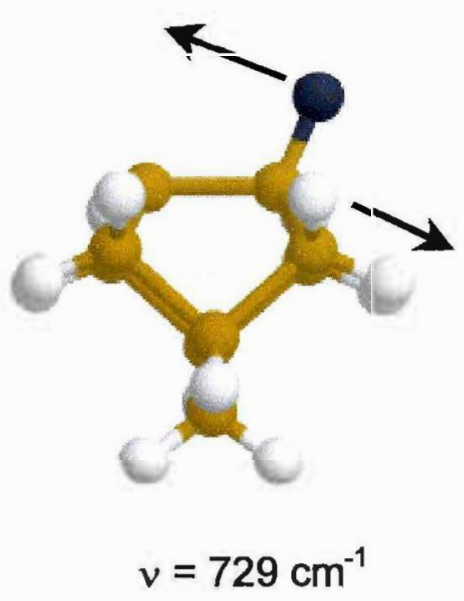

(14)

Figura 19. Freqüências vibracionais $\left(\mathrm{em} \mathrm{cm}^{-1}\right)$ e intensidades (entre parênteses, em $\mathrm{km} / \mathrm{mol}$ ) calculadas para modos vibracionais selecionados das estruturas quarteto I, II e IV. 
Como as estruturas representativas dos casos I e II correspondem a pontos de mínimo, nosso interesse imediato foi verificar a existência ou não de um estado de transição que conecte essas duas geometrias. Para essa busca utilizamos o método Synchronous Transit-Guided Quasi-Newton (STQN) que está implementado no programa Gaussian 98. Na Figura 17 temos os parâmetros geométricos da estrutura III, bem como valores de cargas atômicas e densidades de spin na Figura 18. Na Figura 20 podemos ver o modo vibracional relacionado com a freqüência imaginária. Partindo da estrutura II para I vemos que o estado de transição tem uma geometria intermediária entre esses dois casos. Com a aproximação do nitrogênio ao outro silício ocorre uma distorção nos silícios dímeros no estado de transição, tornando-os assimétrico, sendo que essa distorção deixa de existir quando o nitrogênio liga-se ao outro silício, formando a estrutura I. Além dessa distorção e da aproximação do nitrogênio, os demais parâmetros em III pouco variaram em relaçāo à estrutura II, pois a ligaçāo nitrogênio-silício permaneceu praticamente inalterada, eniquanto a clistância entre os silícios dírieros aumentou em cerca de $0,08 \AA$, sendo o valor obiido de 2,481 $\AA$. Nesse estado de transição a distância entre o nitrogênio e o silício dímero deslocado mais para baixo é de 1,775 $\AA$, enquanto que com o outro silício a distância é bem maior, de 2,180 $\AA$. Com relação aos valores de energia, o estado de transição encontra-se a $42,99 \mathrm{kcal} / \mathrm{mol}$ e $17,73 \mathrm{kcal} / \mathrm{mol}$ das estruturas I e II, respectivamente, conforme podemos ver pela Figura 16. Através dos valores da densidade de spin na Figura 18 pode-se ter uma idéia das ligaçōes químicas envolvidas nessas estruturas. No caso 11 , o valor de 0,998 no silício dímero não ligado ao nitrogênio indica a presença de uma dangling bond, sendo que, no caso do outro silício, o valor muito pequeno $(0,151)$ indica que o elétron que corresponderia ao dangling bond está envolvido na ligação com o nitrogênio, que por sua vez apresenta dois elétrons desemparelhados. Em uma linguagem simplificada em termos de ligações, podemos ver a existência de uma ligação simples entre o silício e o átomo de nitrogênio e entre os silícios dímeros. Portanto, essa imagem pode ser obtida tanto pelos valores das distâncias de ligação quanto pelos valores da densidade de spin dos átomos de interesse. No estado de transição começa a ocorrer a quebra da ligaçāo entre os silícios dímeros. Isso pode ser observado pelo aumento na distância entre os átomos, que passou de 2,397 $\AA$ para $2,481 \AA$, e pela variação na densidade de spin do silício ligado ao nitrogênio, cujo valor passou de $-0,151$ para 0,316. Como seria de se 
esperar, o outro silício, que não se encontra ligado ao nitrogênio, apresenta uma diminuição, passando de 0,998 para 0,743 . Na estrutura I temos os silícios dímeros praticamente separados, e ambos apresentam valores de densidade de spin igual a 0,639 , enquanto que no nitrogênio o valor é de 0,918 , indicando que este apresenta um elétron desemparelhado e outros dois ligados aos dois silícios dímeros. A partir disso e dos valores das distâncias de ligação podemos visualizar uma ligação simples entre os átomos de silício com o nitrogênio e uma interação muito fraca entre os silícios dímeros.

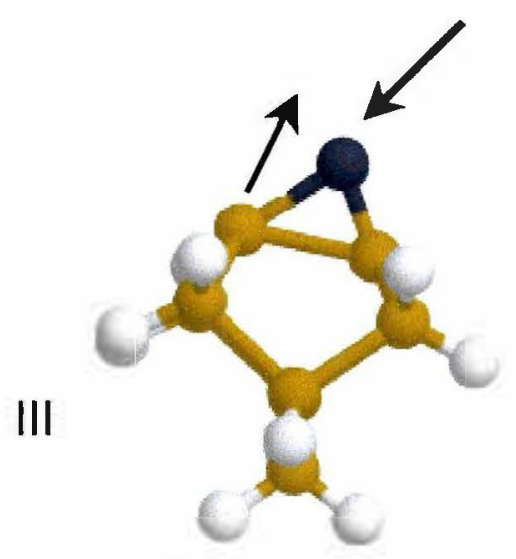

$$
v=340 \mathrm{i} \mathrm{cm}-1
$$

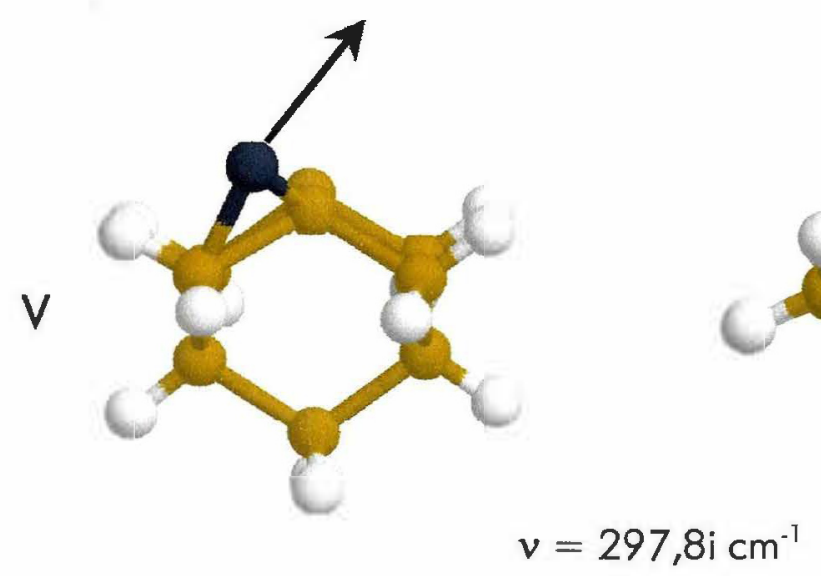

Figura 20. Freqüências vibracionais imaginárias $\left(\mathrm{em} \mathrm{cm}^{-1}\right)$ calculadas para as estrułuras quarteto IIl e V.

Uma terceira estrutura localizada em um ponto de mínimo também foi encontrada e está representada na:Figura 17. Essa estrutura IV é energeticamente mais estável que a II, estando a $17,95 \mathrm{kcal} / \mathrm{mol}$ da estrutura I, e apresenta o nitrogênio ligado a três átomos 
de silício, sendo um deles do dímero e os outros dois da primeira camada interna. Observamos que a inserção do nitrogênio causa uma distorção nos silícios dímeros, mas estes mantêm uma ligação química, apresentando uma distância $(2,349 \AA)$ típica de uma ligação simples. O nitrogênio encontra-se ligado aos silícios por distâncias da ordem de ligações simples. Interessante observar que o nitrogênio se liga a esses três silícios formando uma estrutura praticamente planar, ao contrário de uma estrutura piramidal que é a que poderia se esperar se considerarmos a amônia como referência. $O$ nitrogênio não se encontra posicionado simetricamente em relação aos três silícios, sendo as distâncias iguais a 1,789 $\AA$ e 1,908 $\AA$ em relação ao silício dímero e aos dois silícios internos, respectivamente. Essa forma planar é observada na estrutura do nitreto de silício, tanto na forma alfa quanto na beta, de modo que a estrutura IV é a primeira a apresentar características relacionadas à estrutura cristalina do $\mathrm{Si}_{3} \mathrm{~N}_{4}$. Pelos valores da densidade de spin vemos que os elétrons desemparelhados encontram-se praticamente sobre os silícios dímeros, indicando uma maior concentração de elétron: desemparelhados no silício mais deslocado da superfície. Na Figura 19 temos um modo vibracional envolvendo o nitrogênio que forma a estrutura planar $\mathrm{NSi}_{3}$, e vemos que o pico apresenta uma intensidade apreciável, diferentemente dos casos I e II, de modo que a identificação dessa estrutura é provavelmente mais fácil do ponto de vista experimental.

A partir das estruturas II e IV encontramos um estado de transiçāo que conecta essas duas geometrias, utilizando novamente o método STQN. A estrutura $V$ obtida pode ser vista na Figura 17 e, energeticamente, é $38,91 \mathrm{kcal} / \mathrm{mol}$ menos estável que a estrutura I, mas 13,65 e 20,96 kcal/mol menos estável que II e IV, respectivamente. Esse estado de transição apresenta uma diferença de energia em relação à estrutura II menor que a observada com a estrutura III, e essa diferença não é desprezível, como veremos adiante, para determinarmos a preferência da estrutura final obtida com a inserção de um átomo de nitrogênio. Com relação à geometria, esse estado de transição apresenta como característica o nitrogênio saindo do plano contendo os silícios dímeros, ou seja, saindo da simetria $\mathrm{C}_{s}$ e aproximando dos silícios da primeira camada interna. A distância entre o nitrogênio e o silício dímero apresentou uma pequena diminuição ao passar da estrutura II para $V$, passando de 1,773 $\AA$ para $1,756 \AA$, respectivamente, o mesmo ocorrendo entre a distância entre os silícios dímeros, que passou de 2,397 $\AA$ para 2,386 
$\AA$, respectivamente. Observando os valores da densidade de spin, vemos que na mudança da estrutura II para IV passando pelo estado de transição $V$ ○ nitrogênio apresenta uma diminuição de cerca de 1,8 para zero, refletindo a utilização dos dois elétrons desemparelhados na formação de ligações com os dois silícios da primeira camada interna. Já o silício dímero ligado ao nitrogênio apresenta um aumento, passando de 0,15 para 1,45, o que é de se esperar tendo em vista a quebra de duas ligaçōes silício-silício, diminuindo o total de quatro para duas ligações. Com relação ao outro silício dímero não ocorreu praticamente nenhuma mudança, continuando com o seu elétron desemparelhado. Na Figura 20 está representado o modo de vibração da freqüência imaginária da estrutura $\mathrm{V}$.

Com o interesse em saber qual a primeira etapa no processo de inserção de um átomo de nitrogênio, realizamos alguns testes, visando descobrir se o nitrogênio se liga ans silícios levando inicialmente à estrutura I ou II. Para isso, fizemos uma otimização geométrica partindo do nitrogênio bem afastado do aglomerado e permitindo a aproximação. Esse procedimento foi realizado sem a adoção de vínculos e sem o uso de simetria $\left(C_{1}\right)$. Nessas condições, a otimização leva diretamente ao caso II, e esse processo de incorporação do nitrogênio é bastante favorecido energeticamente, pois a estrutura II é $75,75 \mathrm{kcal} / \mathrm{mol}$ mais estável que a energia do aglomerado $\mathrm{Si}_{9} \mathrm{H}_{12} \mathrm{com}$ o nitrogênio quarteto distante. A partir desse resultádo, podemos imaginar como ocorre a incorporação do nitrogênio nos processos de bombardeamento com átomos de baixa energia. Inicialmente ocorreria a incorporação levando à estrutura II, num processo sem a presença de barreiras energéticas. Em seguida, rearranjos internos podem levar às estruturas I ou IV. A reação levando à formação de I é ativada, com barreira de 17,73 $\mathrm{kcal} / \mathrm{mol}$, e uma exotermicidade de $25,26 \mathrm{kcal} / \mathrm{mol}$, enquanto que a formação de IV encontra uma barreira menor, de 13,65 kcal/mol, além de ser menos exotérmica, 7,31 $\mathrm{kcal} / \mathrm{mol}$. A exotermicidade total do processo que leva dos reagentes à estrutura I é de $100,01 \mathrm{kcal} / \mathrm{mol}$, e a maior das duas barreiras de interconversão a partir de Il é ainda $47,0 \mathrm{kcal} / \mathrm{mol}$ abaixo dos reagentes. Com isso existe energia suficiente para que a reação ocorra sem que o sistema esteja aprisionado em II. A questão que surge é saber em que proporção os produtos finais I e IV podem ser encontrados. Como a reação de deposição envolve um fluxo de átomos colidindo com a superfície, espera-se que a 
reação seja controlada cineticamente. Dentro dessas condições, uma estimativa da proporção dos produtos baseada nas alturas das barreiras, expressa em termos da energia livre de Gibbs, fornece uma preferência de $98 \%$ para que a reaçāo leve à estrutura IV.

Com relação às freqüências vibracionais observadas em todas as estruturas, existem dois modos que possivelmente possuem uma relevância na espectroscopia infravermelho do nitreto de silício, e que podem ser úteis no acompanhamento do processo de deposição e formação deste material. A freqüência de $818 \mathrm{~cm}^{-1}$ associada com o estiramento assimétrico da ligação $\mathrm{Si}-\mathrm{N}$ no plano formado pelo nitrogênio e os três silícios na estrutura IV pode ser vista na Figura 19. Esse modo foi atribuído por nós à freqüência observada de $840 \mathrm{~cm}^{-1}$, atribuída por Liu et al. ${ }^{10}$ para a vibração assimétrica do grupo $\mathrm{NSi}_{3}$. Com relação à estrutura l, o modo de $1015 \mathrm{~cm}^{-1}$, que pode se visto na Figura 19, é povico intenso. e foi atribuído por nós aos pequenos picos próximos a 1090 $\mathrm{cm}^{-1}$ obtidos por tiv et al., que se tornam mais intensos à medida que aumenta o fluxo de gás incidente. 


\section{III.4 O SISTEMA $\mathrm{Si}_{9} \mathrm{H}_{12}+1 \mathrm{~N}$ - DUPLETO}

Além das estruturas quarteto procuramos verificar a possibilidade da existência de estruturas dupleto. Conforme mencionado, a existência de estruturas com essa possibilidade de simetria de spin pode ocorrer durante a neutralização em um processo de deposição com feixe de íons. Isso porque a possibilidade de existência de estados excitados na espécie neutra tomando parte da reação foi sugerida a partir da interação de íons $\mathrm{N}_{2}{ }^{+}$de baixa energia com superfícies metálicas. Como a banda de valência do silício se sobrepõe (overlap) em energia com muitos dos estados excitados do $\mathrm{N}_{2}$, pode ocorrer uma eficiente neutralização por ressonância de um desses estados que possua um tempo de vida razoável para a duração da experiência. Desse modo, estamos nesse trabalho considerando a possibilidade de neutralização do íons $\mathrm{N}^{+}$formando a espécie neutra excitada com simetria de spin dupleto. Experimentalmente, não está explícito na literatura quval o estado eletrônico do átomo $N$ quando ele é neutralizado próximo à superfície e a distância estimada em que essa neutralização ocorre.

Desse modo, realizamos um estudo análogo ao feito com as estruturas quarteto, ou seja, procuramos obter os parâmetros geométricos e dados de freqüência para as estruturas relacionadas com o processo de interaçāo e incorporaçāo do nitrogênio. Antes de discutir o estado dupleto propriamente dito, vamos nos ater primeiro aos resultados para o estado quarteto sem a adoção de vínculos.

\section{Influência da adoção de vínculos na geometria: o estado quarteto revisitado}

Como ponto de partida para o estudo das estruturas dupleto utilizamos as mesmas geometrias iniciais do caso quarteto. A otimização de uma estrutura simétrica similar a I levou a um estado de transição com energia bastante baixa. Era nosso interesse encontrar uma estrutura localizada em um ponto de mínimo, mas não conseguimos dentro das condições adotadas na otimização. Como um teste resolvemos eliminar os vínculos adotados, que consistiam em manter "fixos" os hidrogênios e os três silícios mais internos e obtivemos uma estrutura localizada em um ponto de mínimo. As alterações na 
geometria com esse novo procedimento foram pequenas, e com isso em mente procuramos otimizar novamente as estruturas quarteto descritas na seção III.3 e observar os efeitos que a adoção de vínculos pode causar, tanto com relação aos parâmetros geométricos e freqüências quanto aos aspectos energéticos.

As estruturas obtidas, correspondentes a pontos de mínimo e estados de transição, estão apresentadas na Figura 21. Nessa figura, vemos um caminho de absorção do átomo de nitrogênio similar ao obtido com o uso de vínculos, sendo a principal diferença a maior estabilidade adquirida pela estrutura IV. Na Figura 22 podem ser vistos os parâmetros geométricos dessas estruturas mais importantes. A estrutura I, que apresenta o nitrogênio ligado simetricamente aos dois silícios dímeros, obteve um aumento de estabilidade de $4,95 \mathrm{kcal} / \mathrm{mol}$ com a otimização sem vínculos, comparado com a com vínculos. Esse aumento na estabilidade refletiu na relaxação que os átomos, principalmente os silícios dímeros, tiveram, pois esses átomos apresentaram um ligeiro aumento na dístância, de cerca de 0,1 $\AA$, passando de 3,209 para 3,312 $\AA$. Os demais parâmetros praticamente não variaram, o mesmo com relação às cargas e à densidade de spin.

A estrutura II, onde o nitrogênio encontra-se ligado a apenas um dos silícios dímeros e que corresponde ao primeiro passo no processo de incorporação do átomo de nitrogênio, apresentou uma estabilização muito pequena, de 1,52 kcal/mol. Essa pequena diferença é reflexo da geometria otimizada sem vínculos, pois esta praticamente não sofreu alteração se comparada à obtida com vínculos.

A última estrutura estável obtida corresponde a IV, onde temos o nitrogênio incorporado dentro da estrutura de silício e ligado a três átomos, formando um plano $\mathrm{NSi}_{3}$. Nossos cálculos revelaram que a estrutura sem vínculos é $40,15 \mathrm{kcal} / \mathrm{mol}$ mais estável que a com vínculos. Observando a Figura 22 e comparando-a com a Figura 17 vemos que a mudança estrutural nesse caso foi considerável. As maiores diferenças estão relacionadas com o nitrogênio ligado aos dois silícios mais internos. A distância entre o nitrogênio e o silício diminuiu de 1,908 para 1,774 $\AA$ enquanto a distância entre esses dois silícios internos diminuiu de 3,555 para 3,086 $\AA$. Essas mudanças foram grandes, e é reflexo dos vínculos adotados no estudo anterior. Naquele caso, a geometria foi 
"congelada" a partir da estrutura otimizada do aglomerado $\mathrm{Si}_{9} \mathrm{H}_{12}$, e tal vínculo foi adotado com a suposição de manter uma estrutura externa fixa de modo a procurar simular o efeito causado pelos demais silícios em uma estrutura cristalina "real", que deve limitar a movimentação dos átomos envolvidos na incorporação do nitrogênio. Mas a introdução do nitrogênio levou a uma aproximação com os silícios, sendo a distância final, 1,774 $\AA$, correspondente a de uma ligação simples típica. A flexibilidade dada aos hidrogênios foi fundamental para que isso ocorresse, levando a uma estrutura final com distâncias mais satisfatórias. Isso nos alerta para a necessidade de se tomar um grande cuidado no uso de vínculos, pois estes podem levar a uma situação menos realista, em oposição à idéia que leva ao uso dessas limitações.

Por fim, otimizamos as estruturas $V$ e III, que são estados de transição que conectam as estruturas II com a IV e I, respectivamente. Essas estruturas foram obtidas com o método Synchronous Transit-Guided Quasi-Newton (STQN), quve no proarama Gaussian 94 é realizado sem o uso de vínculos na geometria. Desse modo, as estruturas V e III são idênticas nas otimizaçōes com e sem vínculos.

Otimizamos a estrutura quarteto com o nitrogênio muito afastado, a algumas dezenas de Ångstrom, do aglomerado de silício, e a energia e geometria do aglomerado indica que corresponde a um nitrogênio quarteto e um aglomerado singleto. Essas espécies é que correlacionam, ao reagirem, com a estrutura II. A estrutura com o nitrogênio afastado é $106 \mathrm{kcal} / \mathrm{mol}$ menos estável que o mínimo encontrado, IV, e 61 $\mathrm{kcal} / \mathrm{mol}$ acima da estrutura II.

Portanto, a nāo utilização de restrições geométricas foi a responsável pela diferença apresentada na Figura 21, onde a estrutura IV, que antes era $17,95 \mathrm{kcal} / \mathrm{mol}$ menos estável que 1, passasse a ser a mais estável, sendo $17,25 \mathrm{kcal} / \mathrm{mol}$ mais estável que I. A adoção de vínculos, que é uma prática bastante adotada no estudo da interação de aglomerados com átomos e moléculas, deve ser feita com muita cautela, pois, se por um lado tenta reproduzir a rigidez da estrutura cristalina, leva a uma diminuição de uma flexibilidade que certamente é necessária ao se interagir os silícios com outras substâncias. 


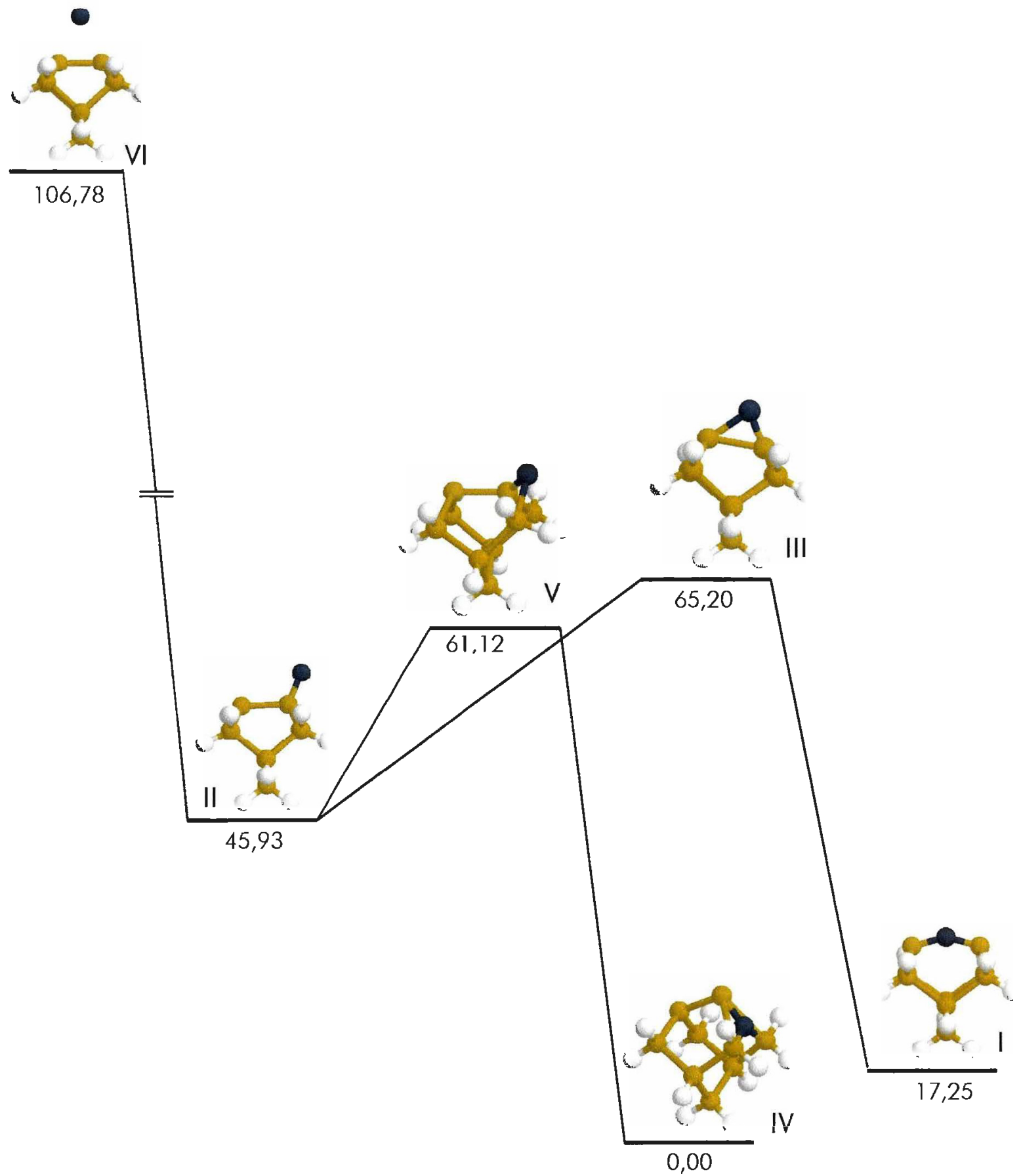

Figura 21. Energias relativas (em $\mathrm{kcal} / \mathrm{mol}$ ) para as estruturas quarteto sem vínculo representativas ao longo do caminho de reação da adsorção de $\mathrm{N}$ na superfície $\mathrm{Si}(100)$ modelada pelo aglomerado $\mathrm{Si}_{9} \mathrm{H}_{12}$. 

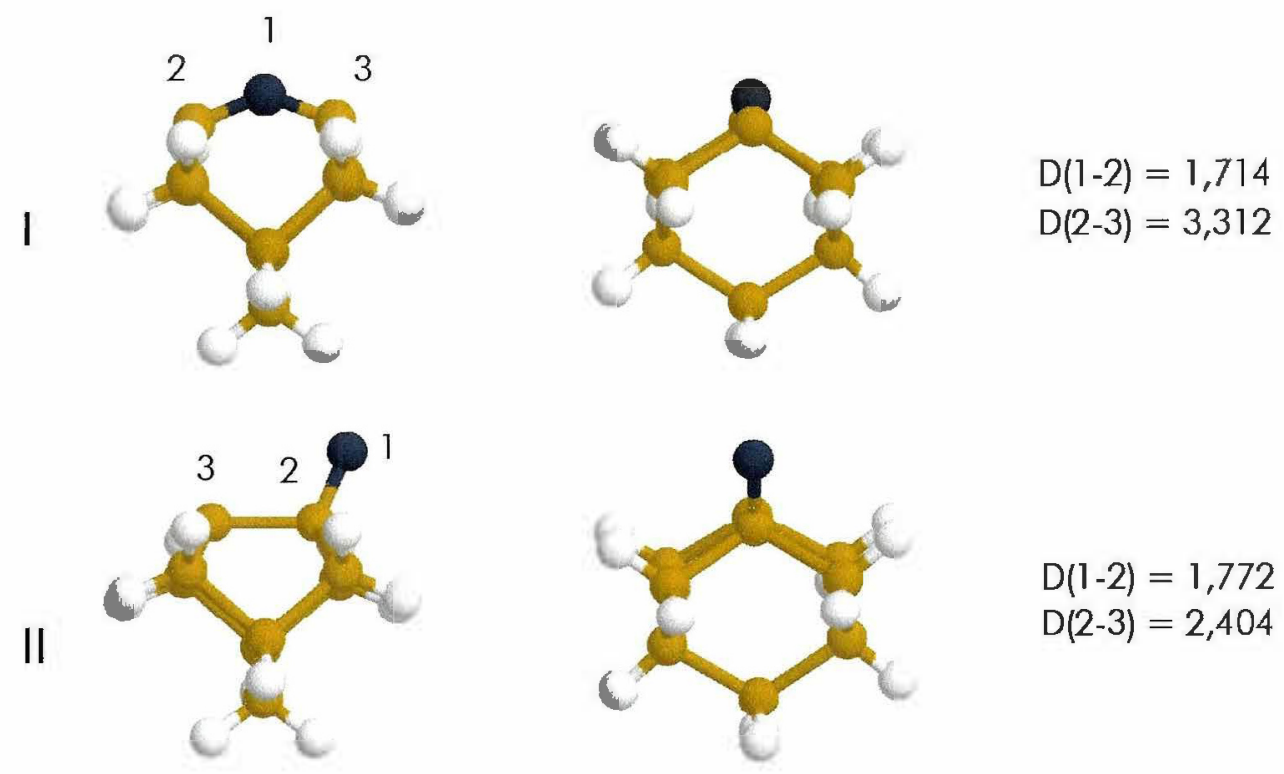

$\mathrm{D}(1-2)=1,772$

$\mathrm{D}(2-3)=2,404$
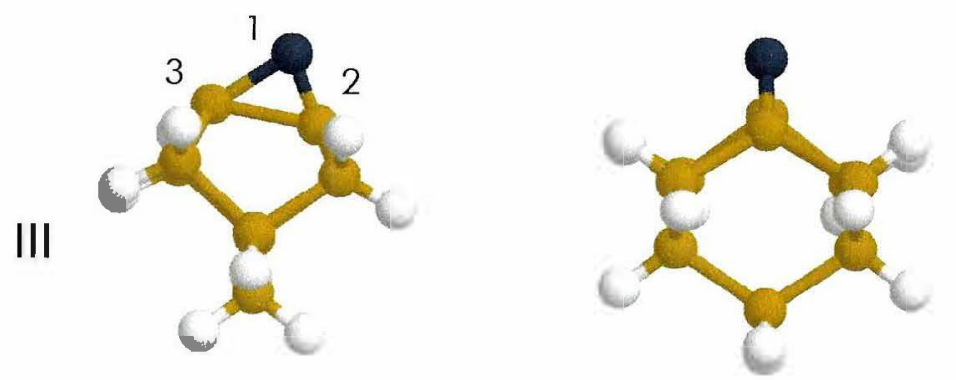

$\mathrm{D}(1-2)=1,775$

$\mathrm{D}(1-3)=2,180$

$\mathrm{D}(2-3)=2,480$
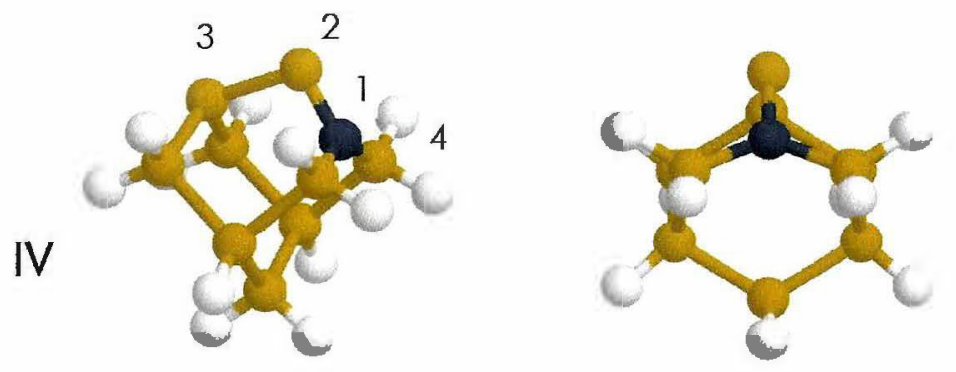

$\mathrm{D}(\mathrm{I}-2)=1,780$

$\mathrm{D}(1-4)=1,774$

$\mathrm{D}(2-3)=2,381$

$\mathrm{D}(2-4)=3,037$

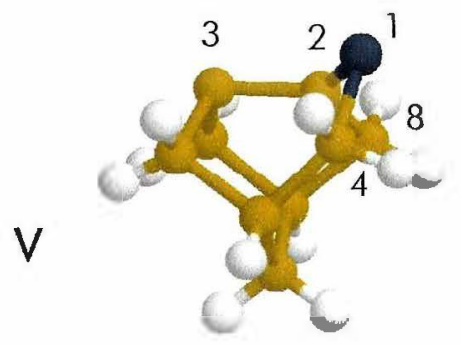

a

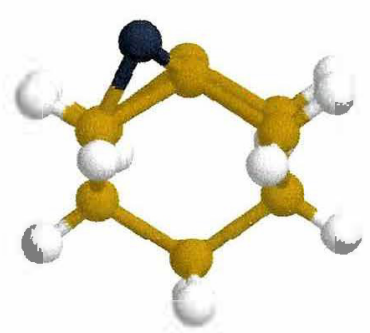

$\mathrm{D}(1-2)=1,756$

$\mathrm{D}(1-4)=2,197$

$\mathrm{D}(1-8)=3,619$

$\mathrm{D}(2-3)=2,386$

$\mathrm{D}(2-4)=2,379$

$\mathrm{D}(2-8)=2,361$

b

Figura 22. Parâmetros geométricos calculados para as estruturas quarteto sem vínculo representativas ao longo do caminho de reação da adsorção de $\mathrm{N}$ na superfície $\mathrm{Si}(100)$ modelada pelo aglomerado $\mathrm{Si}_{9} \mathrm{H}_{12}$. A visão a é perpendicular aos silícios dímeros, e b é ao longo dos dímeros. As distâncias são dadas em Ångstrom. 


\section{Resultados para as estruturas dupleto}

A partir dos resultados discutidos na seção anterior, resolvemos otimizar as estruturas dupleto também sem o uso de vínculos. Na Figura 23 temos a representação das espécies obtidas, mostrando as energias relativas e os caminhos de reação da incorporação do nitrogênio. Na Figura 24 temos os parâmetros geométricos dessas mesmas estruturas, enquanto que na Figura 25 podemos ver as carga atômicas e as densidades de spin.

A espécie mais estável obtida corresponde a IV, com uma geometria semelhante à do quarteto sem vínculos mais estável. As distâncias entre o nitrogênio e os silícios $(1,773$ e 1,783 $\AA$ ) são da ordem de uma ligação simples $(1,72 \AA),{ }^{69,70}$ enquanto os silícios dímeros estāo $2,443 \AA$ afastados, sendo também da ordem de uma ligaçāo simples $(2,34$ A). ${ }^{71}$ Essas distâncias são próximas das obtidas com o quarteto IV sem vínculos, mas com relação à densidade de spin podemos ver a diferença na distribuição dos elétrons, pois na estrutura quarteto os elétrons desemparelhados estão concentrados sobre os dois silícios dímeros, enquanto que na estrutura dupleto o elétron desemparelhado concentrase mais no silício dímero não ligado ao nitrogênio, enquanto que o valor da densidade de spin para o outro silício é quase nulo. Isso deve levar a uma superfície com propriedades químicas diferentes, pois neste último caso o silício menos deslocado deve ser o mais reativo para um reagente eletrófilo, enquanto que com a estrutura quarteto os dois silícios dímeros têm praticamente a mesma reatividade.

A segunda estrutura mais estável corresponde a I, onde temos o nitrogênio ligado aos dois silícios dímeros. Esta encontra-se energeticamente 14,70 kcal/mol acima de IV, e pela Figura 24 vemos que as distâncias Si-N $(1,637 \AA$ e 1,663 $\AA$ ) são intermediárias entre uma ligação simples e uma dupla padrão. Essa estrutura é ligeiramente assimétrica, e a busca de uma que fosse simétrica $\left(C_{2 v}\right)$ resultou em um estado de transição, cujo modo vibracional relacionado com a freqüência imaginária leva à estrutura assimétrica. Não podemos deixar de mencionar a surpresa de obtermos como mínimo uma estrutura assimétrica, em oposição ao que foi obtido com a estrutura quarteto. Essa distorção possivelmente é resultado da metodologia adotada, com um único determinante, que talvez leve a uma dificuldade de distribuir e acoplar adequadamente o elétron 
desemparelhado entre os três átomos superficiais. Acreditamos ser esse o motivo de tal distorção, pois quimicamente não esperamos que exista um motivo para que isso ocorra. Os silícios dímeros apresentam-se completamente separados, sendo a distância entre eles de 3,225 $\AA$. Na estrutura quarteto sem vínculo a separação entre o nitrogênio e os silícios $(1,713 \AA)$ é da ordem de uma ligação simples, enquanto que pelos valores da densidade de spin podemos ver um elétron praticamente centrado no nitrogênio e o outro distribuído entre os dois silícios dímeros. No caso dupleto, o elétron desemparelhado encontra-se praticamente relacionado aos silícios superficiais, enquanto que o valor sobre 0 nitrogênio é muito pequeno.

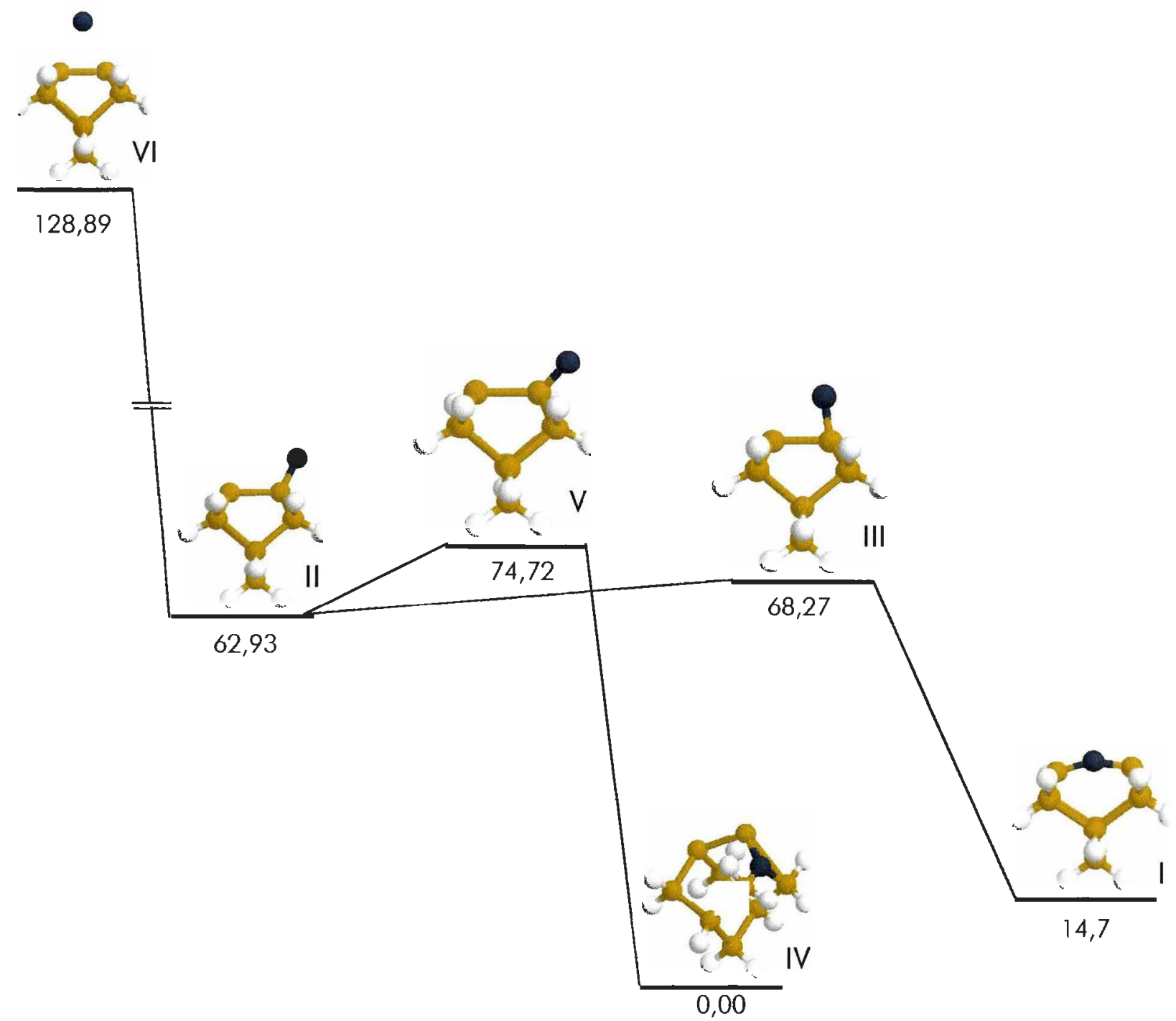

Figura 23. Energias relativas $(\mathrm{em} \mathrm{kcal} / \mathrm{mol}$ ) para as estruturas dupleto sem vínculo representativas ao longo do caminho de reação da adsorção de $N$ na superfície $\mathrm{Si}(100)$ modelada pelo aglomerado $\mathrm{Si}_{9} \mathrm{H}_{12}$. 

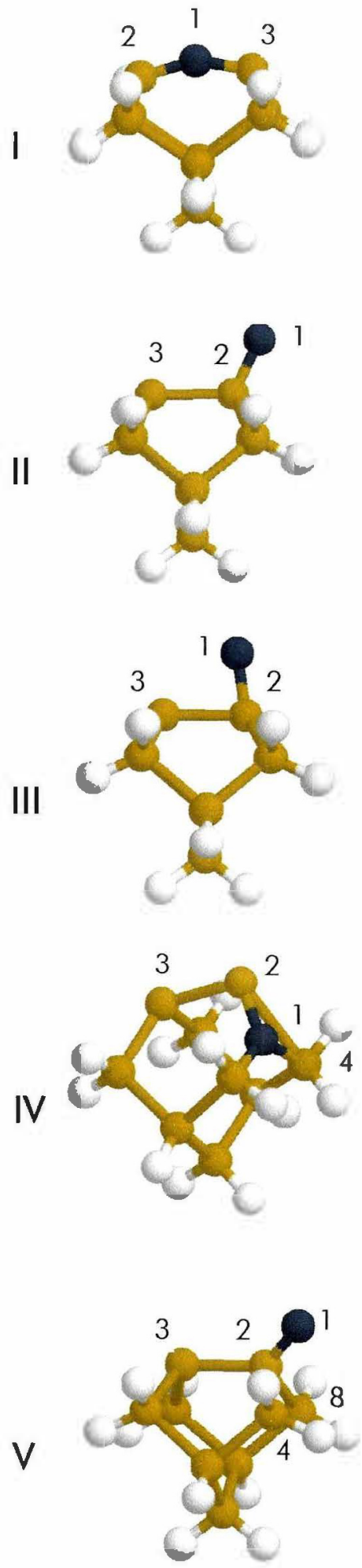

a
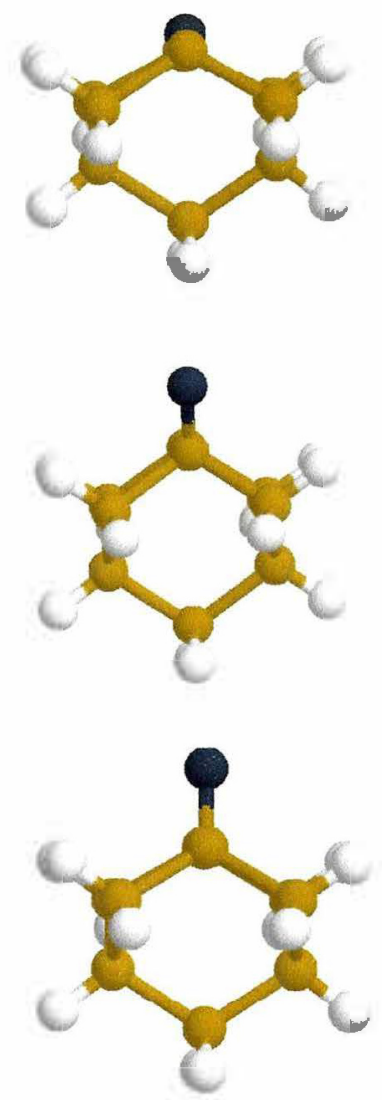

$$
\mathrm{D}(1-2)=1,778
$$$$
D(2-3)=2,337
$$

$\mathrm{D}(1-2)=1,774$

$D(2-3)=2,413$

$\mathrm{D}(1-2)=1,637$
$\mathrm{D}(2-3)=3,225$

$D(1-3)=1,663$

$D(2-3)=2,337$

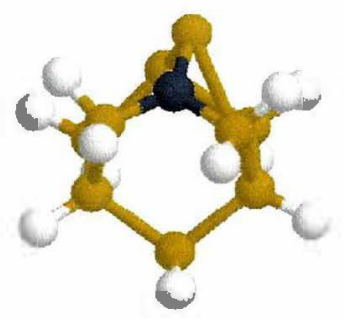

$D(1-2)=1,773$

$\mathrm{D}(1-4)=1,783$

$\mathrm{D}(2-3)=2,443$

$\mathrm{D}(2-4)=2,962$

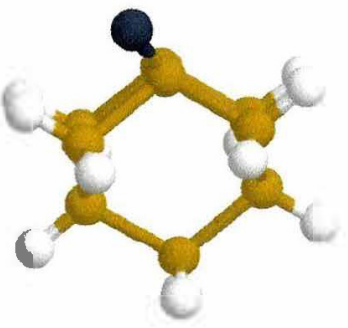

$D(1-2)=1,719$

$D(1-4)=2,845$

$\mathrm{D}(1-8)=3,580$

$\mathrm{D}(2-3)=2,409$

$\mathrm{D}(2-4)=2,415$

$\mathrm{D}(2-8)=2,384$

b

Figura 24. Parâmetros geométricos calculados para as estruturas dupleto sem vínculo representativas ao longo do caminho de reação da adsorção de $N$ na superfície $\mathrm{Si}(100)$ modelada pelo aglomerado $\mathrm{Si}_{9} \mathrm{H}_{12}$. A visão a é perpendicular aos silícios dímeros, e b é ao longo dos dímeros. As distâncias são dadas em Ångstrom. 


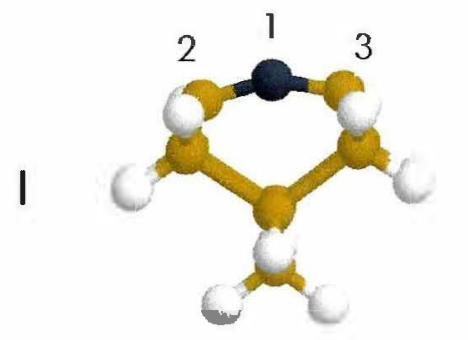

\section{DENSIDADE DE SPIN \\ CARGAS ATÔMICAS: ATÔMICO TOTAL:}

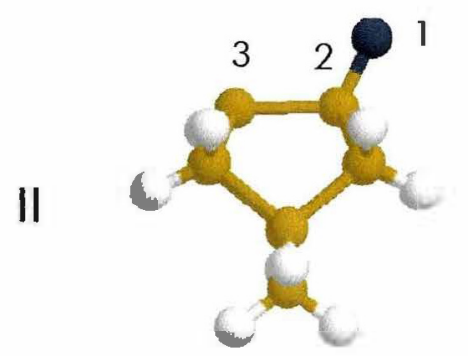

$$
\begin{array}{ll}
1=-0,534 & 1=-0,158 \\
2=0,321 & 2=0,533 \\
3=0,311 & 3=0,730
\end{array}
$$

$1=-0,295$

$1=1,803$

$2=-0,008$

$2=-0,781$

$3=0,258$

$3=-0,182$

III

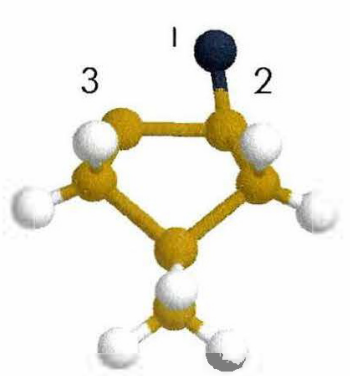

$$
\begin{aligned}
& 1=-0,337 \\
& 2=0,260 \\
& 3=-0,004
\end{aligned}
$$$$
1=1,653
$$

$2=-0,077$

$3=-0,739$

\section{IV}

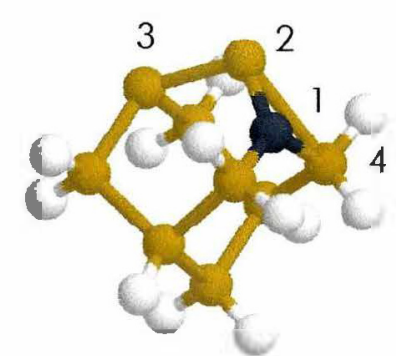

$$
\begin{aligned}
& 1=-0,797 \\
& 2=0,411 \\
& 3=-0,104 \\
& 4=0,380
\end{aligned}
$$$$
1=0,108
$$$$
2=0,023
$$$$
3=0,884
$$$$
4=-0,009
$$

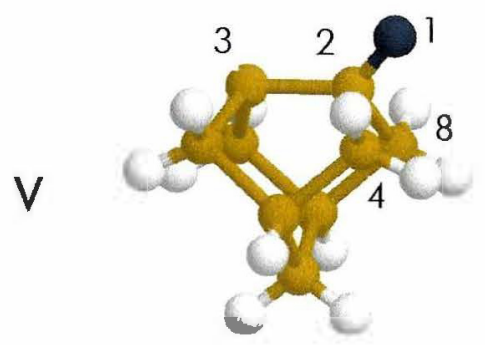

$1=-0,340$

$1=0,055$

$2=-0,016$

$2=0,251$

$3=0,780$

$3=-0,005$

$4=0,013$

$4=0,105$

$8=0,292$

Figura 25. Cargas atômicas e densidade de spin calculadas para as estruturas dupleto sem vínculo representativas ao longo do caminho de reação da adsorção de $\mathrm{N}$ na superfície $\mathrm{Si}(100)$ modelada pelo aglomerado $\mathrm{Si}_{9} \mathrm{H}_{12}$. 
A terceira estrutura estável encontrada é a II, onde temos o nitrogênio ligado a apenas um dos silícios dímeros, conforme podemos ver na Figura 23. Esta corresponde à primeira etapa de incorporação do nitrogênio no aglomerado de silício e encontra-se a $62,93 \mathrm{kcal} / \mathrm{mol}$ acima de IV. Com relação à geometria, a distância Si-N é igual a 1,774 $\AA$, enquanto que entre os silícios dímeros é de $2,413 \AA$. Esses valores são muito próximos dos obtidos com a estrutura similar quarteto sem vínculo, e correspondem a distâncias da ordem de uma ligação simples típica. Os valores de densidade de spin indicam uma distribuição dos elétrons entre o nitrogênio e o silício dímero não ligado a ele. $O$ valor próximo de 2 no nitrogênio e de -1 no silício sugerem que a interação entre o nitrogênio e o silício dímero ligado a ele pode se dar a partir de duas possibilidades: uma simetria de spin quarteto e tripleto, e uma com spin dupleto e singleto, para o átomo de nitrogênio e a superfície representada pelo aglomerado, respectivamente. Para verificar qual dessa possibilidades correlaciona com a estrutura $\mathrm{II}$, realizamos um afostamento progressivo do átomo de nitrogênio sendo que para cada passo otimizamos todo o sistema, mantendo fixa apenas a distância entre o nitrogênio e o aglomerado. Após o afastamento observamos que II correlaciona com o canal de dissociação com o nitrogênio quarteto e o aglomerado tripleto. Esse resultado mostra a neutralização do íon incidente levando à formação do átomo neutro com o estado quarteto e a formação, nesse processo, de uma superfície onde os elétrons dos silícios dímeros estão acoplados numa simetria tripleto. Nas estruturas quarteto estudadas a superfície manteve-se com a simetria de spin singleto, enquanto o nitrogênio também foi neutralizado no estado fundamental do átomo neutro, ou seja, quarteto. Portanto a preferência pela incorporação no estado dupleto ou quarteto depende de como se comporta a superfície de silício durante o processo de neutralização, ou seja, se a transferência de elétron a partir da mesma faz com que os elétrons centrados nos silícios dímeros continuem emparelhados ou passem a estar desemparelhados, numa combinação de spin tripleto. Encontramos uma outra estrutura semelhante a II, com o nitrogênio ligado a apenas um dos silícios dímeros, sendo apenas $9,80 \mathrm{kcal} / \mathrm{mol}$ menos estável que II. Essa estrutura possui uma geometria semelhonte a II, sendo a distância entre o nitrogênio e o silício dímeros igual a 1,754 $\AA$ e entre os silícios dímeros igual a 2,414 $\AA$. A descoberta dessa espécie nos fez questionar a existência de um outro caminho de reação de incorporação 
do nitrogênio no aglomerado de silício, mas um ligeiro afastamento do nitrogênio levou à otimização na espécie II.

Para a busca do estado de transição que conecta a estrutura II a IV e I utilizamos o método Synchronous Transit-Guided Quasi-Newton (STQN), onde obtivemos as estruturas $V$ e III, respectivamente. Temos que $V$ e III estão respectivamente 74,72 e 68,27 $\mathrm{kcal} / \mathrm{mol}$ acima da estrutura mais estável IV e 11,79 e 5,34 kcal/mol acima de II. Essas pequenas diferenças de energia para a conversão da estrutura II em IV e I indicam a facilidade da ocorrência da reação a partir da incorporação do nitrogênio no aglomerado de silício. Em V, o nitrogênio apresenta-se ligeiramente mais deslocado em direção aos silícios internos, se comparado com a estrutura II. O nitrogênio não encontrase na mesma direção da ligação entre os silícios dímeros, conforme podemos ver na Figura 24. Apesar dessa mudança, as distâncias entre os silícios dímeros e entre o silício superficial ligado ao nitrogênio pouco mudaram em relação a II, sendo que o mesmo ocorreu ao passar de $V$ para a estrutura IV. O estado de transição III mostra o nitrogênio aproximando-se do silício dímero não ligado a este. Diferentemente do que foi observado com as estruturas quarteto, esse estado mostra os silícios dímeros se aproximando, de $2,413 \AA$ em II para $2,337 \AA$ em III, e essa diminuiçāo reflete a natureza das ligaçōes que estão sendo formadas. Pelos valores da densidade de spin o nitrogênio possui 1,6 elétrons com um certo spin, enquanto o silício dímero não ligado a ele possui cerca de 0,7 com spin oposto. Ao se aproximarem para formarem a ligação química, esses átomos estarão, usando uma linguagem simplificada de ligação química, unindo esses elétrons de spin opostos para formar uma ligação simples. Essa aproximação leva a uma diminuição da distância entre os silícios dímeros, para que a interação entre o nitrogênio e o silício seja facilitada. No caso do estado de transição quarteto similar, temos que a distância entre os silícios dímeros aumenta à medida que a estrutura II passa pelo estado de transição III. Essa diferença ocorre porque o nitrogênio apresenta dois elétrons e o silício dímero não ligado a ele possui um, todos com o mesmo spin. Com isso, o elétron nitrogênio, ao se aproximar do silício, irá se ligar ao elétron com spin oposto obtido com a quebra da ligação entre os silícios dímeros. Com isso, essa ligação deve ser enfraquecida, com o aumento da distância entre esses silícios superficiais, de modo a permitir a ligação do nitrogênio levando à estrutura I, com este ligado aos dois silícios. 
Com relação aos modos vibracionais, temos na Figura 26 os modos mais importantes das estruturas dupleto I e IV. Alguns cuidados devem ser tomados quando comparamos resultados de cálculos como os nossos com valores experimentais. Isso ocorre porque existem alguns fatores limitantes, como o uso de aglomerado para a representação de uma superfície, e limitaçōes intrínsecas aos cálculos teóricos, como o uso de bases atômicas e metodologia. Os valores de freqüência são obtidos dentro da aproximação de um oscilador harmônico, que é distinto do valor real, experimental. Mencionado isso, temos que alguns trabalhos experimentais foram realizados onde se obteve o espectro infravermelho do nitreto de silício. ${ }^{0,10,19,30}$ Observa-se que os modos mais importantes caem em regiōes da ordem de 800 a $1000 \mathrm{~cm}^{-1}$. A estrutura l apresenta um modo bastante importante e semelhante ao apresentado na Figura 19, relativo ao estado quarteto. $O$ modo com freqüência de $1100 \mathrm{~cm}^{-1}$ possui uma intensidade elevada, não devendo ser de difícil identificação. Esse modo de estiramento assimétrico possui um vislor que é próximo do modo correspondente do estado quarteto $\left(1015 \mathrm{~cm}^{-1}\right)$ e pode ser também associado com o pico pouco intenso em $1090 \mathrm{~cm}^{-1}$ obtido por Liu et al. ${ }^{10} \mathrm{~A}$ estrutura IV apresenta dois modos envolvendo o nitrogênio na estrutura planar $\mathrm{N}-\mathrm{Si}_{3} \mathrm{com}$ intensidades elevadas, a 879 e $917 \mathrm{~cm}^{-1}$. Esses valores são próximos dos obtidos por Honda et al., ${ }^{6}$ Liu et al., ${ }^{10}$ Ito et al., ${ }^{19}$ e Bachurin et al., ${ }^{30}$ para modos envolvendo o nitrogênio e o grupo planar $\mathrm{N}-\mathrm{Si}_{3}$. 


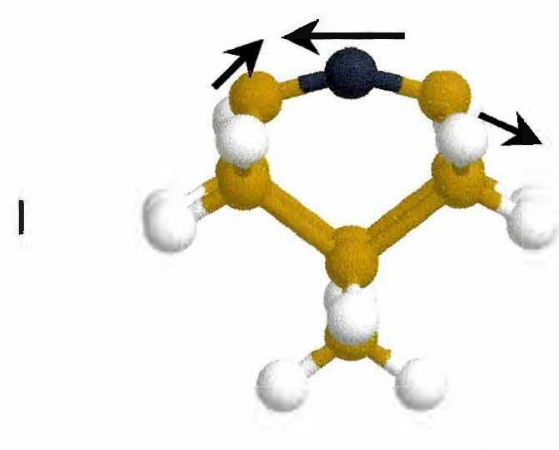

$$
v=1100 \mathrm{~cm}^{-1}
$$

(73)

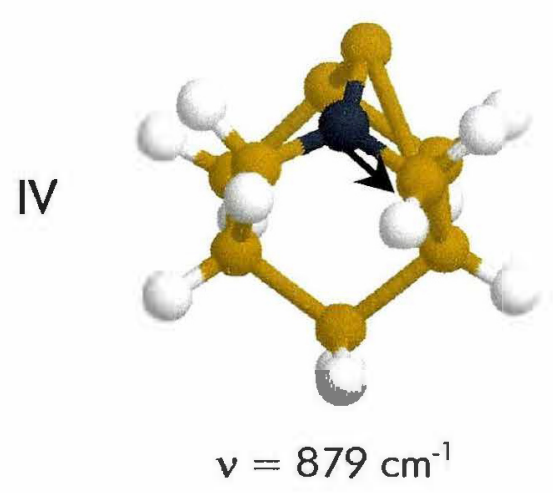

(105)

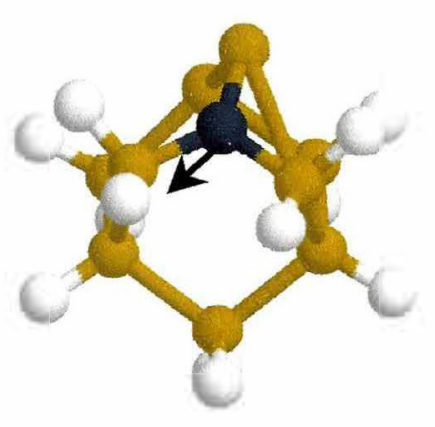

$v=917 \mathrm{~cm}^{-1}$

(271)

Figura 26. Freqüências vibracionais $\left(\mathrm{em} \mathrm{cm}^{-1}\right)$ e intensidades (entre parênteses, em $\mathrm{km} / \mathrm{mol}$ ) calculadas para modos vibracionais selecionados das estruturas dupleto sem vínculo I e IV.

\section{Comparação entre as estruturas dupleto e quarteto}

Na Figura 27 temos mostradas as estruturas otimizadas quarteto e dupleto sem vínculos, com a finalidade de comparar suas energias e estabilidades. Utilizamos a mesma numeração para a indicação das estruturas, acrescida dos índices $d$ e q, que representam, respectivamente, estados dupleto e quarteto. Dela podemos extrair várias informações. A primeira etapa de incorporação do nitrogênio em ambos os casos consiste na ligação deste com um dos silícios dímeros (estruturas II-d e II-q). Energeticamente, ambas apresentam energias muito próximas, 62,93 e $62,33 \mathrm{kcal} / \mathrm{mol}$, acima do mínimo global, respectivamente. A partir de cada uma dessas estruturas, 
obtém-se duas outras, uma com o nitrogênio presente ainda na superfície, ligado aos dois silicios dímeros, e a outra com o nitrogênio incorporado no interior do aglomerado e ligado a três silícios, formando uma estrutura planar com esses três átomos. Esta última estrutura é a mais estável tanto no caso dupleto quanto no quarteto, sendo que a simetria de spin dupleto corresponde ao mínimo global. A estrutura quarteto é 16,39 kcal/mol menos estável que a dupleto.

As espécies com o nitrogênio presente na superfície (estruturas $1-d$ e l-q) correspondem à segunda forma mais estável tanto no caso dupleto como no quarteto. A estrutura l-d é 14,70 kcal/mol menos estável que o mínimo global, enquanto que com l-q a diferença é de $33,65 \mathrm{kcal} / \mathrm{mol}$. A diferença de energia entre $1-q$ e $1 V$-q é de 17,26 $\mathrm{kcal} / \mathrm{mol}$.

Com relação aos estados de transição e considerando as estruturas dupleto, temos que a conversão de II-d para IV-d envolve a passagem por um estado de transição que requer $11,79 \mathrm{kcal} / \mathrm{mol}$, e esse valor é mais que o dobro do necessário para transpor a barreira para a conversão de II-d para I-d, passando por III-d. Essa ordem relativa de energia inverte ao considerarmos as estruturas quarteto, pois a maior barreira passa a corresponder à conversão de II-q para I-q $(19,26 \mathrm{kcal} / \mathrm{mol})$, enquanto esse valor diminui para $15,18 \mathrm{kcal} / \mathrm{mol}$ para a conversão de $I_{-q}$ para IV-q. Podemos observar que as barreiras envolvidas com as estruturas quarteto são maiores que as obtidas para as dupleto, indicando que o processo de conversão é mais difícil do ponto de vista energético, apesar de que em ambas as simetrias de spin dupleto e quarteto a energia de envolvida no processo de incorporação do nitrogênio, levando à estrutura II, é muito maior que as barreiras envolvidas na etapa posterior, da conversão de II para I ou IV, de modo que em ambos os casos as barreiras envolvidas não são impedimentos do ponto de vista energético. 

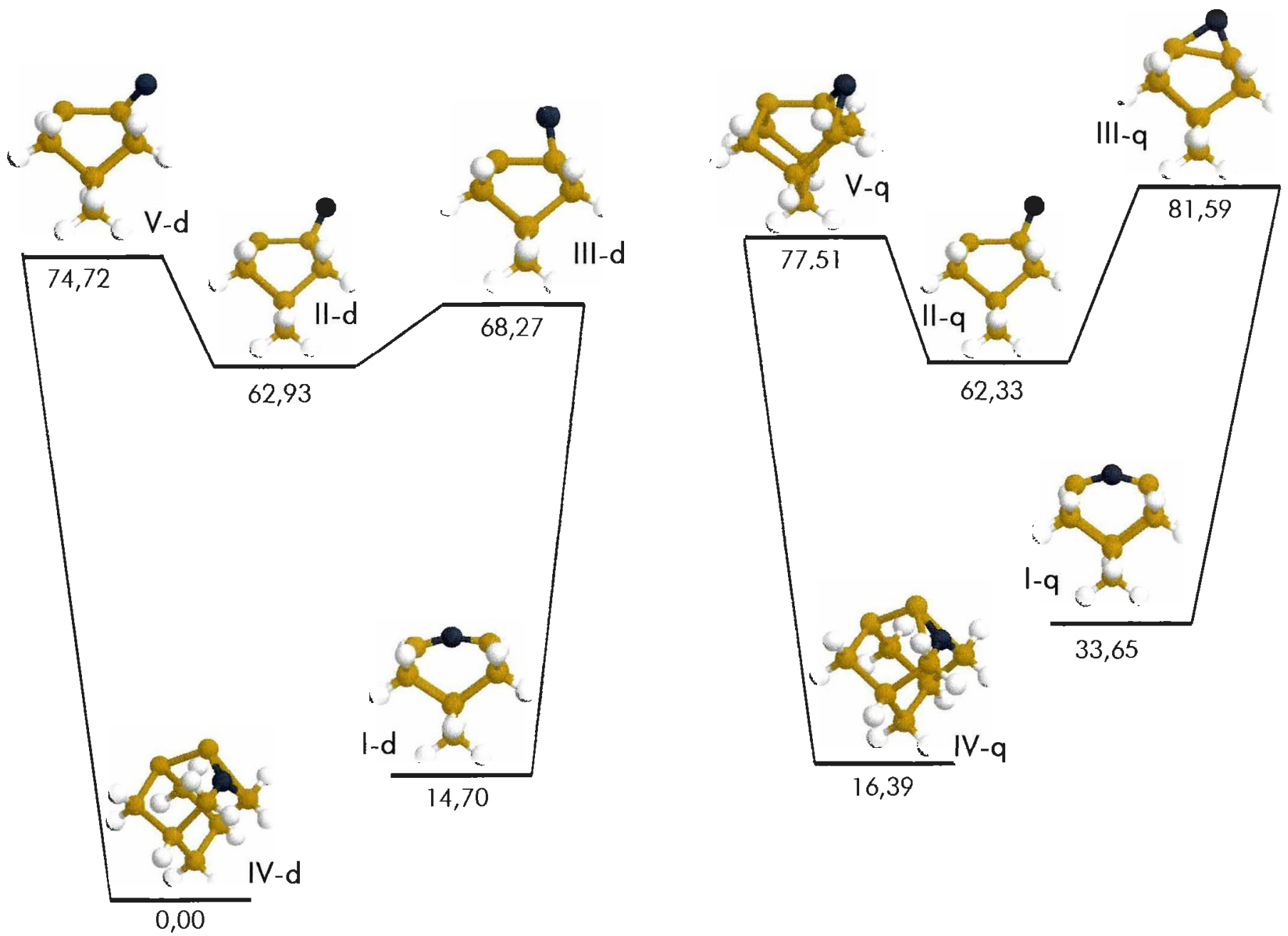

Figura 27. Energias relativas $(\mathrm{em} \mathrm{kcal} / \mathrm{mol})$ para as estruturas dupleto e quarteto sem vínculos representativas ao longo do caminho da reação de adsorção de $N$ na superfície $\mathrm{Si}(100)$ modelada pelo aglomerado $\mathrm{Si}_{9} \mathrm{H}_{12}$. 
Em ambos os casos, dupleto e quarteto, os resultados indicam que a estrutura mais estável corresponde ao nitrogênio incorporado dentro do aglomerado, formando uma estrutura planar com três silícios. Essa estrutura é um primeiro indicativo de uma similaridade com $\circ$ nitreto de silício, $\mathrm{Si}_{3} \mathrm{~N}_{4}$, pois este apresenta em sua estrutura os nitrogênios ligados aos silícios formando também estruturas planares. Outra característica importante é que a incorporação do nitrogênio no interior permite que os silícios dímeros estejam "livres", tornando possível que a reação prossiga com a interação de outros átomos, causando um maior grau de nitretação. Esse processo seria dificultado se, por exemplo, a estrutura mais estável fosse a do nitrogênio ligado aos silícios dímeros como na estrutura I.

Recentemente Musgrave et al..$^{72}$ também estudaram o processo de incorporação de um átomo de nitrogênio na superfície Si(100). Para isso, eles utilizaram as metodologias do Funcional da Densidade, com o funcional híbrido B3LYP, \& o método QCISD(T), e os aglomerados de fórmula $\mathrm{Si}_{9} \mathrm{H}_{12}$ e $\mathrm{Si}_{21} \mathrm{H}_{20}$ para a simulação da superfície de silício. Com relação à base atômica adotada, eles utilizaram a base $6-311++G(2 d, p)$ para os silícios dímeros e os quatro silícios da primeira camada interna, bem como para o nitrogênio, e a base 6-31G(d) para o demais silícios e os hidrogênios. No processo de otimização geométrica, eles introduziram alguns vínculos com a finalidade de simular a estrutura rígida do silício. Inicialmente, os silícios das duas últimas camádas foram mantidos fixos, bem como as direçōes das ligaçōes Si-H. Desse modo, as posiçōes dos silícios mais superficiais e as distâncias $\mathrm{Si}-\mathrm{H}$ foram otimizadas. A partir da estrutura obtida, eles fixaram os hidrogênios e permitiram que os silícios otimizassem livremente, sendo esse o sistema adotado para o estudo da interação do aglomerado com o átomo de hidrogênio. Esse tipo de vínculo é uma das diferenças desse trabalho com o nosso, e isso leva a resultados bastante diferentes, conforme veremos mais a seguir. Eles estudaram três caminhos de incorporação do nitrogênio. A diferença de energia entre o nitrogênio afastado do aglomerado e da estrutura onde ocorre a primeira etapa da interação é de $60 \mathrm{kcal} / \mathrm{mol}$. Essa estrutura é semelhante à II obtida por nós, com o nitrogênio ligado a apenas um dos silícios dímeros. A partir daí três caminhos foram propostos. Um deles leva à formação de uma espécie similar a I, com o nitrogênio ligado simultaneamente aos dois silícios dímeros. Esse processo é exotérmico, com energia de 
$45 \mathrm{kcal} / \mathrm{mol}(48,23$ e $28,68 \mathrm{kcal} / \mathrm{mol}$ em nosso caso, para os casos dupleto e quarteto, respectivamente), e para que ocorra há a necessidade de se ultrapassar uma barreira, com o seu estado de transição correspondente, de $29 \mathrm{kcal} / \mathrm{mol}$ (5,34 e 19,26 kcal/mol em nosso caso). A outra rota leva à formaçāo de uma estrutura estável com o nitrogênio ligado simultaneamente a um dos silícios dímeros e um da primeira camada interna. Esse processo é menos exotérmico que o anterior, sendo a diferença de energia de 32 $\mathrm{kcal} / \mathrm{mol}$, e a barreira de energia para a conversão é menor, $11 \mathrm{kcal} / \mathrm{mol}$. Por fim, o terceiro corresponde à conversão dessa última estrutura em uma outra com o nitrogênio ligado a três silícios, com uma geometria semelhante à IV. Esse processo envolve a formação de um intermediário, fazendo com que existam duas barreiras a serem ultrapassadas. Essa estrutura semelhante à IV é apenas $3 \mathrm{kcal} / \mathrm{mol}$ mais estável que a da segunda roła e $35 \mathrm{kcal} / \mathrm{mol}$ mais que a semelhante à II. No nosso trabalho não estudamos a estrutura com o nitrogênio ligado ao silício dímero e ao interno, e encontramos um estado de transição que conecta dirstamente as estruturas que, para nós, correspondem a II e IV. Interessante notar que para os autores a primeira etapa de interação com o nitrogênio corresponde à estrutura com simetria de spin quarteto. As demais estruturas obtidas a partir dessa correspondem a estados dupleto. Considerando que os caminhos de reação percorrem uma superfície de energia potencial adiabática, como pode uma estrutura com simetria quarteto ser convertida em seguida em um dupleto? Vemos aí uma situação onde um cuidado deve ser tomado, ou seja, as estruturas a serem consideradas, e, consequentemente, os caminhos de reação, não correspondem necessariamente às espécies menor energia, independente do spin. No caso do trabalho apresentado por Musgrave, esse detalhe não causou maiores conseqüências pois a diferença de energia entre a estrutura dupleto e quarteto da espécie semelhante a II é muito pequena, menor que $1 \mathrm{kcal} / \mathrm{mol}$, o que não causa muita diferença em cima dos resultados energéticos apresentados. Esse foi um cuidado que procuramos tomar, ou seja, estudamos os caminhos de reação isoladamente, inicialmente somente sobre as estruturas quarteto e em seguida com as dupleto.

Com relação à geometria, a estrutura onde ocorre a primeira etapa na incorporação do nitrogênio, conforme obtido por nós e por Musgrave et al., apresenta o nitrogênio ligado a um dos silícios dímeros. Eles identificaram uma estrutura quarteto 
como a mais estável e os parâmetros geométricos diferem pouco das obtidas por nós na otimização da estrutura quarteto correspondente, II, sem vínculos. Essa pequena diferença é reflexo do fato da interação estar mais centrada na superfície, de modo que as condições de vínculo utilizadas por Musgrave e a ausência dessas no nosso trabalho pouco influenciaram no resultado final. $O$ mesmo já não ocorreu com a estrutura I, sendo que a estrutura obtida por eles é dupleto e apresenta os silícios dímeros formando uma ligação química, separados por $2,55 \AA$. No nosso caso, esses silícios encontram-se muito separados, e para a estrutura I-d sem vínculo a distância de 3,225 $\AA$. A distância entre os silícios dímeros e o nitrogênio obtida por eles é próxima da nossa. Provavelmente a fonte dessa diferença deve ser o menor grau de liberdade no trabalho de Musgrave, que dificulta a separação desses átomos. Diferenças mais significativas puderam ser observadas com a estrutura IV. A distância entre os silícios dímeros e entre o silício superficial com o nitrogênio é próxima nos dois trabalhos, mas entre o nitrogênio e os silícios internos a situação é outra. Eles obtiveram uira separação de 1,92 $\AA$, e esse valor é grande, se lembrarmos que a distância Si-N simples padrão é da ordem de 1,72 $\AA$. Eles reconheceram essa situação e justificaram ser esse o fator responsável para a formação de um estado menos estável, se comparada com o nitrogênio ligado simetricamente aos silícios dímeros. E por isso eles afirmam que a formação da estrutura planar $\mathrm{N}_{-} \mathrm{Si}_{3}$ resulta em ligações SiN fracas. Essa afirmação para nós é equivocada, pois isso é resultado dos vínculos adotados pelos autores, pois a fixação dos hidrogênios não permite que os silícios ligados a eles possam se aproximar do nitrogênio, e nāo é uma característica estrutural do grupo $\mathrm{N}-\mathrm{Si}_{3}$ apresentar o nitrogênio com uma ligação tão fraca com os silícios ligados a ele. No nosso caso, obtivemos com a estrutura dupleto otimizada sem vínculo uma distância de 1,783 $\AA$, valor esse mais próximo de uma ligação Si-N simples típica, que é de 1,72 $\AA$. Portanto, pelos nossos resultados a estrutura de Musgrave é menos estável por causa das ligações estendidas $\mathrm{Si}-\mathrm{N}$, resultado esse causado pelos hidrogênios fixos, que não permitem que os silícios internos se acomodem durante a reação. Se uma maior flexibilização é adotada, a estrutura fica muito mais estável, conforme já pudemos observar.

Pelos resultados apresentados, observamos que a possibilidade de incorporação de um átomo de nitrogênio levando às estruturas quarteto e dupleto é bastante favorável 
do ponto de vista energético. Em ambos os casos os caminhos possíveis de incorporação são semelhantes, ou seja, com o silício inserido no interior do aglomerado (IV) fornecendo as estruturas mais estáveis, ou com o silício ligado simultaneamente aos dois silícios dímeros. As barreiras de conversão são relativamente baixas, de modo que a reação ocorre espontaneamente com a possibilidade de formação das duas espécies. Nesse nosso trabalho procuramos mostrar os resultados para as duas simetrias de spin pois não encontramos evidências experimentais para a preferência na formação de uma ou outro estado durante o processo de neutralização do $\mathrm{N}^{+}$em uma experiência de deposição de feixe de íns. 


\section{III.5 CONCLUSŌES}

Nesse trabalho, realizamos o primeiro estudo teórico dos aspectos energéticos, estruturais e mecanísticos da reação de um átomo de nitrogênio com a superfície Si(100), que foi modelada com o aglomerado de fórmula $\mathrm{Si}_{9} \mathrm{H}_{12}$. Estudamos essa interação com o sistema apresentando as simetrias de spin dupleto e quarteto.

Inicialmente, estudamos as estruturas quarteto com a adoção de vínculos na geometria com a intenção de procurar simular a característica de rigidez apresentada por uma superfície real. Em seguida, realizamos os mesmos cálculos sem a adoção de vínculos. Em ambos os cálculos, os resultados mostraram que a primeira etapa da reação consiste na ligação do nitrogênio em um dos silícios dímeros, num processo em que não há uma barreira de potencial e que é bastante favorável do ponto de vista energético. Em seguida, duas possibilidades de rearranjo interno passam a existir. Em uma delas o nitrogênio encontra-se ligado aos dois silícios dímeros e na outra encontra-se incorporado dentro do aglomerado de silício, ligado a um dos silícios dímeros e a dois silícios de primeira camada interna. Em ambos os casos determinamos os estados de transição das interconversōes. A otimização realizada com vínculos indica ser a primeira estrutura a mais estável, enquanto que a eliminação destes leva à segunda estrutura como a mais estável. A análise das geometrias mostrou que o uso de vínculos pode não fornecer resultados tão realistas, por impedir que certos movimentos de relaxação ocorram.

O estudo das estruturas dupleto mostrou um mecanismo de incorporaçāo semelhante ao obtido com o quarteto, mas energeticamente fornecem estruturas mais estáveis, sendo que a com o nitrogênio ligados a três silícios corresponde ao mínimo global.

A etapa inicial do mecanismo do sistema quarteto envolve a interação do átomo neutro de nitrogênio quarteto e a superfície singleto, enquanto que no caso dupleto o aglomerado passa a ser tripleto, enquanto o átomo continua sendo quarteto. Portanto, a ocorrência de um mecanismo ou outro depende do comportamento da superfície durante a neutralizaçã̊ no íon numa experiência de deposição de feixe de íons. 
Realizamos comparações dos nossos resultados com posterior trabalho apresentado por Musgrave et. al., sendo que algumas diferenças puderam ser observadas, principalmente as relacionadas com a dependência das propriedades com o uso ou não de vínculos durante o processo de otimização. 


\section{III.6 REFERÊNCIAS}

1. F. Aldinger e H.-J. Kalz, Angew. Chem. Int. Ed. Engl. 26, 371 (1987).

2. T. Devezas, ITA Engenharia 6, 5 (1985).

3. R. Riedel, Naturwissenschaften 82, 12 (1995).

4. D. Segal, J. Mat. Chem. 7(8), 1297 (1997).

5. H. Lange, G. Wötting e G. Winter, Angew. Chem. Int. Ed. Engl. 30, 1579 (1991).

6. K. Honda, S. Yokoyama e S.-1. Tanaka, Appl. Spectr. 52, 1274 (1998).

7. K. Ishizaki, S. Yumoto e K. Tanaka, J. Mat. Sci. 23, 1813 (1988).

8. I. P. Herman, Chem. Rev. 89, 1323 (1989).

9. O. R. Monteiro, Z. Wang e I. G. Brown, J. Mat. Sci. 31, 6029 (1996).

10. Y. C. Liu, K. Furukawa, D. W. Gao, H. Nakashima, K. Uchino e K. Muraoka, Appl. Surf. Sci. 121,233 (1997).

11. M. Birot, J.-P. Pillot e J. Dunoguès, Chem. Rev. 95, 1443 (1995).

12. W.-C. Lee e S.-L. Chung, J. Mat. Res. 12, 805 (1997).

13. R. Heckingbottom e P. R. Wood, Surf. Sci. 36, 594 (1973).

14. M. Björkqvist, M. Göthelid e U. O. Karlsson, Surf. Sci. 394, L155 (1997).

15. Z. Ru-Hong, C. Pei-Lin e F. Song-Bao, Surf. Sci. 249, 129 (1991).

16. F. Bozso e P. Avouris, Phys. Rev. Lett. 57, 1185 (1986).

17. S. Tanaka, M. Onchi e M. Nishiijima, Surf. Sci. 191, L756 (1987). 
18. R. J. Hamers, P. Avouris e F. J. Bozso, J. Vac. Sci. Technol. A 6, 508 (1988).

19. T. Ito, S. Hijiya, T. Nazaki, H. Arakawa, M. Shinoda e Y. Fukukawa, J. Eletrochem. Soc.: Solid-State Sci. and Technol., 448 (1978).

20. T. Watanabe, A. Ichikawa, M. Sakuraba, T. Matsuura e J. Murota, J. Eletrochem. Soc. 145,4252 (1998).

21. I. J. R. Baumvol e F. C. Stedile, Phys. Stat. Sol. 192, 253 (1995).

22. A. Izumi e H. Matsumura, Appl. Phys. Lett. 71, 1371 (1997).

23. R. J. Hussey, T. L. Hoffman, Y. Tao e M. J. Graham, J. Electrochem. Soc. 143, 221 (1996).

24. R. J. Hamers, P. Avouris e F. J. Bozso, J. Vac. Sci. Technol. B 5, 1387 (1987).

25. Y. Bu, D. W. Shinn e M. C. Lin, Surf. Sci. 276, 184 (1992).

26. Y. Bu e M. C. Lin, Surf. Sci. 311,385 (1994).

27. Y. By, J. C. S. Chu e M. C. Lin, Surf. Sci. 264, L151 (1992).

28. B. W. Jong, G. J. Slavens e D. E. Traut, J. Mat. Sci. 27, 6086 (1992).

29. J. S. Pan, A. T. S. Wee, C. H. A. Huan, H. S. Tan e K. L. Tan, Vacuum 47, 1495 (1996).

30. V. I. Bachurin, A. B. Churilov, E. V. Potapov, V. K. Smirnov, V. V. Makarov e A. B. Danilin, Nucl. Instr. Meth. Phys. Res. B147, 316 (1999).

31. K. H. Park, B. C. Kim e H. Kang, J. Chem. Phys. 97, 2742 (1992).

32. K. H. Park, B. C. Kim e H. Kang, Surf. Sci. 283, 73 (1993).

33. T. L. Bush, D. O. Hayward e T. S. Jones, Surf. Sci. 313,179 (1994). 
34. T. L. Bush, D. O. Hayward e T. S. Jones, Surf. Sci. 331 - 333, 306 (1995).

35. Z. L. Li, J. Wong-Leung, P. N. K. Deenapanray, M. Conway, D. J. Chivers, J. D. Fitzgerald e J. S. Williams, Nucl. Instr. Meth. Phys. Res. B 148, 534 (1999).

36. P. S. Lakshminarasimham e P. S. Gopalakrishnan, J. Mat. Sci. Lett. 14, 1801 (1995).

37. E. Wimmer, Mat. Sci. Engin. B37, 72 (1996).

38. Z. Ru-Hong, C. Pei-Lin e F. Song-Bao, Surf. Sci. 249, 129 (1991).

39. E. Fattal, M. R. Radeke, G. Reynolds e E. A. Carter, J. Phys. Chem. B 101, 8658 (1997).

40. K. Raghavachari, Y. J. Chabal e L. M. Struck, Chem. Phys. Lett. 252, 230 (1996).

41. B. B. Stefanov e K. Raghavachari, Surf. Sci. 389, L1 159 (1997).

42. M. K. Weldon, B. B. Stefanov, K. Raghavachari e Y. J. Chabal, Phys. Rev. Lett. 79, 2851 (1997).

43. Y. Okamoto, Phys. Rev. B 60, 10632 (1999).

44. S. Pai e D. Doren, J. Chem. Phys. 103, 1232 (1995).

45. M. R. Radeke e E. A. Carter, Phys. Rev. B 54, 11803 (1996).

46. A. J. R. da Silva, M. R. Radeke e E. A. Carter, Surf. Sci. 381, L628 (1997).

47. G. S. Khoo e C. K. Ong, Phys. Rev. B 52, 2574 (1995).

48. D. Casagrande, G. P. Srivastava e A. C. Ferraz, Surf. Sci. 402-404, 653 (1998).

49. G. A. de Wijs e A. Selloni, Phys. Rev. Lett. 77, 881 (1996).

50. J. Torras, J. M. Ricart, P. Vilarrubias e J. Fraxedas, J. Crystal Growth 172, 106 (1997). 
51. M. Ishida, M. Yoshida, M. Takashima e K. Sawara, Catal. Today 23, 341 (1995).

52. J. E. Northrup, Phys. Rev. B 51 , 2218 (1995).

53. S. C. A. Gay, S. J. Jenkins e G. P. Srivastava, Surf. Sci. 402-404, 641 (1998).

54. F. T. Bacalzo, D. G. Musaev e M. C. Lin, J. Phys. Chem. B 102, 2221 (1998).

55. F. Bacalzo-Gladden e M. C. Lin, J. Phys. Chem. B 103, 7270 (1999).

56. R. Konecny e D. J. Doren, J. Phys. Chem. B 101, 10983 (1997).

57. A. R. Brown e D. J. Doren, J. Chem. Phys. 109, 2442 (1998).

58. A. R. Brown e D. J. Doren, J. Chem. Phys. 110,2643 (1999).

59. J. A. Tossell, Surf. Sci. 431,186 (1999).

60. W. Pan, T. Zhu e W. Yang, J. Chem. Phys. 107, 3981 (1997).

61. A. Liv e R. Hoffmann, J. Am. Chem. Soc. 117, 4082 (1995).

62. R. Konecny e Dt. J. Doren, J. Am. Chem. Soc. 119, 11098 (1997).

63. R. Konecny e R. Hoffmann, J. Am. Chem. Soc. 121, 7918 (1999).

64. P. C. Hariharan e J. A. Pople, Theor. Chim. Acta 28, 213 (1973).

65. M. M. Frand, W. J. Pietro, W. J. Hehre, J. S. Binkley, M. S. Gordon, D. J. Frees e J. A. Pople, J. Chem. Phys. 77, 3654 (1982).

66. A. D. Becke, J. Chem. Phys. 98, 5648 (1993).

67. C. Lee, W. Yang e R. G. Parr, Phys. Rev. B37, 785 (1988).

68. Gaussian 98, Revisāo A.6; M. J. Frisch, G. W. Trucks, H. B. Schlegel, G. E. Scuseria, M. A. Robb, J. R. Cheeseman, V. G. Zakrzewski, J. A. Montgomery Jr., R. E. 
Stratmann, J. C. Burant, S. Dapprich, J. M. Millam, A. D. Daniels, K. N. Kudin, M. C. Strain, O. Farkas, J. Tomasi, V. Barone, M. Cossi, R. Cammi, B. Mennucci, C. Pomelli, C. Adamo, S. Clifford, J. Ochterski, G. A. Petersson, P. Y. Ayala, Q. Cui, K. Morokuma, D. K. Malick, A. D. Rabuck, K. Raghavachari, J. B. Foresman, J. Cioslowski, J. V. Ortiz, B. B. Stefanov, G. Liu, A. Liashenko, P. Piskorz, I. Komaromi, R. Gomperts, R. L. Martin, D. J. Fox, T. Keith, M. A. Al-Laham, C. Y. Peng, A. Nanayakkara, C. Gonzalez, M. Challacombe, P. M. W. Gill, B. Johnson, W. Chen, M. W. Wong, J. L. Andres, C. Gonzalez, M. Head-Gordon, E. S. Replogle e J. A. Pople, Gaussian, Inc., Pittsburgh, PA, 1998.

69. M. S. Gordon, Chem. Phys. Lett. 126, 451 (1986).

70. D. W. Rankin, A. G. Robiette, G. M. Sheldrick, W. S. Shekldrick, B. J. Aylett, I. A. Ellis e J. J. Monaghan, J. Chem. Soc. (London) A 1224 (1990).

71. B. T. Luke, J. A. Pople, M. Krogh-Jespersen, Y. Apeloig, J. Chandrasekhar e P. v. R. Schleyer, J. Am. Chem. Soc. 108, 260 (1986).

72. Y. Widjaja, A. Heyman e C. B. Musgrave, J. Phys. Chem. B 106, 2643 (2002). 


\section{CONCLUSŌES GERAIS}

Nesta tese, estudamos diversos sistemas contendo átomos de silício e nitrogênio com as mais variadas metodologias. O sistema SiNN, aparentemente bastante simples, levou a vários questionamentos desde o início do trabalho. Do ponto de vista experimental, os resultados não eram tão convincentes como se esperaria, e, do ponto de vista teórico, a discrepância observada entre alguns trabalhos mostrou ser necessária a realização de um estudo mais rigoroso. Com a metodologia Coupled Cluster, notamos a grande dependência dos valores de freqüência com a base atômica adotada. $O$ cálculo mais sofisticado, utilizando CCSD(T)/cC-pVQZ, fornece para $\omega_{1}$ um valor de $1859 \mathrm{~cm}^{-1}$, que é $73 \mathrm{~cm}^{-1}$ maior que o valor experimental aceito até então. Essa grande diferença foi também observada na comparação com outros trabalhos teóricos. Um resultado inesperado foi obtido com o uso da metodologia $M R C l$, onde não conseguimos reproduzir os dados $C C S D(T)$, possivelmente pela não inclusão de excitações de ordem superior, presentes no cálculo CCSD(T). Pela primeira vez, foram estudados alguns isômeros do SiNN, sendo que todos correspondem a pontos de mínimo na superfície de energia potencial. Quanto ao aglomerado de fórmula $\mathrm{Si}_{3} \mathrm{~N}_{2}$, um pouco maior que o SiNN, tivemos um grande trabalho na busca de estruturas energeticamente favoráveis. A fim de encontrar uma esffutura que correspondesse ao mínimo global, um número muito. grande de configurações espaciais foram testadas, levando, finalmente, a uma espécie planar contendo apenas ligaçōes Si-N. A mesma dificuldade foi verificada na busca de estados de transição conectando as estruturas obtidas e a correlação destas com os vários canais de dissociação.

Com relação à superfície Si(100), notamos uma grande divergência e dependência dos resultados de acordo com a metodologia adotada para a descrição da estrutura eletrônica. Para o aglomerado $\mathrm{Si}_{9} \mathrm{H}_{12}$, a metodologia Hartree-Fock com o uso de orbitais restrito, levou à formaçāo do que seria uma ligação dupla entre os silícios dímeros, além da estrutura tripleto corresponder à. forma mais estável. Tais deficiências foram corrigidas com o uso de orbitais nāo restritos, onde a estrutura singleto passou a ser a mais estável e as dangling bonds puderam ser melhores descritas. $O$ uso da metodologia do Funcional da Densidade e uma base atômica com funções de 
polarização levaram a uma estrutura distorcida (buckled), sendo que tal resultado não foi obtido com nenhuma outra metodologia. O uso do CASSCF mostrou que a superfície apresenta um caráter multiconfiguracional, onde duas configurações são as mais importantes, mas tal cálculo não levou à obtenção de uma geometria distorcida. Para o sistema $\mathrm{Si}_{15} \mathrm{H}_{16}$, estruturas distorcidas foram obtidas com todas as metodologias, exceto a CASSCF, onde foi obtida apenas a estrutura simétrica.

$O$ passo seguinte no trabalho foi utilizar o aglomerado $\mathrm{Si}_{9} \mathrm{H}_{12}$ para estudar o processo de interação e incorporação de átomos de nitrogênio na superfície de silício, simulando o processo experimental de deposição de feixe de íons. Estudamos os mecanismos com as simetrias de spin dupleto e quarteto. Verificamos a existência de duas rotas de rearranjo a partir da primeira etapa de incorporação, onde o nitrogênio encontra-se ligado a apenas um dos silícios dímeros. Apesar do tamanho limitado do aglomerado de silício utilizado, conseguimos verificar que o nitrogênio pode ser incorporado no interior do aglomerado, deixando a superfície livre para posterior incorporação de outros átomos. Nesse caso, essa estrutura apresenta o nitrogênio ligado a três silícios, formando um grupo com geometria planar, característica essa presente na estrutura da cerâmica $\mathrm{Si}_{3} \mathrm{~N}_{4}$.

Dessa forma, neste trabalho apresentamos resultados diversos para um grande número de sistemas. Para um sistema pequeno, como o SiNN, mas não necessariamente fácil de ser descrito, pudemos utilizar metodologias muito sofisticadas, com resultados bastante confiáveis. O estudo da interação de um átomo de nitrógênio com uma superfície de silício, por sua vez, exigiu uma metodologia mais limitada, mas mesmo assim pudemos obter resultados confiáveis relacionados a mecanismos, geometrias e energias que certamente ajudarão a compreender um processo que é bastante complicado e muito importante do ponto de vista tecnológico. 